\title{
Diversity and Ecological patterns of Bolivian deciduous forests
}

\author{
Dissertation zur Erlangung des Doktorgrades der \\ Mathematisch-Naturwissenschaftlichen Fakultäten der \\ Georg-August-Universität Göttingen
}

vorgelegt von

MSc Reynaldo Linares-Palomino

aus

Cusco, Peru

Göttingen, December, 2008 

Referent: Dr. habil. Michael Kessler

Korreferent: Prof. Dr. Teja Tscharntke

Tag der mündlichen Prüfung: 



\section{Para Susana y Matti}

Three is a magic number, Yes it is, it's a magic number. Somewhere in the ancient, mystic trinity You get three as a magic number.

The past and the present and the future.

Faith and Hope and Charity, The heart and the brain and the body Give you three as a magic number.

A man and a woman had a little baby, Yes, they did. And there were three in the family, And that's a magic number.

Bob Dorough 



\begin{abstract}
This dissertation focuses on two aspects of tropical forests. In the first part I report patterns of plant diversity at local scales in a central Bolivian Andean foothill seasonal forest and evaluate the importance that different life-forms have on contributing to overall diversity. Total vascular plant species surveys from three 1-ha plots yielded species richness values from 297 species and 22360 individuals per hectare to 382 species and 31670 individuals per hectare. Epiphytes, and other non-woody life-forms, contributed to significant numbers of overall species richness and abundances. Comparing the observed patterns with other inventories in the Neotropics, showed that the studied Central Bolivian forest plots were similar in total species richness to other dry deciduous and humid montane forests, but less rich than most Amazonian forests. Nonetheless, species diversity of lianas, terrestrial herbs and especially epiphytes proved to be of equal or higher species richness than most other neotropical forest inventories from which data are available. These results highlight the significant contribution that non-woody life-forms in Andean forest ecosystems have toward overall species diversity and abundances, and show that we need an increased inventory effort of these life-forms in order to obtain accurate information useful for the characterization of vegetation types, for the mapping of diversity hotspots and ultimately for conservation purposes.

However, since woody species (especially trees above a certain diameter cut-off) are still extensively used to characterise tropical vegetation, I also present a detailed account of the tree inventories on the same three one-hectare plots in central Bolivia. Inter-plot comparisons showed remarkable variation eventhough the vegetation of the study area was assigned by a recent classification to one single vegetation unit.
\end{abstract}


Few species were shared among plots and most (between $34 \%$ and $50 \%$ ) were locally rare, i.e., species with only one or two individuals per plot. The species richness values we found in this study were similar to other tree inventories in comparable seasonal forest ecosystems in Bolivia. Species and familial composition, however, were contrastingly different, except for the well-known fact that Leguminosae is the numerically most important family in seasonally dry neotropical forest ecosystems.

In the second part of this dissertation I focus on (meta-)community patterns and address questions about the processes and mechanisms that might have produced them. I first present results from a study at a large geographical scale, covering the whole of Bolivia. Using presence-absence data for species of Acanthaceae, Bromeliaceae, Cactaceae and Pteridophyta occurring in Bolivian Andean seasonally dry forest islands I explore patterns in the beta-diversity of these plant groups. Floristic comparisons among the islands showed that Acanthaceae and Bromeliaceae, showed coincident biogeographic patterns, suggesting two disjunct seasonally dry forest groups in Andean Bolivia: one including all small isolated northern dry valleys and another including all southern valleys with connections to the lowland seasonal forests in southern and western Bolivia. Furthermore, the analysis of the variation of the beta-diversity of each studied plant group suggested an important role of group-specific dispersal characteristic. Thus, plant groups with species that have seed dispersal restricted to short distances (a few tens of metres as in Acanthaceae and Bromeliaceae) were geographically structured. In contrast, groups with species without long-distance dispersal limitation and with a potentially ubiquitous distribution (as in pteridophyta, due to their wind-dispersal system), were rather more influenced by local environmental site conditions suggesting post-dispersal restricting mechanisms (e.g., during establishment).

I a second study, I used the information from the total vascular plant inventories in central Bolivian forest referred to above to evaluate if and to what extent a suite of environmental factors influenced plant species richness and community composition at the local scale. The results suggested a major role of selected above- 
and below-ground environmental gradients in determining small scale patterns of species richness and community composition, of the whole forest community and also of each life-form group (terrestrial herbs, epiphytes, shrubs, lianas and trees). Different life-forms, however, were related to different combinations of these factors and the latter were not able to account for a significant fraction of the variation in the data. In conclusion, spatial and environmental factors (individually or acting together) can be invoked to explain species richness and community composition patterns in the tropical deciduous forests of Bolivia. The importance of each one appears to depend on the geographical scale at which the study is made and on the ecological characteristics of the study group. However, neither of them are able to explain all the variation in the data, and novel methods that include evolutionary information of each taxon need to be explored. 


\section{Acknowledgements}

Foremost I would like to thank Michael Kessler, my advisor, who back in 2003, way before I officially embarked in this odyssey accepted to have me as a $\mathrm{PhD}$ student. He helped to write a research proposal which was successful in being funded by the German Academic Exchange Service. I thank him for giving me the freedom to pursue my own interests in this dissertation, for all his advice, time and friendship he has given me during this time.

I thank Professor Erwin Bergmeier and Professor Teja Tscharntke, for accepting to be members of my dissertation committee.

Whilst in Santa Cruz, Bolivia, I acknowledge logistical support from Sebastian Herzog, D. Soto for local advice and M. Saldias and F. Mamani (both of the Museo de Historia Natural Noel Kempff Mercado) for working space at the USZ herbarium.

Many people have contributed to the wealth of information that was obtained from the Los Volcanes plots, either by being directly involved in the establishment and surveying of the plots, by curating and identifying botanical specimens, by providing relevant data and literature, and a large etcetera. The production of vascular plant inventories is indeed a mammoth task! I would especially like to thank Sebastian Herzog (who together with Michael Kessler developed the idea of a research project at Los Volcanes), Jasmin Lendzion and Ernest Hennig for selflessly sharing unpublished data and information from their own research at Los Volcanes. 
I wish to thank Professor W. Zucchini for encouraging me to keep on using R at a time when I was still struggling to understand it and for introducing me to writing this dissertation in $\mathrm{AT}_{\mathrm{EX}}$.

I acknowledge the financial support from the German Academic Exchange Service (DAAD) in form of a Scholarship during all my period in Göttingen. Especially Rosa Nagel, my personal contact in Bonn, for solving most of my personal and study-related inquires and problems. A WWF Prince Bernhard Scholarship for Nature Conservation allowed me to successfully finish this dissertation.

This dissertation, however, has not only been an academic matter. Thus, on a personal note I would like to mention a few more people. Michael and Elke Kessler helped us so much during Susana's pregnancy and during our early months of parenthood! I do not know what would have been of our little family without your advice. A big thank you to both of you! And it has been a real pleasure to get to know the Gonzales-Toivonen family.

At the Institute I would like to thank my room-mates for great discussions (on topics ranging from generalized linear models, Akaike weights and neutral ecological theory to Half-Life, Käsebrötchen and Simón Bolivar) and a nice working atmosphere: Stefan, Jörn and Rodrigo.

Este viaje comenzó hace mucho tiempo gracias al apoyo, incentivos y sacrificios de mis padres Esther y Carlos. Gracias!

Finally, but most importantly, I have to thank my wife Susana and little Matti. These last years have been a though test for all of us. I thanks both of you so much for all your patience and continuous encouragement. I love you! 


\section{Contents}

1 Plant diversity and ecological patterns in the Neotropics - A general

$\begin{array}{ll}\text { introduction } & 1\end{array}$

1.1 Research Focus 1: Neotropical and Bolivian plant diversity . . . . . . 1

1.2 Research Focus 2: Community assembly in biodiverse tropical forests 3

1.3 Specific Research objectives . . . . . . . . . . . . . . . . . . . . . . 9

1.4 References . . . . . . . . . . . . . . . . . . . . . . . . . . 11

2 Non-woody life-form contribution to vascular plant species richness

$\begin{array}{ll}\text { in a tropical American forest } & 17\end{array}$

2.1 Introduction . . . . . . . . . . . . . . . . . . . . . . . . . . . . 18

2.2 Methods . . . . . . . . . . . . . . . . . . . . . . . . . . . . . . . 20

2.2 .1 Study area . . . . . . . . . . . . . . . . 20

2.2 .2 Vegetation sampling . . . . . . . . . . . . . . . . . . . 21

$2.2 .3 \quad$ Data Analysis . . . . . . . . . . . . . . . . . . 22

2.3 Results $\ldots \ldots \ldots \ldots \ldots$

2.3 .1 Taxonomic Diversity . . . . . . . . . . . . . . . . . . 23

2.3 .2 Life-form composition . . . . . . . . . . . . . . . 27

$2.3 .3 \quad$ Similarity among plots . . . . . . . . . . . . . . . . 27

2.4 Discussion $\ldots \ldots \ldots \ldots \ldots$

$2.4 .1 \quad$ Plot shape and its influence on species richness estimations . . 28

$2.4 .2 \quad$ Alpha diversity and plant density at Los Volcanes . . . . . . . 28

2.4 .3 Los Volcanes plots in a neotropical context . . . . . . . . . . . 29 
2.4.4 Contribution of non-woody plant groups to overall plant species richness . . . . . . . . . . . . . . . 33

2.5 Acknowledgements . . . . . . . . . . . . . . . . . 35

2.6 References . . . . . . . . . . . . . . . . . . . 36

3 Tree community patterns along a deciduous to evergreen forest gradient in central Bolivia 43

$3.1 \quad$ Introduction . . . . . . . . . . . . . . . . . . . . . . 45

3.2 Study area . . . . . . . . . . . . . . . . . . . . . 46

3.3 Methods . . . . . . . . . . . . . . . . . . . . . . . . . . 46

3.4 Results . . . . . . . . . . . . . . . . . . . . . . . . . . . . . . . 48

$3.4 .1 \quad$ Diversity and density . . . . . . . . . . . . . . . . 48

3.4 .2 Diameter distribution in size classes . . . . . . . . . . . . . . . . 49

$3.4 .3 \quad$ Dominant species and families . . . . . . . . . . . . . . 50

3.5 Discussion $\ldots \ldots \ldots \ldots \ldots$

3.5.1 Effect of plot shape on species richness and community composition estimations . . . . . . . . . . . . . . 55

3.5.2 Local variation of tree diversity, dominance and structure at Los Volcanes . . . . . . . . . . . . . . . . . . . 56

3.5.3 The Los Volcanes forests in a Bolivian context . . . . . . . . . 57

3.5.4 Phytogeography of the Los Volcanes species . . . . . . . . . . 59

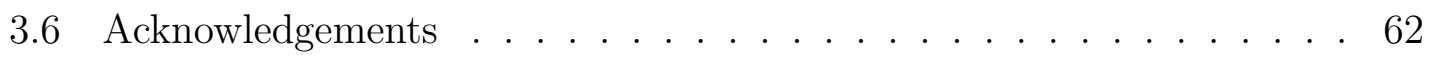

3.7 References . . . . . . . . . . . . . . . . . . . . . . . . . . . . 63

4 The role of dispersal ability, climate and spatial separation in shaping biogeographic patterns of phylogenetically distant plant groups in seasonally dry Andean forests of Bolivia $\quad 67$

$4.1 \quad$ Introduction $\ldots \ldots \ldots \ldots \ldots$

4.2 Methods . . . . . . . . . . . . . . . . . . . . . . . . . . . . . . . . . . . . . . . 71

$4.2 .1 \quad$ Study area and data collation . . . . . . . . . . . . 71 
4.2 .2 Data analyses $\ldots \ldots \ldots$. . . . . . . . . . . . . . . . 74

4.3 Results . . . . . . . . . . . . . . . . . . . . . . . . 76

4.3 .1 Species richness $\ldots \ldots \ldots$. . . . . . . . . . . . . . . 76

$4.3 .2 \quad$ Floristic similarity analysis . . . . . . . . . . . . . . . 77

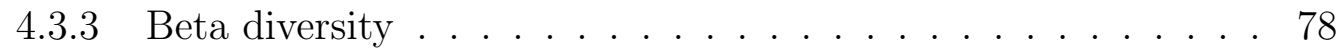

4.3 .4 Multiple matrix regression . . . . . . . . . . . . . . . . . 79

$4.4 \quad$ Discussion $\ldots \ldots \ldots \ldots$. . . . . . . . . . . . . . . . . . . . . . . . . . . . 80

4.5 Acknowledgements . . . . . . . . . . . . . . . . . . . . 84

4.6 References . . . . . . . . . . . . . . . . . . . . 85

5 Small-scale variation of vascular plant species richness and commu-

nity composition in a tropical American forest: the role of selective

$\begin{array}{ll}\text { niche partitioning processes } & 95\end{array}$

5.1 Introduction . . . . . . . . . . . . . . . . . . . . . . 97

5.2 Methods . . . . . . . . . . . . . . . . . . . . . . 98

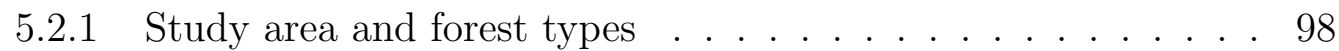

5.2 .2 Environmental data . . . . . . . . . . . . . . . . . . 999

5.2 .3 Data analysis . . . . . . . . . . . . . . . 100

5.3 Results . . . . . . . . . . . . . . . . . . . . . . . . . 102

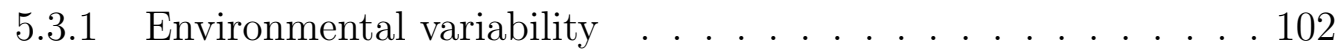

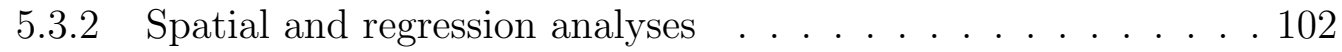

5.4 Discussion . . . . . . . . . . . . . . . . . . 107

5.5 Acknowledgements . . . . . . . . . . . . . . . . . 110

5.6 References . . . . . . . . . . . . . . . . . . 111

\begin{tabular}{llr}
\hline 6 & General conclusions & 117
\end{tabular}

6.1 A summary of major Findings . . . . . . . . . . . . . . . . . . 117

6.2 Implications of the Findings . . . . . . . . . . . . . . . . . 120

6.3 Limitations of the Study and Suggestions for Further Research . . . . 122

6.4 References . . . . . . . . . . . . . . . . . . . . . . . . . . . . . . 124 
\begin{tabular}{ll}
\hline Appendices & 127
\end{tabular}

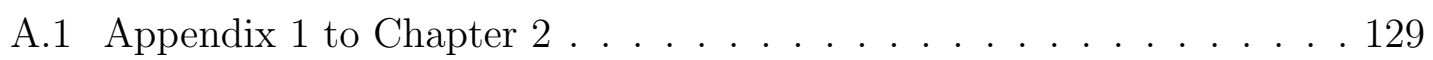

A.2 Appendix 2 to Chapter 2 . . . . . . . . . . . . . . . . . . 141

A.3 Appendix to Chapter 3 . . . . . . . . . . . . . . . . . . . 170

A.4 Appendix to Chapter 4 . . . . . . . . . . . . . . . . 174

A.5 Appendix to Chapter 5 . . . . . . . . . . . . . . . . . 177 


\title{
Chapter 1
}

\section{Plant diversity and ecological patterns in the Neotropics - A general introduction}

\begin{abstract}
"The primeval forests of the equatorial zone are grand and overwhelming by their vastness, and by the display of a force of development and vigour of growth rarely or never witnessed in temperate climates. Among their best distinguishing features are the variety of forms and species which everywhere meet and grow side by side, and the extent to which parasites, epiphytes, and creepers fill up every avail- able station with peculiar modes of life. If the traveller notices a particular species and wishes to find more like it, he may often turn his eyes in vain in every direction. Trees of varied forms, dimensions, and colours are around him, but he rarely sees any one of them repeated. Time after time he goes towards a tree which looks like the one he seeks, but a closer examination proves it to be distinct. He may at length, perhaps, meet with a second specimen half a mile off, or may fail altogether, till on another occasion he stumbles on one by accident. (Alfred R. Wallace, Tropical Nature, and other Essays, 1878, p. 65)"
\end{abstract}

\subsection{Research Focus 1: Neotropical and Bolivian plant di- versity}

The introductory quote from Alfred Russel Wallace (Wallace, 1878) is an excellent and short summary of the enormous plant diversity of tropical forests. Even after 
so may years since he wrote the essay to which it belongs, we are still struggling to document tropical diversity patterns and to understand the processes that have caused them.

It is a well-known fact that the tropics contain an overwhelmingly large number of the world's living species. Prance (1977) and Raven (1988) estimated that approximately two-thirds of all species of flowering plants (angiosperms) are native to the tropics. In turn, Thomas (1999) estimated that approximately 90000 species of flowering plants are present in the tropics of the Western Hemisphere (Neotropics), which include southern Mexico, Central America, most of South America, and the West Indies.

Nevertheless, plant diversity within the Neotropics is unevenly distributed. Major hotspots of diversity have been recognized in the Brazilian Atlantic forests, the Caribbean, the Tropical Andes and Amazonia (Myers et al., 2000; Kier et al., 2005). Traditionally, however, most public and academic attention has been towards tropical rain forests (Henderson et al., 1991), resulting in a large body of research projects and findings. The other side of the coin is that little is known about the diversity patterns in the neglected regions. A recent study to find out the geographical distribution of ecological research in the tropics revealed that considerable scientific productivity has emerged from few biological field stations like the those of the Organization for Tropical Studies (OTS) in Costa Rica or the Smithsonian Tropical Research Institute (STRI) in Panama (Stocks et al., 2008), all located in (Central American!) rain forests.

Bolivia, a landlocked country of ca. 1 million square kilometres located in central South America, is considered as one of the seventeen megadiverse countries of the world (i.e., rich in biological diversity and associated traditional knowledge) (Ibisch \& Merida, 2003). But as recently as the late 1980s, knowledge of the Bolivian flora was considered depauperate (Solomon, 1989). The situation as changed considerably in recent years and much progress has been done in documenting plant diversity in Bolivia (Jørgensen et al., 2006), with currently more than 12700 species of vascular 
plants (including ferns) and 1500 species of bryophytes recorded. Nevertheless, much work still needs to be done and, as in so many other tropical countries of the world (e.g., Laurance \& Peres, 2006), natural habitat fragmentation and destruction are major threats to the long-term conservation of the Bolivian forests (Killeen et al. 2007).

Thus, two major issues arise from the preceding paragraphs. First, there is a need for additional basic information from plant inventories, especially in non-Amazonian ecosystems. Second, there is an urgent need for the rapid and accurate production of this information. In the first two chapters of this dissertation I address this issues by showing results from quantitative plant inventories in the semi-deciduous forests of the eastern Andean foothills of Santa Cruz department.

\subsection{Research Focus 2: Community assembly in biodiverse tropical forests}

The causes of extremely high species diversity in (apparently) homogeneous and small areas of tropical forests has been a debate dating several decades back. Alfred Russel Wallace commented on this subject in the second half of the 19th century by saying:

"In the equable equatorial zone there is no ... struggle against climate. Every form of vegetation has become alike adapted to its genial heat and ample moisture, which has probably changed little even throughout geological periods; and the never-ceasing struggle for existence between the various species in the same area has resulted in a nice balance of organic forces, which gives the advantage, now to one, now to another, species, and prevents any one type of vegetation from monopolising territory to the exclusion of the rest. The same general causes have led to the filling up of every place in nature with some specially adapted form. Thus we find a forest of smaller trees adapted to grow in the shade of greater trees. Thus we find every tree supporting numerous other forms of vegetation, and some so crowded with epiphytes of 
various kinds that their forks and horizontal branches are veritable gardens. Creeping ferns and arums run up the smoothest trunks; an immense variety of climbers hang in tangled masses from the branches and mount over the highest tree-tops. Orchids, bromelias, arums, and ferns grow from every boss and crevice, and cover the fallen and decaying trunks with a graceful drapery. Even these parasites have their own parasitical growth, their leaves often supporting an abundance of minute creeping mosses and hepaticae. But the uniformity of climate which has led to this rich luxuriance and endless variety of vegetation is also the cause of a monotony that in time becomes oppressive.

(Alfred R. Wallace, Tropical Nature, and other Essays, 1878, p. 66-67)"

Since then, much has been written about determinants of species diversity (e.g., Huston, 1994; Rosenzweig, 1995). Brown \& Lomolino (1998) stated that the restriction of a taxon to a particular geographic range is consequence of both historical events and ecological processes. Both can help to explain how the taxon became confined to its present range and, by using modern molecular tools, we are now able to make inferences about the geographic origin, spread and contraction of the studied taxon (e.g., Hughes \& Eastwood, 2006, Saslis-Lagoudakis et al., 2008). Likewise, we are now able to assess the relative influence of historical events such as the formation of barriers by drifting continents, changing sea levels, glaciation and mountain uplift, but also by other taxon-specific events, such as stochastic long-distance dispersal and extinction of small populations, going on at the same time. Further, geologic, climatic, and other environmental changes caused the expansion and contraction of the ranges of many different species, allowing new combinations of organisms to come into contact and to limit each others distributions through biotic interactions (Brown \& Lomolino, 1998).

Willis \& Whittaker (2002) noted that species diversity is scale-dependant (either in terms of geography or time) and that the processes that best account for patterns of biodiversity at one scale are not necessarily the same at another, smaller or greater scale (Table 1.1). At very large, global scales, plant species richness seems to be primarily determined by potential evapotranspiration, the number of wet days 
per year, and measurements of topographical and habitat heterogeneity (Kreft \& Jetz, 2007). At smaller, continental to regional scales annual rainfall and rainfall seasonality seem to be the most important variables for explaining woody plant species richness in Neotropical forests (Clinebell et al., 1995). At much smaller and even local scales, soil properties (such as P availability, Al toxicity, drainage, waterholding capacity, and availability of $\mathrm{K}, \mathrm{Ca}$, and $\mathrm{Mg}$ ) have been proposed as being most likely to influence the diversity of tropical forests (Sollins, 1998). Endemic species richness, on the other hand, is thought to be a product of either refugia from past extinctions or of high rates of ecological and allopatric speciation (Brown \& Lomolino, 1998; Stattersfield et al., 1998; Jetz \& Rahbek, 2002; Orme et al., 2005).

One of the few studies examining patterns of endemic plant species found that, at a global scale, latitude and area were the strongest independent predictors Cowling \& Samways, 1995).

In a similar vein, much research has been done to identify the most important processes that shape community composition in exceptionally species-rich tropical forests (e.g., Gentry, 1988; Valencia et al., 1994). Two diametrically opposite theories, each with several variants, are currently invoked as the main mechanisms driving the assembly of (meta-) communities: (i) niche theories and (ii) the recently re-postulated neutral theories. The classical Hutchinsonian niche theory proposes that the niche is the sum of all the environmental factors biologically relevant to a certain species (such as soil nutrients, light or water availability) and thus that a given species occupies a N-dimensional environmental hypervolume that represents the range of conditions where it could exist (i.e., Hutchinsonian niche concept $=\mathrm{a}$ species' environmental needs). The alternative niche theory of Elton proposed that the niche of a species represented its functional role within the food-chain (Eltonian niche concept $=$ a species' impacts on the environment). A recent synthesis of niche theory by Chase \& Leibold (2003), termed 'contemporary niche theory', unified both older niche concepts resulting in the following revised definition: "niche is the joint description of the environmental conditions that allow a species to satisfy 


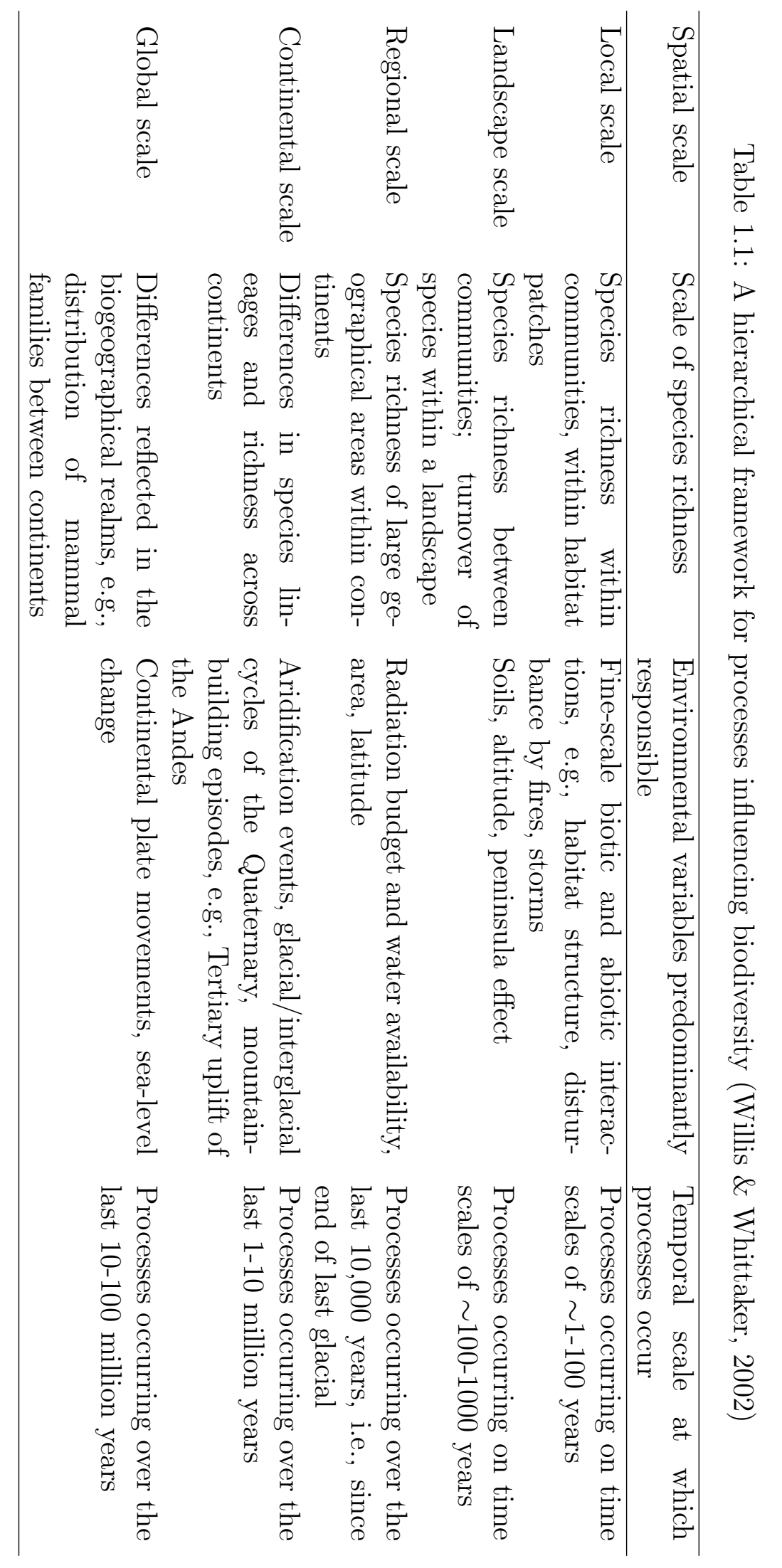


its minimum requirements so that the birth rate of a local population is equal to or greater than its death rate along with the set of per capita effects of that species on these environmental conditions". Similar renewed and more complex visions of the classical niche concept that incorporate the effects of dispersal, competition and stochasticity have been offered by Tilman (2004) and Kneitel \& Chase (2004).

Neutral community models (Bell, 2000; Hubbell, 2001; Chave et al., 2002) have received increased attention after Hubbell's formulation of the 'Unified Neutral Theory of Biodiversity and Biogeography' (Hubbell, 2001). In essence, Hubbell postulated that all individuals in a community are ecologically equivalent or neutral, i.e., "that trophically similar species are, at least to a first approximation, demographically identical on a per capita basis in terms of their vital rates, of birth, death, dispersal - and even speciation" (Hubbell, 2001). This theory invoked dispersal and stochastic demographic processes to explain coexistence and assembly in highly diverse tropical forests, but it was the concept of ecological equivalence, so contrary to our own perceptions and current understanding of the differential ecological requirements of species and individuals (Tilman, 1982), that sparked a multitude of studies (Holyoak \& Loreau, 2006). The bulk of these studies emphasized a major role of environmental heterogeneity at all spatial scales (Table 1.2), and in response to this, Hubbell and his colleagues redefined the equivalence concept a few times, going from treating initially all individuals in a community as completely equivalent in all requirements(Hubbell, 2001), to more restricted versions (Volkov et al., 2003, 2005: Hubbell, 2005). It is in the last two years, however, that evidence for the non-equivalence of species in a community, and thus for a major role of niche-based processes, has been accumulating. Two recently published studies stand particularly out, as they used very different and novel approaches to test the niche-neutral community assembly mechanism. The first study by Kelly et al. (2008) paired woody species from the dry forests in Chamela, Mexico, based on evolutionary similarity. They used resolved terminal dichotomies and distinguished between congeneric pairs and non-congeneric pairs (within the same family) to analyse fractional abundance 
patterns (cf. Sugihara et al., 2003). They argued, that, if neutral processes are operating (and species are ecologically equivalent), then the fractional abundance patterns of congeneric and non-congeneric species pairs should be indistinguishable from that of pairs chosen at random from the Chamela community. What they found was in fact the opposite, and very much at odds with ecological equivalence assumptions, as there appears to be some regulation mechanism within populations of congeneric species pairs that is not present in randomly selected or non-congeneric pairs. The second study by Kraft et al. (2008) tested if tree distribution of 1089 woody species at the 0.04 ha scale in a 25 ha plot of tropical rain forest in Yasuni (Ecuador) were distributed randomly with respect to six critical functional traits (e.g., specific leaf area, seed mass) essential for woody plant strategy. They compared each trait's measures of central tendency (mean) and variability (range, standard deviation and variance) to a null model to infer the occurrence of either environmental filtering and/or classical niche differentiation and found strong evidence for both processes.

It follows from the previous paragraphs that much progress has been achieved in our understanding of community assembly in hyper-diverse tropical forests. Hubbell's theory has certainly been an important driver of novel ecological research, but nevertheless, many questions remain unanswered. For example, for logistical and practical reasons most of the studies have focused on few groups of plant species (Table 1.2), while none has used all plant species within a community. Are the mechanisms of community assembly that operate within one homogeneous forest community the same and of similar importance for different life-forms (e.g., trees, terrestrial herbs, epiphytes) or guilds? What happens at larger regional scales? Are metacommunity assembly mechanisms influenced by taxon-specific characteristics? Within this state-of-the-art of the mechanisms invoked to explain species coexistence and community assembly, I test the relative importance of niche and dispersal (neutral) processes in shaping metacommunities in dry forest islands of Andean Bolivia (Chapter 4). Further, I separately evaluate the relationships between environmental factors 
and community composition for several life-forms at the hectare-scale to assess if gradients in the former influence the latter (Chapter 5).

\subsection{Specific Research objectives}

This dissertation is a compilation of three publications and one manuscript and divided into two major parts corresponding to the two research areas presented above. The first two chapters address issues of Neotropical and Bolivian plant diversity (Research Focus 1), while the latter two address community assembly mechanisms in Bolivian forests at large and local geographical scales (Research Focus 2):

i To document and compare the total vascular plant diversity in three different central Bolivian sub-Andean forest types (decidous, semideciduous and evergreen) (Chapter 2).

ii To quantitatively assess the relative importance that different lifeform groups and taxa (families, genera and species) have on species richness and community composition of a sub-Andean tropical forest (Chapter 2).

iii To compare total vascular plant and life-form diversity in Central Bolivian forest plots with similar studies in the neotropical region (Chapters $2 \& 3$ ).

iv To study the phytogeography of the tree flora of these Central Bolivian forest plots (Chapter 3).

v To assess biogeographical patterns of seasonally dry forests in Andean Bolivia (Chapter 4).

vi To explore the relative importance of environmental or neutral mechanisms to explain species coexistence in tropical forests at large regional and local spacial scales (Chapters $4 \& 5$ ). 


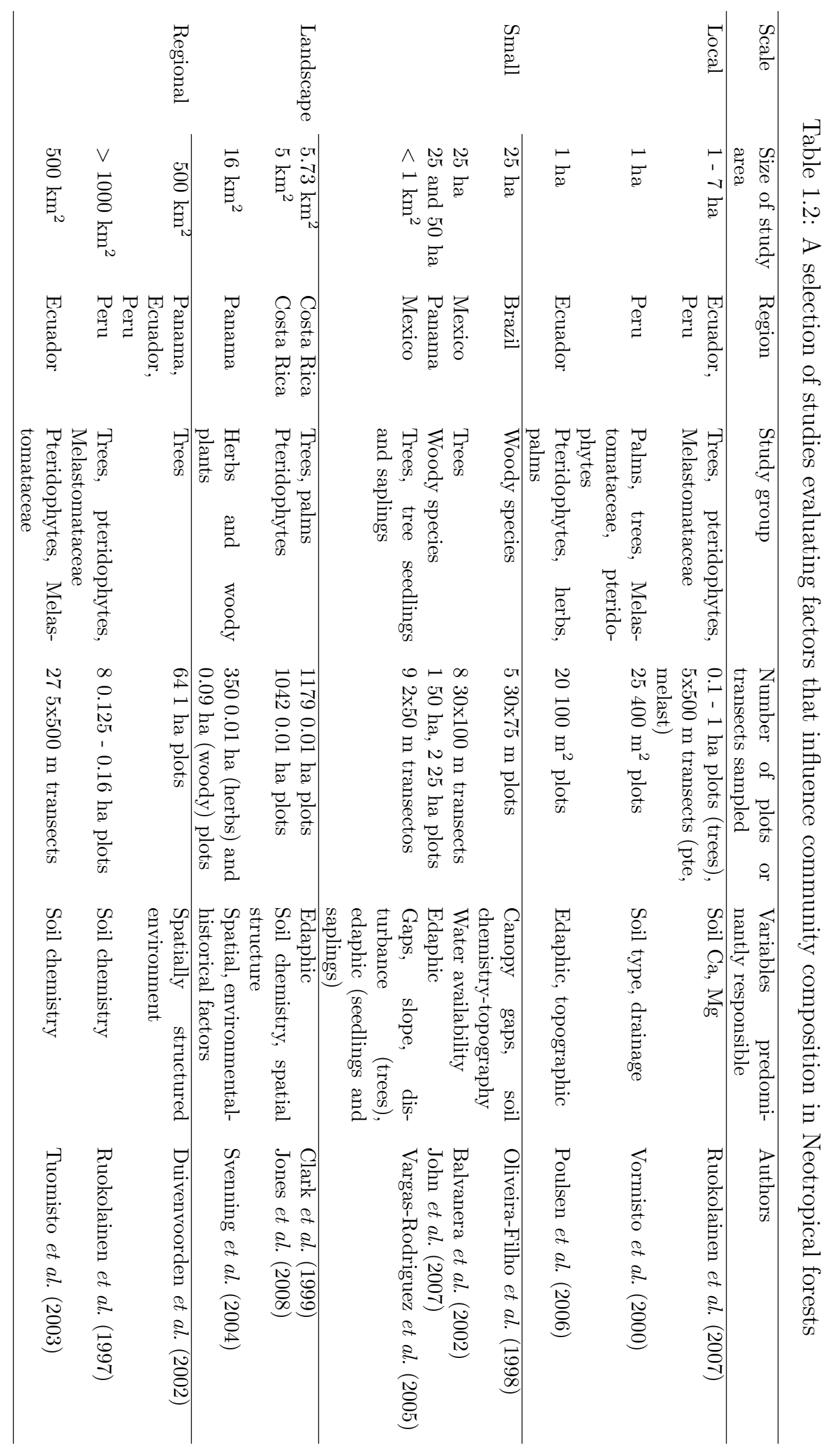




\subsection{References}

Balvanera, P, Lott, E, Segura, G, Siebe, C, \& Islas, A. 2002. Patterns of betadiversity in a Mexican tropical dry forest. Journal of Vegetation Science, 13, $145-158$.

Bell, G. 2000. The distribution of abundance in neutral communities. The American Naturalist, 155, 606-617.

Brown, JH, \& Lomolino, MV. 1998. Biogeography. Sinauer Associates, Sunderland, MA.

Chase, JM, \& Leibold, MA. 2003. Ecological niches: linking classical and contemporary approaches. University of Chicago Press, Chicago, IL.

Chave, J, Muller-Landau, HC, \& Levin, SA. 2002. Comparing classical community models: theoretical consequences for patterns of diversity. The American Naturalist, 159, 1-23.

Clark, DB, Palmer, MW, \& Clark, DA. 1999. Edaphic factors and the landscapescale distributions of tropical rain forest trees. Ecology, 80, 2662-2675.

Clinebell, RR, Phillips, OL, Gentry, AH, Stark, N, \& Zuuring, H. 1995. Prediction of neotropical tree and liana species richness from soil and climatic data. Biodiversity and Conservation, 4, 56-90.

Cowling, RM, \& Samways, MJ. 1995. Predicting global patterns of endemic plant species richness. Biodiversity Letters, 2, 127-131.

Duivenvoorden, JF, Svenning, JC, \& Wright, SJ. 2002. Beta diversity in tropical forests. Science, 295, 636-637.

Gentry, AH. 1988. Tree species richness of upper amazonian forests. Proceedings of the National Academy of Sciences of the United States of America, 85, 156-159. 
Henderson, A, Churchill, SP, \& Luteyn, JL. 1991. Neotropical plant diversity. Nature, 351, 21-22.

Holyoak, M, \& Loreau, M. 2006. Reconciling empirical ecology with neutral community models. Ecology, 87, 1370-1377.

Hubbell, SP. 2001. The unified neutral theory of biodiversity and biogeography. Princeton University Press.

Hubbell, SP. 2005. Neutral theory in community ecology and the hypothesis of functional equivalence. Functional Ecology, 19, 166-172.

Hughes, C, \& Eastwood, R. 2006. Island radiation on a continental scale: exceptional rates of plant diversification after uplift of the Andes. Proceedings of the National Academy of Sciences of the United States of America, 103, 10334-10339.

Huston, MA. 1994. Biological diversity. Cambridge University Press.

Ibisch, PL, \& Merida, G. (eds). 2003. Biodiversidad: la riqueza de Bolivia. Estado de conocimiento y conservacion. Editorial FAN, Santa Cruz, Bolivia.

Jetz, W, \& Rahbek, C. 2002. Geographic range size and determinants of avian species richness. Science, 297, 1548-1551.

John, R, Dalling, JW, Harms, KE, Yavitt, JB, Stallard, RF, Mirabello, M, Hubbell, SP, Valencia, R, Navarrete, H, Vallejo, M, \& Foster, RB. 2007. Soil nutrients influence spatial distributions of tropical tree species. Proceedings of the National Academy of Sciences of the United States of America, 104, 864-869.

Jones, MM, Tuomisto, H, Borcard, D, Legendre, P, Clark, DB, \& Olivas, PC. 2008. Explaining variation in tropical plant community composition: influence of environmental and spatial data quality. Oecologia, 155, 593-604.

Jørgensen, PM, Ulloa, C, \& Maldonado, C. 2006. Riqueza de plantas vasculares. In: Moraes, M, Øllgaard, B, \& Kvist, LP (eds), Botánica Económica de los Andes Centrales. La Paz: Universidad Mayor de San Andrés, Plural Editores. 
Kelly, CK, Bowler, MG, Pybus, O, \& Harvey, PH. 2008. Phylogeny, niches, and relative abundance in natural communities. Ecology, 89, 962-970.

Kier, G, Mutke, J, Dinerstein, E, Ricketts, TH, Kuper, W, Kreft, H, \& Barthlott, W. 2005. Global patterns of plant diversity and floristic knowledge. Journal of Biogeography, 32, 1107-1116.

Killeen, TJ, Calderon, V, Soria, L, Quezada, B, Steininger, MK, Harper, G, Solórzano, LA, \& Tucker, CJ. 2007. Thirty years of land-cover change in Bolivia. AMBIO: A Journal of the Human Environment, 36, 600-606.

Kneitel, JM, \& Chase, JM. 2004. Trade-offs in community ecology: linking spatial scales and species coexistence. Ecology Letters, 7, 69-80.

Kraft, NJB, Valencia, R, \& Ackerly, DD. 2008. Functional traits and niche-based tree community assembly in an Amazonian forest. Science, 322, 580-582.

Kreft, H, \& Jetz, W. 2007. Global patterns and determinants of vascular plant diversity. Proceedings of the National Academy of Sciences of the United States of America, 104, 5925-5930.

Laurance, WF, \& Peres, CA (eds). 2006. Emerging threats to tropical forests. University of Chicago Press, Chicago, Illinois.

Myers, N, Mittermeier, RA, Mittermeier, CG, da Fonseca, GA, \& Kent, J. 2000. Biodiversity hotspots for conservation priorities. Nature, 403, 853-858.

Oliveira-Filho, AT, Curi, N, Vilela, EA, \& Carvalho, DA. 1998. Effects of canopy gaps, topography, and soils on the distribution of woody species in a central Brazilian deciduous dry forest. Biotropica, 30, 362-375.

Orme, CDL, Davies, RG, Burgess, M, Eigenbrod, F, Pickup, N, Olson, VA, Webster, AJ, Ding, TS, Rasmussen, PC, Ridgely, RS, Stattersfield, AJ, Bennett, PM, Blackburn, TM, Gaston, KJ, \& Owens, IPF. 2005. Global hotspots of species richness are not congruent with endemism or threat. Nature, 436, 1016-1019. 
Poulsen, AD, Tuomisto, H, \& Balslev, H. 2006. Edaphic and floristic variation within a 1-ha plot of lowland Amazonian rain forest. Biotropica, 38, 468-478.

Prance, GT. 1977. Floristic inventory of the Tropics: where do we stand? Annals of the Missouri Botanical Garden, 64, 659-684.

Raven, PH. 1988. Tropical floristics tomorrow. Taxon, 37, 549-560.

Rosenzweig, ML. 1995. Species diversity in space and time. Cambridge University Press, NY.

Ruokolainen, K, Linna, A, \& Tuomisto, H. 1997. Use of Melastomataceae and pteridophytes for revealing phytogeographic patterns in Amazonian rain forests. Journal of Tropical Ecology, 13, 243-256.

Ruokolainen, K, Tuomisto, H, Macía, MJ, Higgins, MA, \& Yli-Halla, M. 2007. Are floristic and edaphic patterns in Amazonian rain forests congruent for trees, pteridophytes and Melastomataceae? Journal of Tropical Ecology, 23, 13-25.

Saslis-Lagoudakis, C, Chase, MW, Robinson, DN, Russell, SJ, \& Klitgaard, BB. 2008. Phylogenetics of neotropical Platymiscium (Leguminosae: Dalbergieae): systematics, divergence times, and biogeography inferred from nuclear ribosomal and plastid DNA sequence data. American Journal of Botany, 95, 1270-1286.

Sollins, P. 1998. Factors influencing species composition in tropical lowland rain forest : does soil matter? Ecology, 79, 23-30.

Solomon, J. 1989. Bolivia. Pages 456-463 of: Campbell, DJ, \& Hammond, D (eds), Floristic inventory of tropical forests. The New York Botanical Garden, Bronx, USA.

Stattersfield, AJ, Crosby, MJ, Long, AJ, \& Wege, DC. 1998. Endemic bird areas of the world: priorities for biodiversity conservation. BirdLife International, Cambridge, UK. 
Stocks, G, Seales, L, Paniagua, F, Maehr, E, \& Bruna, EM. 2008. The geographical and institutional distribution of ecological research in the tropics. Biotropica, 40, $397-404$.

Sugihara, G, Bersier, LF, Southwood, TRE, Pimm, SL, \& May, RM. 2003. Predicted correspondence between species abundances and dendrograms of niche similarities. Proceedings of the National Academy of Sciences of the United States of America, 100, 5246-5251.

Svenning, JC, Kinner, DA, Stallard, RF, Engelbrecht, BMJ, \& Wright, SJ. 2004. Ecological determinism in plant community structure across a tropical forest landscape. Ecology, 85, 2526-2538.

Thomas, WW. 1999. Conservation and monographic research on the flora of Tropical America. Biodiversity and Conservation, 8, 1007-1015.

Tilman, D. 1982. Resource Competition and Community Structure. Monographs in Population Biology. Princeton University Press.

Tilman, D. 2004. Niche tradeoffs, neutrality, and community structure: a stochastic theory of resource competition, invasion, and community assembly. Proceedings of the National Academy of Sciences of the United States of America, 101, 1085410861.

Tuomisto, H, Poulsen, AD, Ruokolainen, K, Moran, RC, Quintana, C, Celi, J, \& Canas, G. 2003. Linking floristic patterns with soil heterogeneity and satellite imagery in Ecuadorian Amazonia. Ecological Applications, 13, 352-371.

Valencia, R, Balslev, H, \& Mino, G. 1994. High tree alpha-diversity in amazonian Ecuador. Biodiversity and Conservation, 3, 21-28.

Vargas-Rodriguez, YL, Vázquez-García, JA, \& Williamson, GB. 2005. Environmental correlates of tree and seedling-sapling distributions in a Mexican tropical dry forest. Plant Ecology, 180, 117-134. 
Volkov, I, Banavar, JR, Hubbell, SP, \& Maritan, A. 2003. Neutral theory and relative species abundance in ecology. Nature, 424, 1035-1037.

Volkov, I, Banavar, JR, He, F, Hubbell, SP, \& Maritan, A. 2005. Density dependence explains tree species abundance and diversity in tropical forests. Nature, 438, 658-661.

Vormisto, J, Phillips, OL, Ruokolainen, K, Tuomisto, H, \& Vasquez, R. 2000. A comparison of fine-scale distribution patterns of four plant groups in an Amazonian rainforest. Ecography, 23, 349-359.

Wallace, AR. 1878. Tropical Nature, and other Essays. Macmillan \& Co. London.

Willis, KJ, \& Whittaker, RJ. 2002. Species diversity - scale matters. Science, 295, $1245-1248$. 


\section{Chapter 2}

Non-woody life-form contribution to vascular plant species richness in a tropical American forest

Reynaldo Linares-Palomino, Victor Cardona, Ernest I. Hennig, Isabell Hensen, Doreen Hoffmann, Jasmin Lendzion, Daniel Soto, Sebastian K. Herzog and Michael Kessler

Plant Ecology (In press)

DOI: dx.doi.org/10.1007/s11258-008-9505-Z 


\section{Abstract}

We provide total vascular plant species counts for three 1-ha plots in deciduous, semi-deciduous, and evergreen forests in central Bolivia. Species richness ranged from 297 species and 22360 individuals per hectare in the dry deciduous forest to 382 species and 31670 individuals per hectare in the evergreen forest. Orchidaceae, Pteridophyta and Leguminosae were among the most species-rich major plant groups in each plot and Peperomia (Piperaceae), Pleurothallis (Orchidaceae) and Tillandsia (Bromeliaceae), all epiphytes, were the most species-rich genera. This dominance of a few but very diverse and/or widespread taxa contrasted with the low compositional similarity between plots. In a neotropical context, these Central Bolivian forest plots are similar in total species richness to other dry deciduous and humid montane forests, but less rich than most Amazonian forests. Nevertheless, lianas, terrestrial herbs and especially epiphytes proved to be of equal or higher species richness than most other neotropical forest inventories from which data are available. We therefore highlight the importance of non-woody life-forms (especially epiphytes and terrestrial herbs) in Andean foothill forest ecosystems in terms of species richness and numbers of individuals, representing in some cases nearly $50 \%$ of the species and more than $75 \%$ of the individuals. These figures stress the need for an increased inventory effort on non-woody plant groups in order to accurately direct conservation actions.

Keywords: alpha diversity, Andean foothills forest ecosystem, life-form diversity, non-woody plants, total species inventory

\subsection{Introduction}

Statements about the diversity of plant species in forest ecosystems are usually based on results from vegetation inventories that are mostly restricted to a certain plant subgroup. Woody species, usually trees and shrubs with diameter at breast 
height of $\geq 1 \mathrm{~cm}$ (e.g., the STRI 50 ha plots, Condit 1995), $\geq 2.5 \mathrm{~cm}$ (e.g., 0.1 ha transects, Gentry 1982) and $\geq 10 \mathrm{~cm}$ (e.g., Gentry 1988; Valencia et al. 1994; Smith \& Killeen 1998), are the most commonly studied plant groups. In contrast, herbs (e.g., Poulsen \& Balslev 1991; Poulsen \& Nielsen 1995), lianas (Perez-Salicrup et al., 2001; Mascaro et al., 2004) and epiphytes (Ingram et al., 1996; Arévalo \& Betancur, 2004; Benavides et al., 2005; Krömer et al., 2005) are less commonly used to characterize the diversity of vegetation types. These non-woody life-forms, however, have been shown to be of importance in the few assessments of tropical plant alpha diversity in which all vascular plants were counted (Whitmore et al., 1985; Gentry \& Dodson, 1987; Duivenvoorden, 1994; Balslev et al., 1998, Galeano et al., 1998; Langenberger et al., 2006). The scarcity of such studies can be attributed to the difficulties associated with identification of more (and usually less well-known) plant groups (restricting inventories to some life-form groups in the tropics is already a huge identification task) and the difficulty of collecting epiphyte specimens from the forest canopy. Whitmore and colleagues have undertaken the most comprehensive study of vascular plants to date in a Costa Rican rain forest. To accomplish their task of inventorying all species (including non-vascular plants), destructive sampling of a $10 \mathrm{~m}$ x $10 \mathrm{~m}$ plot was required (Whitmore et al., 1985). The few full tropical plant inventories performed to date have focused on a single and homogeneous vegetation type, usually tropical lowland rain forests. Although some of these studies (e.g., Duivenvoorden 1994; Langenberger et al. 2006) inventoried plots and transects along edaphic and physiographic gradients, only two have inventoried and compared different vegetation types using a uniform sampling methodology throughout. Alvarez, 2003) reported total vascular plant counts in three 0.1 ha plots in Amazonian, Chocoan and Andean forests in Colombia. This study, however, was not published formally and epiphytes in the Amazonian plot were not sampled, restricting the total vascular plant count to the Chocó and Andean forest only. The other study by (Gentry \& Dodson, 1987) compared three 0.1-ha plots in wet, moist and dry forests in Ecuador. The lack of standardized inventory methods hampers the quantitative 
comparison between both of these studies. The use of florulas could be an option to compare different forests (e.g., Gentry 1990), but the size of the areas studied and collection intensities are not uniform (Tobler et al., 2007). We chose Central Bolivia, a region where four major biomes occur in close proximity to each other (humid and moist vegetation from Amazonia, seasonal subtropical lowland vegetation from the Chaco, subtropical highland vegetation from the Andes and seasonal vegetation of the Chiquitanía (Ibisch et al., 2003)) as our study region. We established within this complex biogeographic setting three permanent 1-ha plots. We used a uniform methodology along a humidity gradient from deciduous to evergreen forest, inventorying all vascular plants present. Our main objective was to quantitatively assess the relative importance of different life-form groups and taxa within the different vegetation types we surveyed and to compare our results with similar studies in the neotropical region.

\subsection{Methods}

\subsubsection{Study area}

The study was carried out at the Refugio Los Volcanes in Santa Cruz, Bolivia. Los Volcanes is a private reserve of approximately 300 ha. It is located about $18^{\circ} 06^{\prime} \mathrm{S}$ and $63^{\circ} 36^{\prime} \mathrm{E}$ and is adjacent to the southern border of Amboró National Park, directly on the transition from the humid inner tropics to the seasonally dry subtropics (Fig 2.17). The substrate of the study area consists primarily of red sandstone and locally of loamy sedimentary rocks (lutite). These red sandstones form cliffs several hundred meters high and are intersected by narrow valleys providing the area with dramatic scenery. Annual precipitation is about $1200-1500 \mathrm{~mm}$, with most of the rainfall from October/November to March/April, but with high temporal variability. The general vegetation of the area has been classified as 'subhumid to humid deciduous forest of southeastern Amboró' Navarro et al., 1996), and is usually found at 900-1100 masl. Among the dominant tree species are Aspidosperma cylindrocarpon 


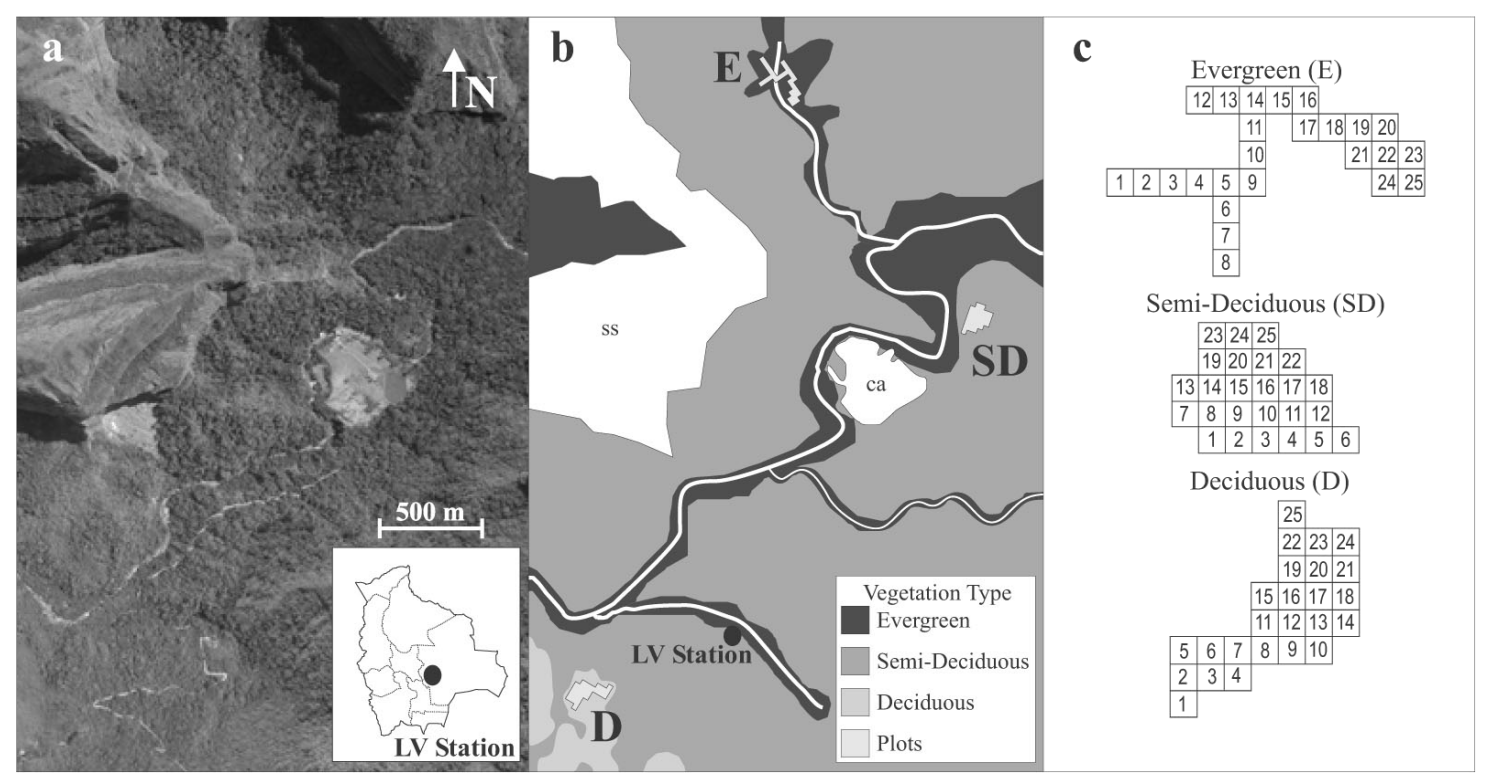

Figure 2.1: Main vegetation types and plot shape and location in the study area. (a) Aerial photograph of the Refugio Los Volcanes area in central Bolivia, inset showing map of Bolivia and location of study area, (b) schematic representation of the major vegetation types and geographical characteristics of the area, showing plot locations and orientation (ss: sandstone, ca: cleared area, LV Station: Los Volcanes Research Station), and (c) shape of inventory plots, where numbers denote subplots.

(Apocynaceae), Cariniana estrellensis (Lecythidaceae), Cedrela lilloi (Meliaceae), Gallesia integrifolia (Phytolaccaceae), Pachystroma longifolium (Euphorbiaceae), Pogonopus tubulosus (Rubiaceae) and Tabebuia lapacho (Bignoniaceae) (Navarro et al., 1996). Locally, however, vegetation types are determined by differences in topography, aspect, and precipitation regime that lead to ecologically relevant differences in water availability within the study area. Consequently, the dominant zonal vegetation is semi-deciduous forest (about 30-50\% deciduous trees) mainly found on shaded south-facing slopes. Steep, sunny and north-facing slopes are occupied by deciduous forest (70-90\% deciduous trees), whereas flat, shaded valleys with groundwater supply support evergreen forest (10-20\% deciduous trees) (Fig 2.1b).

\subsubsection{Vegetation sampling}

A permanent plot of 1 ha was established in each forest type (deciduous, semideciduous and evergreen) between 2002-2003. Each plot was subdivided into 25 adjacent $20 \mathrm{~m}$ x $20 \mathrm{~m}$ subplots. Plots where laid out in such a way as to include 
only the forest type under study, avoiding other forest types, young secondary vegetation, and non-forest vegetation (e.g., rock outcrops). Thus, our plots are not the traditional square $100 \mathrm{~m}$ x $100 \mathrm{~m}$ inventory plots, but have rather irregular shapes (Fig,2.1b). All vascular plants in each plot were inventoried between 2002 and 2004, mainly in the season following the summer rains (i.e., May to August). J. Lendzion inventoried herbs, shrub and tree seedlings, E.I. Hennig epiphytes, D. Hoffmann lianas and V. Cardona, D. Soto and S.K. Herzog woody plants. For the herb inventories, we recorded all species with stem diameter below $1 \mathrm{~cm}$. Additionally, we recorded all Cactaceae, Bromeliaceae and Costaceae below $1 \mathrm{~m}$ height and epiphytes on fallen branches. For lianas, we recorded all individuals, including Araceae, with a diameter of $>1 \mathrm{~cm}$ at $1.3 \mathrm{~m}$ above soil level. All epiphytes were observed and counted. Collections of epiphytes were made either with a clipper pole or with the help of rope climbing techniques. Binoculars were used to aid identification when they were too inaccessible to collect. Finally, we recorded all woody plants, excluding lianas, with diameter at breast height $(\mathrm{dbh})$ of $>1 \mathrm{~cm}$. Voucher specimens of all species were collected for later determination and are deposited at USZ (Santa Cruz) and LPB (La Paz), with a small subset of samples at the Göttingen Herbarium (GOET) (herbarium acronyms follow Holmgren \& Holmgren, 1998). Several sterile specimens could not be fully identified and were sorted into morphospecies. The final stage of data production was completed at USZ (by R. Linares-Palomino) by cross-checking all collected vouchers in order to unify morphospecies delimitations.

\subsubsection{Data Analysis}

We used a conservative approach in calculating species numbers by lumping highly similar morphospecies into one group instead of considering them as several distinct species. The herb inventory, which included life-forms other than herbaceous plants, was split into terrestrial herbs, tree seedlings, shrub seedlings and epiphytes. Thus, terrestrial herbs formed a life-form group by itself in subsequent analyses. The other three subgroups were cross-referenced with the tree, shrub 
and epiphyte inventories, and merged accordingly. We follow the TROPICOS and Flora of Bolivia online databases for nomenclatural purposes (both available at http://mobot.mobot.org/W3T/Search/vast.html and http://www.efloras.org/, respectively). Despite much progress in the understanding of the phylogeny of extant ferns, familial composition and relationships are still unsatisfactorily solved (Smith et al., 2006; Schüttpelz \& Pryer, 2007). We therefore refrained from assigning our collections to families and treated all ferns and fern allies as a single taxon Pteridophyta. We computed species accumulation curves based on the $20 \mathrm{~m}$ x $20 \mathrm{~m}$ subplots using EstimateS (Colwell, 2005). Similarity between forest plots was evaluated by subtracting the Bray-Curtis distance between two forest plots from unity. Pair-wise Bray-Curtis distances (DBC) were calculated in the vegan package for $\mathrm{R}$ (Oksanen et al., 2008, R Development Core Team, 2008) using presence/absence data by $\mathrm{DBC}=2 \mathrm{a} /(2 \mathrm{a}+\mathrm{b}+\mathrm{c})$, where $\mathrm{a}$ : total number of species present in both forest plots, b: number of species present only in the first forest plot, c: number of species present only in the second forest plot (Magurran, 2004). In order to compare the species richness of the Los Volcanes plots with that of other forests in the Neotropics, we searched for other published full plant, epiphyte, liana, terrestrial herb and tree/woody plant inventories (Appendix 1) and plotted species accumulation curves for each forest type at Los Volcanes against the species richness data of the other studies.

\subsection{Results}

\subsubsection{Taxonomic Diversity}

We recorded 80352 individual plants belonging to 670 species (including morphospecies) on the three plots (Appendix 2). We were able to completely identify $52 \%$ of our collections to species level (341 species), an additional 25\% could be assigned to genus (172 morphospecies) and 14\% to family (95 morphospecies). Nine percent (62 morphospecies) could not be assigned to a family or lower taxon. The most 
Table 2.1: Number of families, genera and species of three 1-ha plots in Santa Cruz, Central Bolivia (A: angiosperm, P: pteridophytes). Life-form composition values show the number of species assigned to each plant group.

\begin{tabular}{|c|c|c|c|c|c|c|c|c|c|c|c|c|}
\hline & \multicolumn{3}{|c|}{$\begin{array}{l}\text { Total from the } \\
\text { three forest plots }\end{array}$} & \multicolumn{3}{|c|}{$\begin{array}{l}\text { Deciduous } \\
\text { forest plot }\end{array}$} & \multicolumn{3}{|c|}{$\begin{array}{l}\text { Semi-deciduous } \\
\text { forest plot }\end{array}$} & \multicolumn{3}{|c|}{$\begin{array}{l}\text { Evergreen } \\
\text { forest plot }\end{array}$} \\
\hline & $\mathrm{A}$ & $\mathrm{P}$ & Total & $\mathrm{A}$ & $\mathrm{P}$ & Total & $\mathrm{A}$ & $\mathrm{P}$ & Total & $\mathrm{A}$ & $\mathrm{P}$ & Total \\
\hline Families & 80 & 12 & 92 & 55 & 5 & 60 & 64 & 8 & 72 & 65 & 10 & 75 \\
\hline Genera & 245 & 28 & 273 & 149 & 13 & 162 & 168 & 17 & 185 & 166 & 24 & 190 \\
\hline Species & 617 & 53 & 670 & 279 & 18 & 297 & 353 & 29 & 382 & 337 & 44 & 381 \\
\hline life-form & & & & & & & & & & & & \\
\hline Epiphyte & 142 & & & 67 & & & 80 & & & 109 & & \\
\hline Hemiepiphyte & 9 & & & 1 & & & 4 & & & 8 & & \\
\hline Liana & 153 & & & 64 & & & 86 & & & 44 & & \\
\hline Shrub & 97 & & & 45 & & & 49 & & & 57 & & \\
\hline Tree, liana & 1 & & & 1 & & & - & & & 1 & & \\
\hline Tree, shrub & 39 & & & 17 & & & 16 & & & 20 & & \\
\hline Terrestrial herb & 79 & & & 30 & & & 42 & & & 57 & & \\
\hline Tree & 148 & & & 71 & & & 105 & & & 84 & & \\
\hline Other & 1 & & & - & & & - & & & 1 & & \\
\hline Parasite & 1 & & & 1 & & & - & & & - & & \\
\hline
\end{tabular}

species-rich plots were in the evergreen and semi-deciduous forest, both of which had an almost identical number of species (381 and 382, respectively). The deciduous forest had 297 species. Of the 273 genera, most were recorded in the evergreen and semi-deciduous forest (190 and 185, respectively) compared to 162 genera in the deciduous forest. Of the 92 families, 75 were found in the evergreen, 72 in the semi-deciduous and 60 in the deciduous forest. The contribution of ferns and lycophytes ("pteridophytes") to species richness was higher in the evergreen forest than in the two other forest types (Table 2.1).

Of the ten most species-rich families, seven were shared between all three plots, although with different ranking within each plot (Table 2.2. Taking all three plots together, the most species-rich families were Orchidaceae, pteridophytes, Leguminosae and Bignoniaceae. Orchidaceae, a family containing mostly epiphytic species, was by far the most species-rich in all plots. Pteridophytes, composed mostly of ground herbs, ranked second in the evergreen and semi-deciduous, and fourth in the deciduous forest. Leguminosae, which was mainly composed of woody species in our plots, decreased in importance from the deciduous (second) to the evergreen forest (fourth). Absolute species numbers were similar in the evergreen forest and higher in the semi-deciduous forest as compared to the deciduous forest. Bignoniaceae (a family including liana, shrub and tree species), the third most important family in the 
deciduous forest, was the fourth most important family in the semi-deciduous forest (again with a higher species number), but was ranked only eighth in the evergreen forest. Only two other families were important in terms of species numbers and these were shared by two forest types: Apocynaceae (mostly trees) present in the deciduous and semi-deciduous forest and Rubiaceae (shrubs and trees) present in the semi-deciduous and evergreen forest. In contrast to families, only five species-rich genera were common to all three forest plots (Peperomia, Pleurothallis, Tillandsia, Acalypha and Eugenia). Of these, the three most species-rich genera were Peperomia, Tillandsia and Pleurothallis, although ranking varied between forests plots (Table 2.2).

Two species of Tillandsia had the highest numbers of individuals on all three plots (Table 2.2): T. bryoides had highest numbers in the deciduous forest, whereas T. tenuifolia had most individuals in the semi-deciduous and evergreen forests. The ten species with highest number of individuals in the deciduous forest included epiphytes and terrestrial herbs (three species each) and shrubs and trees (two species each). The contribution of non-woody plants increased in the semi-deciduous forest, including epiphytes (four species), terrestrial herbs (three species) and one species each of shrubs, trees and lianas. Non-woody plant contribution was highest in the evergreen forest with six species of epiphyte, two species of terrestrial herb and one hemiepiphyte species dominating. Only one shrub species was included among the top ten. 


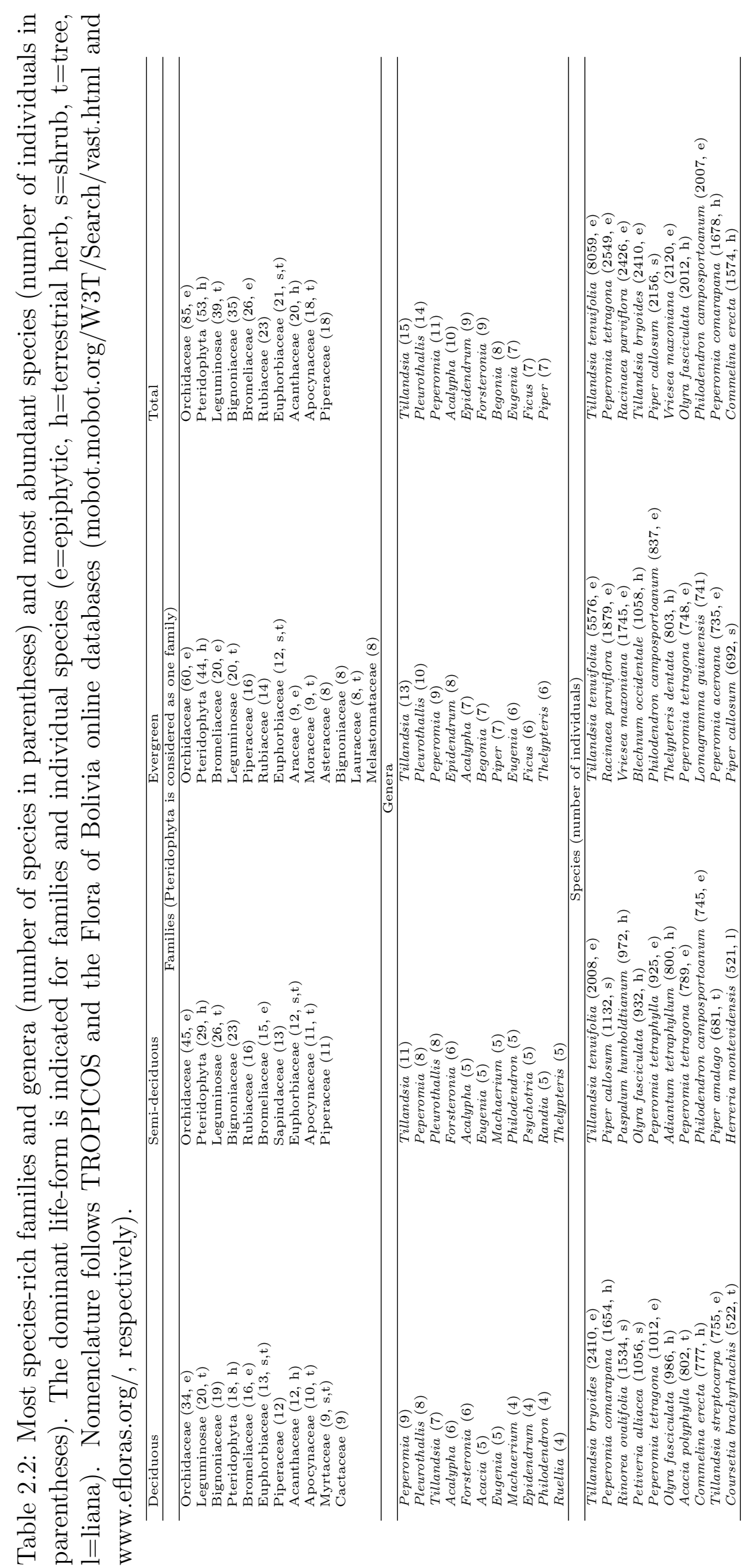




\subsubsection{Life-form composition}

In the deciduous forest, trees, epiphytes and lianas contributed similar species numbers $(22-24 \%$ of the total (Table 2.1). In the semi-deciduous forest, trees were slightly more species-rich than other life-forms (28\%), followed by lianas $(23 \%)$ and epiphytes (21\%). The most species-rich life-form in the evergreen forest was epiphytes (29\%), followed by trees (22\%), shrubs (15\%), and ground herbs $(15 \%)$ (Table 2.1). Woody plants (including lianas and shrubs) contributed to approximately $66 \%, 57 \%$ and $54 \%$ of total species richness in the deciduous, semi-deciduous and evergreen forest plots, respectively. There was a highly significantly statistical difference between the proportions of life-forms in the three studied forest types (Gtest, $G=28.34, p=0.0004$, df $=8$ ). Pearson correlation analyses among life-form richness patterns within each forest plot showed that tree species richness patterns were positively and significantly correlated with total plant species richness: deciduous forest $\mathrm{r}=0.67(p=0.0002)$, semi-deciduous forest $\mathrm{r}=0.54(p=0.0049)$, evergreen forest $\mathrm{r}=0.59(p=0.0021)$. No other significant correlation could be detected between trees and other life-forms, except with shrubs in the semi-deciduous forest $(\mathrm{r}=0.51, p=0.01)$ and with lianas in the evergreen forest $(\mathrm{r}=0.53, p=$ 0.0064). Apart from trees, lianas were the only other life-form that showed similar levels of positive and significant correlations with total plant species richness across the three plots: deciduous forest $\mathrm{r}=0.63(p=0.0007)$, semi-deciduous forest $\mathrm{r}=$ $0.66(p=0.0003)$, evergreen forest $\mathrm{r}=0.54(p=0.0051)$. Other positive significant correlations were detected in the evergreen forest plot between total plant species richness and epiphytes $(\mathrm{r}=0.60, p=0.0017)$ and terrestrial herbs $(\mathrm{r}=0.69, p=$ $0.0001)$.

\subsubsection{Similarity among plots}

Similarity among plots was 0.46 between deciduous and semi-deciduous (155 species shared), 0.37 between deciduous and evergreen (125 species shared) and 0.57 between semi-deciduous and evergreen (216 species shared). We recorded 106 species 
occurring in all three plots. 123 species were recorded only in the deciduous plot, 117 only in the semi deciduous plot and 146 only in the evergreen forest plot.

\subsection{Discussion}

\subsubsection{Plot shape and its influence on species richness estimations}

Spatial distribution patterns of plant species in tropical forests are influenced by niche assembly and/or random dispersal assembly processes acting at both local and landscape scales (Chave, 2004; Gaston \& Chown, 2005; John et al., 2007), resulting in mostly clumped distributions (e.g., Condit et al., 2000). Within this scenario, plot shape has been documented to influence estimates of species richness, i.e., longer and narrower rectangular plots are prone to capture more species than square plots of similar area (Condit et al., 1996; Laurance et al., 1998). The differences, however, were found to be small and statistically non-significant in a study comparing tree species richness in $100 \mathrm{~m}$ x $100 \mathrm{~m}$ square plots versus $40 \mathrm{~m}$ x $250 \mathrm{~m}$ rectangular plots in Central Amazonia (Laurance et al., 1998). Given the patchy and fragmented nature of the deciduous and evergreen forests in our study area, it was impossible to survey the vegetation types in traditional square or rectangular plots. Rather, we tried to survey as environmentally homogeneous an area as possible, leading to our irregular plot shape design. There is little doubt that plot shape has influenced our

results, especially those of the evergreen forest plot. The extent of this influence, however, seems to be small, since the species accumulation curves for all vascular plants together and for individual life-forms significantly decrease or level off when the hectare is completely surveyed, suggesting that sampling was representative in all three forest types.

\subsubsection{Alpha diversity and plant density at Los Volcanes}

Additional plant surveys across the entire Los Volcanes reserve (aprox. 300 ha) have documented 65 species of pteridophytes (M. Kessler, unpub. data), of which 
$53(82 \%)$ were recorded in the plots. The corresponding figures are $83 \%$ for Acanthaceae, $90 \%$ for Araceae, $84 \%$ for Bromeliaceae, and $92 \%$ for Cactaceae. If these groups are considered to be representative of the total flora, then our plots contain roughly $80 \%$ - $90 \%$ of the vascular plant flora of Los Volcanes reserve, which would then be estimated to be around 740 - 840 species, corresponding to about $6.4 \%$ - 7.2\% of the Bolivian vascular plant flora (estimated at 11600 species, Jørgensen et al. 2006). Species that were not encountered in the plots are either forest species that are patchily distributed, or non-forest species occurring on sandstone walls of the area, secondary vegetation on landslides, rock falls, or along streams. The impressive number of individuals of T. tenuifolia and T. bryoides in the Los Volcanes plots is not unique to these forests. Both have been documented as the characteristic and dominant species of some seasonal forests of Central and Southern Bolivia (Navarro, 2001). Likewise, Bonnet (2006) and Bonnet et al. (2008) reported high densities and wide regional distribution for T. tenuifolia in Paraná, Brazil. They attributed the success of this species in humid and seasonal semi-deciduous forests to its small size (ca. $25 \mathrm{~cm}$ long, Smith \& Downs, 1977), the presence of plumose winddispersed diaspores, CAM metabolism, its atmospheric nutrient acquisition strategy (i.e., species that have no form of absorptive root system, in which the tank habit is lacking and where epidermal trichomes cover the whole shoot system and are entirely responsible for nutrient and water uptake, cf. Griffiths \& Smith, 1983) and to the fact that this species usually forms dense monospecific associations with no explicit preference for some position on the phorophyte. Most of these factors are also true for $T$. bryoides, in particular the small size of the plants (usually no longer than $5 \mathrm{~cm}$ ), their plumose diaspores (Smith \& Downs, 1977) and the formation of dense monospecific populations (Navarro, 2001).

\subsubsection{Los Volcanes plots in a neotropical context}

To our knowledge, there is only one other study (Balslev et al., 1998) that includes an inventory of all vascular plants in one hectare of tropical forest and is therefore 
directly comparable to our study (although the mentioned study inventoried trees and shrubs of $1-5 \mathrm{~cm}$ dbh only in a 0.49 -ha subplot). In the Amazonian terra firme rain forest of Cuyabeno, Ecuador, a perhumid area with $3555 \mathrm{~mm}$ of annual rainfall and no dry season, Balslev et al. (1998) found 942 species of vascular plants in 88 families. Our plots contained between 297-382 species in 60-75 families per hectare for the three forest types studied. This is clearly much lower than the Cuyabeno plot, but lower rainfall and strong seasonality set the forests at Los Volcanes apart from the Amazonian site. There were further differences in the relative contribution of different life-forms to overall species richness at both sites. At Cuyabeno, trees (which made up $50 \%$ of species) were clearly the most species-rich group, distantly followed by epiphytes (making up $18 \%$ of species) and shrubs and lianas (both making up $11 \%$ of species). At Los Volcanes, trees were the most species-rich life-form in the deciduous and semi-deciduous forest, but contributed only $32 \%$ of all species. Epiphytes (including hemiepiphytes) and lianas (23\% and $22 \%$ in the deciduous forest, $22 \%$ and $23 \%$ in the semi-deciduous forest, respectively) followed them closely. Shrubs were less important in these forests, contributing $13 \%$ and $15 \%$ of all species in the deciduous and semi-deciduous forest, respectively, and having percentages only slightly higher than terrestrial herbs (ca. 10\%). The most striking difference is in the evergreen forest in which epiphytes $(31 \%)$ were more species-rich than trees (27\%). For a more representative comparison of the Los Volcanes data with other neotropical sites, we constructed species-accumulation curves for Los Volcanes that allowed comparisons with other surveys with plot sizes of up to 1 ha (Fig.2.2). As Los Volcanes is found in a biogeographical transition zone and has high moisture variability between plots, our study plots cannot be easily assigned to any of the usual broad categories used for neotropical forests (lowland humid, montane humid, lowland dry, etc.). We therefore compared our richness counts with data from a wide range of other neotropical forest habitats.

Most inventories in lowland humid forests (mostly in Amazonia) have higher vascular plant, epiphyte, liana, and terrestrial herb counts than any of the plots at 

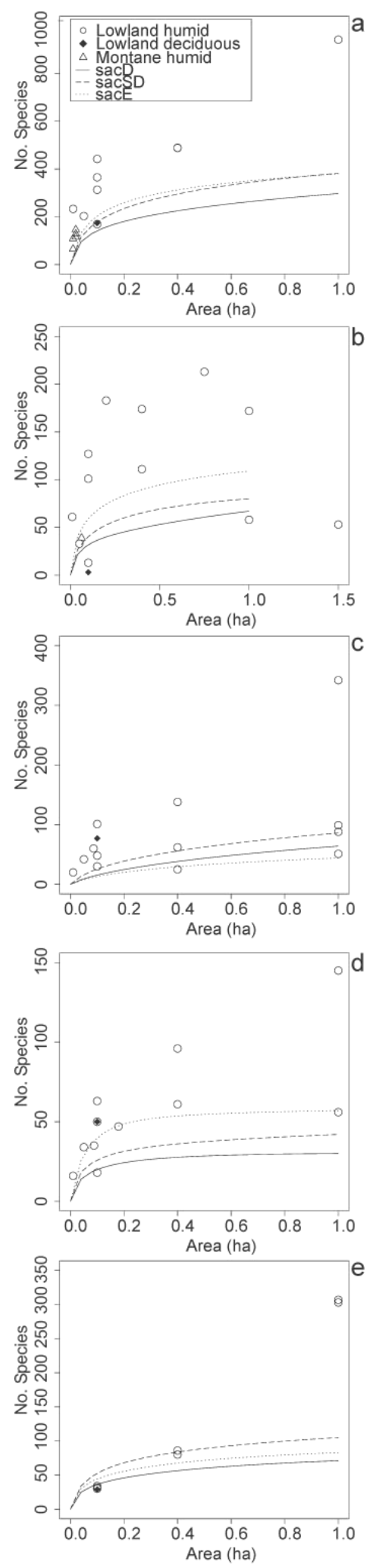

Figure 2.2: Species accumulation curves (sac) for each forest type at Los Volcanes ( $D=$ deciduous, $S D=$ semi-deciduous, $E=$ evergreen) against species richness data of: a) vascular plant counts, b) epiphyte inventories, c) liana inventories, d) terrestrial herb inventories and e) woody plant inventories in the Neotropics. Symbols described in the legend apply to the entire figure. Note the different scales of the $\mathrm{x}$ and $\mathrm{y}$ axes. (Values for individual sites are provided in Appendix 1). 
Los Volcanes (Fig 2.2). In contrast, plots inventoried in dry deciduous or humid montane forests have similar levels of species richness (Fig,2.2). For example, vascular plant counts at Los Volcanes are similar to those in the humid mountains of the Carrasco National Park (Ibisch, 1996) and those in the deciduous forest of Capeira and moist forest of Jauneche in Ecuador (Gentry \& Dodson, 1987), at least at small plot sizes (Fig 2.2a). Epiphytes are perhaps the best represented group at Los Volcanes. They are more diverse here than a humid forest plot in Ecuador (Jauneche, Gentry \& Dodson, 1987)) and at least as diverse as the humid forest plots in French Guyana (Sinamary, Bordenave et al., 1998)), Venezuela (Surumoni, Nieder et al., 2000) ) and interestingly also as the Chocoan forests in Caquetá (Colombia, Duivenvoorden, 1994)). They also have higher species richness than other deciduous forests and similar species richness as montane forests (Fig, 2.2 b). Lianas have similar levels of species richness to several humid forests in Ecuador (Yasuní, Nabe-Nielsen, 2001, Burnham, 2004)), Colombia (Nuqui and Coqui, Galeano et al., 1998)) and Bolivia (Oquiriquia, Perez-Salicrup et al., 2001)). In contrast, the deciduous forest of Capeira in coastal Ecuador (Gentry \& Dodson, 1987) has a much higher species richness of lianas in smaller plots (Fig 2.2 c). Terrestrial herb counts are similar to other humid forests from Costa Rica (Whitmore et al., 1985), Panama (Royo \& Carson, 2005), French Guyana (Bordenave et al., 1998), Colombia (Galeano et al., 1998), Ecuador (Gentry \& Dodson, 1987; Poulsen \& Balslev, 1991) and Brazil (Costa, 2004). The deciduous forest in Capeira (Gentry \& Dodson, 1987) again has a higher count of terrestrial herbs than any plot at Los Volcanes (Fig.2.2d). Tree species richness at Los Volcanes is similar to several other forest types in the Neotropics. If only trees with $\mathrm{dbh}>10 \mathrm{~cm}$ are considered, the plots at Los Volcanes are similar to other deciduous forests in Bolivia and reach the lower end of species richness of 1-ha plots in humid and montane forests (Fig,2.3). If we compare the overall richness of trees on the Los Volcanes plots (including those with dbh ¡10 cm) with several forest types inventoried by A. Gentry (0.1-ha transects using the exploded quadrat method, available at http://www.mobot.org/MOBOT/research/gentry/transect.shtml), the 


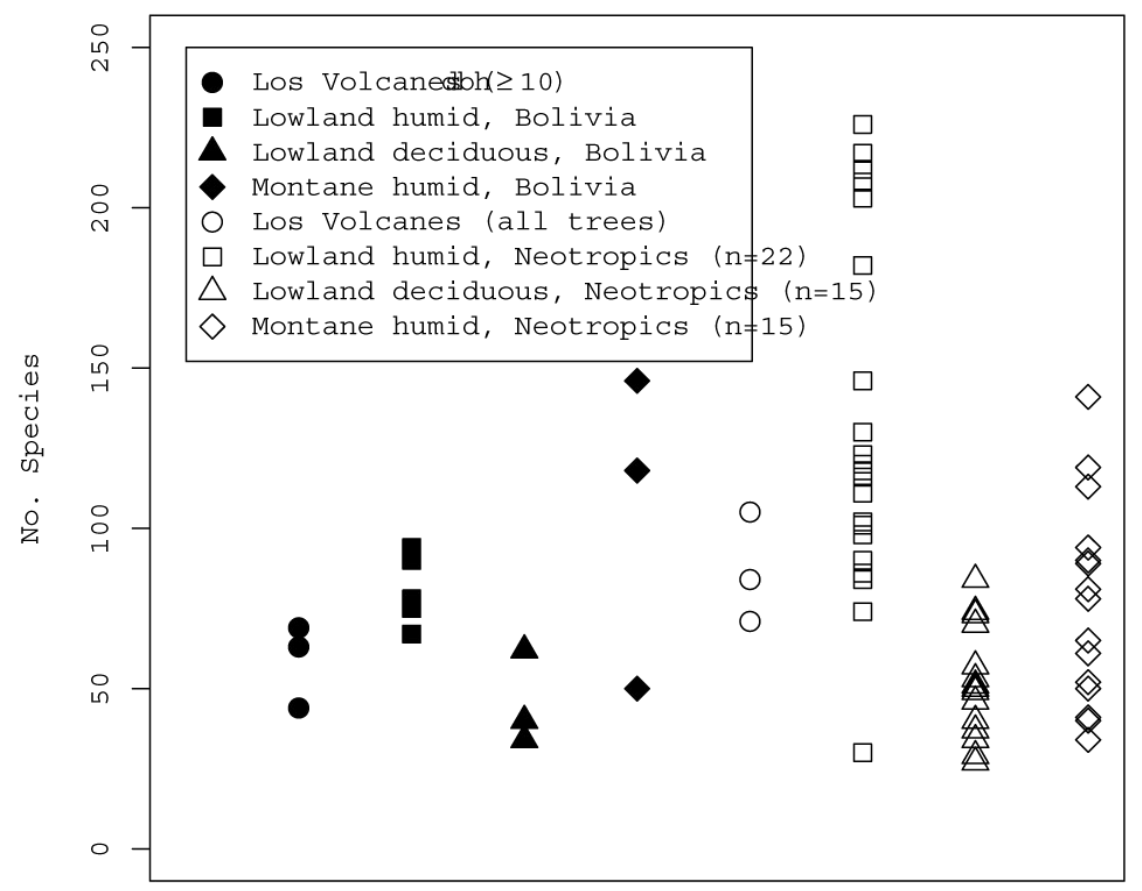

Figure 2.3: Species richness values of woody plants and trees at Los Volcanes (LV) with $d b h \geq 10 \mathrm{~cm}$ compared against species richness data of other woody plant inventories (1 hectare, $d b h \geq 10 \mathrm{~cm}$ ) in Bolivia (filled symbols), and all trees inventoried at Los Volcanes compared to species richness data of woody plant inventories (0.1 hectare, $d b h \geq 2.5 \mathrm{~cm})$ in the Neotropics (empty symbols).

studied plots have higher species richness values than most dry deciduous forests in the Neotropics. They have also values similar to the average species richness of humid montane forests, but only reach the lower end of the species richness values of humid lowland forest (Fig 2.3.

\subsubsection{Contribution of non-woody plant groups to overall plant species richness}

Non-woody plants, and specifically epiphytes, have been highlighted by Gentry \& Dodson (1987) as the most important plant group in terms of species richness and individual numbers in wet tropical rain forests in Ecuador, whereas tree species 
with $\mathrm{dbh} \geq 10 \mathrm{~cm}$ were more or less equally well represented in dry, moist and wet forest. In the wet forest sampled by them, $35 \%$ of the species and $49 \%$ of the individuals were epiphytes. At Los Volcanes, epiphytes (including hemiepiphytes) included ca. $30 \%$ of the species and nearly $60 \%$ of the individuals in the evergreen forest plot. If terrestrial herbs are included, non-woody life-forms represent $45 \%$ of the species and more than $76 \%$ of the individuals. In the semi-deciduous and deciduous forest plots, figures are somewhat lower but still impressive. Epiphytes (including hemiepiphytes) comprised $22 \%$ and $23 \%$ of the species and $36 \%$ and $31 \%$ of the individuals on the semi-deciduous and deciduous forest plots, respectively. If terrestrial herbs are included, the figures are ca. $32 \%$ of the species in both forests and $58 \%$ and $52 \%$ of the individuals, respectively. Non-woody life-forms showed a consistent pattern across the different forest types and represented an important component of neotropical forests. This is certainly overlooked when plots are only sampled for trees. In contrast, trees with $\mathrm{dbh} \geq 10 \mathrm{~cm}$ represented only $14 \%, 18 \%$ and $16 \%$ of the species and $2.4 \%, 2.5 \%$ and $1.7 \%$ of the individuals on our deciduous, semi-deciduous and evergreen forest plot, respectively. Despite these facts, species richness and floristic data arising from tree inventories are often used (for want of better and more complete, but also usually more work-intensive, information) to characterise all the surrounding vegetation because they are the major structural element (e.g., ter Steege et al., 2000a; La Torre-Cuadros et al., 2007). While this may be enough to identify the major forest types, and indeed some studies in tropical forests do confirmed a positive correlation between the richness of the woody component of a forests and its accompanying non-woody component (e.g., Webb et al., 1967), there is also evidence that this is not a consistent pattern (Duivenvoorden \& Lips, 1995 in Colombia; ter Steege et al., 2000b in Guyana; Williams-Linera et al., 2005 in Mexico; Tchouto et al., 2006 in Cameroon). Our own data indicate that that there is no consistent correlation between tree species richness and the other life-forms studied at Los Volcanes. The comparisons of inventories across the Neotropics discussed above also show that forests with higher tree species 
richness do not necessarily contain higher species richness in non-woody life-forms. In a neotropical context, the forests at Los Volcanes may be poor in terms of tree species richness, but they do show remarkable species richness of lianas, terrestrial herbs and, especially, epiphytes, challenging even those of the most diverse forests of the continent, the Colombian Chocó. We have shown that tree species richness alone does not always correlate with species richness patterns in other life-forms (although it consistently did so with total species richness across the three forest types studied, as did the species richness patterns of lianas). We thus advocate that more effort be put into non-woody plant inventories in order to better assess the biodiversity of an area and to allow more informed conservation decisions to be made.

\subsection{Acknowledgements}

We thank three anonymous reviewers who provided helpful critiques of and insightful suggestions to the manuscript. We thank P. Wilkie for his suggestions and for correcting the English of the manuscript. We also thank the owner of Los Volcanes, A. Schwiening, for allowing us to work on his land. SKH and MK are indebted to the Colección Boliviana de Fauna and the Dirección General de Biodiversidad for research permits. We thank the curators of the Herbario Nacional de Bolivia (LPB) and Herbario del Oriente Boliviano (USZ) for providing us with working facilities and allowing access to their collections. Several botanists aided in species identification (S. Beck, T. Krömer, J.F. Morales, M. Nee, C. Taylor, R. Vasquez). We are grateful to C. Hamel and M. Valverde for help in the field. Financial support is acknowledged from the Deutsche Forschungsgemeinschaft (DFG) and the German Academic Exchange Service (DAAD). 


\subsection{References}

Alvarez, E. 2003. Conteo total de plantas vasculares en parcelas de 0.1 ha en Bosques de Amazonía, Chocó y los Andes de Colombia. Page 171 of: Romero-Fernández L, Lucero-Mosquera H, Aguirre-Mendoza Z (ed), Libro de Resúmenes II Congreso de Conservación de la Biodiversidad en los Andes y la Amazonia y IV Congreso Ecuatoriano de Botánica. Loja, Ecuador: Editoral de la Universidad Técnica Particular de Loja.

Arévalo, R, \& Betancur, J. 2004. Diversidad de epífitas vasculares en cuatro bosques del sector Suroriental de la Serranía de Chiribiquete, Guayana Colombiana. Caldasia, 26, 359-380.

Balslev, H, Valencia, R, \& Paz y Miño, G. 1998. Species count of vascular plants in 1-hectare of humid lowland forest in Amazonian Ecuador. In: Dallmeier, F, \& Comiskey, JA (eds), Forest biodiversity in North, Central and South America and the Caribbean: research and monitoring. Man and the Biosphere Series, vol. 21. Lancashire: UNESCO and Parthenon.

Benavides, AM, Duque, AJ, Duivenvoorden, JF, Vasco, GA, \& Callejas, R. 2005. A first quantitative census of vascular epiphytes in rain forests of Colombian Amazonia. Biodiversity and Conservation, 14, 739-758.

Bonnet, A. 2006. Caracterização fitossociológica das bromeliáceas epifíticas e suas relações com os fatores geomorfológicos e pedológicos da planície do Rio Iguaçu, Paraná, Brasil. Dissertation, Universidade Federal do Paraná, Brazil.

Bonnet, A, Curcio, G, Barddal, M, \& Roderjan, C. 2008. Estratificação vertical de bromélias epifíticas na planície do rio Iguaçu, Paraná, Brasil. Revista Brasileira de Biociências, 5, 492-494.

Bordenave, BG, de Granville, JJ, \& Hoff, M. 1998. Measurement of species richness of vascular plants in a Neotropical rain forest in French Guiana. In: Dallmeier, F, \& Comiskey, JA (eds), Forest biodiversity, research, monitoring and modelling: 
conceptual background and Old World case studies. Man and the Biosphere Series, vol. 20. Paris: UNESCO and Parthenon.

Burnham, RJ. 2004. Alpha and beta diversity of lianas in Yasuní National Park, Ecuador. Forest Ecology and Management, 190, 43-55.

Chave, J. 2004. Neutral theory and community ecology. Ecology Letters, 7, 241-253.

Colwell, RK. 2005. EstimateS: Statistical estimation of species richness and shared species from samples. Version 7.5. User's Guide and application published at: http://purl.oclc.org/estimates. Cited 31 May 2007.

Condit, R. 1995. Research in large, long-term tropical forest plots. Trends In Ecology \& Evolution, 10, 18-22.

Condit, R, Hubbell, SP, Lafrankie, JV, Sukumar, R, Manokaran, N, Foster, RB, \& Ashton, PS. 1996. Species-area and species-individual relationships for tropical trees: a comparison of three 50-ha plots. Journal of Ecology, 84, 549-562.

Condit, R, Ashton, PS, Baker, P, Bunyavejchewin, S, Gunatilleke, S, Gunatilleke, N, Hubbell, SP, Foster, RB, Itoh, A, LaFrankie, JV, Lee, HS, Losos, E, Manokaran, N, Sukumar, R, \& Yamakura, T. 2000. Spatial patterns in the distribution of tropical tree species. Science, 288, 1414-1418.

Costa, FRC. 2004. Structure and composition of the ground-herb community in a terra-firme Central Amazonian forest. Acta Amazonica, 34, 53-59.

Duivenvoorden, JF. 1994. Vascular plant-species counts in the rain-forests of the middle Caqueta area, Colombian amazonia. Biodiversity and Conservation, $\mathbf{3}$, $685-715$.

Duivenvoorden, JF, \& Lips, JM. 1995. A land ecological study of soils, vegetation and plant diversity in Colombian Amazonia. Tropenbos Series, vol. 12. Wageningen: The Tropenbos Foundation. 
Galeano, G, Suarez, S, \& Balslev, H. 1998. Vascular plant species count in a wet forest in the Choco area on the Pacific coast of Colombia. Biodiversity and Conservation, $7,1563-1575$.

Gaston, KJ, \& Chown, SL. 2005. Neutrality and the niche. Functional Ecology, 19, $1-6$.

Gentry, AH. 1982. Patterns of neotropical plant-species diversity. Evolutionary Biology, 15, 1-85.

Gentry, AH. 1988. Tree species richness of upper amazonian forests. Proceedings of the National Academy of Sciences of the United States of America, 85, 156-159.

Gentry, AH (ed). 1990. Four Neotropical rainforests. New Haven: Yale University Press.

Gentry, AH, \& Dodson, C. 1987. Contribution of nontrees to species richness of a tropical rain-forest. Biotropica, 19, 149-156.

Griffiths, H, \& Smith, JAC. 1983. Photosynthetic pathways in the Bromeliaceae of Trinidad - relations between life-forms, habitat preference and the occurrence of CAM. Oecologia, 60, 176-184.

Holmgren, PK, \& Holmgren, NH. 1998. Index Herbariorum: A global directory of public herbaria and associated staff. New York Botanical Garden's Virtual Herbarium. Cited 5 February 2008.

Ibisch, PL. 1996. Neotropische Epiphytendiversität, das Beispiel Bolivien. Wiehl: Martina-Galunder-Verlag.

Ibisch, PL, Beck, SG, Gerkmann, B, \& Carretero, A. 2003. Ecoregiones y ecosistemas. Pages 47-88 of: Ibisch, PL, \& Mérida, G (eds), Biodiversidad: la riqueza de Bolivia. Estado de conocimiento y conservación. Santa Cruz: Ministerio de Desarrollo Sostenible y Planificación, Editorial FAN. 
Ingram, SW, Ferrell-Ingram, K, \& Nadkarni, NM. 1996. Floristic composition of vascular epiphytes in a Neotropical cloud forest, Monteverde, Costa Rica. Selbyana, 17, 88-103.

John, R, Dalling, JW, Harms, KE, Yavitt, JB, Stallard, RF, Mirabello, M, Hubbell, SP, Valencia, R, Navarrete, H, Vallejo, M, \& Foster, RB. 2007. Soil nutrients influence spatial distributions of tropical tree species. Proceedings of the National Academy of Sciences of the United States of America, 104, 864-869.

Jørgensen, PM, Ulloa, C, \& Maldonado, C. 2006. Riqueza de plantas vasculares. In: Moraes, M, Øllgaard, B, \& Kvist, LP (eds), Botánica Económica de los Andes Centrales. La Paz: Universidad Mayor de San Andrés, Plural Editores.

Krömer, T, Kessler, M, Gradstein, SR, \& Acebey, A. 2005. Diversity patterns of vascular epiphytes along an elevational gradient in the Andes. Journal of Biogeography, 32, 1799-1809.

La Torre-Cuadros, M, Herrando-Perez, S, \& Young, KR. 2007. Diversity and structural patterns for tropical montane and premontane forests of central Peru, with an assessment of the use of higher-taxon surrogacy. Biodiversity and Conservation, 16, 2965-2988.

Langenberger, G, Martin, K, \& Sauerborn, J. 2006. Vascular plant species inventory of a Philippine lowland rain forest and its conservation value. Biodiversity and Conservation, 15, 1271-1301.

Laurance, WF, Ferreira, LV, Rankin-de Merona, JM, \& Hutchings, RW. 1998. Influence of plot shape on estimates of tree diversity and community composition in central Amazonia. Biotropica, 30, 662-665.

Magurran, AE. 2004. Measuring biological diversity. Blackwell Publishing Limited.

Mascaro, J, Schnitzer, SA, \& Carson, WP. 2004. Liana diversity, abundance, and mortality in a tropical wet forest in Costa Rica. Forest Ecology and Management, $190,3-14$. 
Nabe-Nielsen, J. 2001. Diversity and distribution of lianas in a neotropical rain forest, Yasuni National Park, Ecuador. Journal of Tropical Ecology, 17, 1-19.

Navarro, G. 2001. Contribución al conocimiento fitosociológico de la vegetación de epífitos vasculares del centro y sur de Bolivia. Revista Boliviana de Ecología y Conservación Ambiental, 10, 59-79.

Navarro, G, Vargas, I, Jardim, A, Toledo, M, \& de la Barra, N. 1996. Clasificación y diagnóstico para la conservación de la vegetación de la región del Parque $\mathrm{Na-}$ cional Amboró. Santa Cruz, Bolivia. Universidad Complutense, FAN, MHNNKM, UMSS, New York Botanical Garden.

Nieder, J, Engwald, S, Klawun, M, \& Barthlott, W. 2000. Spatial distribution of vascular epiphytes (including hemiepiphytes) in a lowland amazonian rain forest (Surumoni crane plot) of southern Venezuela. Biotropica, 32, 385-396.

Oksanen, J, Kindt, R, Legendre, P, O'Hara, B, Simpson, GL., Stevens, MHH, \& Wagner, H. 2008. vegan: Community Ecology Package. R package version 1.13-1.

Perez-Salicrup, DR, Sork, VL, \& Putz, FE. 2001. Lianas and trees in a liana forest of Amazonian Bolivia. Biotropica, 33, 34-47.

Poulsen, AD, \& Balslev, H. 1991. Abundance and cover of ground herbs in an amazonian rain-forest. Journal of Vegetation Science, 2, 315-322.

Poulsen, AD, \& Nielsen, IH. 1995. How many ferns are there in one hectare of tropical rain-forest. American Fern Journal, 85, 29-35.

R Development Core Team. 2008. R: A Language and Environment for Statistical Computing. R Foundation for Statistical Computing, Vienna, Austria. ISBN 3-900051-07-0.

Royo, AA, \& Carson, WP. 2005. The herb community of a tropical forest in central Panama: dynamics and impact of mammalian herbivores. Oecologia, 145, 66-75. 
Schüttpelz, E, \& Pryer, KM. 2007. Fern phylogeny inferred from 400 leptosporangiate species and three plastid genes. Taxon, 56, 1037-1050.

Smith, AR, Pryer, KM, Schüttpelz, E, Korall, P, Schneider, H, \& Wolf, PC. 2006. A classification for extant ferns. Taxon, 55, 705-731.

Smith, DN, \& Killeen, TJ. 1998. A comparison of the structure and composition of montane and lowland tropical forest in the Serranía Pilón Lajas, Beni, Bolivia. Pages 681-700 of: Dallmeier, F, \& Comiskey, JA (eds), Forest biodiversity research, monitoring and modeling. New York: The Parthenon Publishing Group.

Smith, LB, \& Downs, RJ. 1977. Tillansioideae (Bromeliaceae). Flora Neotropica Monographs, 4, 663-1492.

Tchouto, MGP, De Boer, WF, De Wilde, JJFE., \& Van der Maesen, LJG. 2006. Diversity patterns in the flora of the Campo-Ma'an rain forest, Cameroon: do tree species tell it all? Biodiversity and Conservation, 15, 1353-1374.

ter Steege, H, Sabatier, D., Castellanos, H, Van Andel, T, Duivenvoorden, J, De Oliveira, AA, Ek, R, Lilwah, R, Maas, P, \& Mori, S. 2000a. An analysis of the floristic composition and diversity of Amazonian forests including those of the Guiana Shield. Journal of Tropical Ecology, 16, 801-828.

ter Steege, H, Ek, R, \& van Andel, T. 2000b. A comparison of diversity patterns of tree and non-tree groups. In: ter Steege, $\mathrm{H}(\mathrm{ed})$, Plant diversity in Guyana. With recommendation for a protected areas strategy. Tropenbos Series, vol. 18. Wageningen: Tropenbos Foundation.

Tobler, M, Honorio, E, Janovec, J, \& Reynel, C. 2007. Implications of collection patterns of botanical specimens on their usefulness for conservation planning: an example of two neotropical plant families (Moraceae and Myristicaceae) in Peru. Biodiversity and Conservation, 16, 659-677.

Valencia, R, Balslev, H, \& Mino, G. 1994. High tree alpha-diversity in amazonian Ecuador. Biodiversity and Conservation, 3, 21-28. 
Webb, LJ, Tracey, JG, Williams, WT, \& Lance, GN. 1967. Studies in numerical analysis of complex rain-forest communities. 2. Problem of species-sampling. Journal of Ecology, 55, 525-538.

Whitmore, TC, Peralta, R, \& Brown, K. 1985. Total species count in a Costa Rican tropical rain forest. Journal of Tropical Ecology, 1, 375-378.

Williams-Linera, G, Palacios-Rios, M, \& Hernandez-Gomez, R. 2005. Fern richness, tree species surrogacy, and fragment complementarity in a Mexican tropical montane cloud forest. Biodiversity and Conservation, 14, 119-133. 


\section{Chapter 3}

\section{Tree community patterns along a deciduous to evergreen forest gradient in central Bolivia}

Reynaldo Linares-Palomino, Victor Cardona, Daniel Soto,

Sebastian K. Herzog and Michael Kessler

2008

Ecología en Bolivia 43(2):1-20. 


\section{Abstract}

We studied trees with a diameter at breast height $\geq 10 \mathrm{~cm}$ on three one-hectare plots in the Refugio Los Volcanes seasonal forests (1000-1400 m altitude), located in the Andean foothills of central Bolivia. The plots included local variants of deciduous, semi-deciduous and evergreen forest vegetation. We recorded a total of 115 species and 43 families. The most diverse plot was the semi-deciduous forest plot with 70 species, 56 genera and 31 families, whereas the evergreen forest plot had slightly lower richness values (63 species, 49 genera, 31 families). The deciduous forest plot had much lower numbers (44 species, 38 genera and 21 families) and shared only 19 and 15 species with the semi-deciduous and evergreen forest plots, respectively. Between $34 \%$ and $50 \%$ of the species in the study plots were locally rare species, i.e., species with only one or two individuals per plot. On the other hand, a high percentage of the total number of individuals and basal area was contributed by a few dominant species in each plot. Pachystroma longifolium (Nees) I.M. Johnst. (Euphorbiaceae) was the only species among the three most important species in each of the three plots. Leguminosae was the most important family in the deciduous and semi-deciduous plots. The evergreen forest plot contained different dominant families compared to the other two plots. The species richness values we found in this study were similar to other tree inventories in comparable seasonal forest ecosystems in Bolivia. Species and familial composition, however, were contrastingly different, except for the well-known fact that Leguminosae is the numerically most important family in seasonally dry neotropical forest ecosystems. Phytogeographically, the tree flora of Los Volcanes is heterogeneous, being composed of elements belonging to seasonal forests as well as to humid tropical forests.

Key-words: Amboró National Park, seasonal forest, tree density, tree dominance, tree inventory 


\subsection{Introduction}

The Amboró National Park located in Santa Cruz department (Bolivia) must be one of the most biodiverse protected areas in the world with vegetation types such as lowland humid evergreen forests, inter-Andean dry forests, high altitude cloud forests and puna vegetation from which more than 3000 plant species have been reported to date $(\mathrm{Nee}, 2004)$. The southeastern part of the national park is mainly composed of deciduous vegetation and previous classifications have tended to include it in single broad categories. Navarro et al. (1996) for example, included this area in the 'subhumid to humid deciduous forest of southeastern Amboró', a vegetation type usually found between 900-1100 $\mathrm{m}$ and where the dominant tree species are Aspidosperma cylindrocarpum (Apocynaceae), Cariniana estrellensis (Lecythidaceae), Cedrela lilloi (Meliaceae), Gallesia integrifolia (Phytolaccaceae), Pachystroma longifolium (Euphorbiaceae), Pogonopus tubulosus (Rubiaceae) and Tabebuia lapacho (Bignoniaceae). More recently, Navarro \& Maldonado (2002) assigned the vegetation in this area to the 'Upper central subandean Cerrado semideciduous forest', found between 1000-1900 m and with P. longifolium and C. estrellensis dominating the 1000-1300 m range. Based on visual inspections of the area, however, we observed substantial variations of the vegetation within these broad categories. During the course of a multidisciplinary study on the ecology of animals and plants at the Refugio Los Volcanes (hereafter LV), an area adjacent to the south of Amboró National Park, we observed that the dominant zonal vegetation in the area was indeed semi-deciduous forest (about 30-50\% deciduous trees), mainly found on the shaded south-facing slopes. Local differences in topography and aspect, however, seemed to lead to ecologically relevant differences in water availability. Consequently, steep, sunny and north-facing slopes were occupied by deciduous forest (70-90\% deciduous), whereas the flat, shaded valleys with groundwater supply supported evergreen forest (10-20\% deciduous). In order to test these visual observations we established three permanent one-hectare plots along the deciduous to evergreen seasonal forests vegetation gradient of LV. Our aims were to characterise the forest types within the 
LV area, to understand the relationship between these distinct types using quantitative tree inventories and to investigate the wider biogeographic affinities (within Bolivia and beyond) of the LV forest.

\section{$3.2 \quad$ Study area}

The study was carried out at the Refugio Los Volcanes (1000-1400 m altitude) in Santa Cruz, Bolivia. LV is located at about $18^{\circ} 06^{\prime} \mathrm{S}$ and $63^{\circ} 36^{\prime} \mathrm{W}$, adjacent to the southern border of Amboró National Park, on the transition from the humid inner tropics to the seasonally dry subtropics (Fig 3.1). The geological substrate of the study area consists primarily of red sandstone and locally of loamy sedimentary rocks (lutite). Annual precipitation is about $1200-1400 \mathrm{~mm}$, with a three month dry season from July to October. The deciduous forest plot (18 06' 48" S, 63 36' 10 "W) was located at an average altitude of $1150 \mathrm{~m}$ on a sunny north-facing slope.

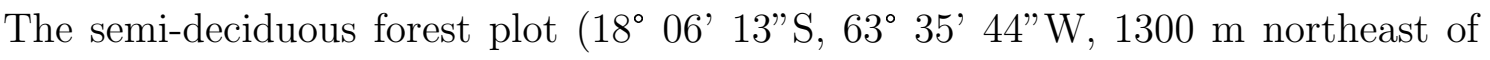
the deciduous forest plot) was located at an average altitude of $1070 \mathrm{~m}$ on a southfacing slope shaded by a rock-wall toward the southeast. The evergreen forest plot (18 $06^{\prime} 03^{\prime \prime} \mathrm{S}, 63^{\circ} 35^{\prime} 58^{\prime \prime} \mathrm{W}, 500 \mathrm{~m}$ northwest of the semi-deciduous forest plot) was located at an average altitude of $1100 \mathrm{~m}$ in a ravine with loose soils and permanent groundwater supply provided by a small watercourse that divided the plot into two parts with steep slopes on both sides of the creek.

\subsection{Methods}

We established one permanent plot of 1 ha in each forest type in 2002-2003. We subdivided each plot into 25 adjacent $20 \mathrm{~m}$ x $20 \mathrm{~m}$ subplots, which where laid out in such a way as to include only a homogeneous representation of the forest type under study (i.e., avoiding secondary vegetation or other forest types). Thus, our plots are not the traditional square $100 \mathrm{~m}$ x $100 \mathrm{~m}$ inventory plots, but have rather irregular shapes (Fig. 3.1). We recorded diameter at breast height (dbh) for each tree 


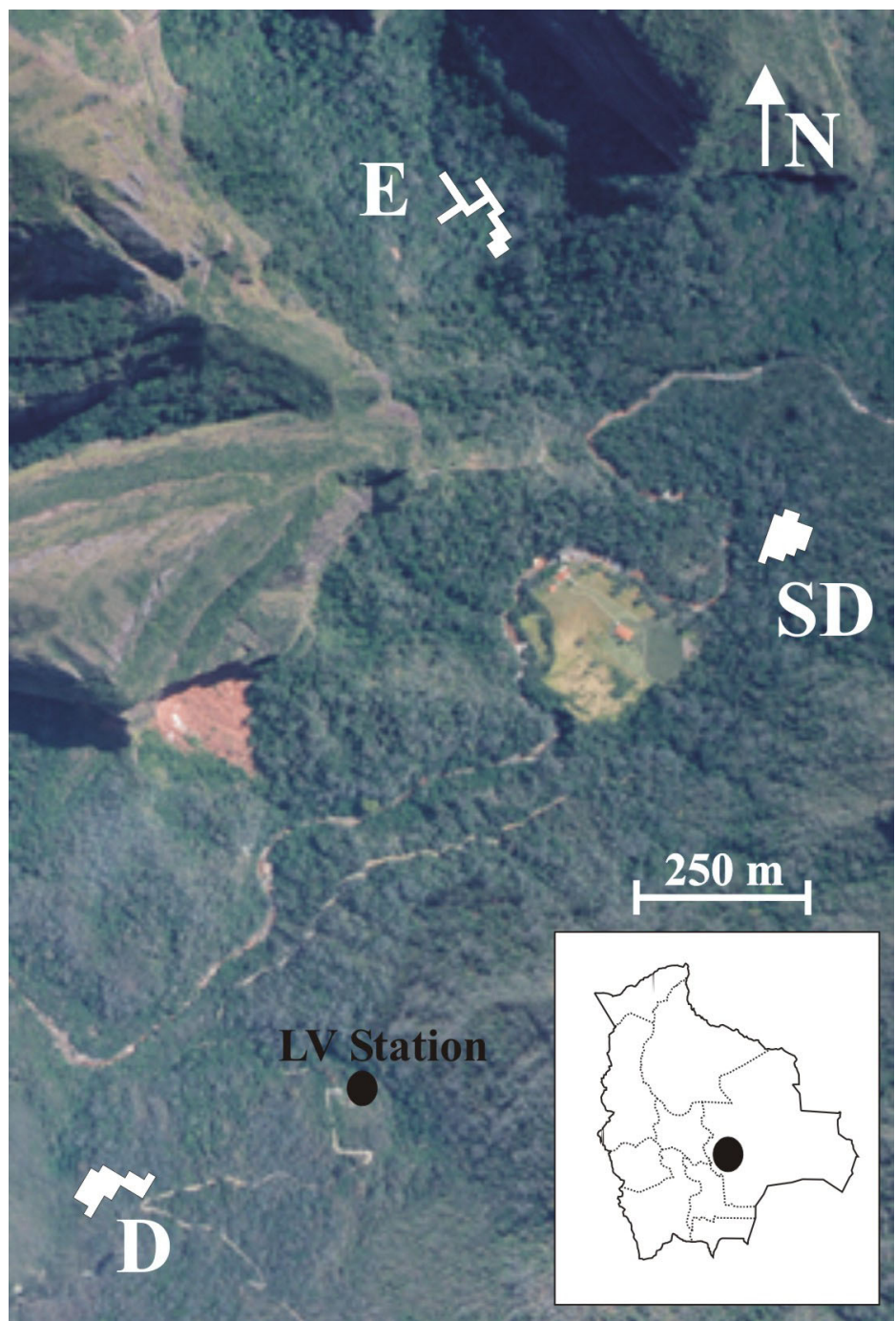

Figure 3.1: Study area in Refugio Los Volcanes, Santa Cruz (inset shows location within Bolivia). Plot shape and approximate location are given by $D$ (deciduous forest), SD (semi-deciduous forest) and E (evergreen forest).

with a diameter of $10 \mathrm{~cm}$ or more. Voucher specimens of all species were collected for later determination and are deposited at USZ (Santa Cruz) and LPB (La Paz) (herbarium acronyms following Holmgren \& Holmgren, 1998). Identification of the most common species was done directly in the field whenever possible. Vouchered specimens were identified at USZ and LPB using local (e.g., Jardim et al., 2003) and national tree floras (Killeen et al., 1993), as well as by comparison with reference collections and expert identification from local and visiting botanists at the mentioned herbaria. Sterile specimens that could not be completely identified were sorted into morphospecies. We calculated relative density, relative dominance (using basal area) 
and relative frequency for each species in order to estimate the importance value index (IVI) following Curtis \& Mcintosh (1951). To calculate the family value index (FVI) we followed Mori et al. (1983) and used relative density, relative dominance and relative diversity (number of species per family). We constructed smoothed individual based species accumulation curves by randomly adding individuals to the species accumulation curve. This procedure was repeated 100 times and we used the mean and 1.96 standard deviations to plot the curve and $95 \%$ confidence intervals (Magurran, 2004).

\subsection{Results}

\subsubsection{Diversity and density}

We recorded 115 tree species from 43 families on the three 1-ha plots (Appendix 1A.3). The semi-deciduous and evergreen forest plots were the most species-rich (Table 3.1). In contrast, density values were much higher on the deciduous forest plot, where multi-stemmed trees were about twice as common as on the other two plots. A higher percentage of species represented by a single individual (singleton) and by two individuals (doubletons) was found in the semi-deciduous and evergreen forest plots (Table 3.1). Overall, locally rare species represented by one or two individuals accounted for $34-50 \%$ of the species on our study plots. We found no lianas or hemi-epiphytes with a $\mathrm{dbh} \geq 10 \mathrm{~cm}$ on the deciduous forest plot. The semi-deciduous forest plot contained five individuals of hemi-epiphytes (Ficus sp., F. obtusifolia Kunth in Humb., Bonpl. \& Kunth and F. trigona L. f., all Moraceae) and two of lianas (Machaerium cf. punctatum (Poir.) Pers. (Leguminosae) and Celtis iguanaea (Jacq.) Sarg. (Ulmaceae)). The evergreen forest plot contained eight individuals of hemi-epiphytes (Ficus cf. eximia Schott in Spreng., F. maxima Mill., F. obtusifolia Kunth in Humb., Bonpl. \& Kunth, F. pertusa L. f. and F. trigona L. f., all Moraceae) and no lianas. Individual based species accumulation curves showed that when up to ca. 180 individuals are sampled randomly from each plot, 
Table 3.1: General diversity and structural characteristics of three one-hectare plots in Central Bolivia.

\begin{tabular}{llll}
\hline & Deciduous & Semi-deciduous & Evergreen \\
\hline Species & 44 & 70 & 63 \\
Genera & 38 & 56 & 49 \\
Families & 21 & 31 & 31 \\
\# Ind & 640 & 572 & 537 \\
\# steems & 706 & 612 & 569 \\
$\%$ multistemmed trees & $9.5 \%$ & $4.9 \%$ & $5.6 \%$ \\
Singletons & $10(23 \%)$ & $24(34 \%)$ & $20(32 \%)$ \\
Doubletons & $5(11 \%)$ & $11(16 \%)$ & $10(16 \%)$ \\
\hline
\end{tabular}

confidence intervals of the estimated species richness values overlap, indicating that the observed differences could have arisen by chance (Fig. 3.2). Increased random sampling of individuals, however, revealed clear differences between the deciduous forest plot and the two other forest plots. Nevertheless, irrespective of increased sampling these two latter forest types showed very similar estimated species richness values up to the total individuals sampled.

\subsubsection{Diameter distribution in size classes}

The range of dbh values increased from the deciduous forest plot $(10-83 \mathrm{~cm})$ to the evergreen forest plot $(10-162 \mathrm{~cm})$, with intermediate values on the semi-deciduous forest plot $(10-125 \mathrm{~cm})$. Basal area was highest on the semi-deciduous and deciduous forest plots with $27.7 \mathrm{~m}^{2}$ and $27.5 \mathrm{~m}^{2}$, respectively. The evergreen forest plot had a somewhat lower basal area with $24.2 \mathrm{~m}^{2}$. All three plots showed a left-skewed "inverted J" distribution of the number of individuals per dbh size class (Fig. 3.3). Nevertheless, there were differences in the dbh size class that contributed most to total basal area (Fig. 3.3). Dbh size classes from 10-50 cm contributed most on the deciduous forest plot (with $11.4 \%$ to $14.9 \%$ of total basal area per size class). On the semi-deciduous forest plot, the $30-40 \mathrm{~cm}$ dbh size class contributed with $22.6 \%$ of total basal area. On the evergreen forest plot low dbh size classes, as well as high dbh classes, were responsible for most of the total basal area (dbh size classes 10-15 


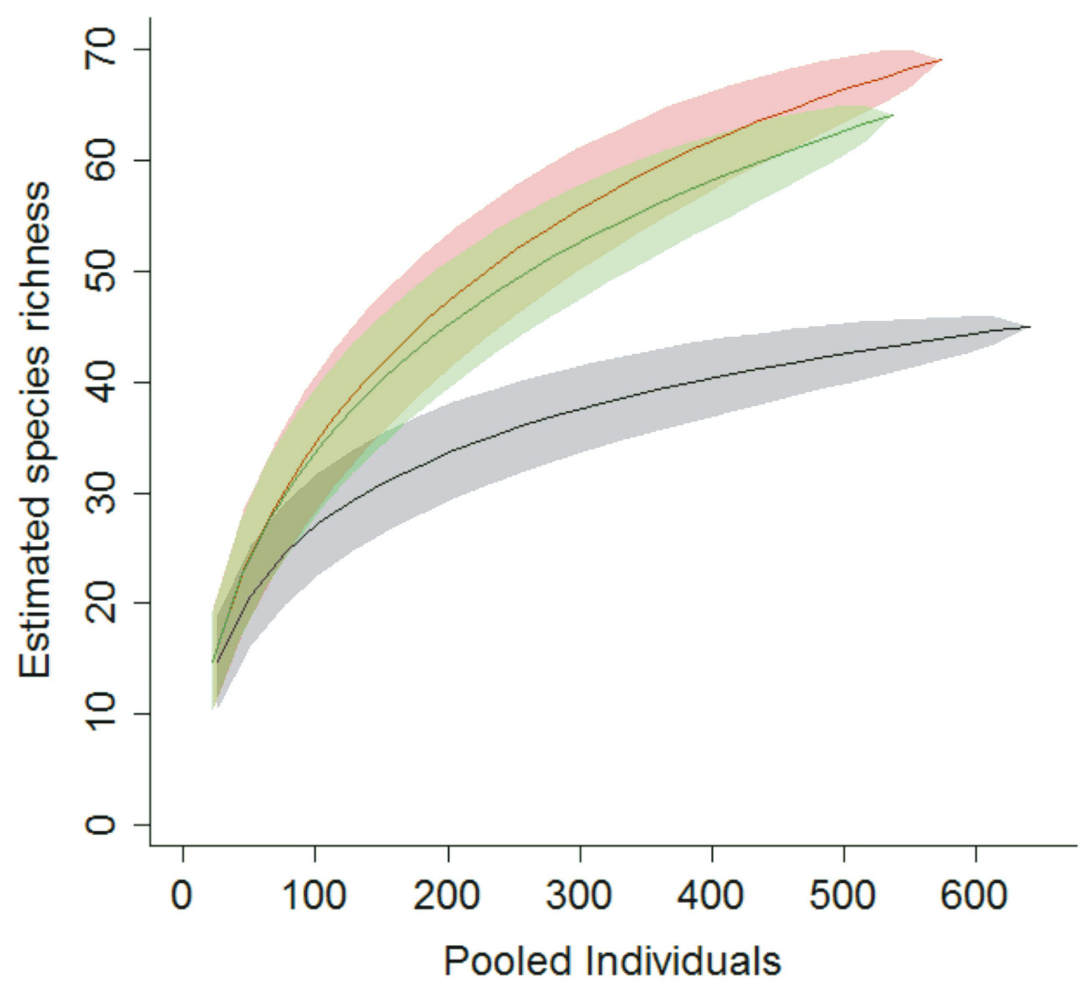

Figure 3.2: Individual based species accumulation curves of the deciduous (black), semideciduous (red) and evergreen (green) forest plots. Lines indicate estimated species richness values by given number of individuals, polygons indicate a $95 \%$ confidence interval.

$\mathrm{cm}$ and $15-20 \mathrm{~cm}$ contributed with $12.1 \%$ and $11.4 \%$ of total basal area, respectively. The dbh size class of $100 \mathrm{~cm}$ or more contributed with $13.1 \%$ ).

\subsubsection{Dominant species and families}

The deciduous forest plot (Table 3.2) was dominated by Parapiptadenia excelsa (Griseb.) Burkart (Leguminosae) and Trichilia claussenii C. DC. (Meliaceae). Both had the highest number of individuals (97 and 98, respectively) and together contributed to more than $30 \%$ of the total number of individuals on the plots and to $24 \%$ of total basal area ( $8 \%$ and $16 \%$, respectively). Other important and dominant species were Aspidosperma cylindrocarpon Mull. Arg. (Apocynaceae), Schinopsis hankeana Engl. (Anacardiaceae), Pachystroma longifolium (Nees) I.M. Johnst. (Euphorbiaceae) and Anadenanthera colubrina (Vell.) Brenan (Leguminosae). They 

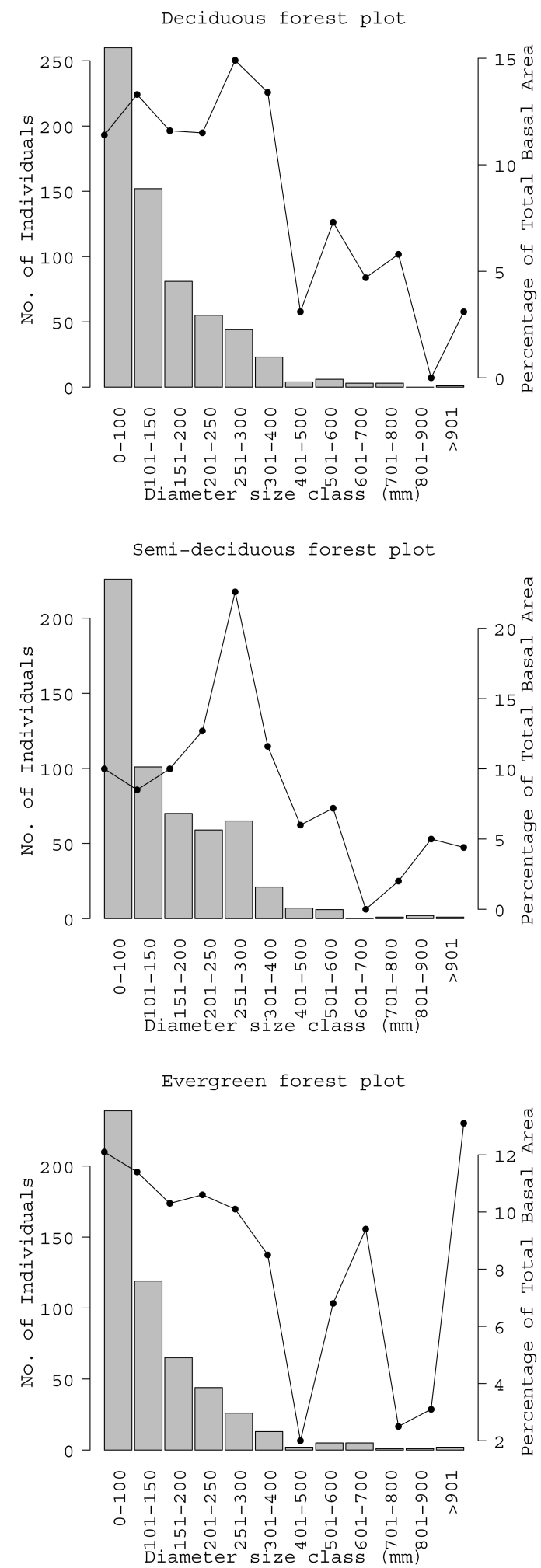

Figure 3.3: Number of individuals (bars) and percentage contribution of total basal area (lines) per diameter size class on three 1-hectare forest plots in central Bolivia. Note different scales of the ordinates for each graph. 
contributed $24 \%$ of the total number of individuals and $41 \%$ of total basal area. Together these six species represented $54 \%$ of all individuals and $62 \%$ of total basal area. The most important family was Leguminosae with $32 \%$ of the individuals, 12 species and $39 \%$ of the basal area, followed by Meliaceae and Euphorbiaceae. These three families contributed $58 \%$ of the number of individuals, $54 \%$ of basal area and $40 \%$ of species richness (Table 3.3). The semi-deciduous forest plot (Table 3.4) was dominated by Pachystroma longifolium and Myrciantes cf. pseudomato (Legrand) Mc. Vough. (Myrtaceae). Pachystroma longifolium had the highest number of individuals $(118,21 \%$ of the total), and both species had the highest basal area, comprising $38 \%$ of total basal area. Other important species in terms of density were Chomelia cf. sessilis Mull. Arg. (Rubiaceae) and Chrysophyllum gonocarpum (Mart. \& Gichl.) Engl. (Sapotaceae). The most important family was Euphorbiaceae, in which only two species contributed $25 \%$ of the individuals and $21 \%$ of basal area, followed by Sapotaceae and Myrtaceae. These three families comprised $47 \%$ of the number of individuals, $55 \%$ of basal area and $13 \%$ of species richness (Table 3.5). The evergreen forest plot (Table 3.6) was dominated by Aniba sp. (Lauraceae), with 76 individuals (14\% of the total) and $8 \%$ of total basal area. Drypetes amazonica Steyerm. (Euphorbiaceae), Pachystroma longifolium and Clarisia biflora Ruiz \& Pav. (Moraceae) were also important. These four species contributed $40 \%$ of the total number of individuals and $26 \%$ of total basal area. The most important family was Moraceae with 74 individuals (14\% of the total), $25 \%$ of total basal area and eight species, followed by Lauraceae, Sapotaceae and Euphorbiaceae. These four families represented $66 \%$ of the individuals, $70 \%$ of basal area and $35 \%$ of species richness (Table 3.7). 
Table 3.2: Ten most dominant woody plants with $\mathrm{dbh} \geq 10 \mathrm{~cm}$ in the deciduous forest plot according to importance value indices (species are ranked by descending importance value index). (\# Ind: no. of individuals, rDe: relative density, BA: basal area, $\mathrm{rDo}$ : relative dominance, $\mathrm{F}$ : frequency, $\mathrm{rF}$ : relative frequency, IVI: importance value indices).

\begin{tabular}{|c|c|c|c|c|c|c|c|c|}
\hline Family & Species & \# Ind & $\mathrm{rDe}$ & $\mathrm{BA}$ & rDo & $\mathrm{F}$ & $\mathrm{rF}$ & IVI \\
\hline LEG & Parapiptadenia excelsa (Griseb.) Burkart & 97 & 15.16 & 3.71 & 13.48 & 20 & 7.33 & 35.96 \\
\hline MEL & Trichilia claussenii C. DC. & 98 & 15.31 & 2.13 & 7.73 & 19 & 6.96 & 30.01 \\
\hline $\mathrm{APO}$ & Aspidosperma cylindrocarpon Mull. Arg. & 43 & 6.72 & 2.55 & 9.27 & 17 & 6.23 & 22.22 \\
\hline ANA & Schinopsis hankeana Engl. & 17 & 2.66 & 4.30 & 15.63 & 10 & 3.66 & 21.95 \\
\hline EUP & Pachystroma longifolium (Nees) I.M. Johnst. & 57 & 8.91 & 1.99 & 7.23 & 15 & 5.49 & 21.63 \\
\hline LEG & Anadenanthera colubrina (Vell.) Brenan & 35 & 5.47 & 2.39 & 8.69 & 12 & 4.40 & 18.56 \\
\hline NYC & Neea sp. & 30 & 4.69 & 0.70 & 2.53 & 15 & 5.49 & 12.71 \\
\hline URT & Pouzolzia sp. & 32 & 5.00 & 0.46 & 1.66 & 15 & 5.49 & 12.16 \\
\hline LEG & Tipuana tipu (Benth.) Kuntze & 11 & 1.72 & 1.98 & 7.19 & 5 & 1.83 & 10.74 \\
\hline LEG & Piptadenia buchtienii Barneby & 21 & 3.28 & 0.84 & 3.05 & 12 & 4.40 & 10.73 \\
\hline
\end{tabular}

Table 3.3: Ten most dominant families of woody plants with dbh $\geq 10 \mathrm{~cm}$ in the deciduous forest plot according to family value indices (families are ranked by descending family importance value). (\# Ind: no. of individuals, rDe: relative density, BA: basal area, rDo: relative dominance, Div: species diversity, rDiv: relative diversity, FIV: family importance value).

\begin{tabular}{llllllll}
\hline Family & \# Ind & rDe & BA & rDo & Div & rDiv & FIV \\
\hline Leguminosae & 208 & 32.50 & 10.70 & 38.89 & 12 & 27.27 & 98.66 \\
Meliaceae & 99 & 15.47 & 2.28 & 8.29 & 2 & 4.55 & 28.30 \\
Euphorbiaceae & 66 & 10.31 & 2.12 & 7.71 & 4 & 9.09 & 27.11 \\
Anacardiaceae & 23 & 3.59 & 4.48 & 16.28 & 2 & 4.55 & 24.42 \\
Apocynaceae & 47 & 7.34 & 2.63 & 9.56 & 2 & 4.55 & 21.45 \\
Nyctaginaceae & 33 & 5.16 & 0.78 & 2.83 & 3 & 6.82 & 14.81 \\
Capparidaceae & 26 & 4.06 & 0.67 & 2.44 & 2 & 4.55 & 11.04 \\
Sapotaceae & 25 & 3.91 & 0.42 & 1.53 & 2 & 4.55 & 9.98 \\
Urticaceae & 32 & 5.00 & 0.46 & 1.67 & 1 & 2.27 & 8.94 \\
Myrtaceae & 5 & 0.78 & 0.10 & 0.36 & 3 & 6.82 & 7.96 \\
\hline
\end{tabular}

Table 3.4: Ten most dominant woody plants with dbh $\geq 10 \mathrm{~cm}$ in the semi-deciduous forest plot according to importance value indices (species are ranked by descending importance value index). (\# Ind: no. of individuals, rDe: relative density, BA: basal area, $\mathrm{rDo}$ : relative dominance, $\mathrm{F}$ : frequency, $\mathrm{rF}$ : relative frequency, IVI: importance value indices).

\begin{tabular}{|c|c|c|c|c|c|c|c|c|}
\hline Family & Species & \# Ind & $\mathrm{rDe}$ & $\mathrm{BA}$ & rDo & $\mathrm{F}$ & $\mathrm{rF}$ & IVI \\
\hline EUP & Pachystroma longifolium (Nees) I.M. Johnst. & 118 & 20.59 & 5.43 & 19.63 & 23 & 7.42 & 47.64 \\
\hline RUB & Chomelia cf. sessilis Mull. Arg. & 40 & 6.98 & 2.11 & 7.63 & 15 & 4.84 & 19.45 \\
\hline SAPO & Sarcaulus sp. & 35 & 6.11 & 0.44 & 1.59 & 15 & 4.84 & 12.54 \\
\hline EUP & Drypetes amazonica Steyerm. & 28 & 4.89 & 0.48 & 1.74 & 16 & 5.16 & 11.78 \\
\hline $\mathrm{APO}$ & Aspidosperma rigidum Rusby & 25 & 4.36 & 0.48 & 1.74 & 12 & 3.87 & 9.97 \\
\hline PHY & Gallesia integrifolia (Sprengel) Harms & 6 & 1.05 & 1.74 & 6.29 & 5 & 1.61 & 8.95 \\
\hline
\end{tabular}


Table 3.5: Ten most dominant families of woody plants with $\mathrm{dbh} \geq 10 \mathrm{~cm}$ in the semi-deciduous forest plot according to family value indices (families are ranked by descending family importance value). (\# Ind: no. of individuals, rDe: relative density, BA: basal area, rDo: relative dominance, Div: species diversity, rDiv: relative diversity, FIV: family importance value).

\begin{tabular}{llllllll}
\hline Family & \# Ind & rDe & BA & rDo & Div & rDiv & FIV \\
\hline Euphorbiaceae & 146 & 25.48 & 5.91 & 21.37 & 2 & 2.50 & 49.35 \\
Sapotaceae & 80 & 13.96 & 4.08 & 14.75 & 4 & 5.00 & 33.71 \\
Myrtaceae & 42 & 7.33 & 5.15 & 18.62 & 3 & 3.75 & 29.70 \\
Leguminosae & 33 & 5.76 & 1.66 & 6.00 & 9 & 11.25 & 23.01 \\
Rubiaceae & 46 & 8.03 & 2.2 & 7.95 & 3 & 3.75 & 19.73 \\
Lauraceae & 38 & 6.63 & 0.98 & 3.54 & 6 & 8.75 & 18.92 \\
Apocynaceae & 49 & 8.55 & 1.43 & 5.17 & 4 & 5.00 & 18.72 \\
Moraceae & 35 & 6.11 & 0.69 & 2.49 & 6 & 7.50 & 16.10 \\
Tiliaceae & 3 & 0.52 & 0.12 & 0.43 & 11 & 13.75 & 14.71 \\
Meliaceae & 22 & 3.84 & 0.36 & 1.30 & 4 & 5.00 & 10.14 \\
\hline
\end{tabular}

Table 3.6: Ten most dominant woody plants with $\mathrm{dbh} \geq 10 \mathrm{~cm}$ in the evergreen forest plot according to importance value indices (species are ranked by descending importance value index). (\# Ind: no. of individuals, rDe: relative density, BA: basal area, rDo: relative dominance, $\mathrm{F}$ : frequency, $\mathrm{rF}$ : relative frequency, IVI: importance value indices).

\begin{tabular}{|c|c|c|c|c|c|c|c|c|}
\hline Family & Species & \# Ind & $\mathrm{rDe}$ & BA & rDo & $\mathrm{F}$ & $\mathrm{rF}$ & IVI \\
\hline LAU & Aniba sp. & 76 & 14.18 & 1.95 & 8.05 & 23 & 7.42 & 29.65 \\
\hline EUP & Drypetes amazonica Steyerm. & 60 & 11.19 & 0.91 & 3.76 & 22 & 7.10 & 22.05 \\
\hline EUP & Pachystroma longifolium (Nees) I.M. Johnst. & 43 & 8.02 & 1.81 & 7.47 & 17 & 5.48 & 20.98 \\
\hline MOR & Clarisia biflora Ruiz \& Pav. & 38 & 7.09 & 1.53 & 6.31 & 19 & 6.13 & 19.53 \\
\hline SAPO & Pouteria nemorosa Baehni & 11 & 2.05 & 2.64 & 10.90 & 10 & 3.23 & 16.17 \\
\hline URT & Myriocarpa stipitata Benth. & 35 & 6.53 & 0.78 & 3.22 & 10 & 3.23 & 12.97 \\
\hline SAPO & Chrysophyllum gonocarpum (Mart. \& Gichl.) Engl. & 21 & 3.92 & 0.69 & 2.85 & 14 & 4.52 & 11.28 \\
\hline MOR & Ficus cf. eximia Schott in Spreng. & 3 & 0.56 & 2.26 & 9.33 & 3 & 0.97 & 10.85 \\
\hline NYC & Guapira aff. olfersiana (Link et al) Standl. & 17 & 3.17 & 0.79 & 3.26 & 11 & 3.55 & 9.98 \\
\hline MOR & Sorocea guilleminiana Gaudich. & 22 & 4.10 & 0.25 & 1.03 & 15 & 4.84 & 9.97 \\
\hline
\end{tabular}


Table 3.7: Ten most dominant families of woody plants with $\mathrm{dbh} \geq 10 \mathrm{~cm}$ in the evergreen forest plot according to family value indices (families are ranked by descending family importance value). (\# Ind: no. of individuals, rDe: relative density, BA: basal area, rDo: relative dominance, Div: species diversity, rDiv: relative diversity, FIV: family importance value).

\begin{tabular}{llllllll}
\hline Family & \# Ind & rDe & BA & rDo & Div & rDiv & FIV \\
\hline Moraceae & 74 & 13.81 & 6.04 & 24.93 & 8 & 12.90 & 51.64 \\
Lauraceae & 118 & 22.01 & 3.21 & 13.25 & 6 & 9.68 & 44.94 \\
Sapotaceae & 56 & 10.45 & 4.69 & 19.36 & 5 & 8.06 & 37.87 \\
Euphorbiaceae & 104 & 19.40 & 2.87 & 11.84 & 3 & 4.84 & 36.09 \\
Urticaceae & 40 & 7.46 & 0.88 & 3.63 & 2 & 3.23 & 14.32 \\
Leguminosae & 7 & 1.31 & 0.63 & 2.60 & 4 & 6.45 & 10.36 \\
Rubiaceae & 12 & 2.24 & 0.58 & 2.39 & 3 & 4.84 & 9.47 \\
Araliaceae & 13 & 2.43 & 0.7 & 2.89 & 2 & 3.23 & 8.54 \\
Meliaceae & 16 & 2.99 & 0.17 & 0.70 & 3 & 4.84 & 8.53 \\
Apocynaceae & 15 & 2.80 & 0.6 & 2.48 & 2 & 3.23 & 8.50 \\
\hline
\end{tabular}

\subsection{Discussion}

\subsubsection{Effect of plot shape on species richness and community com- position estimations}

Spatial distribution patterns of plant species in tropical forests have been reported to show mostly clumped distributions (e.g., Condit et al., 2000). Within this scenario, longer and narrower rectangular plots are prone to capture more species than square plots of similar area, because the former could include a potentially more heterogeneous area (Condit et al., 1996; Laurance et al., 1998). Nevertheless, small and statistically non-significant differences were found in a study comparing tree diversity in square plots versus rectangular plots in Central Amazonia (Laurance et al., 1998). Given the patchy and fragmented nature of the deciduous and evergreen forests in our study area, it was impossible to survey all vegetation types in regular square or rectangular plots. Rather, we tried to survey as environmentally homogeneous an area as possible, leading to our irregular plot shape design. We acknowledge that plot shape has influenced our results, especially those of the transect-like evergreen forest plot. The extent of this influence, however, seems to be variable, as 
can be seen from the species accumulation curves. It significantly decreased in the irregularly shaped deciduous forest plot when the hectare was completely surveyed, suggesting that sampling was representative. In contrast, the species accumulation curves did not level off in the more-or-less regularly shaped semi-deciduous plot and in the long and transect-like evergreen forest plot, suggesting, that sampling, irrespective of plot shape, was incomplete.

\subsubsection{Local variation of tree diversity, dominance and structure at Los Volcanes}

There were obvious differences in the diversity and floristic composition between the deciduous forest plot and the two other plots, which where rather similar in diversity and structure. Not only was the deciduous forest plot poorer in terms of generic and familial diversity, it also shared fewer species with the semi-deciduous and the evergreen forest plot. The deciduous forest plot shared 19 species with the semi-deciduous and 15 with the evergreen forest plot, whereas the latter two shared 39 species. Eleven species were present in all three plots and represented a selection of the tree species characteristic of the Amboró region like Aspidosperma cylindrocarpum, Gallesia integrifolia and Pachystroma longifolium Navarro et al., 1996). Of these species, few were dominant and abundant on each of the plots, like Chrysophyllum gonocarpum. On the contrary, most were locally rare species, at least at the hectare-scale, with abundances of one individual per hectare (e.g., Cariniana estrellensis (Raddi) Kuntze, Swartzia jorori Harms, Eugenia sp.). Differences in diversity and composition between the three plots, especially between the deciduous forest plot and the two other, was mirrored by several environmental factors. For example, soil humidity and $\mathrm{pH}$ increased from the deciduous forest plot to the evergreen forest plot (Lendzion, 2003). Therefore, even though there is a dominant regional flora, small-scale environmental variations produce significant differences in the composition and dominance of the local tree flora. This fact has already been shown for terrestrial herbs at LV (Lendzion, 2003) and for woody species in seasonal 
forests elsewhere (Oliveira-Filho et al., 1998; Balvanera et al., 2002). Lianas have been considered important components of tropical forests (Medina, 1995), constituting in some cases $20 \%$ or more of the local flora Gentry, 1995; Schnitzer \& Bongers, 2002). In this study, however, we were not able to record lianas with a dbh $\geq 10$ $\mathrm{cm}$ in the deciduous and evergreen forest plots. Only the semi-deciduous forest plot contained two individuals belonging to two tree species (Machaerium cf. punctatum and Celtis iguanaea), which occasionally also grow as lianas, with a dbh $\geq 10 \mathrm{~cm}$. This agrees with another study in Bolivian deciduous forests that found similar low levels of liana diversity and density using the same sampling methodology (Cayola et al. 2005$)$. Nonetheless, this does not mean that the LV forests are devoid of vines and climbers. In fact, most of the liana diversity and abundance in each of the studied forest plots is found in dbh classes below $10 \mathrm{~cm}$ (Hoffmann, 2004), so that our results have to be interpreted as a sampling artefact. In mountainous areas, with forest growing on steep slopes, one of the factors than can influence and produce low basal area values are landslides (Chazdon, 2003). Since the humid forest plot was located on steeper slopes than the other two plots and additionally had rather loose soils, we suggest that an increased frequency of localized landslides could have produced the lower basal area as compared to the other two plots.

\subsubsection{The Los Volcanes forests in a Bolivian context}

Our inventory on the deciduous forest plot contained species richness and densities of trees with $\mathrm{dbh} \geq 10 \mathrm{~cm}$ within the range of other inventories in Bolivian seasonal forests (Table 3.8). It was much richer and denser than that of the Santa Cruz Botanical Garden (inventoried by Uslar et al., 2004), which is located in a slightly drier lowland area $(350 \mathrm{~m})$. Our plots in the semi-deciduous and evergreen forest variants, although much more species-rich, were less dense than the San Rafael (1500 m, Vargas, 1995) and Río Tuichi (880 m, Cayola et al., 2005) plots. The dominant and most diverse family in seasonal deciduous forests in the Neotropics is usually Leguminosae (Gentry, 1995; Pennington et al., 2006). There is, however, 
ample variation as to which are the next most diverse and dominant families. This is confirmed by several other inventories in Bolivian deciduous forests (Killeen et al. 1998; Kessler \& Helme, 1999; Fuentes et al., 2004) and by our study, where we had six different families following Leguminosae in importance. In nearby Santa Cruz (Uslar et al., 2004) Leguminosae was the overwhelmingly dominant family (seven species), all other families with only one or two species (Table 3.8). In the adjacent Amboró National Park (Vargas, 1995), they were Lauraceae and Myrtaceae. Finally, the Tuichi valley dry forests inventory in La Paz department (Cayola et al., 2005) reported also Myrtaceae and Bombacaceae as important. The dominant families on the evergreen forest plot in LV showed contrasting results with Moraceae, Lauraceae and Sapotaceae as the most diverse families (Table 3.8). The diversity of Moraceae, whose members are prominent components of tropical rain forests, already suggests the prevalence of different local environmental conditions on this plot. In contrast, species composition and densities of trees with $\mathrm{dbh} \geq 10 \mathrm{~cm}$ on the LV plots differed from other tree inventories in Bolivia with similar annual rainfall and similar seasonal vegetation. For instance, the Santa Cruz plot in the deciduous Chiquitanía forests (Uslar et al., 2004) reported Aspidospermum cylindrocarpon (Apocynaceae), Myrciaria cauliflora (Myrtaceae) and Phyllostylon rhamnoides (Ulmaceae) as the most abundant species (Table 3.8). The Río San Rafael plot in Amboró contained Nectandra sp. (Lauraceae), Casearia sp. (Flacourtiaceae) and Chrysophyllum cf. gonocarpum (Sapotaceae) as the most frequent species (Vargas, 1995). The three most common species in the Tuichi plot were Phyllostylon rhamnoides (Ulmaceae), Trichilia catigua (Meliaceae) and Anadenanthera colubrina (Leguminosae) (Cayola et al., 2005). At LV, the most abundant species were Trichilia claussenii, Parapiptadenia excelsa and Pachystroma longifolium on the deciduous forest plot, Pachystroma longifolium, Chomelia cf. sessilis and Myrciantes cf. pseudo-mato on the semi-deciduous forest plot, and Aniba sp., Drypetes amazonica and Pachystroma longifolium on the evergreen forest plot (Table 3.8). In terms of basal area, our deciduous and semi-deciduous forest inventories reached similar values of around 27 
$\mathrm{m}^{2}$, which is comparable to other seasonal forest inventories in Bolivia, except for the Tuichi plot in La Paz $\left(20 \mathrm{~m}^{2}\right)$ and our evergreen forest plot in $\mathrm{LV}\left(24.2 \mathrm{~m}^{2}\right)$. Murphy \& Lugo (1986) stated that seasonal forests were less complex structurally than wet tropical forests, with basal area values in the range from $17 \mathrm{~m}^{2}$ to $40 \mathrm{~m}^{2}$. Several other studies have reaffirmed this statement (e.g., Reis Lopes et al., 2008). Basal area values of the LV plots, however, were also within the range of other tree inventories in several vegetation types in South America, using the same diameter cut-off, and particularly within Bolivia. For instance, basal area values of several 1-ha inventories in humid tropical forests ranged between $21.4 \mathrm{~m}^{2}$ (Beni, Bolivia) and $39.2 \mathrm{~m}^{2}$ (Amboró, Bolivia) (Smith \& Killeen, 1998).

\subsubsection{Phytogeography of the Los Volcanes species}

Based on the distribution of over 70 plant taxa, Prado \& Gibbs (1993) proposed the existence of a Pleistocenic Arc of seasonal forest formations. The extant fragments of this arc are mainly located in three nuclei: the Caatinga nucleus in northeastern Brazil; the Misiones nucleus comprising the area from the Bolivia-Brazil border in Corumbá southward to the Paraguay-Paraná river confluence and eastward to Santa Catarina in Brazil; and the Piedmont nucleus extending from Santa Cruz de la Sierra in Bolivia southward to Tucumán and the sierras of Catamarca in Argentina. Because our study area is located within the area of the Piedmont nucleus (cf. Prado, 2000), we examined the distribution patterns of the 115 species found at LV. We recorded Anadenanthera colubrina, Myracrodruon urundeuva Allemao and Celtis iguanaea in our plots, all of which have been reported as characteristic to the wider Pleistocenic Arc formation (Prado \& Gibbs, 1993). We also found Diatenopteryx sorbifolia Radlk., classified as a restricted Arc species since it only occurs in the Misiones and Piedmont nuclei. Navarro \& Maldonado (2002), who considered the area around LV as transitional between the Brasilian-Paraná biogeographic region and the Bolivian-Tucuman biogeographic province, also noted this affinity with the seasonal vegetation in the Misiones and Piedmont nuclei. In total, we identified 


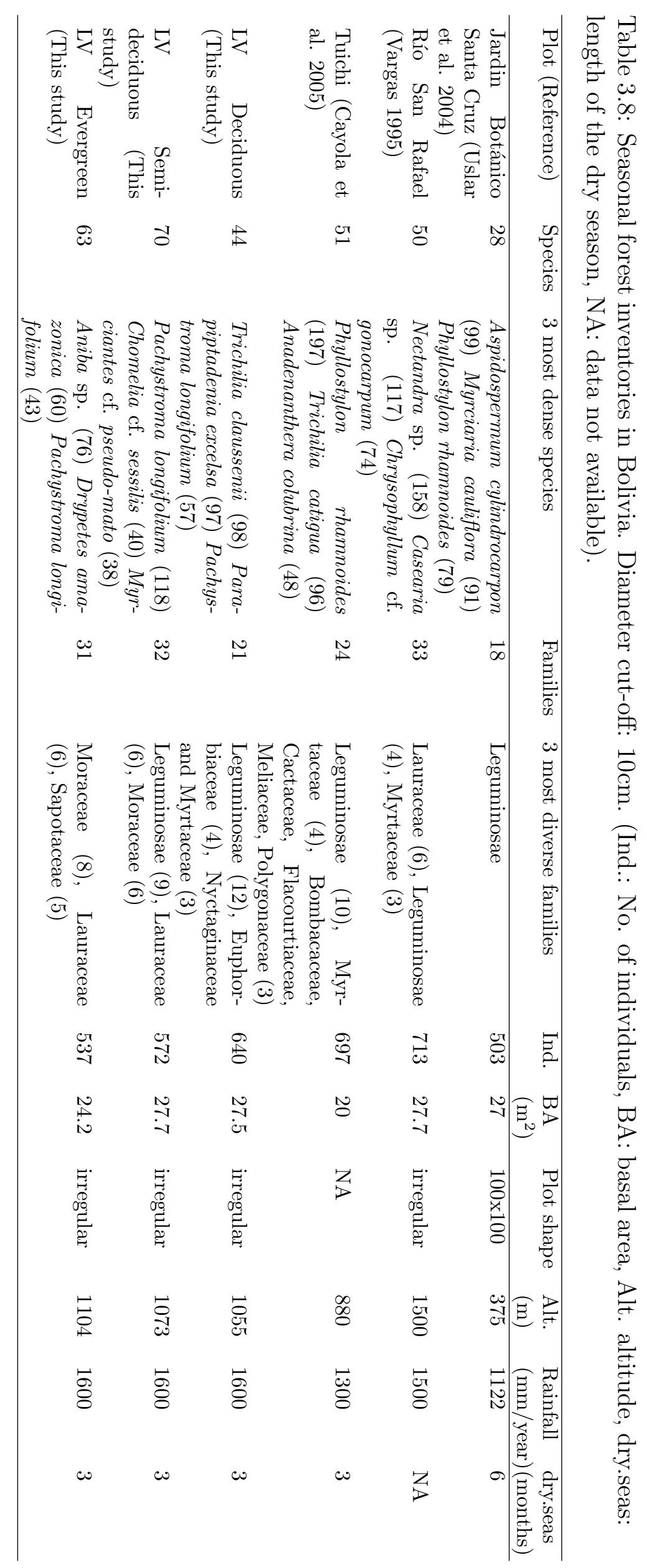


21 species as typical of Bolivian seasonal forest formations. More complex and widespread distribution patterns are attributed to Cordia alliodora (Ruiz \& Pav.) Cham. and Ximenia americana L., the later occurring in diverse vegetation types throughout the Neotropics. On a local scale, the forests at LV shared only 21\% (24 species) of all recorded tree species with the inventories in Santa Cruz, San Rafael and Tuichi. As expected, the deciduous forest plot shared most species (10 species, $23 \%)$ with the nearby $(65 \mathrm{~km})$ deciduous forests in the Santa Cruz Botanical Garden and less than $12 \%$ with the other two inventories (43 km to San Rafael, $660 \mathrm{~km}$ to Tuichi). In contrast, the semi-deciduous forest plot shared only $13 \%$ of its species with the inventory in the Santa Cruz Botanical Garden, and less than $10 \%$ of its species were also present in the other two inventories. The evergreen forest shared even fewer species with any of the other seasonal forest inventories (less than 11\%). Low percentages of shared species between seasonal forest inventories, irrespective of geographical distance, have also been reported for the seasonally dry forest in Mexico and attributed to the existence of processes of high local diversification, possibly due to particular historical processes (Trejo \& Dirzo, 2002). Indeed, the complex vegetational arrangement of the area, a region, where four major biomes come into contact: the humid vegetation from Amazonia, the seasonal subtropical lowland vegetation from the Chaco, the subtropical highland vegetation from the Andes and the seasonal vegetation of the Chiquitanía (Ibisch et al., 2003), would have provided an optimal setting for the extraordinary floristic diversification in the Santa Cruz region. Thus, even though we are comparing seasonal forest with similar rainfall, dry season length or at similar altitude, their low floristic similarity seems to be strongly influenced by the biome they are closest to. The San Rafael plot in Amboró National Park will be more likely influenced by the Andean biome, the Tuichi plot by the northern Bolivian Andes and Amazonia and Santa Cruz Botanical Garden by the Chiquitanía and the Chaco. In similar fashion, the different vegetation types reported at LV have probably been influenced by all these major biomes, and it is the varied local environmental characteristics that have allowed 
the co-existence of species with differing ecological requirements.

\subsection{Acknowledgements}

We thank the reviewers and the handling editor for suggestions and critique that improved the original manuscript. We thank the owner of Los Volcanes, A. Schwiening, for allowing us to work on his land. SKH and MK are indebted to the Colección Boliviana de Fauna and the Dirección General de Biodiversidad for research permits. We thank the curators of the Herbario Nacional de Bolivia (LPB) and Herbario del Oriente Boliviano (USZ) for providing us with working facilities and allowing access to their collections. We are grateful to C. Hamel and M. Valverde for help in the field and to J. Lendzion for providing unpublished soil and environmental data from the plots. Financial support was provided by the Deutsche Forschungsgemeinschaft (DFG) and the German Academic Exchange Service (DAAD). 


\subsection{References}

Balvanera, P, Lott, E, Segura, G, Siebe, C, \& Islas, A. 2002. Patterns of betadiversity in a Mexican tropical dry forest. Journal of Vegetation Science, 13, $145-158$.

Cayola, L, Fuentes, A, \& Jørgensen, PM. 2005. Estructura y composición florística de un bosque seco subandino yungueño en el Valle del Tuichi, Área Natural de Manejo Integrado Madidi, La Paz (Bolivia). Ecología en Bolivia, 40, 396-417.

Chazdon, RL. 2003. Tropical forest recovery: legacies of human impact and natural disturbances. Perspectives in Plant Ecology, Evolution and Systematics, 6, 51-71.

Condit, R, Hubbell, SP, Lafrankie, JV, Sukumar, R, Manokaran, N, Foster, RB, \& Ashton, PS. 1996. Species-area and species-individual relationships for tropical trees: a comparison of three 50-ha plots. Journal of Ecology, 84, 549-562.

Condit, R, Ashton, PS, Baker, P, Bunyavejchewin, S, Gunatilleke, S, Gunatilleke, N, Hubbell, SP, Foster, RB, Itoh, A, LaFrankie, JV, Lee, HS, Losos, E, Manokaran, N, Sukumar, R, \& Yamakura, T. 2000. Spatial patterns in the distribution of tropical tree species. Science, 288, 1414-1418.

Curtis, JT, \& Mcintosh, RP. 1951. An upland forest continuum in the prairie-forest border region of Wisconsin. Ecology, 32, 476-496.

Fuentes, A, Araujo, A, Cabrera, H, Canqui, F, Cayola, L, Maldonado, C, \& Paniagua, N. 2004. Estructura, composición y variabilidad del bosque subandino xérico en un sector del valle del río Tuichi, ANMI Madidi, La Paz (Bolivia). Revista Boliviana de Ecología y Conservación Ambiental, 15, 41-62.

Gentry, AH. 1995. Diversity and floristic composition of neotropical dry forests. Pages 146-194 of: Bullock, SH, Mooney, HA, \& Medina, E (eds), Seasonally dry tropical forests. Cambridge, U.K.: Cambridge University Press. 
Hoffmann, D. 2004. Lianen dreier Waldtypen im Übergang der Tropen zu den Subtropen in Zentralbolivien. Diploma thesis, Halle-Wittenberg University, Germany.

Holmgren, PK, \& Holmgren, NH. 1998. Index Herbariorum: A global directory of public herbaria and associated staff. New York Botanical Garden's Virtual Herbarium. Cited 5 February 2008.

Ibisch, PL, Beck, SG, Gerkmann, B, \& Carretero, A. 2003. Ecoregiones y ecosistemas. Pages 47-88 of: Ibisch, PL, \& Mérida, G (eds), Biodiversidad: la riqueza de Bolivia. Estado de conocimiento y conservación. Santa Cruz: Ministerio de Desarrollo Sostenible y Planificación, Editorial FAN.

Jardim, A, TJ, Killeen, \& Fuentes, A. 2003. Guía de los árboles y arbustos del bosque seco Chiquitano, Bolivia. Editorial FAN, Santa Cruz de la Sierra, Bolivia.

Kessler, M, \& Helme, N. 1999. Floristic diversity and phytogeography of the central Tuichi Valley, an isolated dry forest locality in the Bolivian Andes. Candollea, $\mathbf{5 4}, 341-366$.

Killeen, TJ, García, E, \& Beck, SG. 1993. Guía de árboles de Bolivia. La Paz: Herbario Nacional de Bolivia/Missouri Botanical Garden.

Killeen, TJ, Jardim, A, Mamani, F, \& Rojas, N. 1998. Diversity, composition and structure of a tropical semideciduous forest in the Chiquitania region of Santa Cruz, Bolivia. Journal of Tropical Ecology, 14, 803-827.

Laurance, WF, Ferreira, LV, Rankin-de Merona, JM, \& Hutchings, RW. 1998. Influence of plot shape on estimates of tree diversity and community composition in central Amazonia. Biotropica, 30, 662-665.

Lendzion, J. 2003. Krautflora dreier Waldtypen im Übergang der Tropen zu den Subtropen in Zentralbolivien. Diploma thesis, Göttingen University, Germany.

Magurran, AE. 2004. Measuring biological diversity. Blackwell Publishing Limited. 
Medina, E. 1995. Diversity of life forms of higher plants in neotropical dry forests. Pages 221-242 of: Bullock, SH, Mooney, HA, \& Medina, E (eds), Seasonally dry tropical forests. Cambridge, U.K.: Cambridge University Press.

Mori, SA, Boom, BM, Decarvalho, AM, \& Dossantos, TS. 1983. Southern Bahian moist forests. Botanical Review, 49, 155-232.

Murphy, PG, \& Lugo, AE. 1986. Ecology of tropical dry forest. Annual Review of Ecology and Systematics, 17, 67-88.

Navarro, G, \& Maldonado, M. 2002. Geografía ecológica de Bolivia: vegetación y ambientes acuáticos. Cochabamba, Bolivia: Fundación Simón I. Patiño.

Navarro, G, Vargas, I, Jardim, A, Toledo, M, \& de la Barra, N. 1996. Clasificación y diagnóstico para la conservación de la vegetación de la región del Parque $\mathrm{Na-}$ cional Amboró. Santa Cruz, Bolivia. Universidad Complutense, FAN, MHNNKM, UMSS, New York Botanical Garden.

Nee, M. 2004. Flora de la Región del Parque Nacional Amboró. Bolivia. Vol. 2: Magnoliidae, Hamamelidae y Caryophyllidae. Santa Cruz, Bolivia: FAN.

Oliveira-Filho, AT, Curi, N, Vilela, EA, \& Carvalho, DA. 1998. Effects of canopy gaps, topography, and soils on the distribution of woody species in a central Brazilian deciduous dry forest. Biotropica, 30, 362-375.

Pennington, RT, Lewis, GP, \& Ratter, JA. 2006. An overview of the plant diversity, biogeography and conservation of Neotropical savannas and seasonally dry forests. Pages 1-29 of: Pennington, RT, Ratter, JA, \& Lewis, GP (eds), Neotropical savannas and seasonally dry forests. CRC Press, Boca Raton, FL.

Prado, DE. 2000. Seasonally dry forests of tropical South America: from forgotten ecosystems to a new phytogeographic unit. Edinburgh Journal of Botany, 57, $437-461$. 
Prado, DE, \& Gibbs, PE. 1993. Patterns of species distributions in the dry seasonal forests of South-America. Annals of the Missouri Botanical Garden, 80, 902-927.

Reis Lopes, CG, Nogueira Ferraz, EM, \& Araujo, EL. 2008. Physiognomic-structural characterization of dry- and humid-forest fragments (Atlantic Coastal Forest) in Pernambuco State, NE Brazil. Plant Ecology, 198, 1-18.

Schnitzer, SA, \& Bongers, F. 2002. The ecology of lianas and their role in forests. Trends in Ecology \& Evolution, 17, 223-230.

Smith, DN, \& Killeen, TJ. 1998. A comparison of the structure and composition of montane and lowland tropical forest in the Serranía Pilón Lajas, Beni, Bolivia. Pages 681-700 of: Dallmeier, F, \& Comiskey, JA (eds), Forest biodiversity research, monitoring and modeling. New York: The Parthenon Publishing Group.

Trejo, I, \& Dirzo, R. 2002. Floristic diversity of Mexican seasonally dry tropical forests. Biodiversity and Conservation, 11, 2063-2084.

Uslar, YV, Mostacedo, B, \& Saldías, M. 2004. Composición, estructura y dinámica de un bosque seco semideciduo en Santa Cruz, Bolivia. Ecología en Bolivia, 39, $25-43$.

Vargas, I. 1995. Estructura y composición de cuatro sitios boscosos en el Parque Nacional Amboro. Tesis de Grado, Universidad Autónoma Gabriel René Moreno, Santa Cruz, Bolivia. 


\title{
Chapter 4
}

The role of dispersal ability, climate and spatial separation in shaping biogeographic patterns of phylogenetically distant plant groups in seasonally dry Andean forests of Bolivia

Reynaldo Linares-Palomino and Michael Kessler

\author{
Journal of Biogeography (In press) \\ DOI:10.1111/j.1365-2699.2008.02028.x
}




\section{Abstract}

Aim: To assess biogeographic patterns of Acanthaceae, Bromeliaceae, Cactaceae and Pteridophyta in Bolivian Andean seasonally dry forest islands and to explain current floristic differences between these islands by means of extrinsic (precipitation, elevation) and intrinsic (dispersal ability) factors.

Location: Ten isolated and disjunct seasonally dry forest areas in the Bolivian Andes and the adjacent seasonal forest areas of the Chiquitanía and Chaco regions. Methods: We collated species data from recently updated and revised taxonomic treatments and herbarium collections for Acanthaceae, Bromeliaceae, Cactaceae and Pteridophyta, constructed floristic distance matrices to estimate beta diversity at the study sites, and subjected them to Mantel correlation analyses. Multiple regressions on distance matrices allowed us to test the influence of geographical distance and environmental (elevation and precipitation) differences on floristic differentiation.

Results: Acanthaceae and Bromeliaceae, and to a lesser extent Cactaceae, showed coincident biogeographic patterns and suggested the presence of two seasonally dry forest groups in Andean Bolivia: one including all small isolated northern dry valleys and another including all southern valleys with connections to the lowland seasonal forests of the Chiquitanía and the Chaco. Most of the variation in the floristic distance matrices in these plant groups, with seed dispersal typically restricted to short distances, was explained by spatial separation between habitat islands. In contrast, pteridophytes showed a different biogeographic pattern. Their floristic differences between sites were determined by the environmental variables. The anemochorous and spore-based dispersal system of this plant group seems to be a highly effective mechanism allowing pteridophytes to easily reach even the isolated dry valleys in inter-Andean Bolivia.

Main conclusions: Current biogeographic patterns in dry Andean habitat islands can provide insights into the factors that control processes of community assembly. We show that differences in community composition of phylogenetically distant 
plant groups in the understorey of seasonally dry forest islands can be explained by a combination of the habitat characteristics where the group is present (either precipitation, elevation, or both) and, more interestingly, by group specific dispersal limitation (as inferred by geographical distance between island habitats).

Keywords: Andes, Bolivia, dispersal limitation, environmental factors, floristic dissimilarity, island biogeography, plant geography, seasonal forest island

\subsection{Introduction}

Plant dispersal is a central theme in plant community ecology Bullock \& Nathan, 2008). The fact that most plant species cannot disperse their seeds over distances beyond a few metres implies that they are effectively dispersal limited van Oudtshoorn \& van Rooyen, 1999; Cain et al., 2000). Within these shorter spatial scales, diaspore dispersal is an important process influencing the structure of communities. At larger geographical scales, rare long distance dispersal events of diaspores are considered an important factor for shaping and maintaining metacommunities (Holyoak et al. 2005). This is because these diaspores, aided by vectors such as vertebrates (especially birds), wind and water (Cain et al., 2000; Willson \& Traveset, 2000, Nathan, 2006), have the potential to reach sites that are separated from the source populations by great distances, physical barriers or surrounded by an adverse habitat matrix (Levin et al., 2003, Nathan, 2006, Soons \& Bullock, 2008).

Seed dispersal and life history processes occurring after it (such as germination and seedling establishment), depend heavily on the environmental conditions prevailing in the newly colonized habitat van Oudtshoorn \& van Rooyen, 1999). These environmental conditions act as filters, removing all species lacking a specified combination of traits (Keddy, 1992). Thus, ecological communities appear to be mainly structured by two important albeit contrasting processes: dispersal and niche related environmental factors, known as the dispersal assembly and niche assembly view, respectively (Ozinga et al., 2005; Gravel et al., 2006; Leibold \& McPeek, 2006, 
Thompson \& Townsend, 2006, Chase, 2007). Consequently, observed differences in beta diversity between communities may be due to dissimilar environments, may reflect spatial patterns of dispersal, or may be the result of both. Much empirical evidence supports the view that environmental heterogeneity, especially soil factors, contributes to differences in present day plant distribution and community composition patterns at very local to landscape scales (e.g., Clark et al., 1999; Condit et al., 2000; Tuomisto et al., 2003b; John et al., 2007; Jones et al., 2008). There is also some evidence in support of dispersal (as measured by degree of isolation or distance between two communities) as an important factor (e.g., Kadmon \& Pulliam, 1993; Gilbert \& Lechowicz, 2004), but the bulk of studies point to a coupled influence of both processes (e.g., Balvanera et al., 2002; Duivenvoorden et al., 2002; Cottenie, 2005).

Biogeographic "island" systems with spatially discrete entities such as oceanic islands, mountains, or valley systems, have long played a central role in biogeographic research (MacArthur \& Wilson, 1967; Prance, 1996; Lomolino et al., 2005). Seasonally dry forests, a tree-dominated ecosystem in which grasses are a minor element (Mooney et al., 1995), occur in disjunct areas throughout the Neotropics (Pennington et al., 2000). The smallest and most isolated of these areas occur in the rain-shadowed Andean valleys from Colombia to Bolivia Pennington et al. 2006b) where they are currently isolated by more humid vegetation types and can consequently be considered as island-like habitats (Herzog \& Kessler, 2002). This situation provides a superb opportunity to explore the biogeography of an Andean vegetation island system. Following the distance decay biogeographical rule Nekola $\&$ White, 1999), we would expect valleys that are geographically and environmentally close to each other (or which are connected by other nearby valley systems) to show similar faunal and floral characteristics, whereas valleys separated by greater geographic or environmental distances should be inhabited by distinct faunal and floral assemblages. Partial evidence in support of this for some Andean valleys comes from ornithological (Herzog \& Kessler, 2002) and botanical data (Killeen et al., 1998; 
Kessler \& Helme, 1999; Fuentes et al., 2004; Cayola et al., 2005). Vegetation model simulations provide further evidence (Mayle, 2004).

In recent years, some plant groups occurring in Bolivia have been taxonomically revised based on extensive and intensive fieldwork (e.g., Wasshausen \& Wood, 2004), providing up-to-date distribution data and taxonomically uniform treatments suitable for regional scale biogeographic analyses. Of these, we selected four phylogenetically distant and ecologically distinct plant groups (Acanthaceae, Bromeliaceae, Cactaceae, Pteridophyta) conspicuously present in the understorey of Bolivian seasonally dry forests. Our aims in this study were to assess to what degree the distribution and community composition patterns of these plant groups in the isolated seasonally dry forests in Bolivia coincide and whether these patterns can be attributed to environmental determinants such as current local rainfall conditions and topography (as inferred by altitudinal distribution), to dispersal limitation (as inferred by current geographical separation between isolated seasonally dry forest areas), or to a combination of both.

\subsection{Methods}

\subsubsection{Study area and data collation}

We identified 12 seasonal vegetation areas in Bolivia with sizes ranging from 30 $\mathrm{km}^{2}$ to $140000 \mathrm{~km}^{2}$, the smallest being located in the northern inter-Andean valleys (Fig.4.17, Table 4.1). Eleven were true seasonally dry forests (SDFs) as defined by (Mooney et al., 1995). Of these seven are discrete, isolated SDF areas, occurring in narrow inter-Andean dry valleys in the departments of La Paz, Cochabamba and Potosí. The rest of the SDF areas have no sharp boundaries separating them from adjacent vegetation formations and we used topographical data and an unpublished vegetation map of Bolivia by M. Kessler to delimit them. Three occur in more extended river catchments originating in the Andes and opening out into the southern lowlands, whilst the Chiquitanía region constitutes one of the most extensive sea- 
Table 4.1: Seasonal vegetation areas defined for the biogeographical analysis of selected plant groups in Bolivia.

\begin{tabular}{lllll}
\hline Area & Departamento & $\begin{array}{l}\text { Elevation } \\
\text { range } \\
(\mathrm{m} \text { a.s.l. })\end{array}$ & $\begin{array}{l}\text { Rainfall range } \\
(\mathrm{mm} \text { year }\end{array}$ & Area $\left(\mathrm{km}^{2}\right)$ \\
\hline Río Tuichi & La Paz & $700-1300$ & $1200-1600$ & 700 \\
Camata valley & La Paz & $1150-1500$ & $1200-1600$ & 30 \\
Consata valley & La Paz & $1100-1500$ & $1200-1600$ & 50 \\
Coroico valley & La Paz & $700-1300$ & $1400-1600$ & 100 \\
Río La Paz & La Paz & $800-3000$ & $800-1600$ & 400 \\
Río Cotacajes & Cochabamba, La Paz & $1500-2300$ & $1100-1600$ & 200 \\
Río Caine & Cochabamba, Potosí & $2000-3300$ & $550-900$ & 5000 \\
Río Grande & Santa Cruz & $500-2000$ & $900-1600$ & 10000 \\
Río Parapetí & Chuquisaca & $500-1800$ & $800-1600$ & 10000 \\
Río Pilcomayo & Chuquisaca, Tarija & $500-3000$ & $500-1600$ & 10000 \\
Chiquitanía & Santa Cruz & $200-1200$ & $900-1600$ & 140000 \\
Chaco & Santa Cruz & $250-500$ & $400-900$ & 100000 \\
\hline
\end{tabular}

sonal forest areas in south-western Bolivia. In addition, we included the adjacent seasonal lowland forests of the Bolivian Chaco, comprising the northernmost section of the Chaco sensu stricto as delimited by (Prado, 1993). Despite being considered a different vegetation unit, inclusion of the Chaco is justified because several herbaceous to woody plant species show consistent distribution patterns pointing to a strong link with the seasonal forests in southern Bolivia (López, 2003; Killeen et al. 2006, Wood, 2006).

We collated species lists for four relatively well known and recently taxonomically revised plant groups for each seasonal forest area: Bromeliaceae (Krömer et al. 1999. B. Steudel et al., unpub. data), Acanthaceae (Ezcurra, 2002; Wasshausen \& Wood, 2004, M. Kessler, unpub. data), Pteridophyta (M. Kessler \& A.R. Smith, in prep.) and Cactaceae (Navarro, 1996 used as baseline data and modified according to Ritter, 1980 and Ibisch et al., 2000, updated following Hunt et al., 2006). Synonymies were checked and records modified (merged or split) accordingly. To limit our data to species naturally occurring in seasonally dry forest vegetation we excluded species showing exclusive occurrences above $3000 \mathrm{~m}$, as well as introduced and cultivated 
(a)

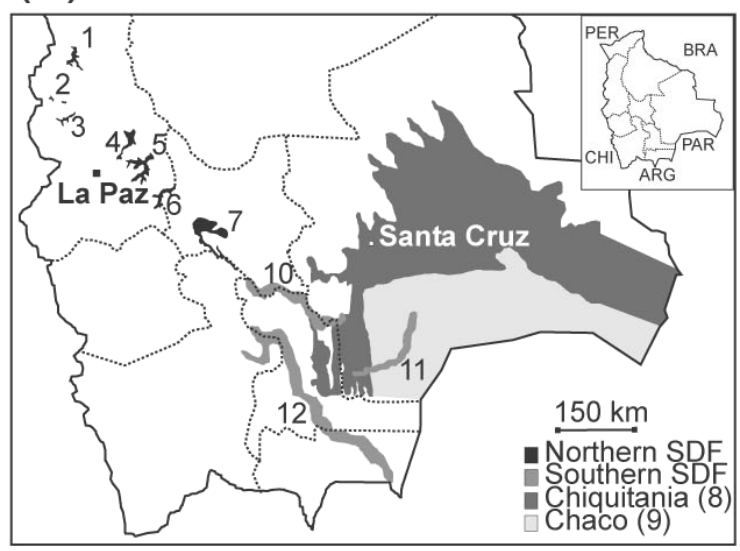

(c)

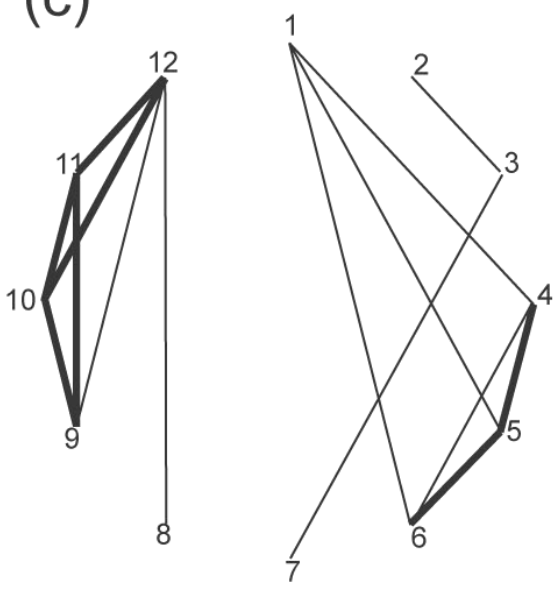

(e)

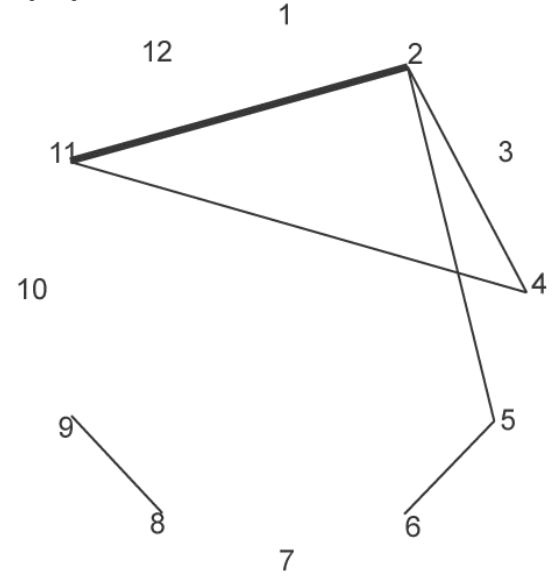

(b)

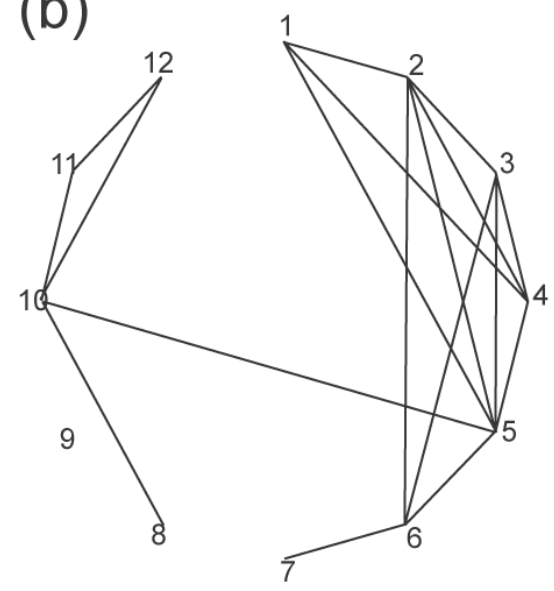

(d)

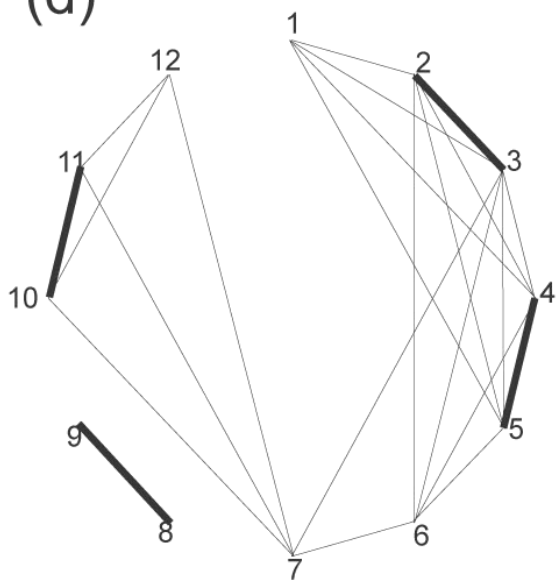

(f)

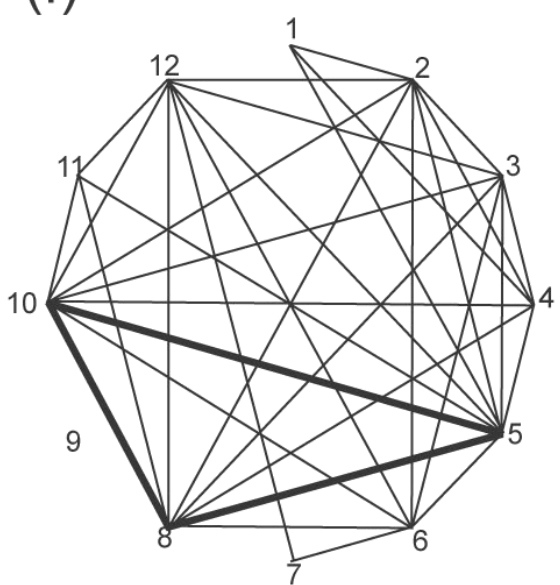

Figure 4.1: a. Seasonally dry forest (SDF) areas studied in Bolivia. Northern SDF: 1. Río Tuichi, 2. Camata, 3. Consata, 4. Coroico, 5. Río La Paz, 6. Río Cotacajes. Southern SDF: 7. Río Caine, 10. Río Grande, 11. Río Parapetí, 12. Río Pilcomayo. Sørensen similarity relationships among areas: b. All Plant Groups (ALL), c. Acanthaceae, d. Bromeliaceae, e. Cactaceae, f. Pteridophyta. Thin lines show similarities above 0.5, thick lines show similarities above 0.7. Numbers follow those in the map, and additionally: 8. Chiquitanía, 9. Chaco. 
species. Our choice of these four groups had practical reasons. First, there are only incomplete vascular plant checklists (or any subgroup of these, e.g., woody plants or trees) for few of the studied seasonally dry forest areas (e.g., the trees and shrubs guide for the Chiquitanía region by Jardim et al., 2003), whilst most of the smaller and isolated areas have none. Second, including more groups would have required a broader taxonomic expertise and the taxonomic treatment of individual groups, between taxa and between areas, would not have been uniform.

\subsubsection{Data analyses}

All species were coded as present (1) or absent (0) in the 12 seasonal vegetation areas. We produced separate data matrices for each plant group plus an additional matrix containing all four groups (henceforth called "ALL").

In an initial step, to assess if diversity among the plant groups was similar or not, we calculated all possible pairwise Pearson's product-moment correlations of their species richness at the 12 seasonal forest areas. In a second step, we estimated beta diversity by constructing Sørensen dissimilarity matrices for each individual plant group. We used the Sørensen (Bray-Curtis) distance index D because this index is simple to calculate for presence-absence data and easy to interpret Vellend, 2001; Magurran, 2004), and has been used repeatedly in similar studies (e.g., Vormisto et al., 2000; Tuomisto et al., 2003b). To assess whether the plant groups performed similarly in reflecting biogeographic relationships among the sites we calculated Mantel correlation coefficients between all possible pairwise combinations of floristic dissimilarity matrices. When we used similarity values (S), we calculated them with the formula: Sørensen similarity $(\mathrm{S})=1$ - D. We used a normalised Mantel statistic, $r_{M}$, and evaluated its statistical significance through 10000 permutations (Manly, 1997).

We estimated dispersal limitation by constructing a matrix of log-transformed nearest horizontal geographical distances among the studied areas using geographical coordinates of each area, as dispersal limitation is expected to cause distance decay 
(Condit et al., 2002). In case they were adjoining, we considered a distance of zero. We also constructed an altitudinal, a precipitation and a combined elevationprecipitation environment distance matrix as follows. We coded the presence or absence of each seasonal forest area in a table summarizing the total elevation (200$3300 \mathrm{~m}$ a.s.l.) and precipitation (400-1600 $\mathrm{mm}$ ) ranges of the study area in 100 $\mathrm{m}$ and $100 \mathrm{~mm}$ increments, respectively (e.g., the Consata SDF area ranging from 1100-1500 m a.s.l. would be only present in the 1100 to 1500 columns). Based on these tables, we calculated Sørensen distance matrices summarizing altitudinal and precipitation differences, or both combined. We used the Sørensen coefficient because it is an asymmetric index that measures overlap over the average range of values and excludes double-zero matches, preventing sites with many zeros being considered as similar. We then calculated all possible pairwise correlations of each environmental distance matrix with each of the floristic distance matrices using a simple Mantel test and evaluated statistical significance as in the floristic matrix comparisons. We then performed a Mantel test to evaluate whether there was a correlation between the geographical and all other floristic matrices. We evaluated this correlation with $\alpha=0.05$ (1000 permutations).

We then used a multiple regression on distance matrices procedure to evaluate which of all possible combinations of the two sets of matrices (dispersal/space and environment) best explained total variation in the floristic matrices. To quantify the proportion of variation in floristic distances between SDF areas explained uniquely by dispersal limitation (as horizontal geographical distance) we subtracted the variation produced by environmental factors (combined matrix) from the total variation produced by both environmental factors and dispersal/space. To quantify the proportion of variation in floristic distances between SDF areas explained uniquely by environmental factors we subtracted the variation produced by dispersal/space from the total variation produced by both environmental factors and dispersal/space (Tuomisto et al., 2003a; Lichstein, 2007). We evaluated the statistical significance of each regression by performing 10000 permutations. We did all calculations with the 
R software (R Development Core Team, 2008) and package Vegan (Oksanen et al., 2008).

\subsection{Results}

\subsubsection{Species richness}

Our complete database included 411 species of which 137 (33.3\%) were recorded in a single area, whilst only three species occurred in all areas (Tillandsia recurvata (L.) L., T. streptocarpa Baker and T. tricholepis Baker, all Bromeliaceae). The number of species per seasonal forest area varied between 83 (Chaco) and 176 (Río Grande) (mean 122, Table 4.2). Of the 411 species, 116 (28\%) were classified as endemic to Bolivia. 71 (52\%) of the 137 species recorded in one single area have been recognised as endemic to Bolivia (either from a single collection as in several locally rare Cactaceae, or from several collections as in the case of the locally abundant Justicia kessleri Wassh. \& J.R.I. Wood). With the exceptions of species richness and endemism values of Bromeliaceae, which decreased significantly with increasing seasonal forest area (Pearson's product-moment correlation: $\mathrm{r}=-0.82, P=0.001$ and $\mathrm{r}=-0.75, P=0.005$, respectively), we found no correlation between species richness or endemism and total area of each seasonal forest.

Acanthaceae contributed 72 species to the total (17.5\%), of which 18 were endemic to Bolivia. The number of species per area varied between 4 (Río Camata) and 35 (Río Grande) (mean 20). Bromeliaceae had 132 species (32.1\%; 55 endemic), varying between 15 (Chaco) and 53 (Río Tuichi) species per area (mean 37). Cactaceae had 88 species (21.4\%; 42 endemic), varying between 1 (Río Tuichi) and 40 (Río Pilcomayo) species per area (mean 14). Pteridophytes had 119 species (29\%; 1 endemic), varying between 15 (Chaco) and 76 (Chiquitanía) species per area (mean 51) (Table 4.2).

Pearson's product-moment correlations between species richness among the four vascular plant groups at the 12 seasonal forest areas were positive and statistically 
Table 4.2: Number of species/endemics per seasonally dry forest area and plant group $(\mathrm{ACA}=$ Acanthaceae, $\mathrm{BRO}=$ Bromeliaceae, $\mathrm{CAC}=$ Cactaceae, $\mathrm{PTE}=$ Pteridophyta, $\mathrm{ALL}=$ all plant groups).

\begin{tabular}{llllll}
\hline & ACA & BRO & CAC & PTE & ALL \\
\hline Río Tuichi & $14 / 3$ & $53 / 11$ & $1 / 0$ & $39 / 0$ & $107 / 14$ \\
Camata & $4 / 1$ & $39 / 4$ & $5 / 0$ & $51 / 0$ & $99 / 5$ \\
Consata & $9 / 4$ & $39 / 7$ & $3 / 1$ & $47 / 0$ & $98 / 13$ \\
Coroico & $19 / 4$ & $43 / 8$ & $4 / 1$ & $47 / 0$ & $113 / 13$ \\
Río La Paz & $20 / 5$ & $43 / 10$ & $14 / 6$ & $69 / 0$ & $146 / 23$ \\
Río Cotacajes & $19 / 6$ & $31 / 8$ & $15 / 8$ & $50 / 0$ & $115 / 25$ \\
Río Caine & $7 / 2$ & $42 / 12$ & $10 / 7$ & $48 / 0$ & $107 / 21$ \\
Chiquitanía & $29 / 1$ & $17 / 1$ & $14 / 3$ & $76 / 0$ & $136 / 5$ \\
Chaco & $24 / 2$ & $15 / 1$ & $29 / 8$ & $15 / 1$ & $83 / 12$ \\
Río Grande & $35 / 6$ & $46 / 11$ & $32 / 16$ & $63 / 1$ & $176 / 36$ \\
Río Parapetí & $29 / 4$ & $44 / 5$ & $6 / 1$ & $42 / 0$ & $121 / 10$ \\
Río Pilcomayo & $34 / 6$ & $30 / 8$ & $40 / 13$ & $61 / 0$ & $165 / 29$ \\
Total & $72 / 18$ & $132 / 55$ & $88 / 42$ & $119 / 1$ & $411 / 116$ \\
\hline
\end{tabular}

Table 4.3: Pearson Correlation coefficients between species richness values of 12 seasonally dry forest areas $(P$-values are given in parentheses; significance levels: ${ }^{*} P<0.05,{ }^{*} * P<0.01 ; \mathrm{ACA}=$ Acanthaceae, $\mathrm{BRO}=$ Bromeliaceae, $\mathrm{CAC}=$ Cactaceae, $\mathrm{PTE}=$ Pteridophyta, $\mathrm{ALL}=$ all plant groups).

\begin{tabular}{lllll}
\hline & ACA & BRO & CAC & PTE \\
\hline BRO & -0.29 & & & \\
CAC & $0.71^{* *}$ & -0.46 & & \\
PTE & 0.27 & 0.07 & 0.12 & \\
ALL & $0.72^{* *}$ & 0.13 & $0.59^{*}$ & $0.74^{* *}$ \\
\hline
\end{tabular}

significant only for the combinations ALL with Acanthaceae, Cactaceae or Pteridophytes, as well as between Acanthaceae and Cactaceae (Table 4.3).

\subsubsection{Floristic similarity analysis}

Pairwise similarity values calculated between the seasonal forest areas ranged from 0.15 to 0.69 (mean $=0.43 \pm 0.13)$ when all plant groups were considered (see Table A.4 in Supplementary Material). Values for individual plant groups were between 0.06 and $0.88($ mean $=0.33 \pm 0.22)$ for Acanthaceae, between 0.21 and 0.82 (mean $=0.46 \pm 0.16)$ for Bromeliaceae, between 0.0 and $0.73($ mean $=0.18 \pm 0.18)$ for 
Cactaceae and between 0.15 and 0.78 (mean $=0.49 \pm 0.16)$ for pteridophytes. Two of the four plant groups (Acanthaceae and Bromeliaceae) and the combined matrix ALL showed similar floristic patterns (Fig 4.1b-f) consisting mainly of two groups of SDF areas: one included all small isolated northern dry valleys and the other included all southern valleys with connections to the lowland seasonal forests of the Chiquitanía and the Chaco. The two clusters in Cactaceae separated some of the northern inter-Andean SDF from those in the south and the lowlands, but the northern inter-Andean SDF cluster included the Río Parapetí SDF located well in the south of Bolivia (Fig 4.1 ). Pteridophyta on the other hand, produced a nearly unresolved cluster network with no clear biogeographical structure (Fig 4.1 f). The Río Caine SDF functions as a link between the northern SDFs and the southern SDFs, showing stronger affinities with either one or the other cluster depending on the plant group used as the basis of the analysis.

\subsubsection{Beta diversity}

Mantel correlations between estimates of beta-diversity for each of the vascular plant groups were positive and statistically significant to very highly significant for all pairwise community composition distances, except for the Cactaceae vs Pteridophyta (Table 4.4). The highest correlations were found between ALL and Bromeliaceae $\left(r_{M}=0.78, P=0.0001\right)$, and between ALL and Pteridophyta $\left(r_{M}=0.78, P=\right.$ 0.0001). The lowest statistically significant value was between Acanthaceae and Pteridophyta $\left(r_{M}=0.26, P=0.047\right)$. All Mantel correlations between floristic differences and geographical distance were significant at $\alpha=0.05$, except for Pteridophyta (Table 4.4).

Mantel correlations between floristic differences and altitudinal differences were significant to highly significant for all plant groups (Table 4.4). Mantel correlations between floristic differences and precipitation differences were highly significant for Pteridophyta and ALL, showing high correlation values. Mantel correlations between floristic differences and a combined environmental matrix showed significant 
Table 4.4: Mantel correlations between floristic differences of 12 seasonally dry forest areas based on four different plant groups in Bolivia, and between plant groups and environmental factors and dispersal limitation (as horizontal geographic distance). Distance matrices for plant groups and environmental factors were based on the Sørensen distance index. Significance was evaluated by performing 10000 permutations for an alpha of ${ }^{*} P<0.05,{ }^{* *} P<0.01$, ${ }^{* * *} P<0.001$. Mantel correlations between floristic differences and dispersal limitation were evaluated on significance tests based on 1000 permutations for an $\alpha$ of $* P<0.05$.

\begin{tabular}{llllll}
\hline & ALL & ACA & BRO & CAC & PTE \\
\hline ACA & $0.66^{* * *}$ & & & & \\
BRO & $0.78^{* * *}$ & $0.49^{* * *}$ & & & \\
CAC & $0.43^{* *}$ & $0.32^{*}$ & $0.38^{* *}$ & & \\
PTE & $0.78^{* * *}$ & $0.26^{*}$ & $0.37^{*}$ & 0.20 & \\
Geographical distance & $0.42^{*}$ & $0.66^{*}$ & $0.39^{*}$ & $0.27^{*}$ & 0.05 \\
Altitudinal distance & $0.58^{* * *}$ & $0.29^{*}$ & $0.40^{* *}$ & $0.30^{*}$ & $0.62^{* * *}$ \\
Precipitation distance & $0.55^{* * *}$ & 0.25 & 0.23 & 0.17 & $0.63^{* * *}$ \\
Environmental distance & $0.63^{* * *}$ & $0.29^{*}$ & $0.37^{*}$ & 0.26 & $0.70^{* * *}$ \\
\hline
\end{tabular}

to highly significant correlations for all plant groups, except for Cactaceae.

\subsubsection{Multiple matrix regression}

Total statistically significant variation in floristic distances explained by environmental differences (either as a single combined matrix or as individual precipitation and elevation matrices), geographical distances, or both, per plant group ranged from $6 \%$ in Acanthaceae to $55 \%$ in the combined ALL matrix (Table 4.5). There were, however, differences among plant groups in the combinations of distance matrices that best explained this variation. The combination precipitation/geographical distance best explained the variation in Acanthaceae (49\%). In Bromeliaceae and Cactaceae it was elevation-geographical distance (28\% and $15 \%$, respectively), in Pteridophyta elevation-precipitation (50\%) and the combination elevation-precipitationgeographical distance in ALL (Table 4.5). The unique contribution of each of the factors changed significantly for each plant group. In Acanthaceae, dispersal limitation alone (i.e. spatial separation) explained $40 \%$ of the total variation, whereas pure environment explained only 7\%. In Bromeliaceae and Cactaceae both pure dispersal limitation and pure environment explained similar levels of variation ( $12 \%$ and 
Table 4.5: Coefficients of multiple determination $\left(\mathrm{R}^{2}\right)$ of the multiple regressions on distance matrices performed on four different plant groups in Bolivia. Floristic and environmental distance matrices were based on the Sørensen distance index. Significance values were based on 10000 permutations for an alpha of ${ }^{*} P<0.05$, ${ }^{* *} P<0.01$, *** $P<0.001$. [Abbreviations of plant groups follow those in 4.3 ; $\mathrm{sp}=$ floristic distance matrix, $\mathrm{pp}=$ precipitation distance matrix, ele $=$ elevation distance matrix, geo = geographical distance matrix (dispersal limitation), env = environmental distance matrix].

\begin{tabular}{llllll}
\hline & ALL & ACA & BRO & CAC & PTE \\
\hline sp.geo & $0.17^{* * *}$ & $0.43^{* * *}$ & $0.15^{* *}$ & $0.07^{*}$ & 0.00 \\
sp.pp & $0.30^{* * *}$ & $0.06^{*}$ & 0.05 & 0.03 & $0.40^{* * *}$ \\
sp.(pp.geo) & $0.47^{* * *}$ & $0.49^{* * *}$ & $0.21^{* *}$ & $0.10^{*}$ & $0.41^{* * *}$ \\
sp.ele & $0.34^{* * *}$ & $0.08^{*}$ & $0.16^{* *}$ & $0.09^{*}$ & $0.39^{* * *}$ \\
sp.(ele.geo) & $0.46^{* * *}$ & $0.48^{* * *}$ & $0.28^{* * *}$ & $0.15^{* *}$ & $0.39^{* * *}$ \\
sp.(ele.pp) & $0.40^{* * *}$ & $0.09^{*}$ & $0.16^{* *}$ & 0.09 & $0.50^{* * *}$ \\
sp.env & $0.40^{* * *}$ & $0.09^{*}$ & $0.14^{* *}$ & 0.07 & $0.49^{* * *}$ \\
sp.(ele.pp.geo) & $0.55^{* * *}$ & $0.50^{* * *}$ & $0.28^{* * *}$ & $0.15^{*}$ & $0.50^{* * *}$ \\
sp.(env.geo) & $0.54^{* * *}$ & $0.49^{* * *}$ & $0.27^{* * *}$ & $0.13^{*}$ & $0.49^{* * *}$ \\
\hline
\end{tabular}

$13 \%$, and $6 \%$ and $8 \%$, respectively). All the variation in Pteridophyta was purely explained by the environmental variables (whether these were or not combined into a single matrix).

\subsection{Discussion}

Species presence-absence data of Acanthaceae, Bromeliaceae, and to a lesser extent Cactaceae, from 12 seasonal forest areas in Bolivia showed roughly congruent biogeographic relationships. The resolution of these relationships varied somewhat between taxa. Nevertheless, all three plant groups suggested the existence of two main groups of seasonally dry forests in Bolivia: the seasonally dry forest sites in the northern Bolivian Andes, and the seasonally dry forests in the southern Bolivian Andes, which have stronger links to the adjoining Chaco and Chiquitanía seasonal forests. The same pattern was also evident when all four plant groups were combined and analysed together (ALL matrix). Significant to very highly significant Mantel correlations run between each plant group and a matrix containing all other plant groups (data not shown) further supported this congruence. In contrast, 
pteridophytes showed only weakly resolved patterns in all analyses. The extent to which these results can be extrapolated to the whole flora or to other plant groups present in the studied seasonal forest remains to be explored as different patterns can be expected from different plant groups. Thus, generalizations will be difficult, as the Bolivian inter-Andean dry valleys are in a complex biogeographical position, adjacent to and influenced by other major biomes (Wood, 2006; Linares-Palomino et al., in press).

Current biogeographic vegetation patterns in the Neotropics are the result of complex historical and biological processes (Burnham \& Graham, 1999). The Andes had already reached about half of their modern elevation by $10 \mathrm{Ma}$ (million years ago) (Gregory-Wodzicki, 2000). A rain-shadow effect, causing semi-arid to arid climates in the Central Andes, has probably been influencing the region since $15 \mathrm{Ma}$, as shown by geological and palaeobotanical data and models, and it prevailed until $4 \mathrm{Ma}$ (Hartley, 2003). (Hughes \& Eastwood, 2006) have recently argued that Andean uplift is probably one of the most important factors that shaped current plant diversity and vegetation patterns in the region: Andean uplift presented the extant organisms with a large area subjected to repeated vegetation fragmentations due to altitudinal shifts, glacial fluctuations and a dissected topography, promoting geographical isolation. This generated habitat and environmental heterogeneity and provided new ecological opportunities. Dated phylogenies for SDF representative taxa (e.g., Coursetia, Leguminosae) show geographically structured evolutionary radiations well within the Andean uplift timeframe (Pennington et al. 2004) and it has been argued that SDF might have had a long history of discontinuous distributions and relative floristic stability of at least 5-7 Ma (Lavin, 2006). Indeed, molecular phylogenies for some of our study groups suggest radiations congruent with the rise of the Andes and the formation of new seasonal vegetation areas to colonise, thus favouring speciation. Much of the current diversity in Andean Bromeliaceae Givnish et al., 2004, Barfuss et al., 2005) and Cactaceae Ritz et al. 2007) appears to have originated during and/or after the major uplift of the 
Andes. In addition, there is evidence that at least one genus in the pteridophytes has primarily radiated during Andean uplift (e.g., Lehnert et al., in press). Current phylogenetic resolution in Acanthaceae is still too poor to elucidate Neotropical biogeographic patterns (McDade et al., 2005; Daniel et al., 2008). However, their mostly Andean distribution (Gentry, 1982) and the significant amount of species and endemics in dry Andean environments (Wood, 2006) hint of a comparable dynamic and explosive speciation phase during the rise of the Andes, as in the above mentioned vascular plant groups. Such shared historic factors may be hypothesised to be partly the cause of the repeated and consistent floristic patterns found in Acanthaceae and Bromeliaceae (and to a lesser extent in Cactaceae), and reflected in analyses of all plant groups combined.

In addition, Acanthaceae, Bromeliaceae and Cactaceae seem to be little influenced by environmental factors such as elevation and precipitation. Instead, spatial separation mostly accounts for differences in floristic composition among these groups, as they are restricted to specific sites due to by their limited dispersal ability. Indeed, Acanthaceae have autochorous ballistic seed dispersal that takes place on the order of less than a metre to a few metres (Ridley, 1930; Wasshausen, 2004) and Bromeliaceae have anemochorous and zoochorous seed dispersal that strongly influences the range sizes of the species (Kessler, 2002). Especially in subfamily Tillandsioideae, which has wind-dispersed seeds, bromeliads have dispersal distances beyond the range of those of Acanthaceae, but there still appears to be marked dispersal limitation (Kessler, 2002; Mondragon \& Calvo-Irabien L., 2006). The zoochorous Bromeliaceae, as well as Cactaceae, which also have zoochorous seed dispersal syndromes, are mainly dispersed by birds and partly by mammals. Although quantitative data on dispersal distances for these taxa is lacking, the isolated position of Andean seasonally dry forests, separated from each other by high mountain ranges clothed in humid montane forest, strongly suggests that dispersal of these taxa between the individual seasonally dry forest regions might be rare. Acanthaceae, Bromeliaceae, and Cactaceae all show high levels of endemism for most of the stud- 
ied areas and several of these endemics are rare and of narrow distribution (e.g., Aphelandra kolobantha Lindau, a very rare endemic species of scrubfilled gullies in relatively dry Andean valleys, only collected three times; Wasshausen \& Wood, 2004).

Pteridophytes, on the contrary, are more influenced by environmental variables than by spatial separation. The difference in geographical resolution seen between pteridophytes and the three other study groups may reflect the overall wider distribution of the individual pteridophyte species. In fact, all the pteridophyte species had geographical ranges spanning at least 5 degrees latitude, with $92 \%$ of the species having ranges extending over at least 10 degrees latitude. If we consider that some of the northern inter-Andean valleys in La Paz cover areas of less than $100 \mathrm{~km}^{2}$, then the distributional amplitude of the pteridophyte species explains the low resolution in our biogeographical analyses. This is also evident in the lack of pteridophyte endemics restricted to these valleys, the only endemic species being Elaphoglossum cruziense M. Kessler \& Mickel, restricted to the Chaco and the adjacent Río Grande. It is probable that the highly effective spore-based anemochorous dispersal system of pteridophytes (Barrington, 1993), possibly aided by anisotropic (directiondependent) transport along "wind highways" (Muñoz et al., 2004), has contributed many widely dispersed species to these isolated valleys and lowland SDF areas. On the other hand, pteridophytes are well known to be highly dependent on humidity in their distribution (Kessler, 2001) and our analyses reflect this relationship accordingly. Apparently, the geographical separation of SDF sites is less than the maximum distance typically dispersed by spores of most of the pteridophyte species we studied, enabling pteridophytes to colonise most climatically suitable sites, independently of their location. Clearly, at the spatial resolution of our analysis, pteridophytes are not suitable for historic biogeographic analyses.

In conclusion, we found that dispersal efficiency, in combination with spatial separation and differences in environmental conditions, leads to distinct biogeographic patterns in phylogenetically distant plant groups in the island-like SDF system of the 
Bolivian inter-Andean valleys. Lower dispersal ability results in a stronger spatial signal in the resulting biogeographic pattern, whereas high dispersal ability leads to a stronger environmental signal. These conclusions are based, however, on a coarse environmental model, which does not necessarily reflect subtle climatic, soil or geological differences. The inclusion of information on e.g., dry season length, minimum and maximum temperatures, soil nutrient composition or human modifications of the habitat (as yet not available uniformly and accurately for each of our studied areas, and in fact for much of the Neotropics) might reveal that some of the studied plant groups are not as dispersal limited as they appear, and that they instead respond to subtle environmental differences. Dated molecular phylogenies on global as well as on more local and recent timescales (Pennington et al., 2006a) and population genetic studies of species characteristic of seasonal forests (e.g., Caetano et al., 2008) should provide additional information on the timing and intensity of dispersal events and, consequently, on the assembly of these communities.

\subsection{Acknowledgements}

S. Bridgewater and M. Jones provided comments and suggestions on an early version of this paper. Constructive critique and suggestions by two anonymous reviewers and the editor greatly improved the paper. J. Oksanen advised on the use of similarity indices, J. Wood and D. Wasshausen clarified Acanthaceae distribution data. RLP acknowledges financial support from the German Academic Exchange Service (DAAD). 


\subsection{References}

Balvanera, P, Lott, E, Segura, G, Siebe, C, \& Islas, A. 2002. Patterns of betadiversity in a Mexican tropical dry forest. Journal of Vegetation Science, 13, $145-158$.

Barfuss, MHJ, Samuel, R, Till, W, \& Stuessy, TF. 2005. Phylogenetic relationships in subfamily Tillandsioideae (Bromeliaceae) based on DNA sequence data from seven plastid regions. American Journal of Botany, 92, 337-351.

Barrington, DS. 1993. Ecological and historical factors in fern biogeography. Journal of Biogeography, 20, 275-279.

Bullock, JM, \& Nathan, R. 2008. Plant dispersal across multiple scales: linking models and reality. Journal of Ecology, 96, 567-568.

Burnham, RJ, \& Graham, A. 1999. The history of neotropical vegetation: New developments and status. Annals of the Missouri Botanical Garden, 86, 546-589.

Caetano, S, Prado, D, Pennington, RT, Beck, S, Oliveira-Filho, A, Spichiger, R, \& Naciri, Y. 2008. The history of Seasonally Dry Tropical Forests in eastern South America: inferences from the genetic structure of the tree Astronium urundeuva (Anacardiaceae). Molecular Ecology, 17, 3147-3159.

Cain, ML, Milligan, BG, \& Strand, AE. 2000. Long-distance seed dispersal in plant populations. American Journal of Botany, 87, 1217-1227.

Cayola, L, Fuentes, A, \& Jørgensen, PM. 2005. Estructura y composición florística de un bosque seco subandino yungueño en el Valle del Tuichi, Área Natural de Manejo Integrado Madidi, La Paz (Bolivia). Ecología en Bolivia, 40, 396-417.

Chase, JM. 2007. Drought mediates the importance of stochastic community assembly. Proceedings of the National Academy of Sciences of the United States of America, 104, 17430-17434. 
Clark, DB, Palmer, MW, \& Clark, DA. 1999. Edaphic factors and the landscapescale distributions of tropical rain forest trees. Ecology, 80, 2662-2675.

Condit, R, Ashton, PS, Baker, P, Bunyavejchewin, S, Gunatilleke, S, Gunatilleke, N, Hubbell, SP, Foster, RB, Itoh, A, LaFrankie, JV, Lee, HS, Losos, E, Manokaran, N, Sukumar, R, \& Yamakura, T. 2000. Spatial patterns in the distribution of tropical tree species. Science, 288, 1414-1418.

Condit, R, Pitman, N, Leigh, EG, Chave, J, Terborgh, J, Foster, RB, Nuñez, P, Aguilar, S, Valencia, R, Villa, G, Muller-Landau, HC, Losos, E, \& Hubbell, SP. 2002. Beta-diversity in tropical forest trees. Science, 295, 666-669.

Cottenie, K. 2005. Integrating environmental and spatial processes in ecological community dynamics. Ecology Letters, 8, 1175-1182.

Daniel, TF, McDade, LA, Manktelow, M, \& Kiel, CA. 2008. The "Tetramerium" Lineage (Acanthaceae: Acanthoideae: Justicieae): delimitation and intra-lineage relationships based on cp and nrITS sequence data. Systematic Botany, 33, 416436.

Duivenvoorden, JF, Svenning, JC, \& Wright, SJ. 2002. Beta diversity in tropical forests. Science, 295, 636-637.

Ezcurra, C. 2002. The genus Justicia (Acanthaceae) in the southern region of South America. Annals of the Missouri Botanical Garden, 89, 225-280.

Fuentes, A, Araujo, A, Cabrera, H, Canqui, F, Cayola, L, Maldonado, C, \& Paniagua, N. 2004. Estructura, composición y variabilidad del bosque subandino xérico en un sector del valle del río Tuichi, ANMI Madidi, La Paz (Bolivia). Revista Boliviana de Ecología y Conservación Ambiental, 15, 41-62.

Gentry, AH. 1982. Neotropical floristic diversity - phytogeographical connections between Central and South-America, Pleistocene climatic fluctuations, or an accident of the Andean orogeny. Annals of the Missouri Botanical Garden, 69, $557-593$. 
Gilbert, B, \& Lechowicz, MJ. 2004. Neutrality, niches, and dispersal in a temperate forest understory. Proceedings of the National Academy of Sciences of the United States of America, 101, 7651-7656.

Givnish, TJ, Millam, KC, Evans, TM, Hall, JC, Pires, JC, Berry, PE, \& Sytsma, KJ. 2004. Ancient vicariance or recent long-distance dispersal? Inferences about phylogeny and South American-African disjunctions in rapateaceae and bromeliaceae based on ndhF sequence data. International Journal of Plant Sciences, 165, S35-S54.

Gravel, D, Canham, CD, Beaudet, M, \& Messier, C. 2006. Reconciling niche and neutrality: the continuum hypothesis. Ecology Letters, 9, 399-409.

Gregory-Wodzicki, KM. 2000. Uplift history of the Central and Northern Andes: a review. Geological Society of America Bulletin, 112, 1091-1105.

Hartley, AJ. 2003. Andean uplift and climate change. Journal of the Geological Society, 160, 7-10.

Herzog, SK, \& Kessler, M. 2002. Biogeography and composition of dry forest bird communities in Bolivia. Journal fur Ornithologie, 143, 171-204.

Holyoak, M, Leibold, MA, Mouquet, NM, Holt, RD, \& Hoopes, MF. 2005. Metacommunities: a framework for large-scale community ecology. Pages 1-31 of: Holyoak, M, Leibold, MA, \& Holt, RD (eds), Metacommunities: spatial dynamics and ecological communities. University of Chicago Press, Chicago, IL.

Hughes, C, \& Eastwood, R. 2006. Island radiation on a continental scale: exceptional rates of plant diversification after uplift of the Andes. Proceedings of the National Academy of Sciences of the United States of America, 103, 10334-10339.

Hunt, D, Taylor, N, \& Charles, G (eds). 2006. The New Cactus Lexicon. DH Books, Milborn Port, UK. 
Ibisch, PL, Kessler, M, Nowicki, C, \& Barthlott, W. 2000. On the ecology, biogeography and diversity of the Bolivian epiphytic cacti. Bradleya, 18, 2-30.

Jardim, A, TJ, Killeen, \& Fuentes, A. 2003. Guía de los árboles y arbustos del bosque seco Chiquitano, Bolivia. Editorial FAN, Santa Cruz de la Sierra, Bolivia.

John, R, Dalling, JW, Harms, KE, Yavitt, JB, Stallard, RF, Mirabello, M, Hubbell, SP, Valencia, R, Navarrete, H, Vallejo, M, \& Foster, RB. 2007. Soil nutrients influence spatial distributions of tropical tree species. Proceedings of the National Academy of Sciences of the United States of America, 104, 864-869.

Jones, MM, Tuomisto, H, Borcard, D, Legendre, P, Clark, DB, \& Olivas, PC. 2008. Explaining variation in tropical plant community composition: influence of environmental and spatial data quality. Oecologia, 155, 593-604.

Kadmon, R, \& Pulliam, HR. 1993. Island biogeography - effect of geographical isolation on species composition. Ecology, 74, 977-981.

Keddy, PA. 1992. Assembly and response rules - 2 goals for predictive community ecology. Journal of Vegetation Science, 3, 157-164.

Kessler, M. 2001. Pteridophyte species richness in Andean forests in Bolivia. Biodiversity and Conservation, 10, 1473-1495.

Kessler, M. 2002. Environmental patterns and ecological correlates of range-size among bromeliad communities of Andean forests in Bolivia. The Botanical Review, $68,100-127$.

Kessler, M, \& Helme, N. 1999. Floristic diversity and phytogeography of the central Tuichi Valley, an isolated dry forest locality in the Bolivian Andes. Candollea, 54, 341-366.

Killeen, TJ, Jardim, A, Mamani, F, \& Rojas, N. 1998. Diversity, composition and structure of a tropical semideciduous forest in the Chiquitania region of Santa Cruz, Bolivia. Journal of Tropical Ecology, 14, 803-827. 
Killeen, TJ, Chávez, E, Peña-Claros, M, Toledo, M, Arroyo, L, Caballero, J, Correa, L, Guillén, R, Quevedo, R, Saldías, M, Soria, L, Uslar, Y, Vargas, I, \& Steininger, M. 2006. The Chiquitano dry forest, the transition between humid and dry forest in eastern lowland Bolivia. Pages 213-233 of: Pennington, RT, Ratter, JA, \& Lewis, GP (eds), Neotropical savannas and seasonally dry forests. CRC Press, Boca Raton, FL.

Krömer, T, Kessler, M, Holst, BK, Luther, HE, Gouda, E, Till, W, Ibisch, P, \& Vásquez, R. 1999. Checklist of Bolivian Bromeliaceae with notes on species distribution and levels of endemism. Selbyana, 20, 201-223.

Lavin, M. 2006. The Chiquitano dry forest, the transition between humid and dry forest in eastern lowland Bolivia. Pages 433-447 of: Pennington, RT, Ratter, JA, \& Lewis, GP (eds), Neotropical savannas and seasonally dry forests. CRC Press, Boca Raton, FL.

Lehnert, M, Kessler, M, Schmidt-Lebuhn, AN, Klimas, SA, Fehlberg, S, \& Ranker, TA. in press. Phylogeny of the fern genus Melpomene (Polypodiaceae) inferred from morphology and chloroplast DNA analysis. Systematic Botany.

Leibold, MA, \& McPeek, MA. 2006. Coexistence of the niche and neutral perspectives in community ecology. Ecology, 87, 1399-1410.

Levin, SA, Muller-Landau, HC, Nathan, R, \& Chave, J. 2003. The ecology and evolution of seed dispersal: A theoretical perspective. Annual Review of Ecology Evolution and Systematics, 34, 575-604.

Lichstein, JW. 2007. Multiple regression on distance matrices: a multivariate spatial analysis tool. Plant Ecology, 188, 117-131.

Linares-Palomino, R, Oliveira-Filho, AT, \& Pennington, RT. in press. Neotropical seasonally dry forests: diversity, endemism and biogeography of woody plants. In: Dirzo, R, \& Young, HS (eds), Seasonally dry tropical forests: ecology and conservation. Island Press, Washington, DC. 
Lomolino, MV, Riddle, BR, \& Brown, JH. 2005. Biogeography. 3rd edn. Sinauer Associates, Inc, Sunderland, MA.

López, RP. 2003. Phytogeographical relations of the Andean dry valleys of Bolivia. Journal of Biogeography, 30, 1659-1668.

MacArthur, RH, \& Wilson, EO. 1967. The theory of island biogeography. Princeton University Press.

Magurran, AE. 2004. Measuring biological diversity. Blackwell Publishing Limited.

Manly, BFJ. 1997. Randomization and Monte Carlo methods in biology. London, UK: Chapman \& Hall.

Mayle, FE. 2004. Assessment of the Neotropical dry forest refugia hypothesis in the light of palaeoecological data and vegetation model simulations. Journal of Quaternary Science, 19, 713-720.

McDade, LA, Daniel, TF, Kiel, CA, \& Vollesen, K. 2005. Phylogenetic relationships among Acantheae (Acanthaceae): Major lineages present contrasting patterns of molecular evolution and morphological differentiation. Systematic Botany, 30, $834-862$.

Mondragon, D, \& Calvo-Irabien L., M. 2006. Seed dispersal and germination of the epiphyte Tillandsia brachycaulos (Bromeliaceae) in a tropical dry forest, Mexico. Southwestern Naturalist, 51, 462-470.

Mooney, HA, Bullock, SH, \& Medina, E. 1995. Introduction. Pages 1-8 of: Bullock, SH, Mooney, HA, \& Medina, E (eds), Seasonally dry tropical forests. Cambridge University Press, New York.

Muñoz, J, Felicisimo, AM, Cabezas, F, Burgaz, AR, \& Martinez, I. 2004. Wind as a long-distance dispersal vehicle in the Southern Hemisphere. Science, 304, $1144-1147$.

Nathan, R. 2006. Long-distance dispersal of plants. Science, 313, 786-788. 
Navarro, G. 1996. Catálogo ecológico preliminar de las cactáceas de Bolivia. Lazaroa, $17,33-84$.

Nekola, JC, \& White, PS. 1999. The distance decay of similarity in biogeography and ecology. Journal of Biogeography, 26, 867-878.

Oksanen, J, Kindt, R, Legendre, P, O'Hara, B, Simpson, GL., Stevens, MHH, \& Wagner, H. 2008. vegan: Community Ecology Package. R package version 1.13-1.

Ozinga, WA, Schaminee, JHJ, Bekker, RM, Bonn, S, Poschlod, P, Tackenberg, O, Bakker, J, \& van Groenendael, JM. 2005. Predictability of plant species composition from environmental conditions is constrained by dispersal limitation. Oikos, 108, $555-561$.

Pennington, RT, Prado, DE, \& Pendry, CA. 2000. Neotropical seasonally dry forests and Quaternary vegetation changes. Journal of Biogeography, 27, 261-273.

Pennington, RT, Lavin, M, Prado, DE, Pendry, CA, Pell, SK, \& Butterworth, CA. 2004. Historical climate change and speciation: neotropical seasonally dry forest plants show patterns of both Tertiary and Quaternary diversification. Philosophical Transactions of the Royal Society B-Biological Sciences, 359, 515-537.

Pennington, RT, Richardson, JE, \& Lavin, M. 2006a. Insights into the historical construction of species-rich biomes from dated plant phylogenies, neutral ecological theory and phylogenetic community structure. New Phytologist, 172, 605-616.

Pennington, RT, Lewis, GP, \& Ratter, JA. 2006b. An overview of the plant diversity, biogeography and conservation of Neotropical savannas and seasonally dry forests. Pages 1-29 of: Pennington, RT, Ratter, JA, \& Lewis, GP (eds), Neotropical savannas and seasonally dry forests. CRC Press, Boca Raton, FL.

Prado, DE. 1993. What is the Gran Chaco vegetation in South America? II. A redefinition. Candollea, 48, 615-629. 
Prance, GT. 1996. Islands in Amazonia. Philosophical Transactions of the Royal Society of London Series B-Biological Sciences, 351, 823-833.

R Development Core Team. 2008. R: A Language and Environment for Statistical Computing. R Foundation for Statistical Computing, Vienna, Austria. ISBN 3-900051-07-0.

Ridley, HN. 1930. The dispersal of plants throughout the world. L. Reeve \& Co., Ltd. Ashford, Kent, UK.

Ritter, F. 1980. Kakteen in Südamerika. Argentinien/Bolivien. Friedrich Ritter Selbstverlag, Spangeberg.

Ritz, CM, Martins, L, Mecklenburg, R, Goremykin, V, \& Hellwig, FH. 2007. The molecular phylogeny of Rebutia (Cactaceae) and its allies demonstrates the influence of paleogeography on the evolution of South American mountain cacti. American Journal of Botany, 94, 1321-1332.

Soons, MB, \& Bullock, JM. 2008. Non-random seed abscission, long-distance wind dispersal and plant migration rates. Journal of Ecology, 96, 581-590.

Thompson, R, \& Townsend, C. 2006. A truce with neutral theory: local deterministic factors, species traits and dispersal limitation together determine patterns of diversity in stream invertebrates. Journal of Animal Ecology, 75, 476-484.

Tuomisto, H, Ruokolainen, K, \& Yli-Halla, M. 2003a. Dispersal, environment, and floristic variation of western Amazonian forests. Science, 299, 241-244.

Tuomisto, H, Poulsen, AD, Ruokolainen, K, Moran, RC, Quintana, C, Celi, J, \& Canas, G. 2003b. Linking floristic patterns with soil heterogeneity and satellite imagery in Ecuadorian Amazonia. Ecological Applications, 13, 352-371.

van Oudtshoorn, K, \& van Rooyen, MW. 1999. Dispersal biology of desert plants. Springer, Berlin. 
Vellend, M. 2001. Do commonly used indices of beta-diversity measure species turnover? Journal of Vegetation Science, 12, 545-552.

Vormisto, J, Phillips, OL, Ruokolainen, K, Tuomisto, H, \& Vasquez, R. 2000. A comparison of fine-scale distribution patterns of four plant groups in an Amazonian rainforest. Ecography, 23, 349-359.

Wasshausen, DC. 2004. Acanthaceae. Pages 3-7 of: Smith, N, Mori, SA, Henderson, A, Stevenson, DW, \& Heald, SV (eds), Flowering plants of the Neotropics. Princeton University Press, Princeton.

Wasshausen, DC, \& Wood, JRI. 2004. Acanthaceae of Bolivia. Contributions from the United States National Herbarium, 49, 1-152.

Willson, MF, \& Traveset, A. 2000. The ecology of seed dispersal. Pages 85-110 of: Fenner, M (ed), Seeds: the ecology of regeneration in plant communities. CAB International, Wallingford, UK.

Wood, JRI. 2006. Inter-Andean dry valleys of Bolivia - floristic affinities and patterns of endemism: insights from Acanthaceae, Asclepiadaceae and Labiatae. Pages 235-256 of: Pennington, RT, Ratter, JA, \& Lewis, GP (eds), Neotropical savannas and seasonally dry forests. CRC Press, Boca Raton, FL. 


\section{Chapter 5}

Small-scale variation of vascular plant species richness and community composition in a tropical American forest: the role of selective niche partitioning processes

Reynaldo Linares-Palomino, Jasmin Lendzion, Sebastian K. Herzog \& Michael Kessler 


\section{Summary}

1 Using information from total vascular plant inventories in a central Bolivian semideciduous forest, we evaluated the relationships that a suite of edaphic, topographic, light and forest structural factors had with plant species richness and community composition of selected plant groups.

2 Our sample, which included 75 0.04-ha square plots located in three adjacent forest types and a total of 670 species of vascular plant and 80352 individuals, was partitioned into the following life-form groups: terrestrial herbs (including pteridophytes), epiphytes, shrubs, lianas and trees.

3 A principal coordinates of neighbor matrices procedure (PCNM) indicated little spatial structure of species richness and abundances of the whole forest community and also of each life-form group.

4 Of 36 Regression and Redundancy Analysis models that we tested for association of species richness and community composition with spatial and environmental factors, four models of species richness patterns could neither be explained by spatial nor by environmental variables. Only one model included spatial structure as the only variable (species richness of herbs in one of the forest types) and two models included the combined effects of spatial and environmental variables. In contrast, 29 models (either species richness or community composition) were explained solely by environmental variables.

5 Although environmental factors were detected as more important than spatial variables, total explained variation for the models was moderate to low $\left(\mathrm{R}_{a d j}^{2}\right.$ for species richness: mean $=0.40$, range $=0.20-72 ; \mathrm{R}_{a d j}^{2}$ for community composition: mean $=0.22$, range $=0.04-45)$.

Synthesis. Our results suggest a major role of above- and below-ground environmental gradients in determining small scale patterns of species richness and community composition of several life-form groups in homogeneous tropical semi-deciduous forest types. Different life-forms, however, were related to different combinations of these factors. And although it is clear that environmental variables (especially 
edaphic) play a significant role in species co-existence and community assembly processes at the local scale, other additional factors (such as phylogenetic diversity within the studied communities) must be invoked as well if we are to better understand these processes.

Key-words: Andes, Bolivia, niche-assembly, edaphic factors

\section{$5.1 \quad$ Introduction}

The traditional view in community ecology is that the niche is partitioned among competing species, and it is their relative fitness within this niche that determines their abundances (Tilman, 1982, 1988; Chase \& Leibold, 2003; Silvertown, 2004). Theoretical models in which stochastic demography and dispersal are more important than niche-related factors, widely known as neutral community models (Hubbell, 2001; Bell, 2000; Chave et al., 2002), have challenged this view by supplying tools and possible answers to the same question: how can so many species co-exist in apparently uniform places like tropical forests and coral reefs. Recent evidence from the very same tropical forests that inspired the development of modern neutral theories is suggesting a much more important role of niche-related processes than advocated by the proponents of neutral theories.

The past years, especially since the publication of Hubbell's Unified Neutral Theory of Biodiversity and Biogeography (Hubbell, 2001), have seen an upsurge of theoretical and empirical tests of neutral community models at all spatial scales. Studies trying to find evidence for an environmental control of species richness or community composition in tropical forests have principally focused on soils and woody species, mostly trees (e.g., Jha \& Singh, 1990; Oliveira-Filho et al., 1998, 2001; Sollins, 1998). Few other studies analised the effect of other environmental variables. Clinebell et al. (1995); Kreft \& Jetz (2007), for example, found that some measure of water availability, topography and habitat heterogeneity (and not soil chemistry) was particularly relevant in predicting richness patterns of woody species 
at large geographical scales $\left(>1 \mathrm{~km}^{2}\right)$, whereas studies on much smaller scales $(<$ $1 \mathrm{~km}^{2}$ ) showed relationships with light and past disturbances (e.g., Vargas-Rodriguez et al., 2005).

There are also few studies that have focused on other life-forms within homogeneous vegetation (e.g., Poulsen et al., 2006; Tuomisto et al., 2003; Svenning et al., 2004 Tuomisto \& Ruokolainen, 2005, Ruokolainen et al., 2007; Jones et al., 2008). For studies assessing the complete plant community we would have to look outside the tropics for additional examples (Gilbert \& Lechowicz, 2004).

In this paper, we use detailed quantitative inventory data from an entire vascular plant community in a central Bolvian forest to explore the extent to which different environmental niche gradients (e.g., soil nutrients, light, forest structure) might have influenced the species richness and abundances of the major life-form groups (terrestrial herbs, shrubs, trees, lianas and epiphytes) at local spatial scales.

\subsection{Methods}

\subsubsection{Study area and forest types}

The Refugio Los Volcanes is situated in Santa Cruz, Central Bolivia, on the transition from the humid inner tropics to the seasonally dry subtropics. Annual precipitation is about 1200-1400 mm, with high intra-annual variability, although usually with a dry season from April to September/October, where temperatures average $18{ }^{\circ} \mathrm{C}$. The rainy season is slightly warmer with $21{ }^{\circ} \mathrm{C}$ (S.K. Herzog, unpublished data).

The vegetation in the region has been broadly classified as subhumid to humid deciduous forests of southeastern Amboró (Navarro et al. 1996). Although much of the study area is covered by semi-deciduous forest, the dominant zonal vegetation mainly found on the shaded south-facing slopes, local differences in topography and aspect lead to the presence of deciduous forest (on the steep, sunny and north-facing slopes) and to evergreen forest (in the flat, shaded valleys with groundwater supply). 
Within this vegetation matrix, we inventoried 25 adjacent $20 \mathrm{~m}$ x 20 m subplots in each forest type (deciduous, semi-deciduous and evergreen) and recorded all vascular plants (terrestrial herbs, epiphytes, lianas, shrubs and trees), yielding 80352 vascular plant individuals belonging to 670 species, including morphospecies. The most species-rich plots were those in the evergreen and semi-deciduous forest with similar numbers of species (381 and 382, respectively), whilst the deciduous forest plot had 297 species. In terms of the number of individuals, the highest density was recorded in the evergreen forest plot (31674 individuals), followed by the deciduous forest plot (26333 individuals) and the semi-deciduous forest plot (22360 individuals). An outstanding aspect of our inventories in these forests was that non-woody life-forms (epiphytes and terrestrial herbs) contributed important proportions to total vascular plant species richness and total abundance. For detailed sampling methodology and complete results of the inventories (including a complete species list), the reader is referred to Linares-Palomino et al. (in press).

\subsubsection{Environmental data}

Soil samples were obtained from each $20 \mathrm{~m}$ x $20 \mathrm{~m}$ subplot based on three random subsamples taken from 0-20 cm depth. Subsamples were pooled to form one single soil sample per subplot, for a total of 25 samples for the entire hectare, air-dried and sent for analysis to the Department of Plant Ecology and Ecosystems Research, University of Göttingen, Germany. The concentration of salt-extractable soil cations was determined by percolating $2.5 \mathrm{~g}$ of soil with $100 \mathrm{ml}$ of $1 \mathrm{M} \mathrm{BaCl}_{2}$ solution for 6 hours. The concentrations of $\mathrm{Mg}, \mathrm{Ca}, \mathrm{Mn}, \mathrm{Al}$ and Fe were analyzed by atomic absorption spectroscopy. Iron was assumed to be $\mathrm{Fe}^{2+}$. Phosphorus was measured after percolation by photometric absorption of a phosphate-molybdate-complex. The $\mathrm{C}$ and $\mathrm{N}$ contents were measured with an elemental analyser (Elementar, Hanau, Germany). pH was measured for the litter layer and each soil horizon (Oh/Of horizon, Ah horizon and B horizon) in the middle of the subplot with a glass electrode in a 1:2.5 water solution and with $\mathrm{KCl}$. 
Soil moisture was estimated in each subplot following the Ad-hoc-Arbeitsgruppe Boden (1996). The percentage of tree, shrub and herb cover, as well as the percentage of the subplot covered by rocks and stones and dead wood was estimated visually. Slope of each subplot was estimated in percentage. Tree height was calculated based on the woody plant inventory of each subplot (Linares-Palomino et al. 2008).

Hemispheric photos taken in the centre of each subunit at $1 \mathrm{~m}$ above the ground were used to assess light levels on the forest floor. The images were analysed in Adobe Photoshop and the percentage of light intensity reaching the forest floor was then estimated as the proportion of sky (bright areas) to the proportion of area covered by vegetation (darker areas).

\subsubsection{Data analysis}

We analysed species richness and community composition (abudance) patterns separately for the complete inventory and for each life-form (terrestrial herbs, epiphytes, lianas, shrubs and trees). Species abundance data were Hellinger-transformed to represent proportionate abundances prior to any analysis (Legendre \& Gallagher, 2001). All calculations were performed in the $\mathrm{R}$ software environment $\mathrm{R}$ Development Core Team, 2008).

We assessed the assumption of a normal distribution for each untransformed environmental variable graphically. Next, we compared each environmental variable among forest type with an analysis of variance. A significant difference among forest type was further assessed with a Tukey Honest Significant Difference test. Next we transformed the environmental variables, except $\mathrm{pH}$ which is already a logarithmically transformed value. Soil nutrients were log-transformed to model the responses of organisms to soil nutrient concentration (ter Braak, 1987). Data represented as percentages were arcsin-sqrt transformed (Zar, 1999), whilst categorical variables were split into separate binary variables.

Since we analysed several different life-forms, we produced different sets of ex- 
plicative environmental variables for each one (not all measured variables were equally applicable to all studied life-forms). We used all variables for the complete dataset including all life-forms and for terrestrial herbs. For epiphytes, we excluded shrub cover, herb cover, percentage of stones and death wood. For lianas, we excluded herb and shrub cover; for shrubs, shrub and herb cover; and for trees, tree, shrub and herb cover.

We checked for spatial structure in the species richness and community composition data with a principal coordinates of neighbor matrices analysis (PCNM) and used the coordinates of the centre of each subplot to calculate the spatial variables. We used the quickPCNM function (version 7.7, developed by D. Borcard, available at www.bio.umontreal.ca/legendre/indexEn.html) to automatically carry out all steps of the PCNM spatial analysis.

Next we checked the influence of the environmental variables on species richness and community composition with a forward selection analysis by permutation under a reduced model(we used the packfor 0.0-7 package by Dray et al. (2007), available at http://biomserv.univ-lyon1.fr/dray/software.php), selecting those variables with a significant ( $p=0.05$ after 999 random permutations) contribution to explaining variation in floristic composition (Blanchet et al., 2008). Only selected variables of soil factors (mineral macro- and micronutrients, $\mathrm{pH}$, soil humidity), topography, vegetation structure (vegetation cover and forest height), and/or habitat variables (light, death wood, stones), in addition to the previously selected spatial PCNM variables, were used to partition the variation of species richness and community composition using multiple regression and redundancy analysis (RDA), respectively, with function varpart in package vegan (Oksanen et al., 2008). This procedure allowed us to quantify the individual and combined contribution of each selected variable. Thus, we were able to assess the partial contributions of spatial structure alone, environmental variables alone, that of spatially structured environmental variables and finally, to quantify the amount of variation left unexplained by our models (Borcard \& Legendre, 1994; Legendre \& Legendre, 1998). 


\section{$5.3 \quad$ Results}

\subsubsection{Environmental variability}

The ANOVAs indicated no significant differences between forest types for three edaphic ( $\mathrm{Ca}, \mathrm{Mn}$ and $\mathrm{Al}$ ), two structural (shrub cover and tree height) and one environmental variable (light). All other variables showed significant differences between at least one of the forest types and the other two (Table 5.1). Half of all the variables showed either increasing or decreasing values along the deciduous - semi-deciduous - evergreen humidity gradient. It is especially the micro- and macronutrients that showed decreasing values with increasing humidity, whilst $\mathrm{pH}$, tree and herb cover increased with decreasing deciduousness.

High concentrations of $\mathrm{C}$ were accompanied by high concentrations in $\mathrm{N}$ and $\mathrm{Ca}$ in all three forest types (Appendix A.5). Soil humidity decreased with increasing slope in the deciduous forest plot and acted negatively on Fe levels and litter $\mathrm{pH}$. In the semi-deciduous plot, moderate increases in $\mathrm{P}$ levels were paralleled by increasing C, N or Ca concentrations. Soil Humidity, however, which also decreased with increasing slope as in the deciduous plot, had moderate to strong negative effects on $\mathrm{C}, \mathrm{N}, \mathrm{P}, \mathrm{Ca}$, litter $\mathrm{pH}$ levels.

\subsubsection{Spatial and regression analyses}

The PCNM analyses detected statistically significant spatial structure in only three cases, all involving terrestrial herbs. In the deciduous forest the analysis detected spatial structure both in species richness and in community composition patterns, whilst in the semi-deciduous only community composition was detected to possess spatial structure. It is only for these combinations of life-form and forest type that we incorporated spatial structure into forward selection analyses (see below).

We tested 36 models by forward selection to find factors potentially influencing species richness and community composition (Table 5.2). Of these, four models of species richness patterns in the deciduous (all vascular plants and lianas) and semi- 
Table 5.1: Edaphic, structural and environmental variables in the $7520 \mathrm{~m} \times 20$ $m$ subplots classified by forest type. Figures are means \pm standard errors. In forest types where ANOVAs rejected the null hypothesis of no difference between the means, means followed by different bold letters indicate significant differences detected by a Tukey test $(p<0.05)$.

\begin{tabular}{|c|c|c|c|}
\hline \multirow{3}{*}{ Variable } & \multicolumn{3}{|c|}{ Forest type } \\
\hline & Deciduous & Semi-deciduous & Evergreen \\
\hline & $\mathrm{N}=25$ & $\mathrm{~N}=25$ & $\mathrm{~N}=25$ \\
\hline $\mathrm{C}(\mathrm{mmol} / \mathrm{g})$ & $3.03 \pm 1.45 \mathbf{a}$ & $1.71 \pm 0.29 \mathbf{b}$ & $1.49 \pm 0.80 \mathbf{b}$ \\
\hline $\mathrm{N}(\mathrm{mmol} / \mathrm{g})$ & $0.26 \pm 0.11 \mathbf{a}$ & $0.15 \pm 0.02 \mathrm{~b}$ & $0.13 \pm 0.06 \mathbf{b}$ \\
\hline $\mathrm{P}(\mu \mathrm{mol} / \mathrm{g} \mathrm{TB})$ & $11.55 \pm 8.46 \mathbf{a}$ & $6.35 \pm 2.00 \mathrm{~b}$ & $7.59 \pm 6.49 \mathrm{ab}$ \\
\hline $\mathrm{K}(\mu \mathrm{mol} \mu \mathrm{eq} / \mathrm{g})$ & $0.18 \pm 0.09 \mathbf{a}$ & $0.11 \pm 0.04 \mathbf{b}$ & $0.10 \pm 0.05 \mathbf{b}$ \\
\hline $\mathrm{Ca}(\mu \mathrm{mol} \mu \mathrm{eq} / \mathrm{g})$ & $131.56 \pm 68.46$ & $116.38 \pm 58.94$ & $144.73 \pm 162.15$ \\
\hline $\mathrm{Mg}(\mu \mathrm{mol} \mu \mathrm{eq} / \mathrm{g})$ & $51.21 \pm 10.77 \mathbf{a}$ & $9.65 \pm 4.53 \mathbf{b}$ & $12.30 \pm 6.13 \mathrm{~b}$ \\
\hline Mn ( $1 \mathrm{~mol} \mu \mathrm{eq} / \mathrm{g})$ & $0.17 \pm 0.09$ & $0.16 \pm 0.08$ & $0.12 \pm 0.05$ \\
\hline $\mathrm{Fe}(\mu \mathrm{mol} \mu \mathrm{eq} / \mathrm{g})$ & $0.29 \pm 0.22 \mathbf{a}$ & $0.20 \pm 0.26 \mathbf{a b}$ & $0.09 \pm 0.17 \mathbf{b}$ \\
\hline $\mathrm{Al}(\mu \mathrm{mol} \mu \mathrm{eq} / \mathrm{g})$ & $3.83 \pm 5.60$ & $2.12 \pm 3.18$ & $3.23 \pm 5.62$ \\
\hline pH soil litter (pHL) & $6.48 \pm 0.33 \mathbf{a}$ & $6.71 \pm 0.66 \mathbf{a}$ & $7.25 \pm 0.29 \mathbf{b}$ \\
\hline pH organic matter $(\mathrm{pHO})$ & $6.38 \pm 0.39 \mathbf{a}$ & $6.61 \pm 0.40 \mathbf{a}$ & $7.08 \pm 0.23 \mathbf{b}$ \\
\hline pH A horizon (pHA) & $6.03 \pm 0.60 \mathbf{a}$ & $5.97 \pm 0.61 \mathbf{a}$ & $6.64 \pm 0.41 \mathrm{~b}$ \\
\hline pH B horizon (pHB) & $5.16 \pm 0.88 \mathbf{a}$ & $5.25 \pm 0.68 \mathbf{a}$ & $6.09 \pm 0.33 \mathbf{b}$ \\
\hline Soil Humidity (SH) & NA & NA & NA \\
\hline Tree cover $(\%)(\mathrm{TC})$ & $52.40 \pm 17.68 \mathbf{a}$ & $63 \pm 11.27 \mathbf{b}$ & $68.60 \pm 13.35 \mathrm{~b}$ \\
\hline Shrub cover $(\%)(\mathrm{SC})$ & $52.80 \pm 25.25$ & $43.48 \pm 17.27$ & $42.88 \pm 10.76$ \\
\hline Herb cover $(\%)(\mathrm{HC})$ & $62.80 \pm 8.91 \mathbf{a}$ & $70.60 \pm 9.17 \mathbf{b}$ & $75.20 \pm 13.27 \mathrm{~b}$ \\
\hline Slope (\%) (Sl) & $42.00 \pm 12.08 \mathbf{a}$ & $30.80 \pm 11.52 \mathrm{~b}$ & $41.60 \pm 16.18 \mathbf{a}$ \\
\hline Stone (\%) (St) & $13.00 \pm 12.50 \mathbf{a}$ & $2.40 \pm 2.93 \mathrm{~b}$ & $13.00 \pm 10.41 \mathbf{a}$ \\
\hline Dead wood $(\%)(\mathrm{DW})$ & $15.20 \pm 4.67 \mathbf{a}$ & $27.52 \pm 10.27$ b & $21.00 \pm 12.99 \mathrm{ab}$ \\
\hline Light (\%) (L) & $13.80 \pm 5.51$ & $11.73 \pm 4.70$ & $13.82 \pm 4.72$ \\
\hline Tree height (m) (TH) & $10.23 \pm 1.48$ & $11.13 \pm 1.92$ & $10.71 \pm 1.55$ \\
\hline
\end{tabular}


deciduous forest plots (epiphytes and shrubs) could neither be explained by spatial nor by environmental variables. Species richness of herbs in the deciduous forest was the only model that included spatial structure as the only variable (six PCNM vectors, $\mathrm{R}_{a d j}^{2}=0.72$ ). In contrast, 29 models (either species richness or community composition) could be explained solely by environmental variables (depending on the plant group and forest type, one to six variables were included). Two models, community composition of herbs in the deciduous and semi-deciduous forest, where explained by both selected environmental variables $\left(\mathrm{R}_{a d j}^{2}=0.37\right.$ and $\mathrm{R}_{a d j}^{2}=0.14$, respectively) and spatial structure $\left(\mathrm{R}_{a d j}^{2}=0.02\right.$ and $\mathrm{R}_{a d j}^{2}=0.10$, respectively). A higher variance was always explained in species richness models than in the corresponding community composition models.

Of the environmental variables, the variables that entered most models were soil $\mathrm{Mg}$, soil $\mathrm{Ca}$ and soil humidity. In the deciduous forest plot, soil humidity, $\mathrm{P}$ and $\mathrm{Mg}$ were the variables responsible for explaining most community variation. In the semi-deciduous plot, it was mainly $\mathrm{Ca}$, in the evergreen plot they were soil humidity and $\mathrm{Mg}$.

All vascular plants (Table 5.2): we found no combination of spatial or environmental variables to adequately explain species richness in the deciduous forest. Different variables were found to explain species richness in the semi-deciduous and evergreen forest plots and the highest predictive power was attained in the evergreen forest $\left(\mathrm{R}_{a d j}^{2}=0.43\right)$. Total community composition was also predicted by a different set of variables in each forest type. Soil humidity was the only variable included in all forest types. Other variables entered the models at most in two different forests (Mg, tree height and shrub cover).

Terrestrial herbs (Table 5.2): the spatial configuration of the plants seemed to be an important factor in herb species richness, less so in community composition. In the deciduous forest, space alone explained most of the variation $\left(\mathrm{R}_{a d j}^{2}=0.72\right)$, with no additional environmental variables included in the models. In contrast, variation in species richness patterns in the semi-deciduous and evergreen forest plots was 


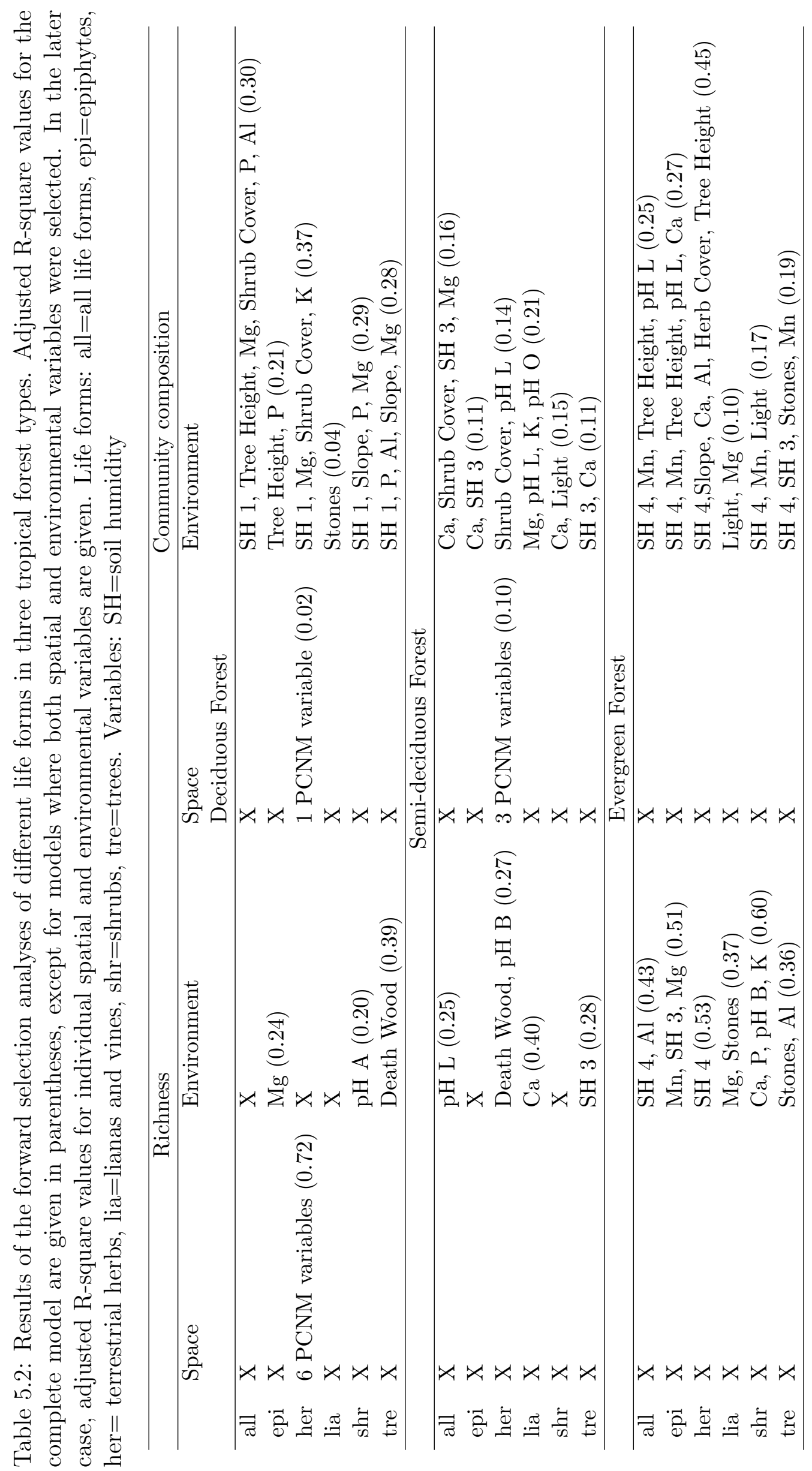


related to the environment. Community composition patterns were mostly related to soil variables and overall forest structure, and no single variable was repeated in all forest types.

Epiphytes (Table 5.2): soil magnesium content seemed to be an important factor influencing species richness patterns in the deciduous and evergreen forest plots. It was in the latter were we found a higher explained variance with the combination of $\mathrm{Mg}, \mathrm{Mn}$ and soil humidity $\left(\mathrm{R}_{a d j}^{2}=0.51\right)$. Several and different variables were related to the composition of epiphyte communities. It was again in the evergreen forest that the variables explained most of the variation, although including five variables, whereas in the other two plots only two variables were selected. Soil calcium and soil humidity seemed to be important in the more humid forests.

Lianas (Table 5.2): specie richness of lianas in the semi-deciduous and evergreen forest plots was related to few soil characteristics that explained a relatively high amount of variance $\left(\mathrm{R}_{a d j}^{2}=0.40\right.$ and $\mathrm{R}_{a d j}^{2}=0.37$, respectively). Community composition of lianas, in contrast, was related to several different variables explaining little variance in the models $\left(\mathrm{R}_{a d j}^{2}\right.$ values from 0.04 to 0.21$)$, and none was included in models of all three forest types. Neither spatial nor environmental variables explaining a substantial amount of the variation of specie richness and composition patterns in the deciduous forest could be detected.

Shrubs and trees (Table 5.2): species richness patterns were related to several and different soil characteristics explaining a substantial amount of variation $\left(\mathrm{R}_{a d j}^{2}\right.$ values from 0.20 to 0.60 ). Soil $\mathrm{Ca}, \mathrm{P}, \mathrm{K}$ and $\mathrm{pH} \mathrm{B}$ explained $60 \%$ of the variation in species richness of shrubs in the evergreen forest plot. Within the same plot, there was a high coincidence in both the variables that best explained community composition patterns and the amount of variance explained. Between forest types, however, different sets of variables best explained community composition patterns. Soil humidity was the exception, being included in the models for all three forest types. 


\subsection{Discussion}

Within homogeneous forest types, the patterns of species richness and community composition of several life-form groups seemed to be primarily determined by gradients in above- and below-ground environmental factors. Different life-forms, however, were related to different suites of these factors. This is the main conclusion suggested by our results. The strength and nature of these relationships (as inferred from explained variation and the combination of the several environmental factors, respectively), varies as well, and is higher when analysing species richness than when looking at species abundances. In order to better visualize these results we calculated Pearson correlations for species richness and Mantel correlations for abundances with all environmental factors and performed a PCA of the latter with each one of the correlation coefficients (Fig. 5.1a,b). The graphical representation of these relationships confirms our previous assertions.

These results agree with the observation of Gilbert \& Lechowicz (2004) who noted that even though environmental factors were consistently important in determining the distribution of vascular plants in a Canadian temperate forest, different plant groups were not affected equally by the various environmental gradients. We also show, that neither species richness nor community composition patterns had significant spatial structure, if any at all. In fact, only species richness patterns of terrestrial herbs showed some degree of spatial structure that explained part of their total variation. A similar conclusion was reached in a study looking at relationships between floristic and edaphic variation in the lowland rain forests of Amazonian Ecuador (Poulsen et al., 2006) and Peru (Ruokolainen et al., 2007). These studies found that the strongest predictors of floristic variation in angiosperm ground herbs, pteridophytes, palms and trees were topography and selected soil cations ( $\mathrm{Na}$ and $\mathrm{Ca}$ in the Ecuador study, $\mathrm{Ca}$ and $\mathrm{Mg}$ in the Peru study). The contribution of spatial distance between sampling units was in contrast little or negligible (see also Phillips et al., 2003, Potts et al., 2002, for equivalent results at the landscape and regional spatial scales). The novel methodological addition from our work is 


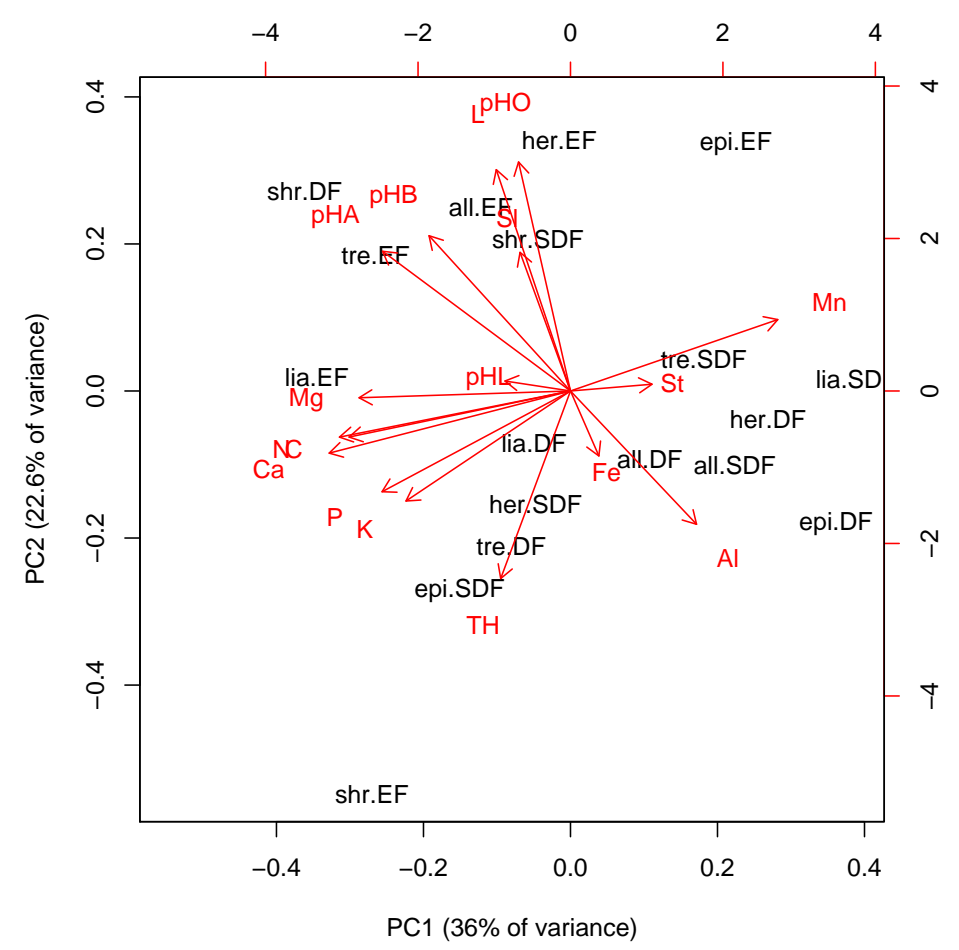

(a) Species richness

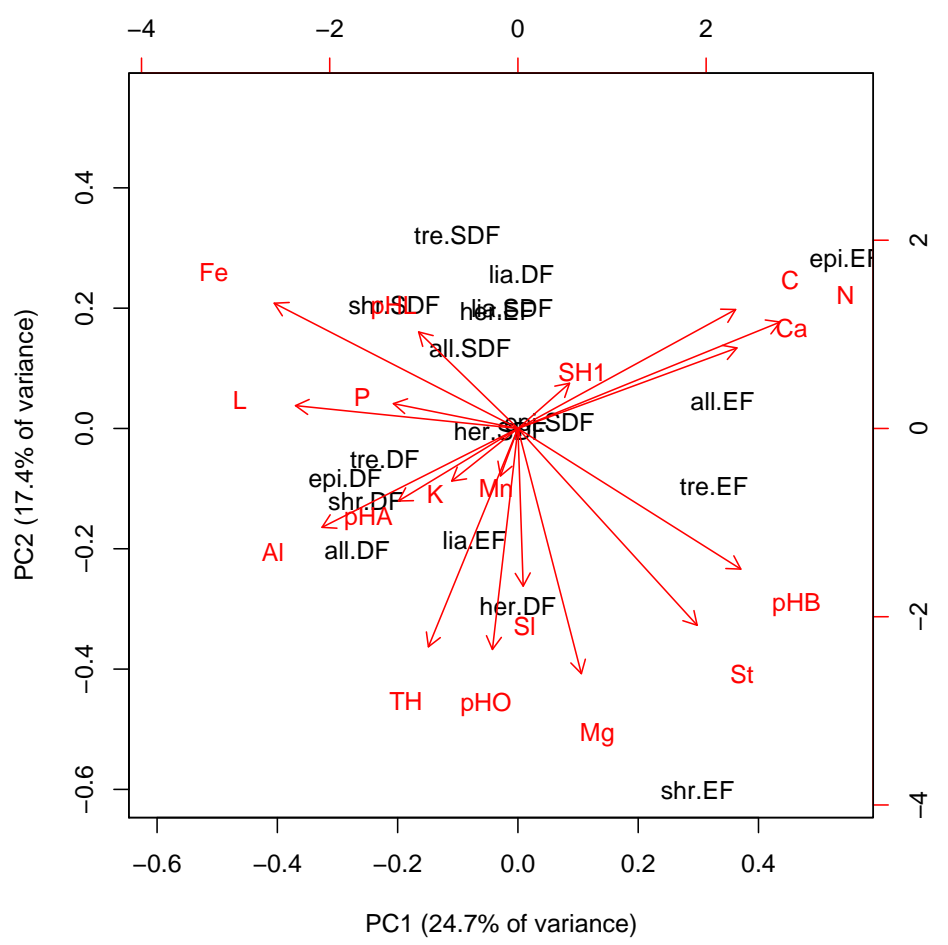

(b) Community composition

Figure 5.1: Behaviour of Pearson (a) and Mantel (b) correlation values between environmental variables and plant groups in three different forest types. Abbreviations of the variables follow those in Table 5.1 
that we included additional environmental factors, and the floristic composition of several life-forms in the Los Volcanes forest plots was significantly correlated with edaphic and topographic variables, but also with structural characteristics of the forests, presence of stone outcrops, death wood and light incidence. Several of these last factors have been shown to contribute to explain variation of community composition at the local to small scale, especially in trees. For instance, Balvanera et al. (2002); Vargas-Rodriguez et al. (2005); Oliveira-Filho et al. (1998); Webb \& Peart (2001) report several measures of light (e.g., measured as gaps in the canopy or at lower levels, or solar radiation interception in the canopy) as an important predictor of tree distributions (including their seedlings and saplings), together with soil and topographical variables.

It is notable, that the explained variation of species richness or community composition included such an extensive range of values $\left(R_{a d j}^{2}\right.$ values from 0.20 to 0.72 in species richness models and from 0.04 to 0.45 in community composition models, respectively). Most of the times, however, unexplained variation constituted the greater value. What is more, some of the data from Los Volcanes could not be predicted at all by any combination of our suite of variables (spatial nor environmental). Bell et al. (1993) showed that environmental factors have a strong spatial structure, even at scales below the metre. Since our sampling units were composed of $20 \mathrm{~m}$ x $20 \mathrm{~m}$ square plots, this could have been too coarse a scale and a possible reason for some of our models not being adequately predicted by our data. But even finer grained studies (e.g., Jones et al., 2008) failed to explain much of the variation in their data, and it is more probable that important factors such as phylogenetic information and regional scale population dynamics of the species present in the Los Volcanes communities were left out. The inclusion of phylogenetic information of the species that compose a community as an additional explanatory factor in the search for species co-existence and assembly mechanisms is a promising new research area (Webb, 2000; Webb et al., 2002; Graham \& Fine, 2008; Kelly et al., 2008; Lavin \& Beyra-Matos, 2008). Similarly, since local species 
assemblages are not isolated entities (neither in time nor in space), but interact constantly with neighbouring communities (i.e., the metacommunity concept, Hubbell, 2001; Holyoak et al., 2005), inclusion of regional population dynamics and ranges of the species that compose the community have a great potential to add to our understanding of these mechanisms (Harrison \& Cornell, 2008; Ricklefs, 2008).

\subsection{Acknowledgements}

RLP acknowledges financial support from the German Academic Exchange Service (DAAD). 


\subsection{References}

Ad-hoc-Arbeitsgruppe Boden. 1996. Bodenkundliche Kartieranleitung. 4th edn.

Balvanera, P, Lott, E, Segura, G, Siebe, C, \& Islas, A. 2002. Patterns of betadiversity in a Mexican tropical dry forest. Journal of Vegetation Science, 13, $145-158$.

Bell, G. 2000. The distribution of abundance in neutral communities. The American Naturalist, 155, 606-617.

Bell, G, Lechowicz, MJ, Appenzeller, A, Chandler, M, Deblois, E, Jackson, L, Mackenzie, B, Preziosi, R, Schallenberg, M, \& Tinker, N. 1993. The spatial structure of the physical environment. Oecologia, 96, 114-121.

Blanchet, FG, Legendre, P, \& Borcard, D. 2008. Forward selection of explanatory variables. Ecology, 89, 2623-2632.

Borcard, D, \& Legendre, P. 1994. Environmental control and spatial structure in ecological communities: an example using Oribatid mites (Acari, Oribatei). Environmental and Ecological Statistics, 1, 37-61.

Chase, JM, \& Leibold, MA. 2003. Ecological niches: linking classical and contemporary approaches. University of Chicago Press, Chicago, IL.

Chave, J, Muller-Landau, HC, \& Levin, SA. 2002. Comparing classical community models: theoretical consequences for patterns of diversity. The American Naturalist, 159, 1-23.

Clinebell, RR, Phillips, OL, Gentry, AH, Stark, N, \& Zuuring, H. 1995. Prediction of neotropical tree and liana species richness from soil and climatic data. Biodiversity and Conservation, 4, 56-90.

Dray, S, Legendre, P, \& Blanchet, G. 2007. packfor: Forward Selection with permutation. $R$ package version 0.0-7. 
Gilbert, B, \& Lechowicz, MJ. 2004. Neutrality, niches, and dispersal in a temperate forest understory. Proceedings of the National Academy of Sciences of the United States of America, 101, 7651-7656.

Graham, CH, \& Fine, PVA. 2008. Phylogenetic beta diversity: linking ecological and evolutionary processes across space in time. Ecology Letters, 11, 1265-1277.

Harrison, S, \& Cornell, H. 2008. Toward a better understanding of the regional causes of local community richness. Ecology Letters, 11, 969-979.

Holyoak, M, Leibold, MA, Mouquet, NM, Holt, RD, \& Hoopes, MF. 2005. Metacommunities: a framework for large-scale community ecology. Pages 1-31 of: Holyoak, M, Leibold, MA, \& Holt, RD (eds), Metacommunities: spatial dynamics and ecological communities. University of Chicago Press, Chicago, IL.

Hubbell, SP. 2001. The unified neutral theory of biodiversity and biogeography. Princeton University Press.

Jha, CS, \& Singh, JS. 1990. Composition and dynamics of dry tropical forest in relation to soil texture. Journal of Vegetation Science, 1, 609-614.

Jones, MM, Tuomisto, H, Borcard, D, Legendre, P, Clark, DB, \& Olivas, PC. 2008. Explaining variation in tropical plant community composition: influence of environmental and spatial data quality. Oecologia, 155, 593-604.

Kelly, CK, Bowler, MG, Pybus, O, \& Harvey, PH. 2008. Phylogeny, niches, and relative abundance in natural communities. Ecology, 89, 962-970.

Kreft, H, \& Jetz, W. 2007. Global patterns and determinants of vascular plant diversity. Proceedings of the National Academy of Sciences of the United States of America, 104, 5925-5930.

Lavin, M, \& Beyra-Matos, A. 2008. The impact of ecology and biogeography on legume diversity, endemism, and phylogeny in the Caribbean region: a new direction in historical biogeography. The Botanical Review, 74, 178-196. 
Legendre, P, \& Gallagher, ED. 2001. Ecologically meaningful transformations for ordination of species data. Oecologia, 129, 271-280.

Legendre, P, \& Legendre, L. 1998. Numerical ecology. 2 edn. Amsterdam: Elsevier Science BV.

Linares-Palomino, R, Cardona, V, Soto, D, Herzog, SK, \& Kessler, M. 2008. Tree community patterns along a deciduous to evergreen forest gradient in central Bolivia. Ecología en Bolivia, 43, 1-20.

Linares-Palomino, R, Cardona, V, Hennig, EI, Hoffmann, D, Lendzion, J, Soto, D, Herzog, SK, \& Kessler, M. in press. Non-woody life-form contribution to vascular plant species richness in a tropical American forest. Plant Ecology.

Oksanen, J, Kindt, R, Legendre, P, O’Hara, B, Simpson, GL., Stevens, MHH, \& Wagner, H. 2008. vegan: Community Ecology Package. R package version 1.13-1.

Oliveira-Filho, AT, Curi, N, Vilela, EA, \& Carvalho, DA. 1998. Effects of canopy gaps, topography, and soils on the distribution of woody species in a central Brazilian deciduous dry forest. Biotropica, 30, 362-375.

Oliveira-Filho, AT, Curi, N, Vilela, EA, \& Carvalho, DA. 2001. Variation in tree community composition and structure with changes in soil properties within a fragment of semideciduous forest in south-eastern Brazil. Edinburgh Journal of Botany, 58, 139-158.

Phillips, OL, Vargas, P Núñez, Monteagudo, AL, Peña-Cruz, A, Chuspe-Zans, ME, Galiano-Sánchez, W, Yli-Halla, M, \& Rose, S. 2003. Habitat association among Amazonian tree species: a landscape-scale approach. Journal of Ecology, 91, $757-775$.

Potts, Matthew D., Ashton, Peter S., Kaufman, Les S., \& Plotkin, Joshua B. 2002. Habitat patterns in tropical rain forests: a comparison of 105 plots in northwest Borneo. Ecology, 83, 2782-2797. 
Poulsen, AD, Tuomisto, H, \& Balslev, H. 2006. Edaphic and floristic variation within a 1-ha plot of lowland Amazonian rain forest. Biotropica, 38, 468-478.

R Development Core Team. 2008. R: A Language and Environment for Statistical Computing. R Foundation for Statistical Computing, Vienna, Austria. ISBN 3-900051-07-0.

Ricklefs, RE. 2008. Disintegration of the ecological community. The American Naturalist, 172, 741-750.

Ruokolainen, K, Tuomisto, H, Macía, MJ, Higgins, MA, \& Yli-Halla, M. 2007. Are floristic and edaphic patterns in Amazonian rain forests congruent for trees, pteridophytes and Melastomataceae? Journal of Tropical Ecology, 23, 13-25.

Silvertown, J. 2004. Plant coexistence and the niche. Trends in Ecology ES Evolution, 19, 605-611.

Sollins, P. 1998. Factors influencing species composition in tropical lowland rain forest : does soil matter? Ecology, 79, 23-30.

Svenning, JC, Kinner, DA, Stallard, RF, Engelbrecht, BMJ, \& Wright, SJ. 2004. Ecological determinism in plant community structure across a tropical forest landscape. Ecology, 85, 2526-2538.

ter Braak, CJF. 1987. Ordination. Pages $91-173$ of: R.H.G. Jongman, C.J.F. ter Braak \& O.F.R. van Tongeren (ed), Data analysis in community and landscape ecology. Pudoc, Wageningen, Netherlands.

Tilman, D. 1982. Resource Competition and Community Structure. Monographs in Population Biology. Princeton University Press.

Tilman, D. 1988. Plant Strategies and the Dynamics and Structure of Plant Communities. Monographs in Population Biology,. Princeton University Press. 
Tuomisto, H, \& Ruokolainen, K. 2005. Environmental heterogeneity and the diversity of pteridophytes and Melastomataceae in western Amazonia. Biologiske Skrifter, 55, 37-56.

Tuomisto, H, Poulsen, AD, Ruokolainen, K, Moran, RC, Quintana, C, Celi, J, \& Canas, G. 2003. Linking floristic patterns with soil heterogeneity and satellite imagery in Ecuadorian Amazonia. Ecological Applications, 13, 352-371.

Vargas-Rodriguez, YL, Vázquez-García, JA, \& Williamson, GB. 2005. Environmental correlates of tree and seedling-sapling distributions in a Mexican tropical dry forest. Plant Ecology, 180, 117-134.

Webb, CO. 2000. Exploring the phylogenetic structure of ecological communities: an example for rain forest trees. The American Naturalist, 156, 145-55.

Webb, CO, \& Peart, DR. 2001. Habitat associations of trees and seedlings in a Bornean rain forest. Journal of Ecology, 88, 464-478.

Webb, CO, Ackerly, DD, McPeek, MA, \& Donoghue, MJ. 2002. Phylogenies and community ecology. Annual Review of Ecology and Systematics, 33, 475-505.

Zar, J. 1999. Biostatistical analysis. Prentice Hall, NJ. 


\section{Chapter 6}

\section{General conclusions}

\subsection{A summary of major Findings}

- Vascular plant diversity in central Bolivian sub-Andean forest types. The complete vascular plant inventory of three 1-ha plots in a central Bolivian forest contained an estimated 6-7\% of all the currently known Bolivian plants, with 670 species and 80352 individuals. Orchidaceae, Pteridophyta and Leguminosae were among the most species-rich major plant groups in each plot and Peperomia (Piperaceae), Pleurothallis (Orchidaceae) and Tillandsia (Bromeliaceae), all epiphytes, were the most species-rich genera. Despite these commonalities, species turnover between the decidous, semi-deciduous and evergreen forest plots was relatively high with less than $60 \%$ similarity. More importantly though was the fact that the non-woody life-forms in these Andean foothill forest ecosystems were outstanding in terms of species richness and numbers of individuals, representing roughly $30-50 \%$ of the species and between $50-75 \%$ of the individuals in the community. This was especially true for epiphytes and terrestrial herbs and in stark contrast with the levels of diversity and abundance found for woody life-forms and especially for trees with a dbh $\geq 10 \mathrm{~cm}$.

Together, these data show that these Central Bolivian forest plots are similar in total and individual life-form species richness to other dry deciduous and humid montane forests in the neotropics, but less rich than most Amazonian 
forests.

- The phytogeography of the tree flora of a central Bolivian forest. Of the 115 tree species found at Los Volcanes, eleven that were present in all three plots represented a selection of the tree species characteristic of the Amboró region like Aspidosperma cylindrocarpum, Gallesia integrifolia and Pachystroma longifolium. Interestingly, however, few of these species were dominant and abundant on each of the plots, with most being locally rare species (at least at the hectare-scale) and with abundances of one individual per hectare.

Although the general vegetation of the region is characterised as semi-deciduous (Navarro \& Maldonado, 2002), a comparison with other similar vegetation types in Bolivia showed surprisingly little similarity. This might have been caused by the complex vegetational arrangement of the study area (Ibisch \& Merida, 2003), composed of the adjacent humid vegetation from Amazonia, seasonal subtropical lowland vegetation from the Chaco, subtropical highland vegetation from the Andes and seasonal vegetation of the Chiquitanía. This setting suggests an answer for the high turnover of species in the Los Volcanes plots and their low resemblance to other similar vegetation types in Bolivia.

On a wider geographical context, and considering that Los Volcanes is located within the dry forest Pleistocenic Arc formation in the Neotropics (Prado \& Gibbs, 1993; Prado, 2000), we found some species in our plots that have been considered as characteristic (Anadenanthera colubrina, Myracrodruon urundeuva and Celtis iguanaea) and restricted to certain areas (Diatenopteryx sorbifolia) of this arc. Together with other species said to belong to this arc, although with more complex distribution patterns, we found a total of 21 species as typical of Bolivian seasonal forest formations.

- Biogeographical patterns of seasonally dry forests in Andean Bolivia. Separate floristic analyses of presence-absence data obtained for species 
of Acanthaceae, Bromeliaceae, Cactaceae and Pteridophyta found in 12 seasonal forest areas in Bolivia showed incongruent biogeographic relationships. Only Acanthaceae and Bromeliaceae, and partly Cactaceae, showed coincident patterns, suggesting the existence of two main groups of seasonally dry forests in Bolivia. A first group would be composed of the northern sites and characterized by small areas isolated in the inter-Andean dry valleys and heavily affected by anthropogenic activities. The second group includes the seasonally dry forests in the southern Bolivian Andes and lowlands, characterized by covering greater expanses of land and with strong links to the adjoining Chaco and Chiquitanía seasonal forests. They are, nevertheless, also seriously under constant threat from land conversion, fragmentation and similar anthropogenic activities. Pteridophytes on the other hand proved to be of little use in revealing biogeographic patterns among the studied areas. Their ubiquitous presence in most of the dry forest sites, facilitated by their spore-based dispersal mechanism, hindered the recognition of clear patterns, with most sites having similar levels of similarity.

\section{- The relative importance of environmental or neutral mechanisms to} explain species coexistence in tropical forests at large regional and local spacial scales. The large scale study in the seasonally dry forest islands of Andean Bolivia showed that, depending on the dispersal characteristics of the studied plant group, either environmental factors or the distance between suitable areas were more important in explaining current community composition in these forests. Most of the variation in the beta-diversity of the plant groups with seed dispersal typically restricted to short distances (Acanthaceae: ballistichory, and Bromeliaceae: anemochory and zoochory) was explained by spatial separation between habitat islands, suggesting dispersal limitation and an inadequacy to reach even adjacent areas suitable for colonization. In contrast, the floristic differences between dry forest sites using pteridophyte data were primarily determined by the environmental variables (total annual rain- 
fall and altitudinal range of the sites). The spore-based dispersal system of this plant group, easily transported by wind over large distances, seems to be a highly effective mechanism for the colonization of even the most isolated dry valleys in inter-Andean Bolivia. Successful establishment of these spores is then finally dependent on the environmental conditions of each reached area. Accordingly, at the large scale it seems that both niche-related mechanism and spatial dispersal processes structure the dry forest metacommunities in the Bolivian Andes. The relative importance of each one, however, seems to depend ultimately on dispersal traits specific to each taxon.

The local scale study at Los Volcanes showed that gradients in several aboveand below-ground environmental variables were the best predictors of the observed patterns in species richness and community composition. They also showed little support for space (dispersal) related variables having any influence on species richness and community composition patterns of the whole plant assemblage nor of individual life-form groups. A notable exception was species richness of terrestrial herbs (and to a lesser extent their abundances), showing strong spatial structure. Although soil variables (such as soil Mg, soil $\mathrm{Ca}$ and soil humidity) entered most models, there were ample differences in the combination of factors determining each pattern in each life-form group. Finally, a substantial portion of the variation in the data of the local (Los Volcanes) and large scale (Bolivia) study could not be explained by the chosen variables, indicating a need for the inclusion of additional, especially historical (i.e., temporal) and phylogenetic factors.

\subsection{Implications of the Findings}

Total vascular plant inventories in tropical forests are logistically difficult and timeconsuming tasks and surely the reason why there are so few of them. However, they provide extremely relevant information. In addition to giving basic information about species diversity, vegetation structure and floristic relationships, the whole- 
plant survey from Los Volcanes reported in Chapter 2, showed that non-woody lifeforms contribute to a major part of the species richness and community abundances in these central Bolivian forests. This information is of utmost relevance to tropical forest characterization and conservation because tree inventories are still being used extensively as a major source of information to define vegetation types. Although trees are the major structural element of these forests, the present results also showed that there is not always a strong correlation between them and other life-forms. Thus, forests characterized by high species richness and/or abundances of trees and woody species are not necessarily equally rich and abundant in other life-forms. As a result, we might be missing an important component of the forest diversity. These findings point to a necessary change in the way conservation decisions are made: we also need to take into account the non-woody component of the forest to make more informed decisions.

The phytogeography of the seasonally dry forests in Andean Bolivia is interesting because of the uplift history of the Andes, considered to be major cause of biogeographical barriers in the region (Sarmiento, 1975). Separate biogeographical analyses of plant groups differing in ecological characteristics and phylogenetic relationships, as those performed in Chapter 3, can lead to diametrically opposite scenarios. This hinders the extrapolation of the results to the whole flora in the seasonally dry forests in Andean Bolivia. Thus, a definitive answer as to the true biogeographical relationships and subdivisions of the seasonally dry forests in Andean Bolivia must necessarily take into account information from other plant groups present in the studied seasonal forests.

The findings presented in this dissertation (Chapter 4 and 5) add to the increasing evidence (Balvanera et al., 2002; Duivenvoorden et al., 2002, Cottenie, 2005, Holyoak \& Loreau, 2006) that gradients in environmental variables and distancedispersal related processes act, sometimes together and sometimes decoupled, with different strength at different spatial scales influencing species richness and community composition. Thus, any study of the mechanisms influencing them should 
necessarily consider both neutral and non-neutral processes.

\subsection{Limitations of the Study and Suggestions for Further Research}

As stated above, complete vascular plant inventories like that done in Los Volcanes are notoriously difficult. Worldwide, there are very few other comparable studies and most were performed in neotropical rain forests (Whitmore et al., 1985; Gentry \& Dodson, 1987; Duivenvoorden, 1994; Balslev et al., 1998; Galeano et al., 1998; Langenberger et al., 2006). The data presented in Chapter 2 suggest some very important patterns, but it would be interesting to explore how different life-forms contribute to overall species richness and total abundances in other (neo-)tropical vegetation types.

The phytogeographic study in Andean Bolivia had an important limitation, namely the use of (mostly) understorey members of the studied seasonally dry forest. Since trees are the main structural element of these forests, it is unclear to what extent these results are valid for other plant groups or families, or even the whole seasonally dry forest flora. Unfortunately, few plant groups have been revised so intensively taxonomically and using geographically extensive collections as those used in Chapter 4. There is clearly a need for accurate taxonomy based on extensive distributional data for most taxa in the tropics (Campbell \& Hammond, 1989; Thomas, 1999), but this information is fundamental for a better understanding of extant floristic relationships. When this information becomes available for each of the dry forest areas in Bolivia, a biogeographical analysis of a suite of representative woody genera or families (together with more and finer grained environmental data) will surely increase our understanding of the floristics and evolution of the vegetation in Andean Bolivia.

A substantial amount of the variation in species richness and community composition of the Los Volcanes plots remained unexplained. This fraction can be under the influence of unmeasured variables or it may be determined by community pro- 
cesses such as competition or dispersal that need to be explored (Jones et al., 2008, Legendre, 2008). A promising new avenue of research is the combination of community ecology methods such as those used in this dissertation (i.e., including several critical environmental factors and space as explanatory variables) with phylogenetic methods. The increasing resolution in many of the world's organisms phylogenies due to faster acquirement of molecular data and more powerful analyses, has the potential to bring evolutionary and phylogenetic information into a combined community assembly model (Webb et al., 2002, 2006). For now, an end of the niche assembly - neutral assembly controversy is as yet not foreseeable. The final result will be most probably a synthetic theory integrating both, as well as the evolutionary history of the species in the community. 


\subsection{References}

Balslev, H, Valencia, R, \& Paz y Miño, G. 1998. Species count of vascular plants in 1-hectare of humid lowland forest in Amazonian Ecuador. In: Dallmeier, F, \& Comiskey, JA (eds), Forest biodiversity in North, Central and South America and the Caribbean: research and monitoring. Man and the Biosphere Series, vol. 21. Lancashire: UNESCO and Parthenon.

Balvanera, P, Lott, E, Segura, G, Siebe, C, \& Islas, A. 2002. Patterns of betadiversity in a Mexican tropical dry forest. Journal of Vegetation Science, 13, $145-158$.

Campbell, DJ, \& Hammond, D (eds). 1989. Floristic inventory of tropical forests. The New York Botanical Garden, Bronx, USA.

Cottenie, K. 2005. Integrating environmental and spatial processes in ecological community dynamics. Ecology Letters, 8, 1175-1182.

Duivenvoorden, JF. 1994. Vascular plant-species counts in the rain-forests of the middle Caqueta area, Colombian amazonia. Biodiversity and Conservation, 3, $685-715$

Duivenvoorden, JF, Svenning, JC, \& Wright, SJ. 2002. Beta diversity in tropical forests. Science, 295, 636-637.

Galeano, G, Suarez, S, \& Balslev, H. 1998. Vascular plant species count in a wet forest in the Choco area on the Pacific coast of Colombia. Biodiversity and Conservation, $7,1563-1575$.

Gentry, AH, \& Dodson, C. 1987. Contribution of nontrees to species richness of a tropical rain-forest. Biotropica, 19, 149-156.

Holyoak, M, \& Loreau, M. 2006. Reconciling empirical ecology with neutral community models. Ecology, 87, 1370-1377. 
Ibisch, PL, \& Merida, G. (eds). 2003. Biodiversidad: la riqueza de Bolivia. Estado de conocimiento y conservacion. Editorial FAN, Santa Cruz, Bolivia.

Jones, MM, Tuomisto, H, Borcard, D, Legendre, P, Clark, DB, \& Olivas, PC. 2008. Explaining variation in tropical plant community composition: influence of environmental and spatial data quality. Oecologia, 155, 593-604.

Langenberger, G, Martin, K, \& Sauerborn, J. 2006. Vascular plant species inventory of a Philippine lowland rain forest and its conservation value. Biodiversity and Conservation, 15, 1271-1301.

Legendre, P. 2008. Studying beta diversity: ecological variation partitioning by multiple regression and canonical analysis. Journal of Plant Ecology, 1, 3-8.

Navarro, G, \& Maldonado, M. 2002. Geografía ecológica de Bolivia: vegetación y ambientes acuáticos. Cochabamba, Bolivia: Fundación Simón I. Patiño.

Prado, DE. 2000. Seasonally dry forests of tropical South America: from forgotten ecosystems to a new phytogeographic unit. Edinburgh Journal of Botany, 57, $437-461$.

Prado, DE, \& Gibbs, PE. 1993. Patterns of species distributions in the dry seasonal forests of South-America. Annals of the Missouri Botanical Garden, 80, 902-927.

Sarmiento, G. 1975. The dry plant formations of South America and their floristic connections. Journal of Biogeography, 2, 233-251.

Thomas, WW. 1999. Conservation and monographic research on the flora of Tropical America. Biodiversity and Conservation, 8, 1007-1015.

Webb, CO, Ackerly, DD, McPeek, MA, \& Donoghue, MJ. 2002. Phylogenies and community ecology. Annual Review of Ecology and Systematics, 33, 475-505.

Webb, CO, Losos, JB, \& Agrawal, AA. 2006. Integrating phylogenies into community ecology. Ecology, 87, 1-2. 
Whitmore, TC, Peralta, R, \& Brown, K. 1985. Total species count in a Costa Rican tropical rain forest. Journal of Tropical Ecology, 1, 375-378. 
Appendices 



\section{A.1 Appendix 1 to Chapter 2}

Whole plant, epiphyte, liana, terrestrial herb and tree/woody plant inventories in the Neotropics. All references are cited in the main text except:

Boom, BM (1987) Un inventario selvatico en la zona amazónica de Bolivia. Ecol Bolivia 10:1-14

Hietz P, Hietz-Seifert, U (1995) Structure and ecology of epiphyte communities of a cloud forest in central Veracruz, Mexico. J Veg Sci 6:719-728

Saldias, M (1991) Inventario de árboles en el bosque alto del Jardín Botánico de Santa Cruz, Bolivia. Ecol Bolivia 17:31-46

Saldias, M, Guillen, R, Mostacedo, VB et al. (1994) Composición y estructura de un bosque alto húmedo del Parque Nacional "Noel Kempff Mercado". Paper presented at the 6th Congreso Latinoamericano de Botánica, Mar de Plata, 2-8 October 1994 Vargas, I (1995) Estructura y composición de cuatro sitios boscosos en el Parque Nacional Amboro. Tesis de Grado, Universidad Autónomo Gabriel René Moreno, Santa Cruz, Bolivia

Vargas, I, de Centurión, TR, Saldias, M (1994) Parcela permanente de investigación en la Reserva de Vida Silvestre Ríos Blanco y Negro, Santa Cruz, Bolivia. Rev Soc Estud Bot (Santa Cruz) 1:9-32 


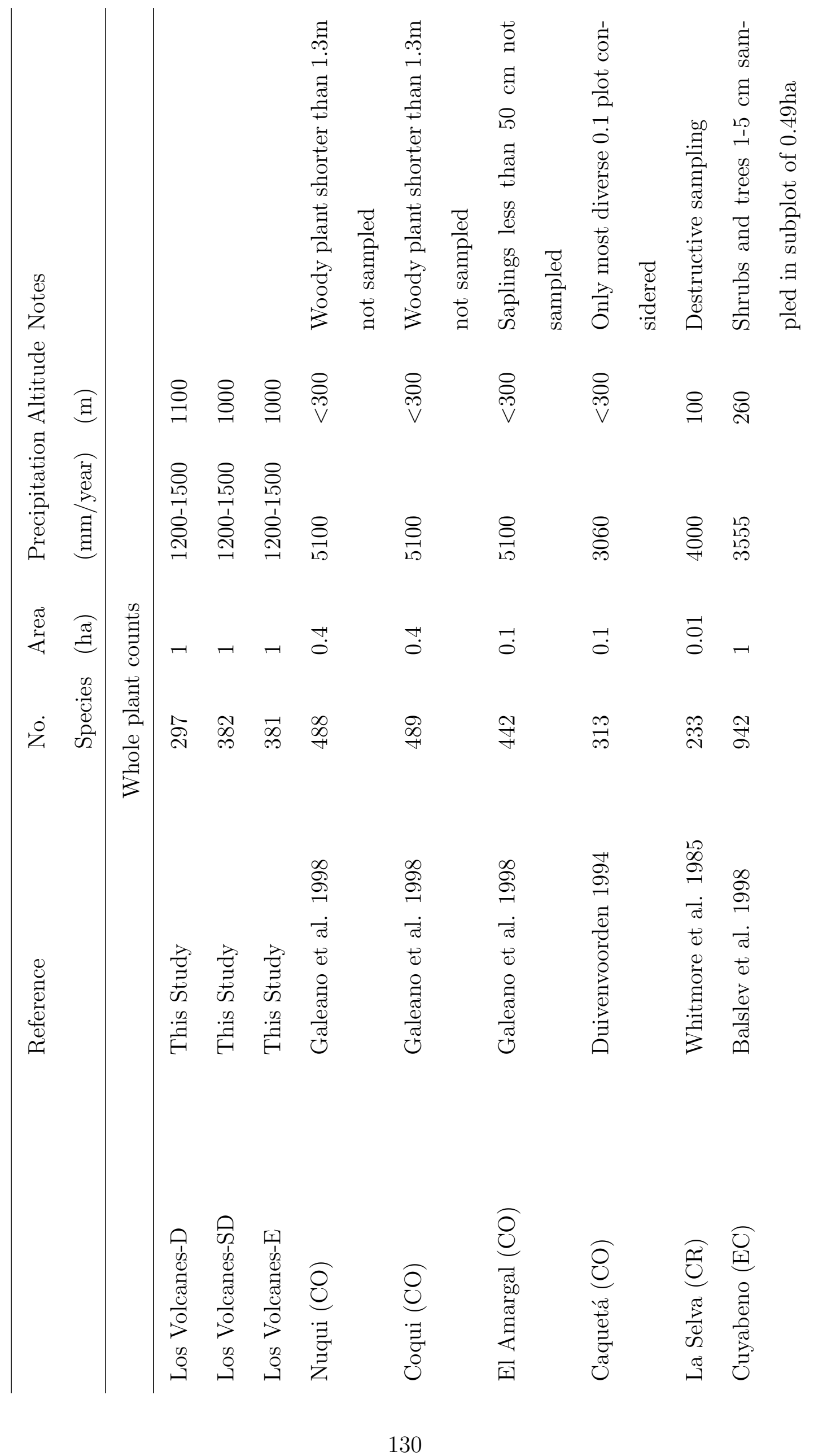




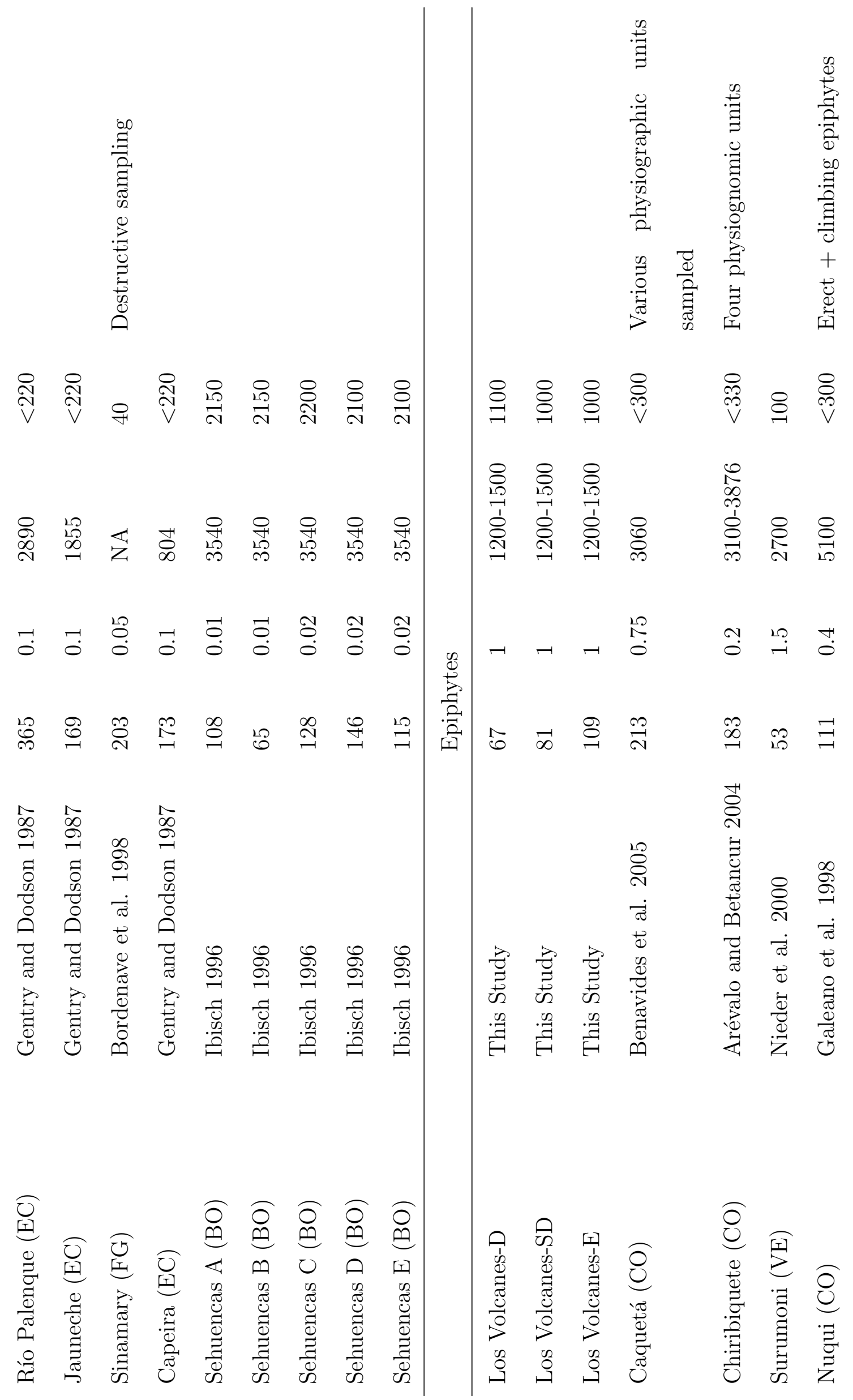



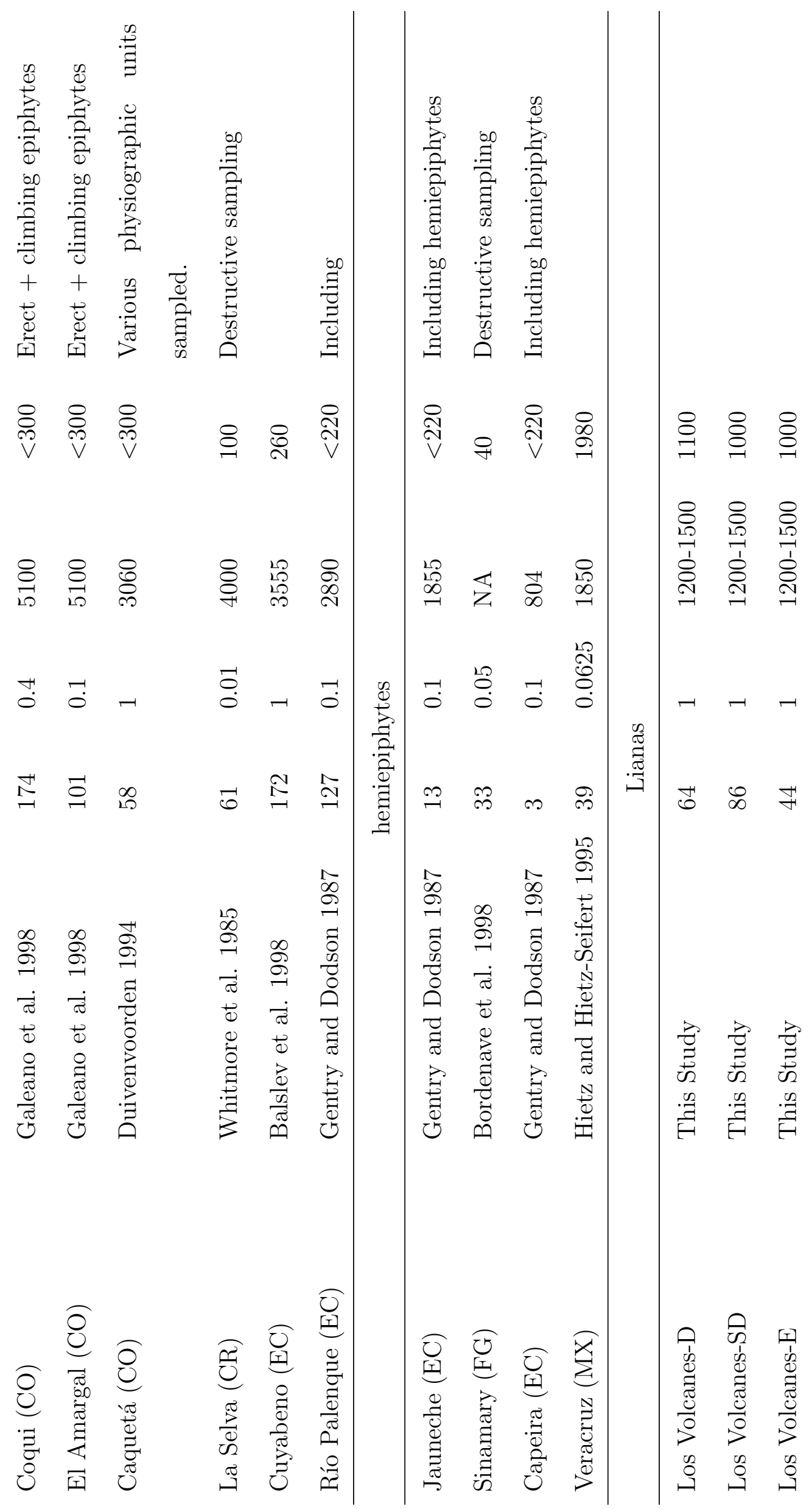

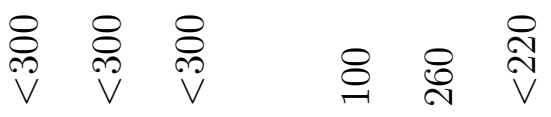

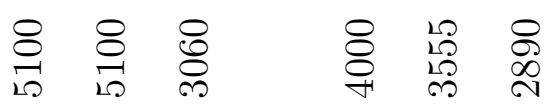

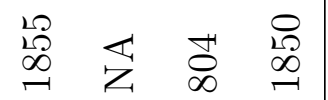

$\vec{a} \overrightarrow{0}-\vec{a}+\overrightarrow{0}$

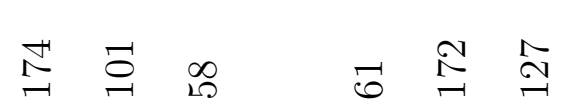

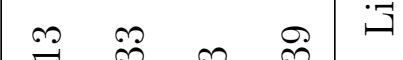

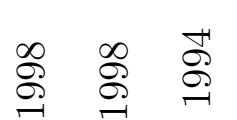

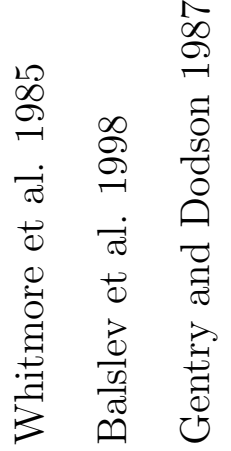

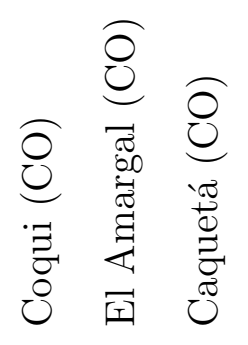

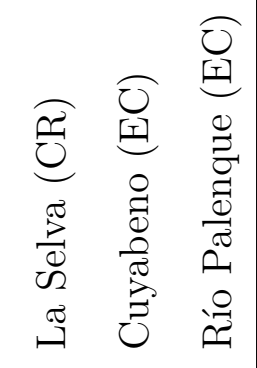

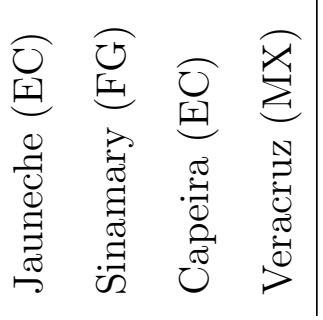

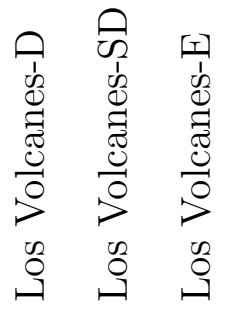




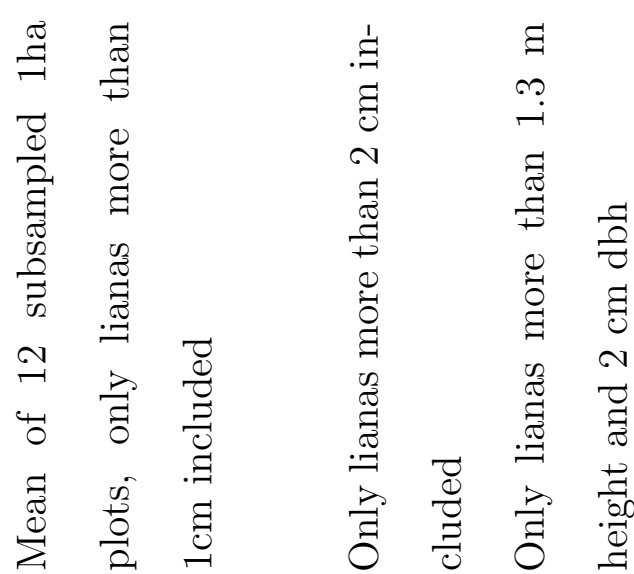

$\stackrel{n ?:}{. !}$
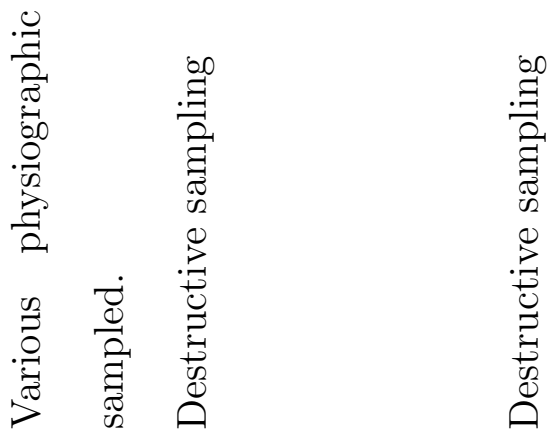

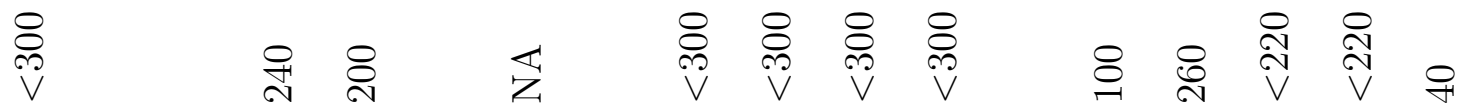
ำ

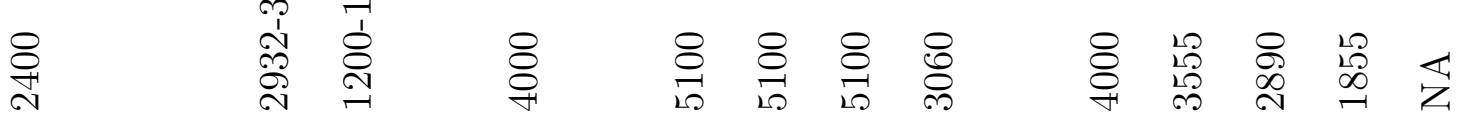

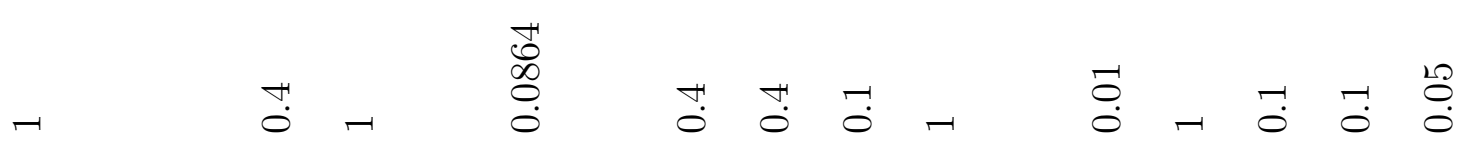

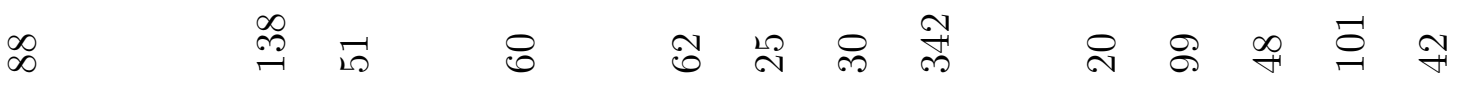

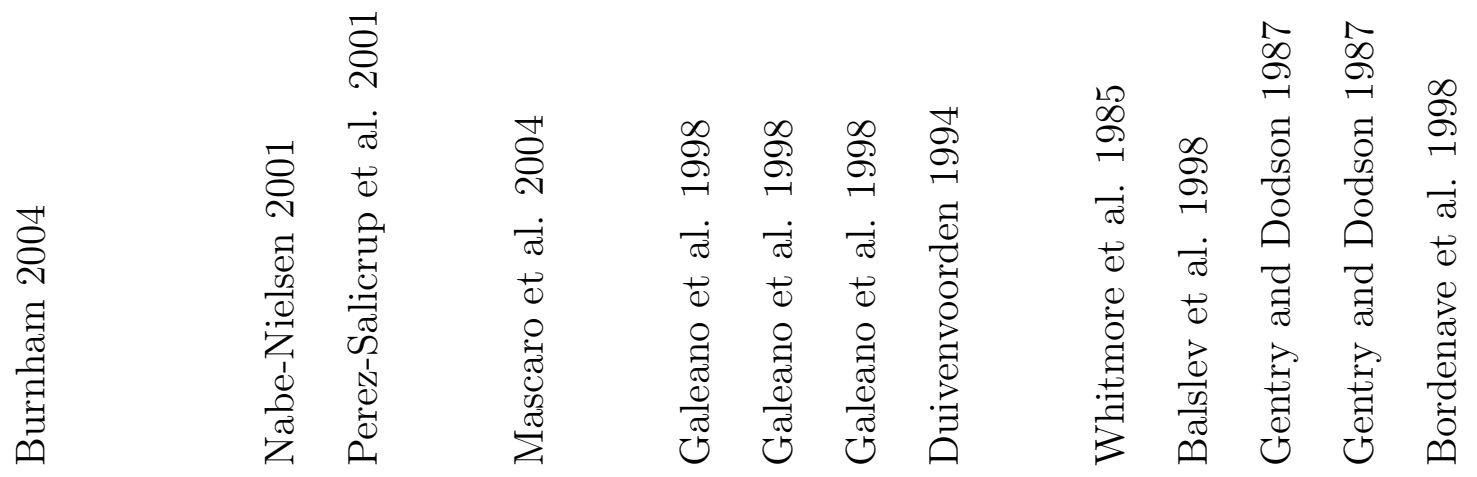

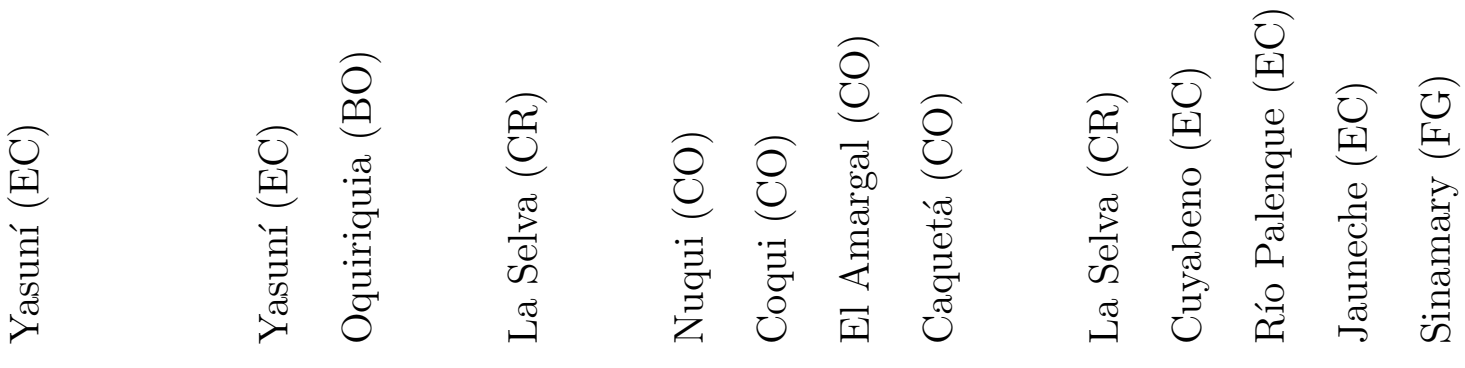




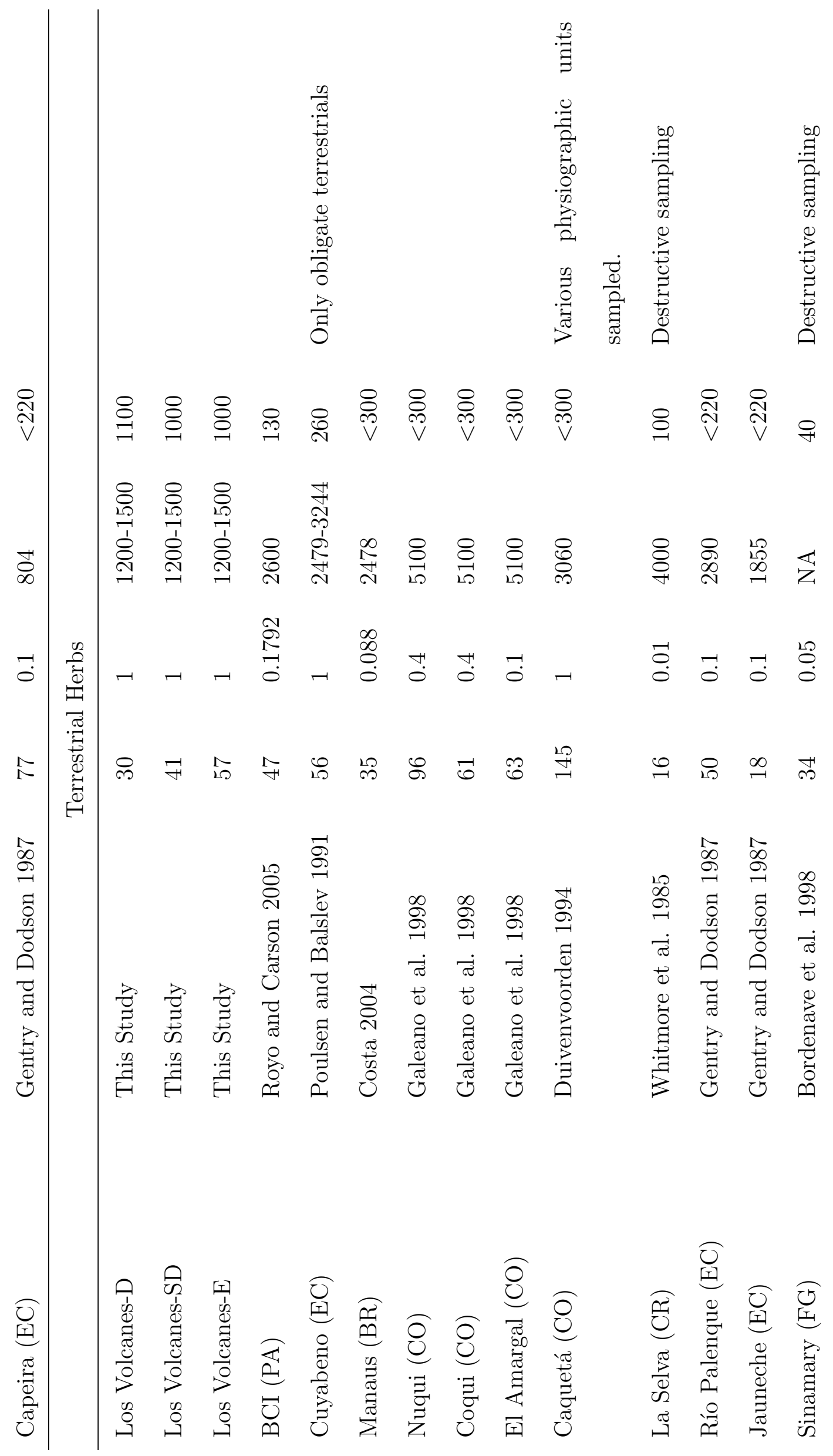




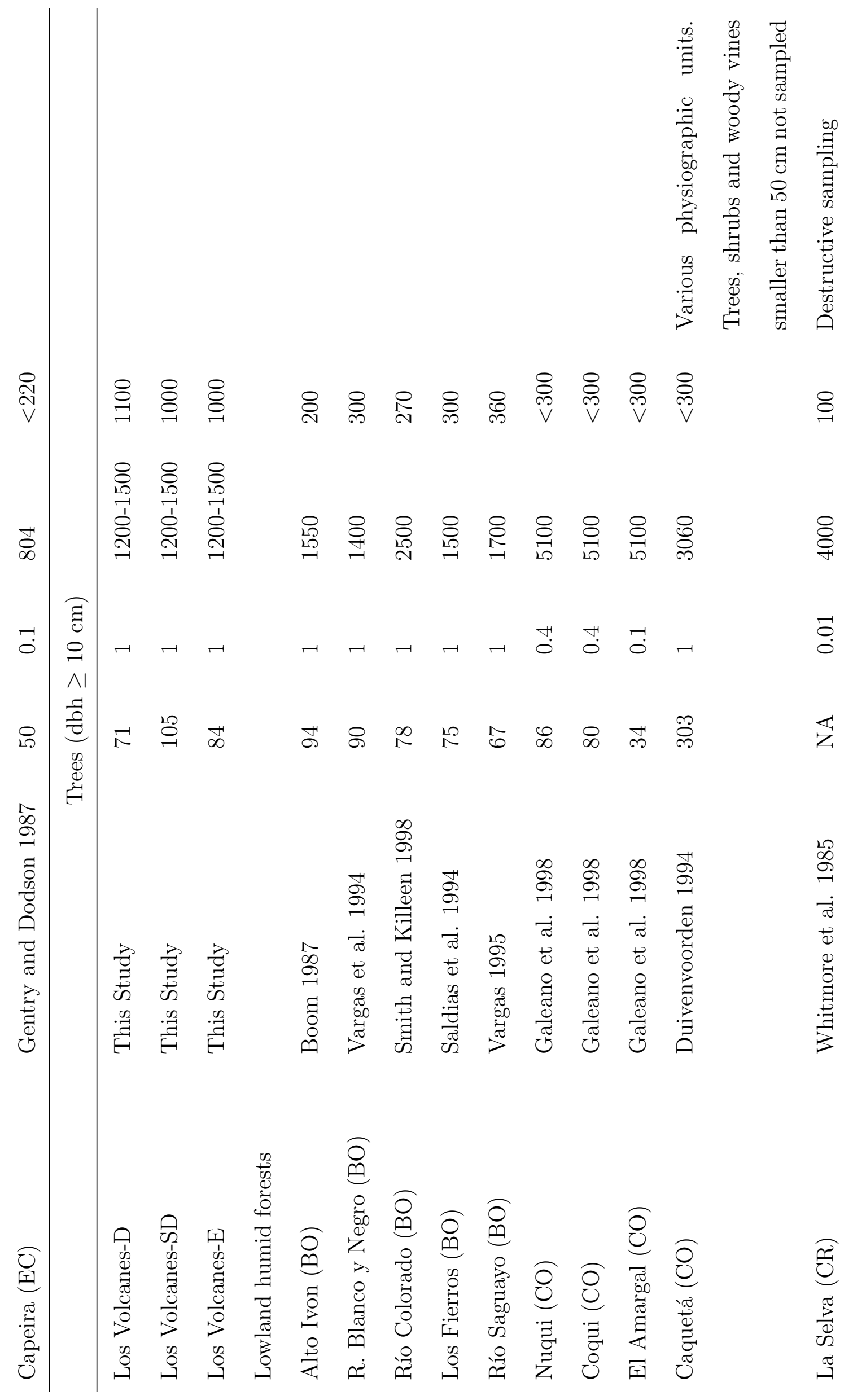




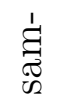

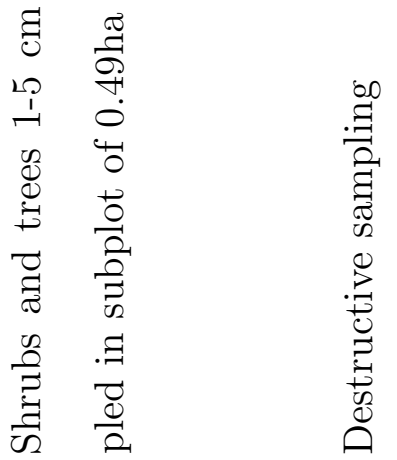

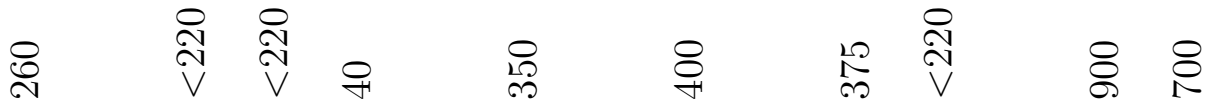

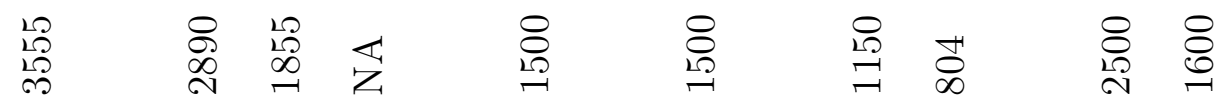

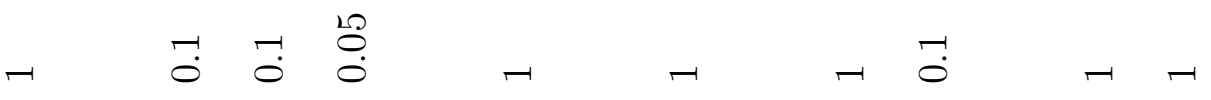

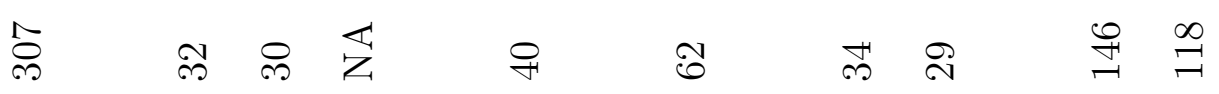

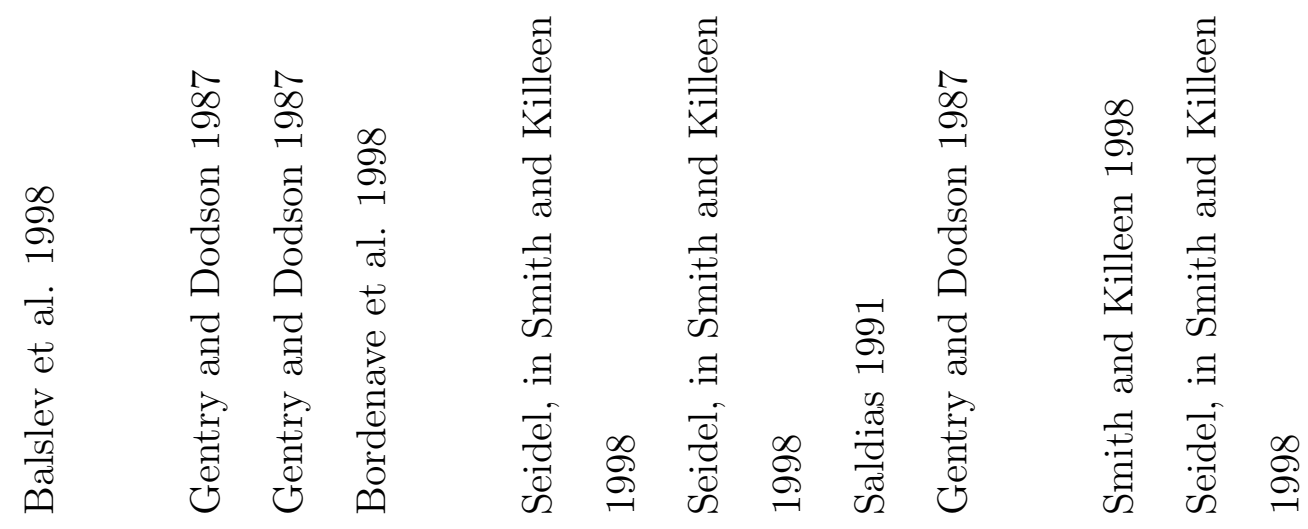

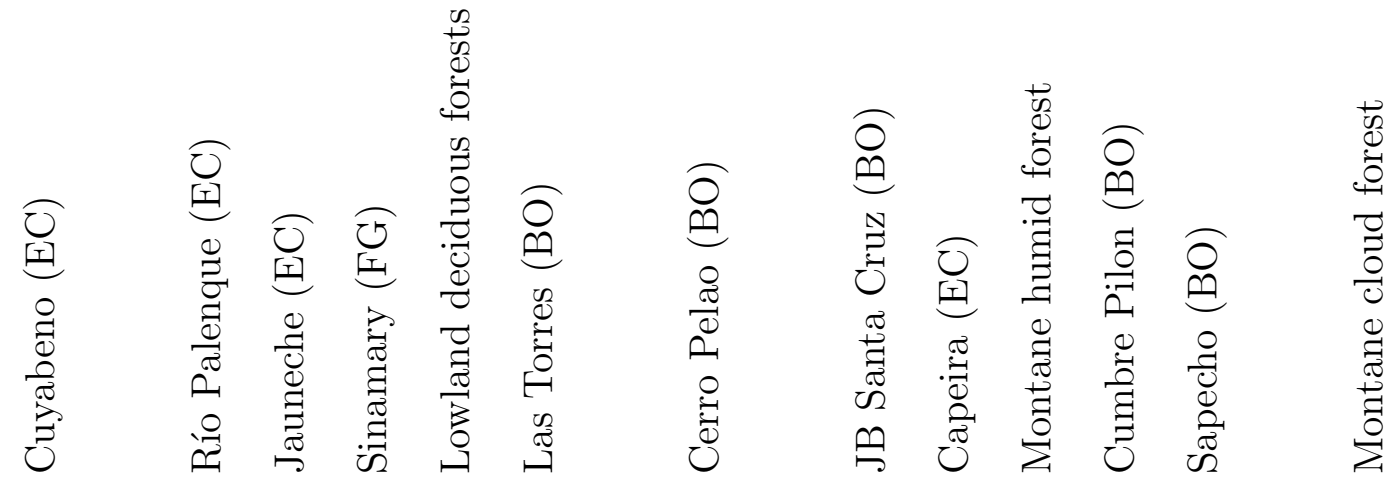




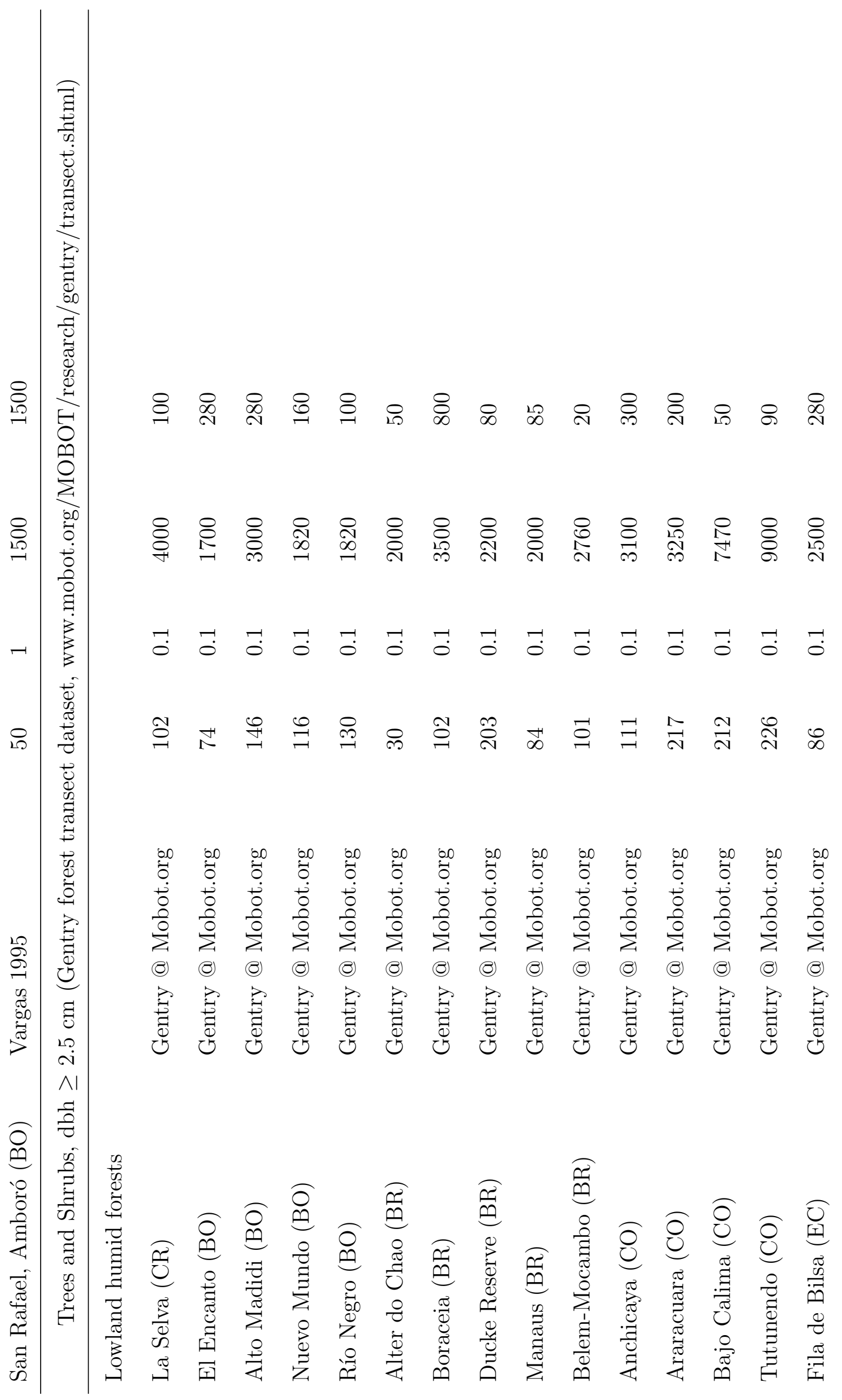




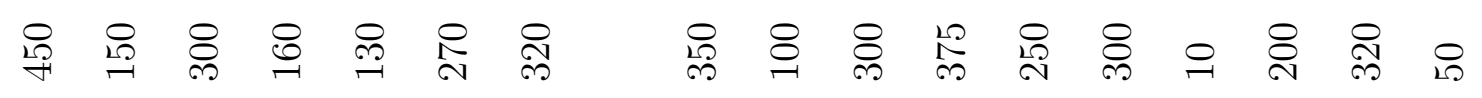

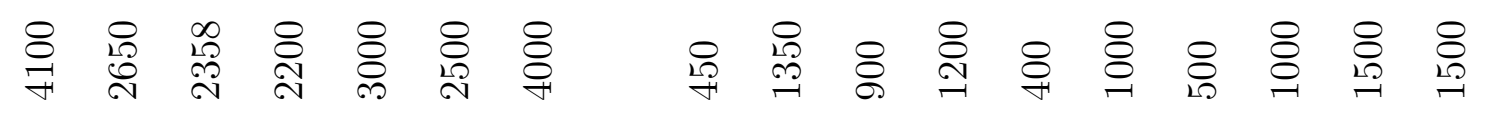

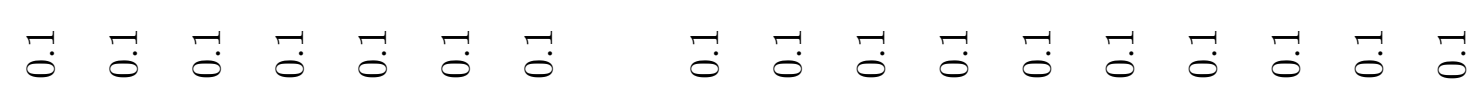

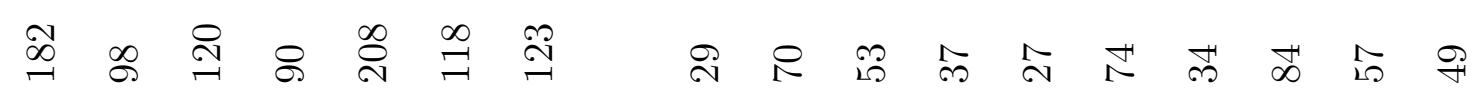

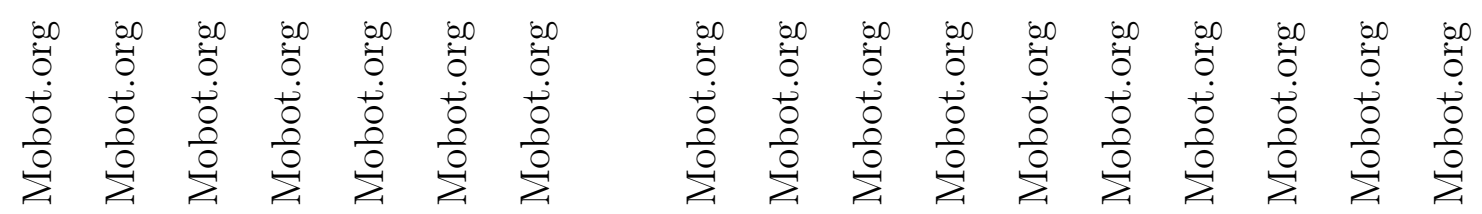

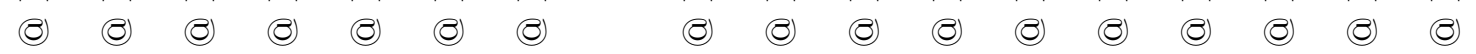

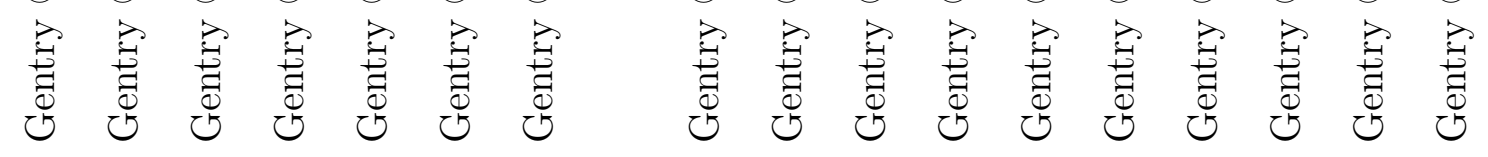

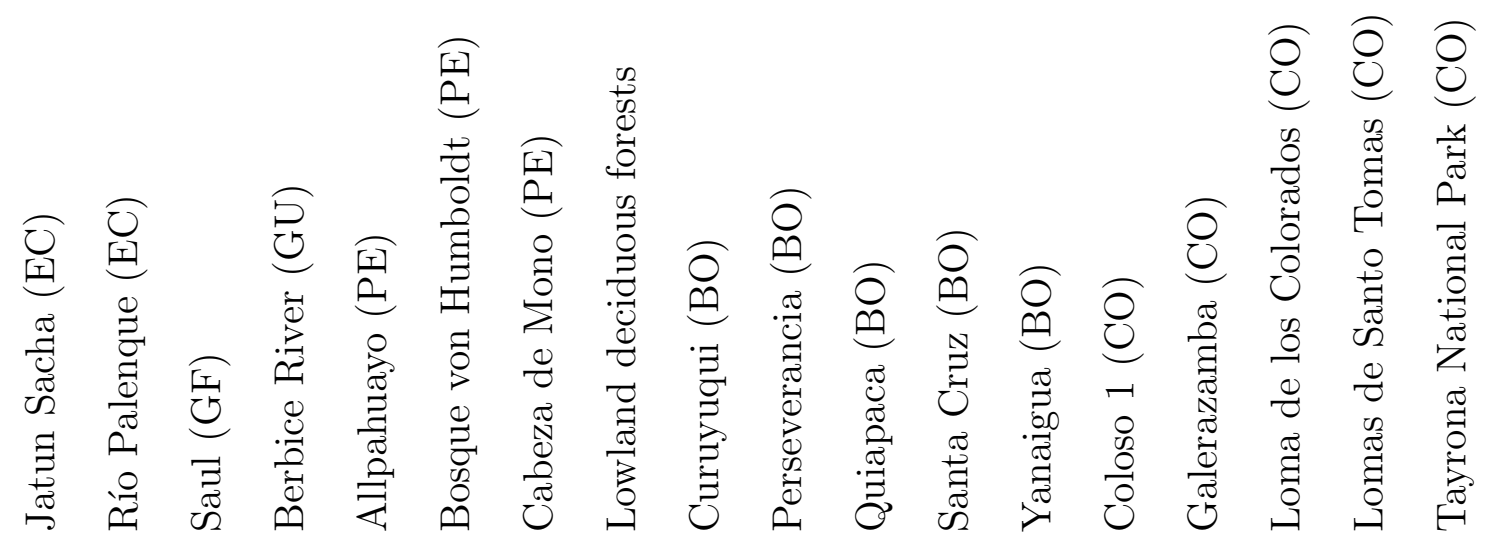




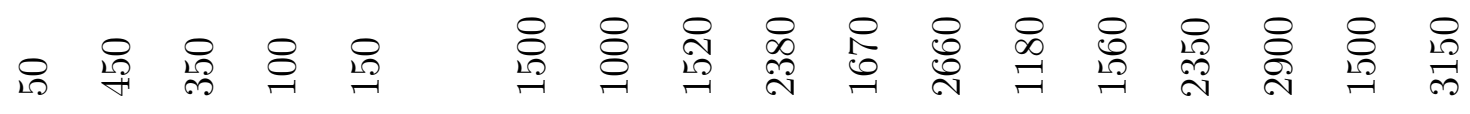

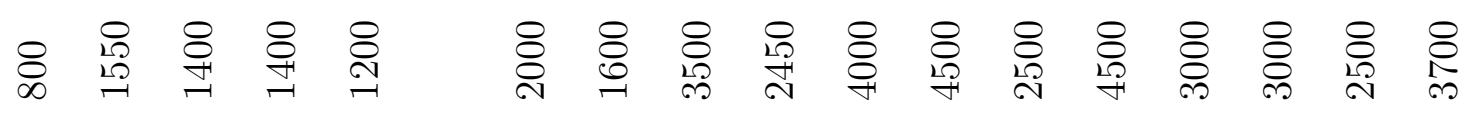

$\vec{a} \overrightarrow{0} \overrightarrow{0} \overrightarrow{0} \overrightarrow{0} \overrightarrow{0} \overrightarrow{0}$ 量 $\overrightarrow{0} \overrightarrow{0} \overrightarrow{0} \overrightarrow{0} \overrightarrow{0} \overrightarrow{0} \overrightarrow{0} \overrightarrow{0} \overrightarrow{0} \overrightarrow{0} \overrightarrow{0} \overrightarrow{0} \overrightarrow{0} \overrightarrow{0} \overrightarrow{0}$

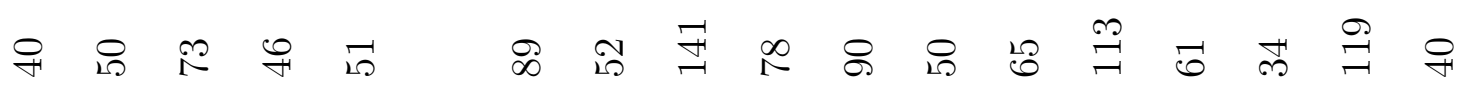

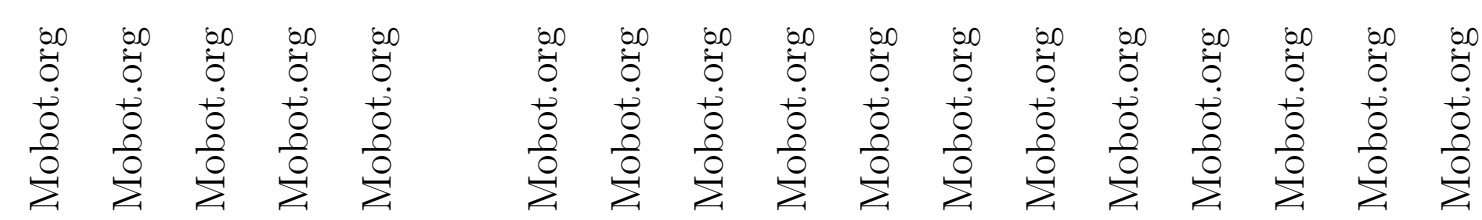

(8) (8) (8) (6) (8) (8) (8) (6) (8) (8) (8) (8) (6) (8) (6) (8) (8)

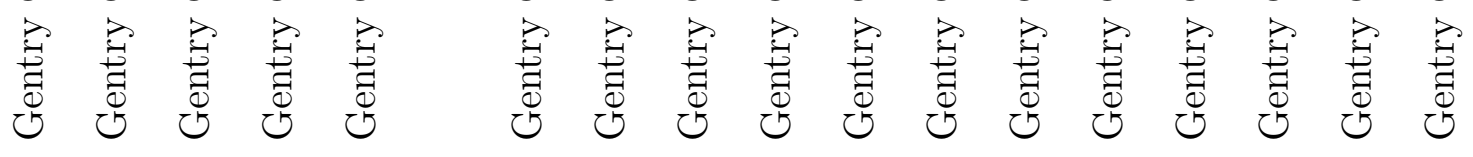

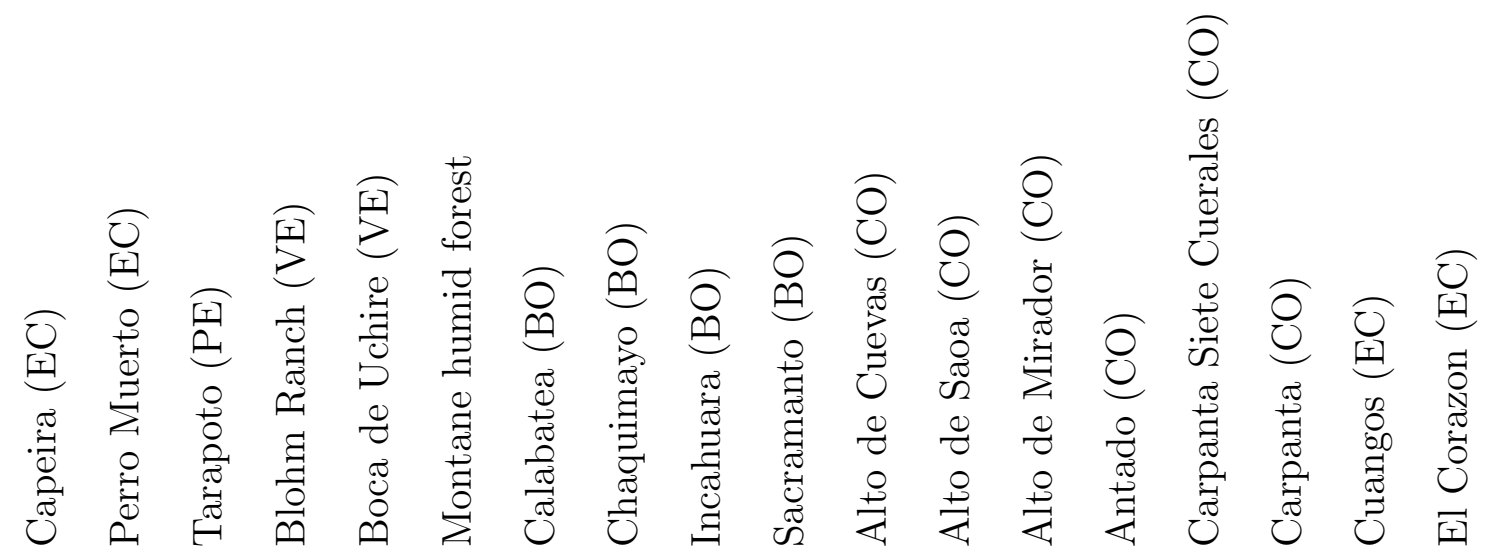




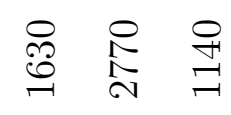

옳욨 옳

궁ㅎㅇ

ஓ Ұ

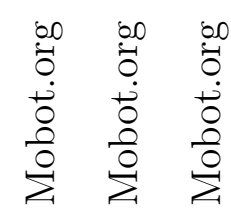

(8) (8) (8)

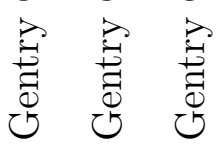

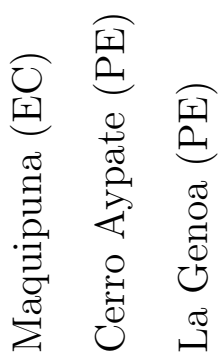




\section{A.2 Appendix 2 to Chapter 2}

Presence/Absence species list collected in the Los Volcanes deciduous (DF), semideciduous (SDF) and evergreen (EF) forest plots in Santa Cruz, Bolivia. Life-forms: $\mathrm{h}=$ terrestrial herb, e=epiphyte, he=hemiepiphyte, $\mathrm{l}=$ liana, $\mathrm{s}=$ shrub, ss=subshrub, $\mathrm{t}=$ tree, $\mathrm{tl}=$ treelet, $\mathrm{p}=$ parasite 


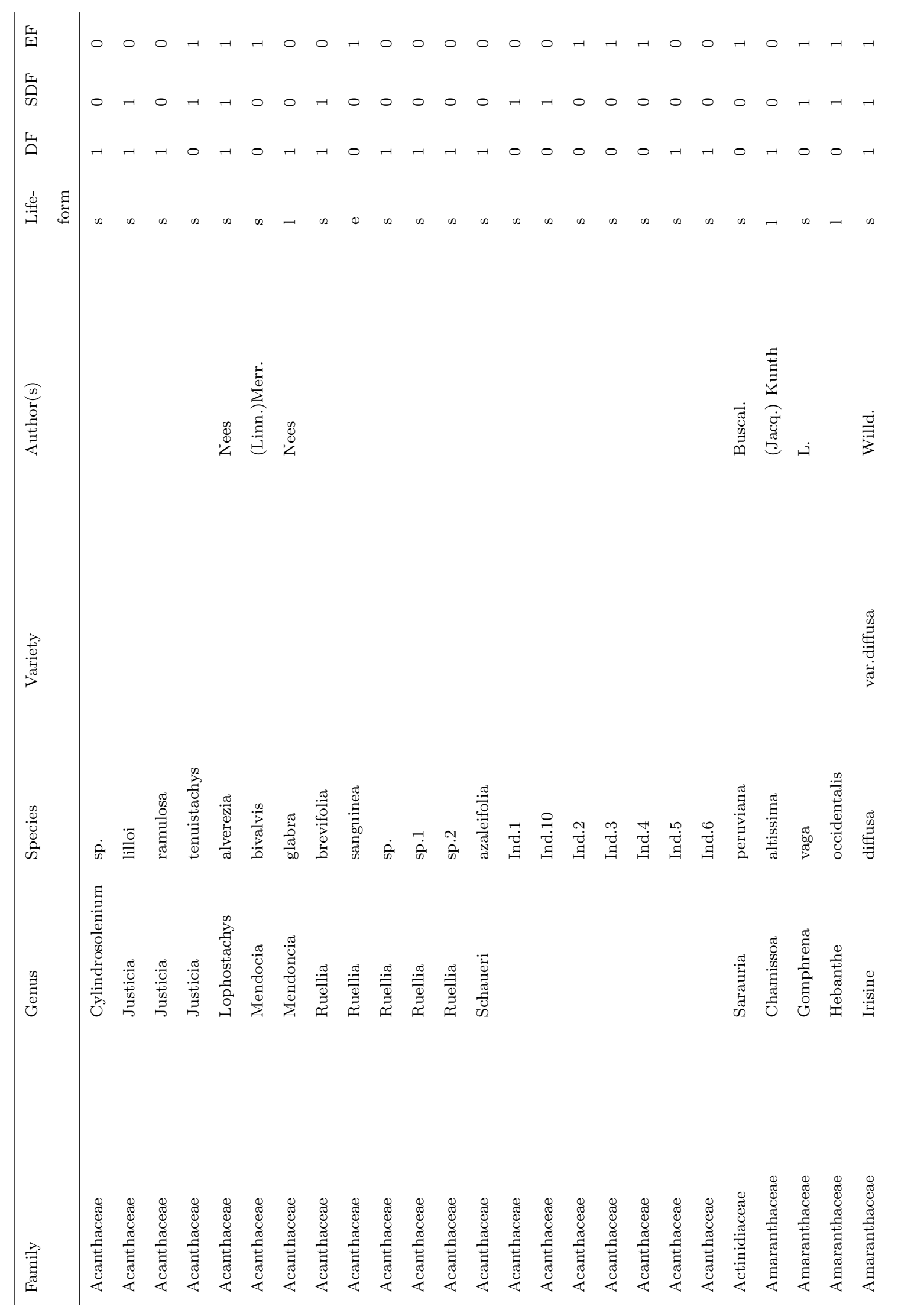




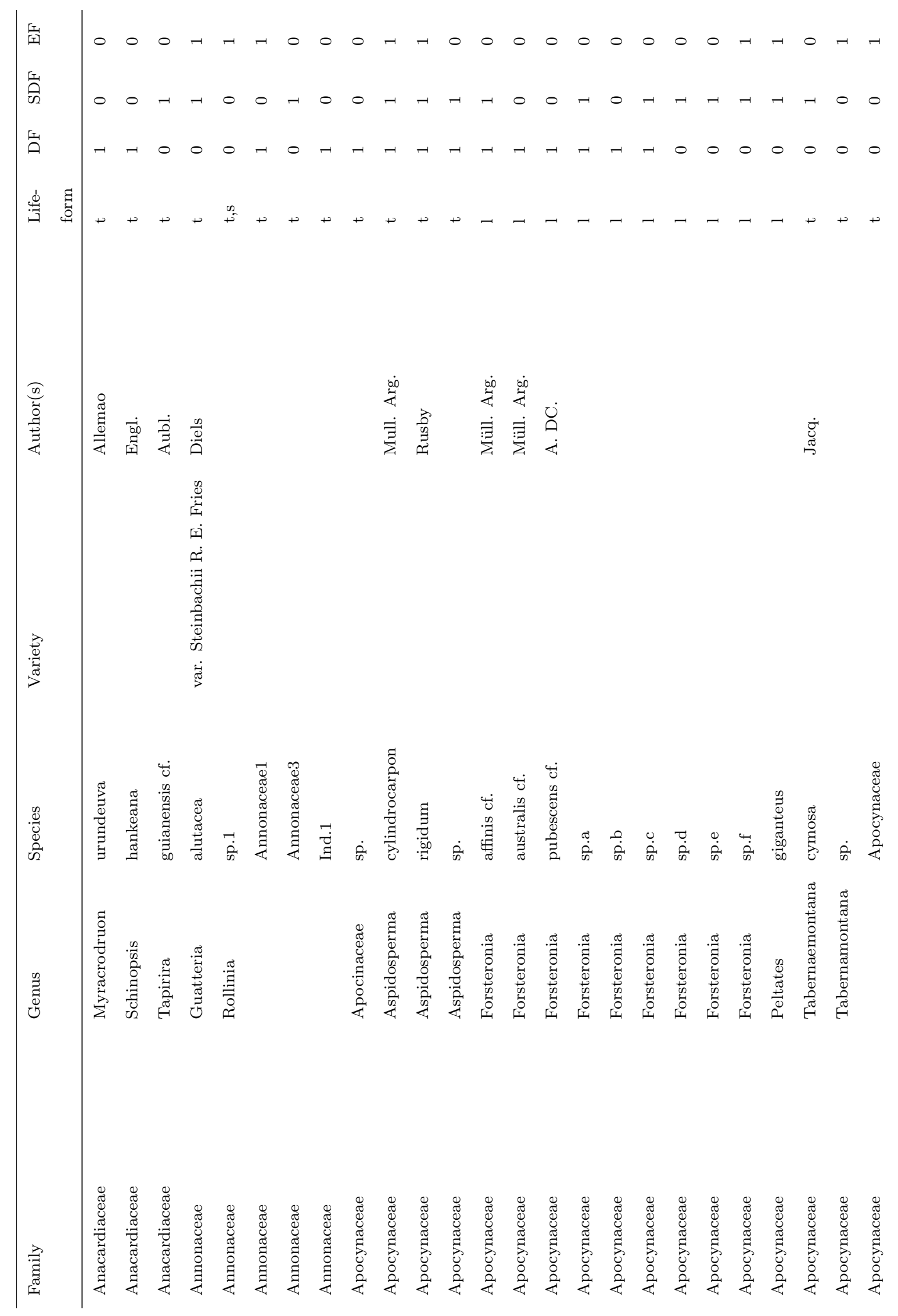




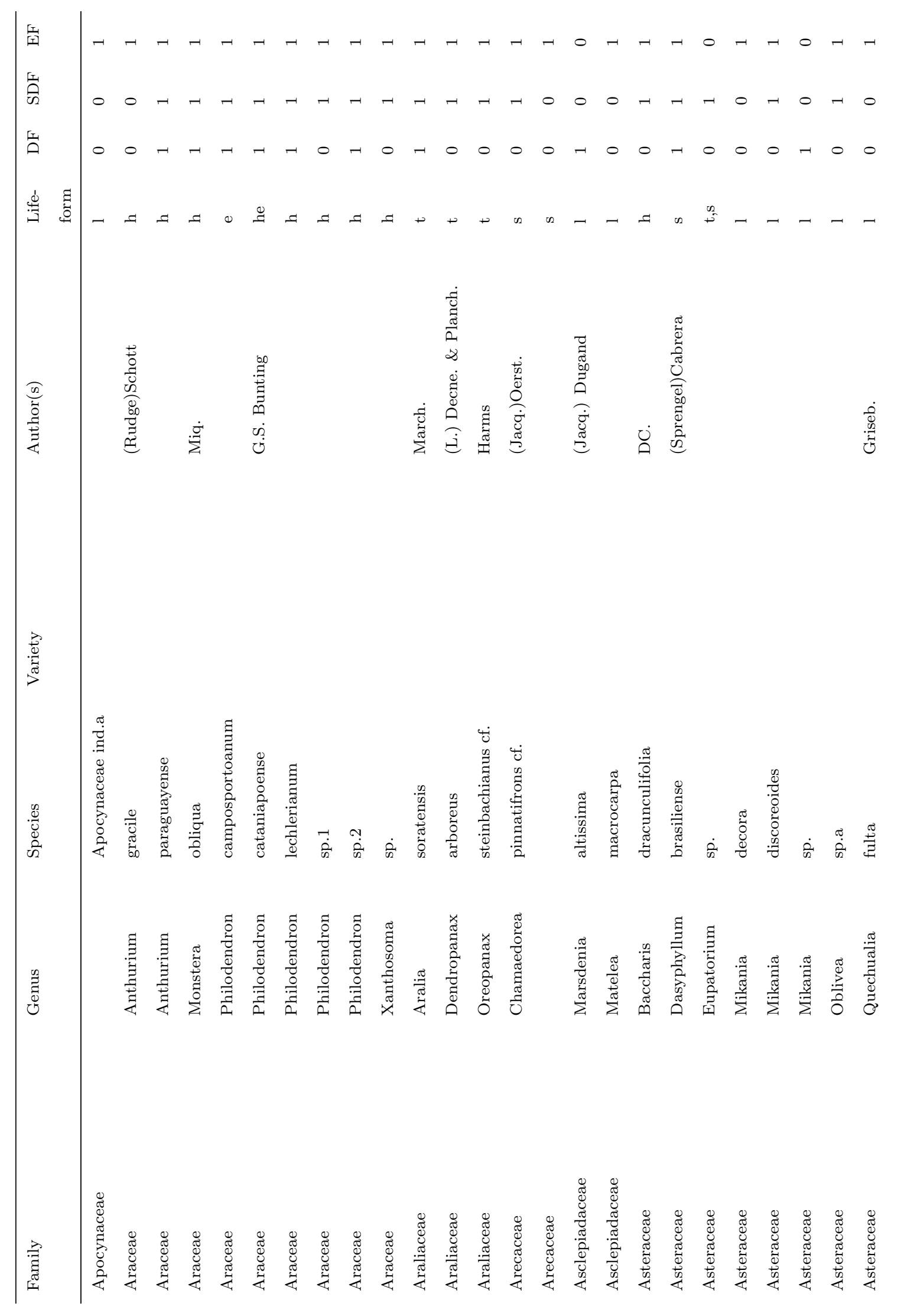




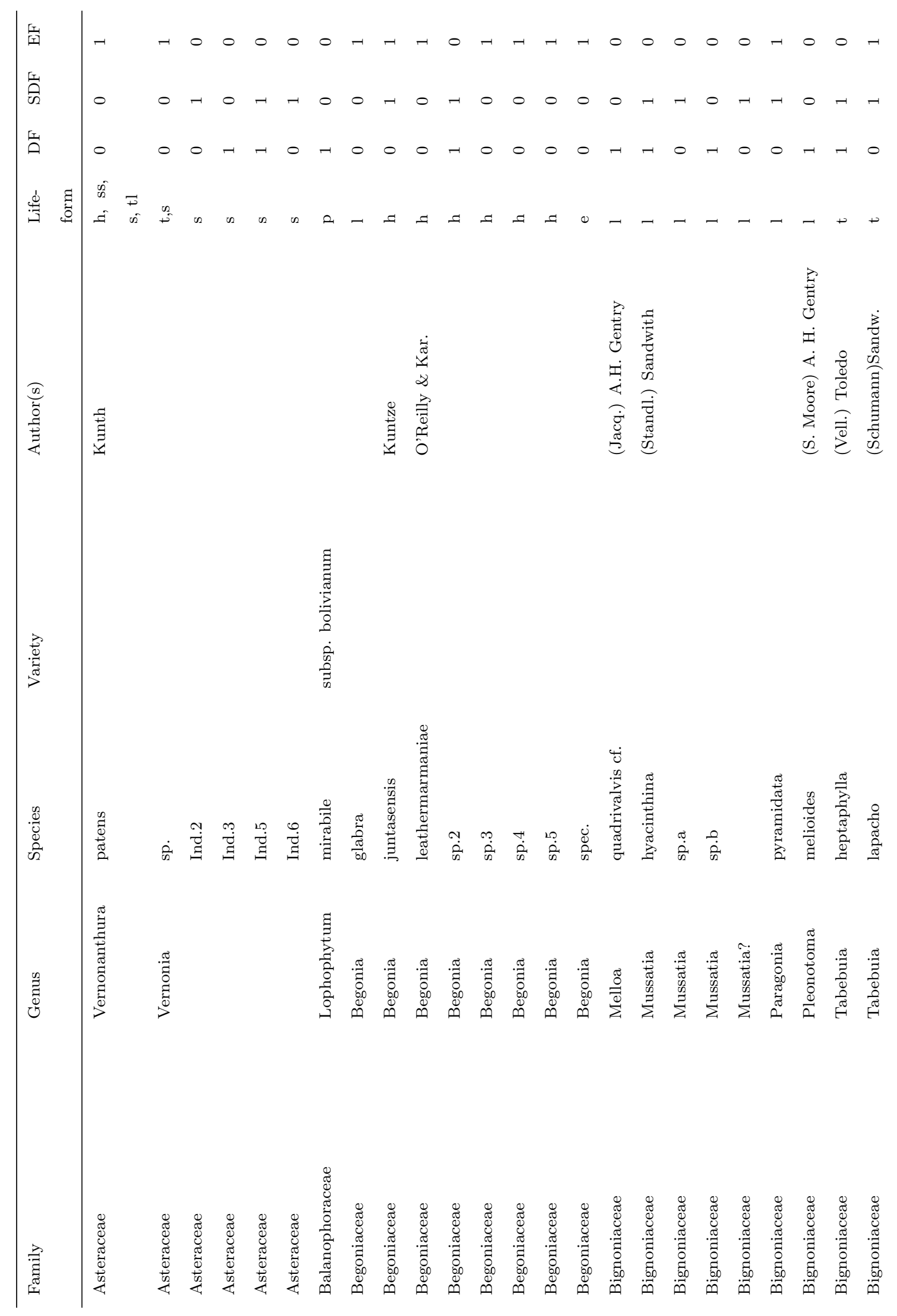




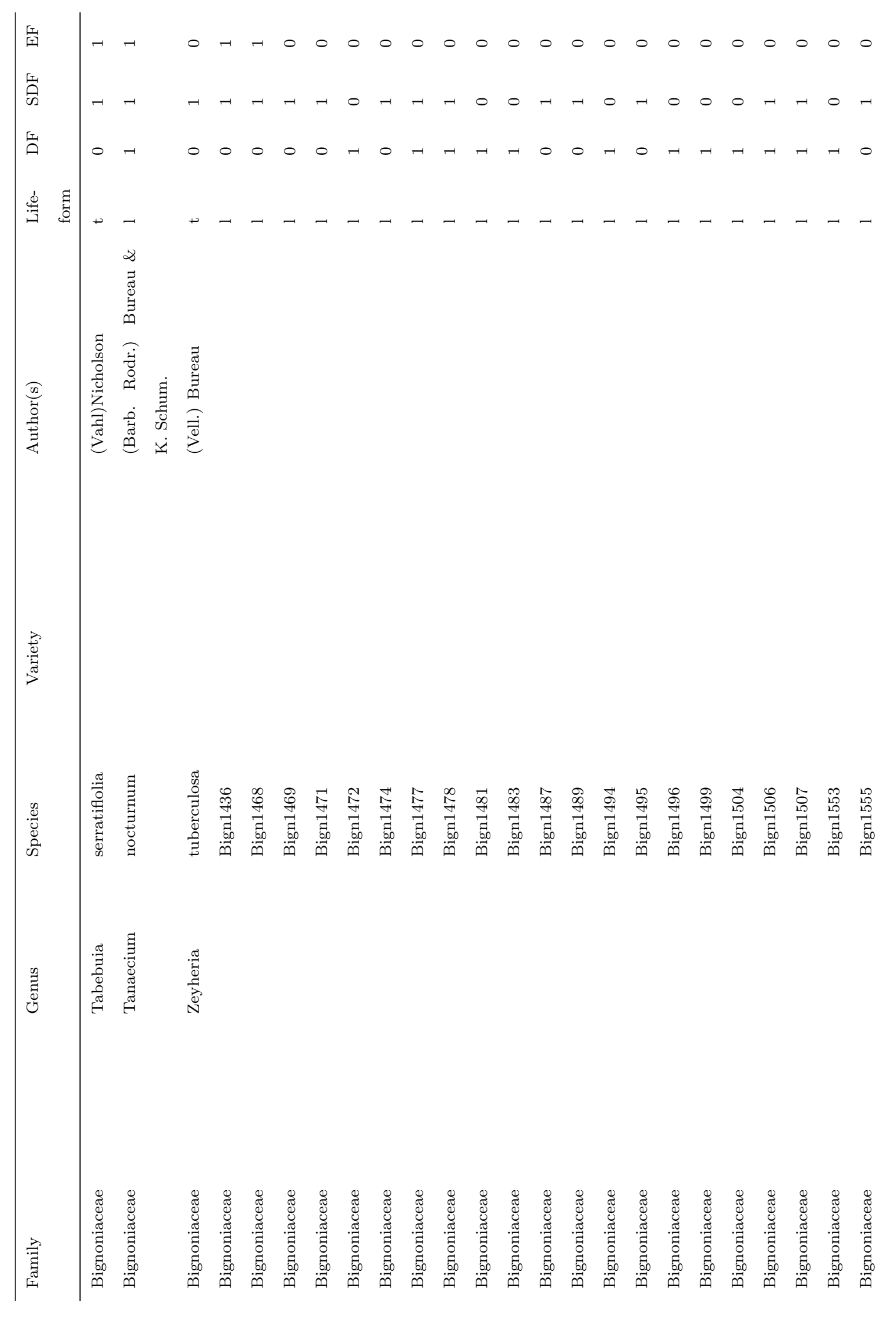




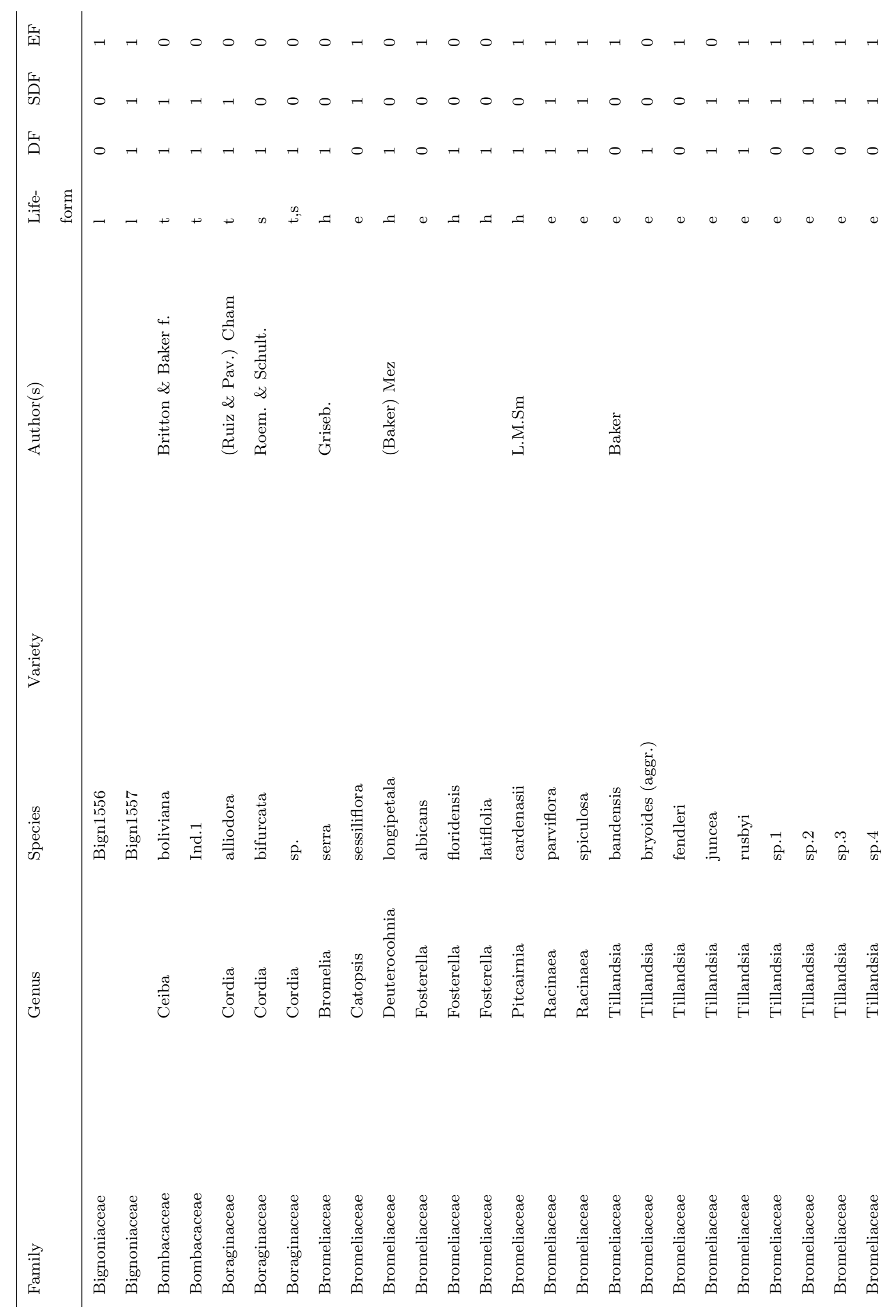




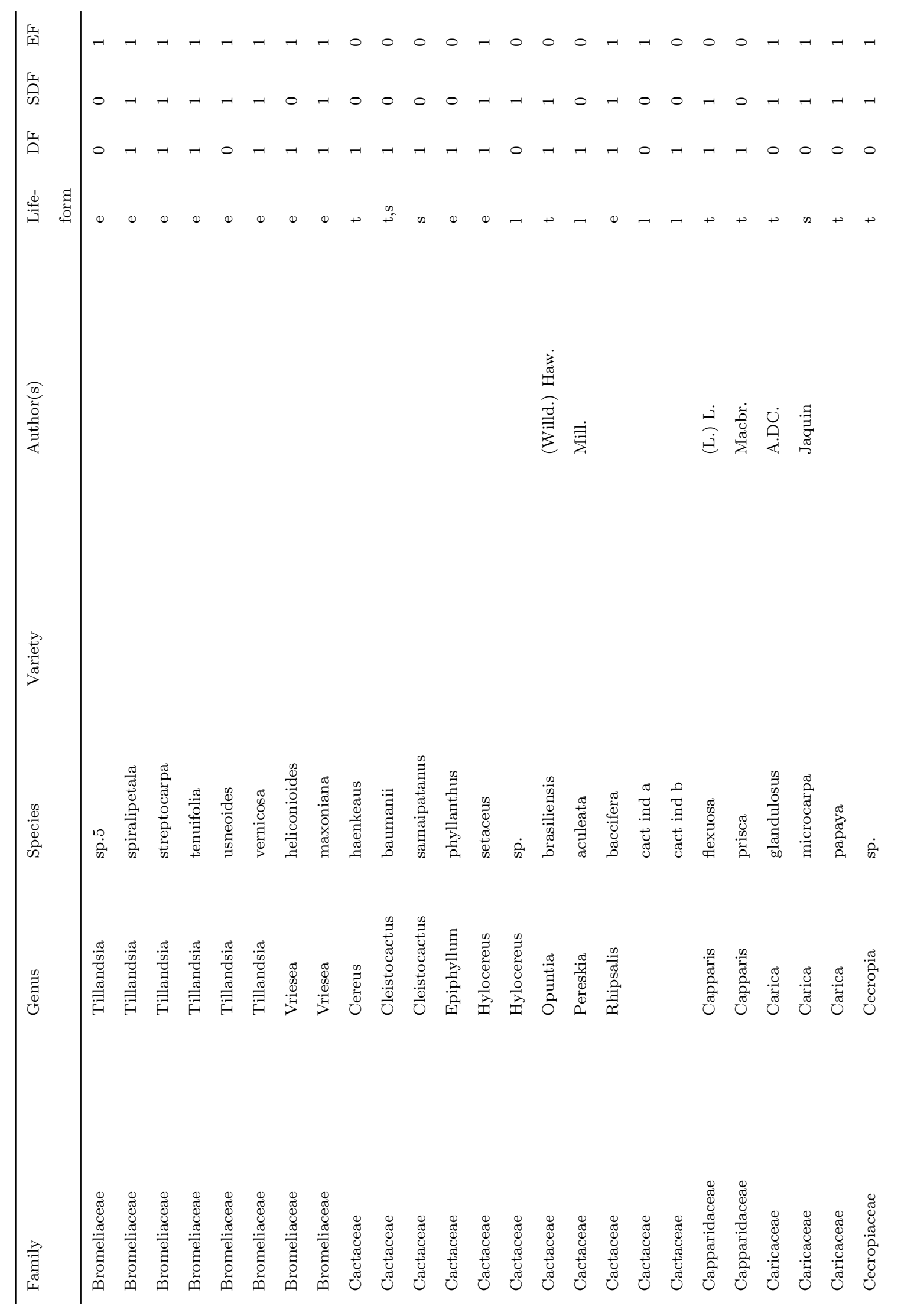




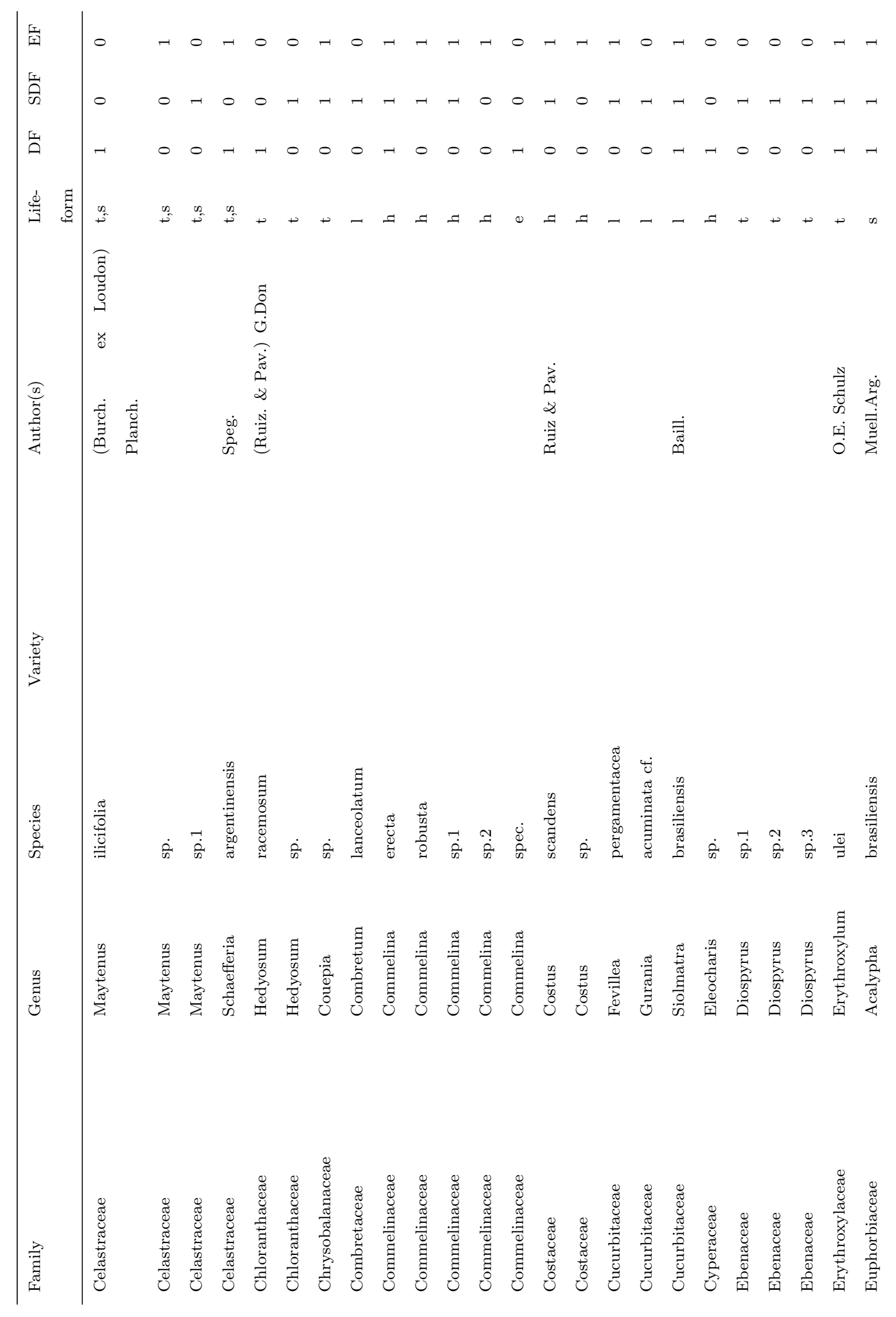




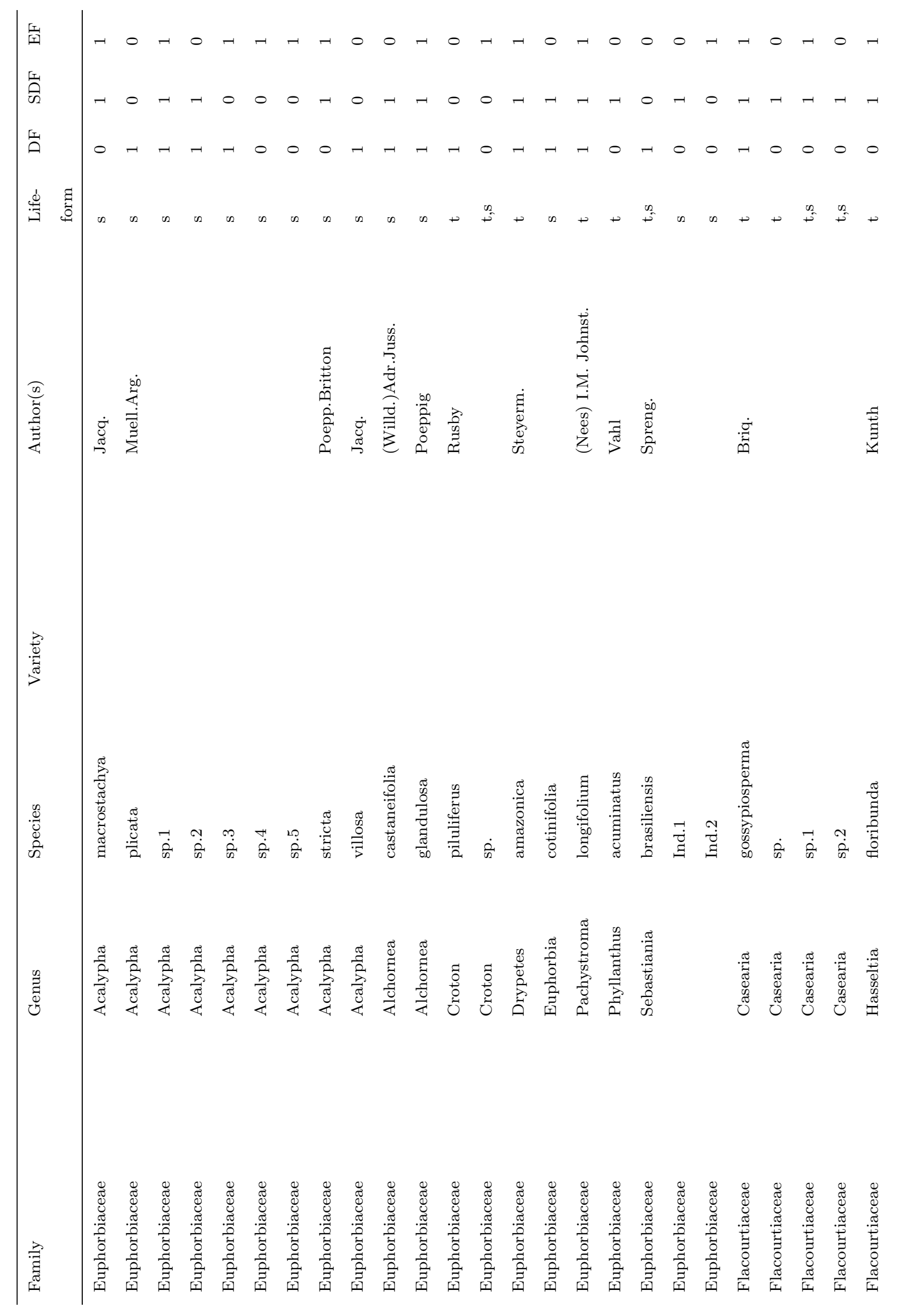




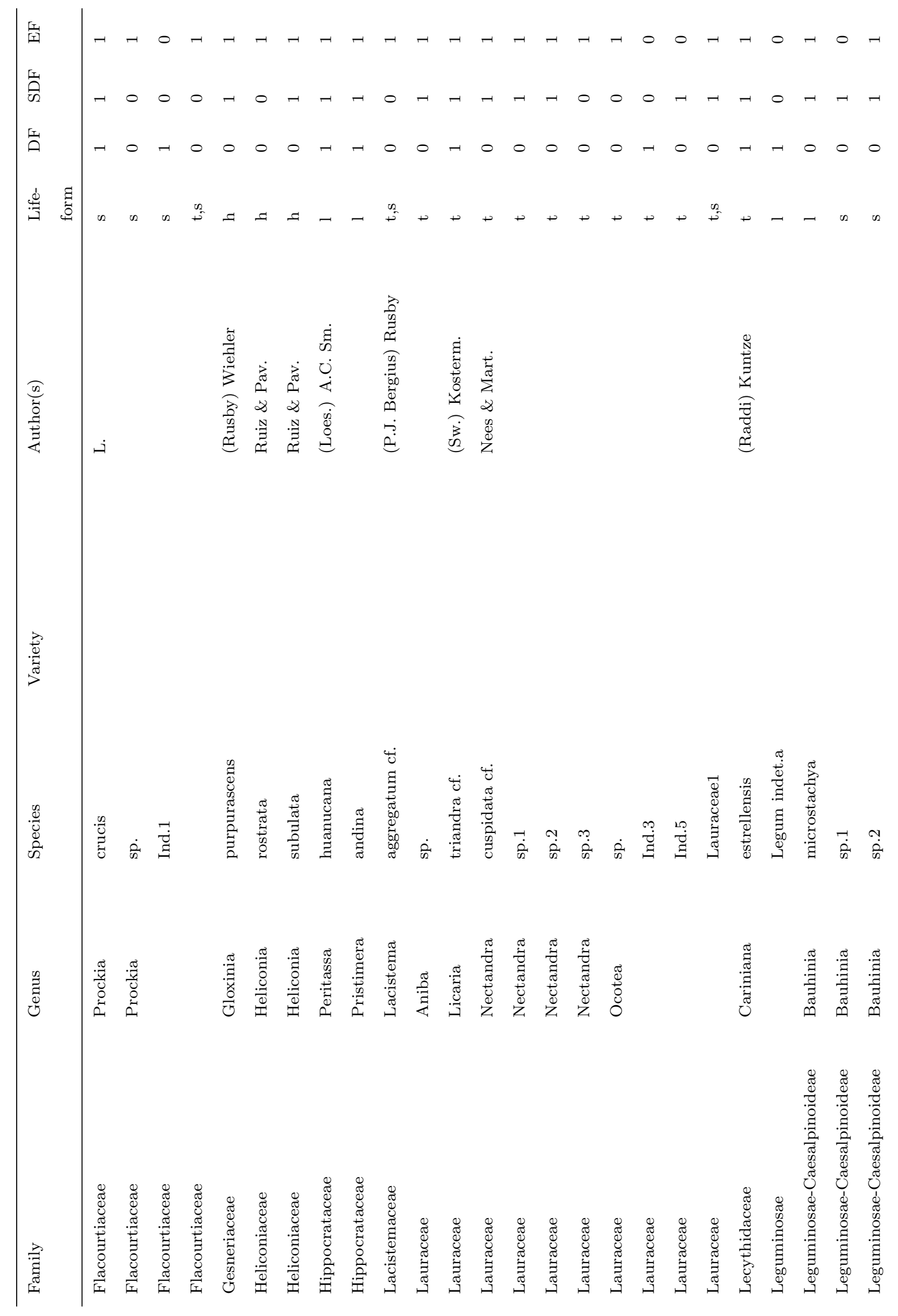




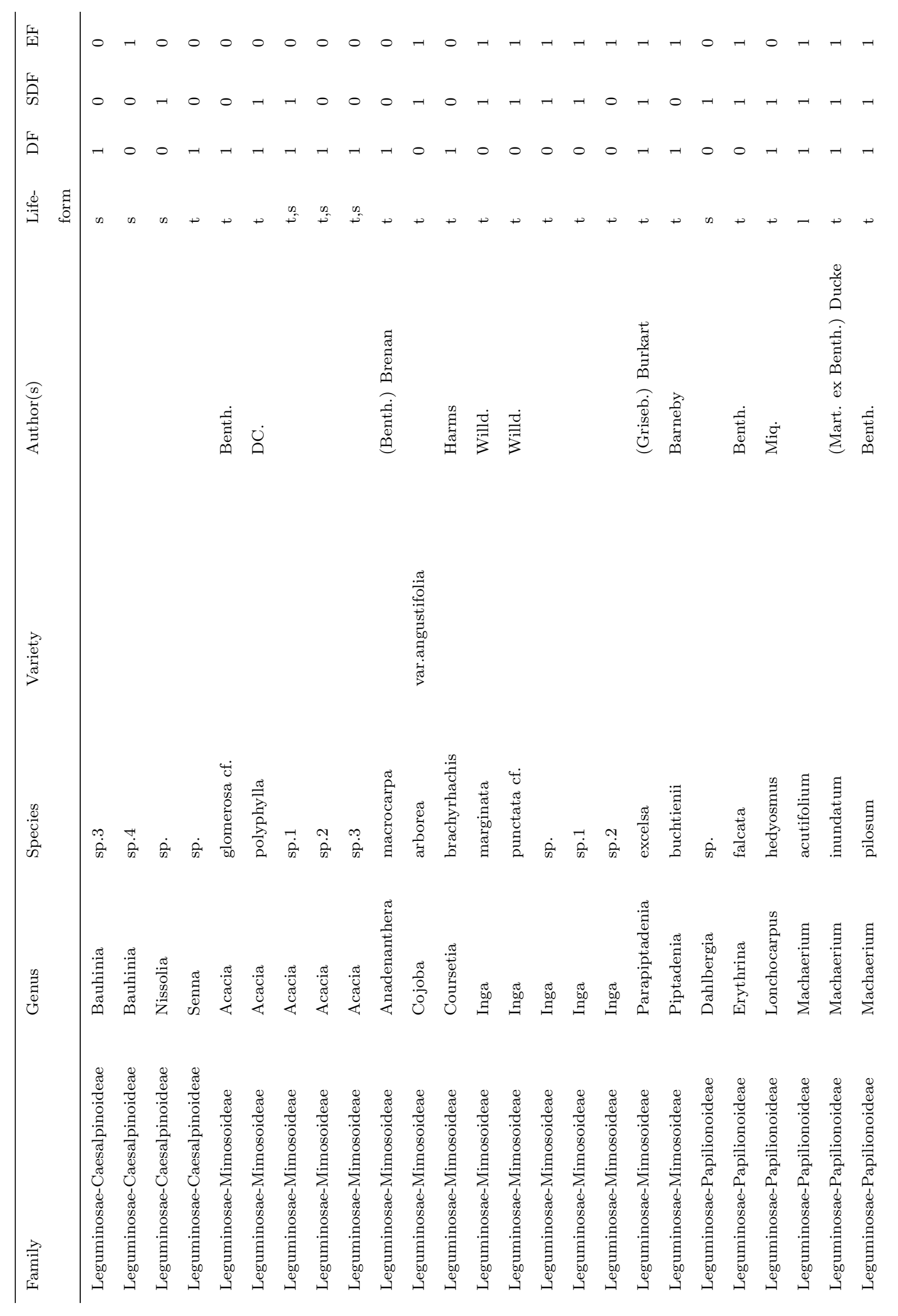




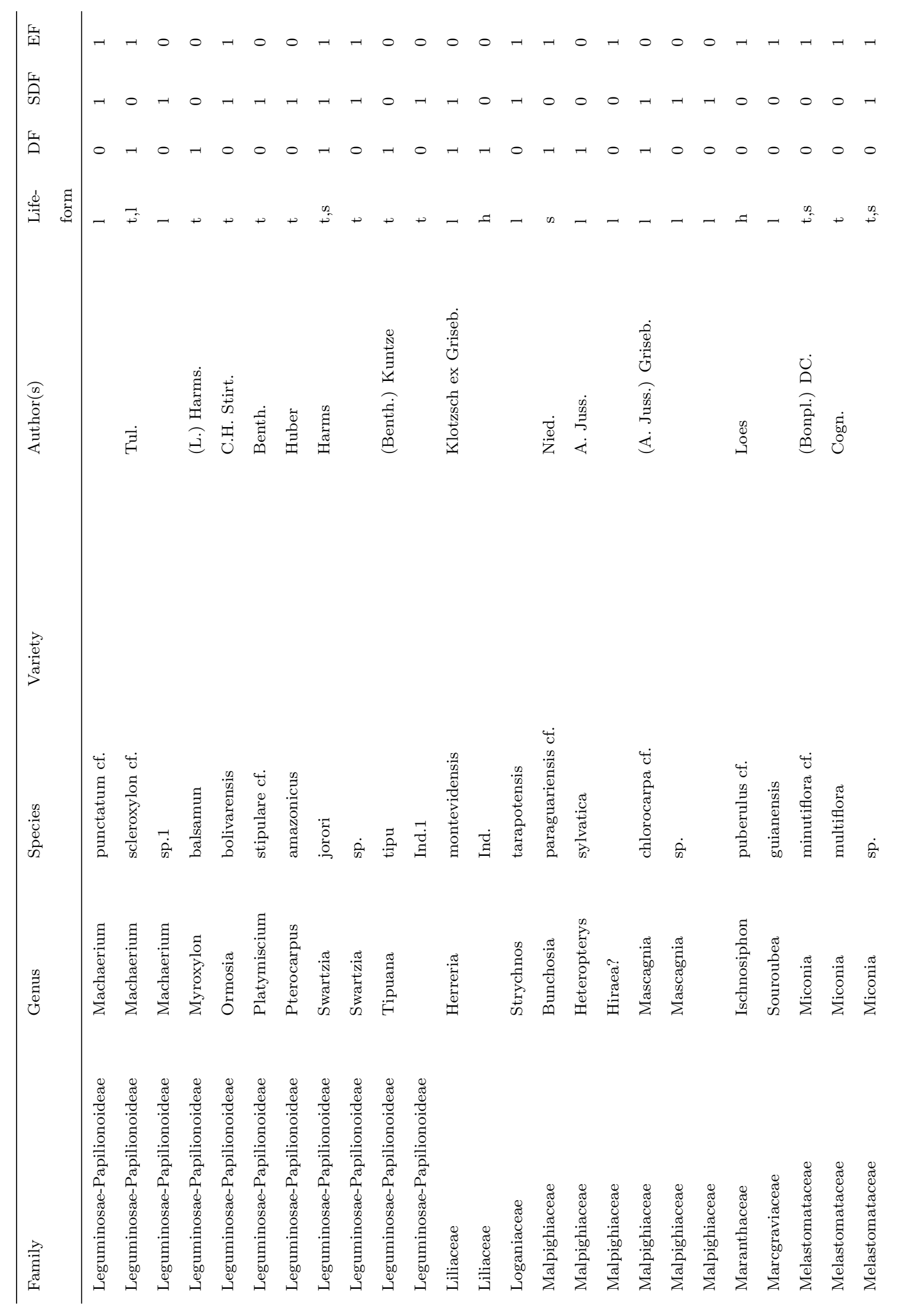




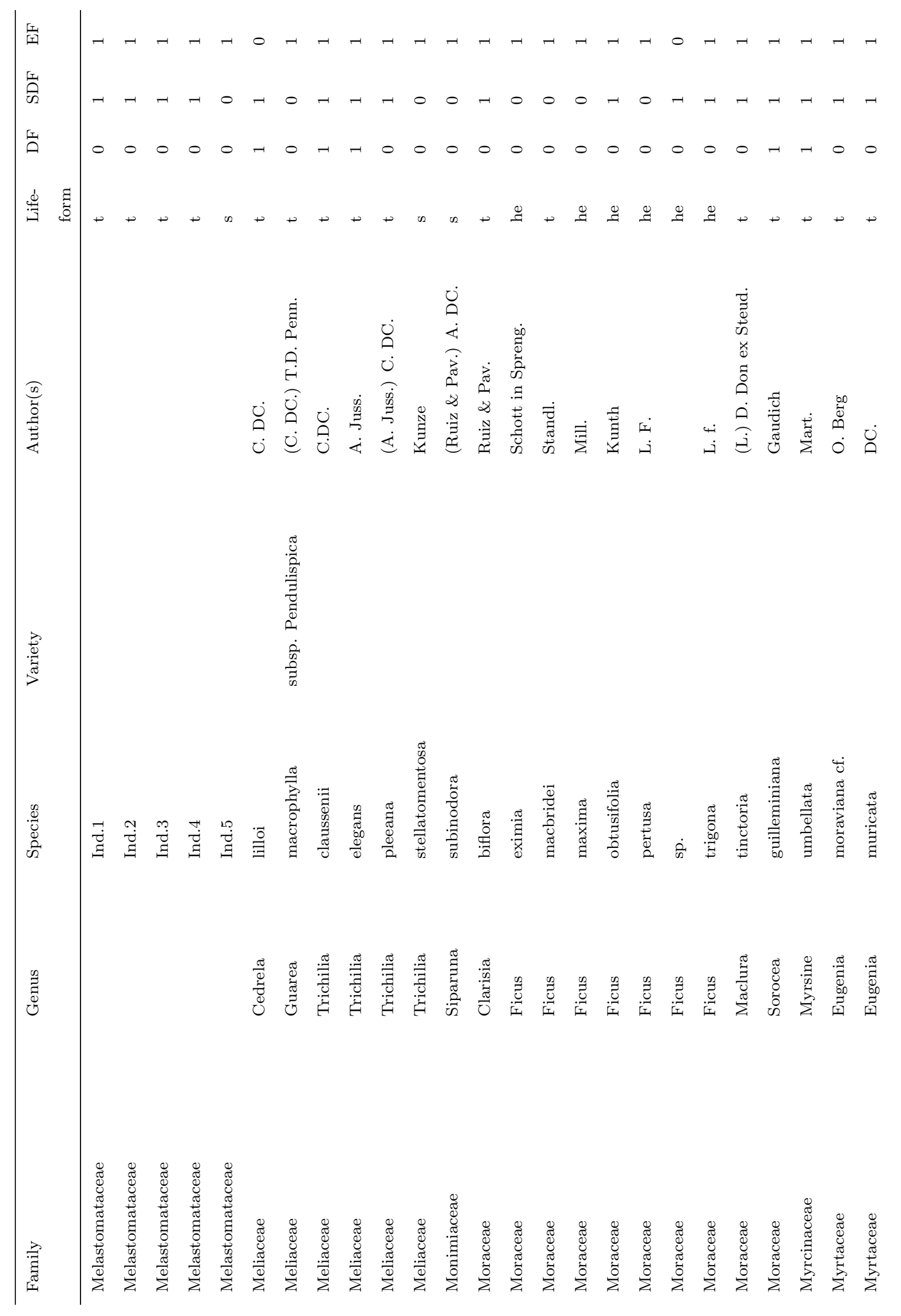




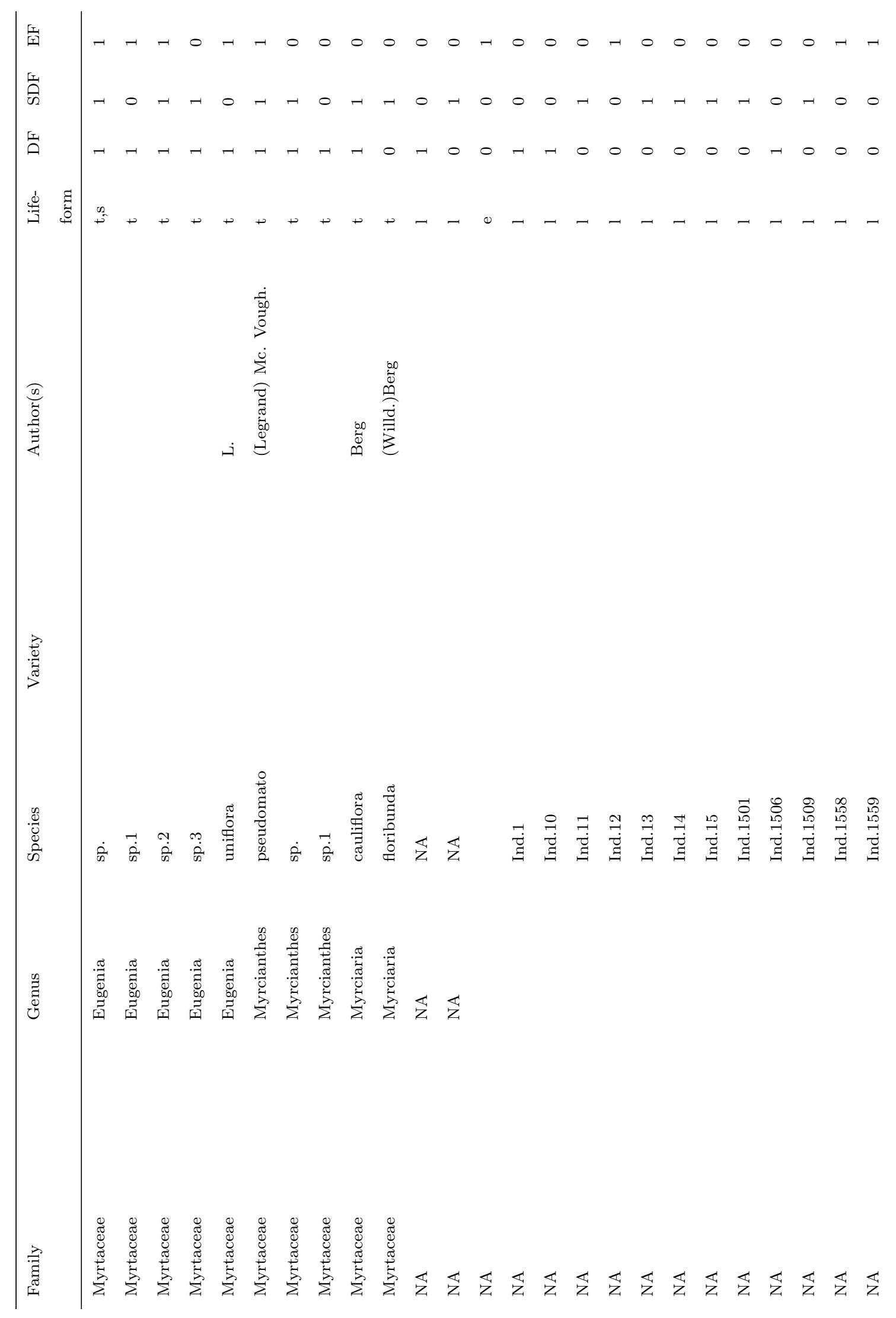




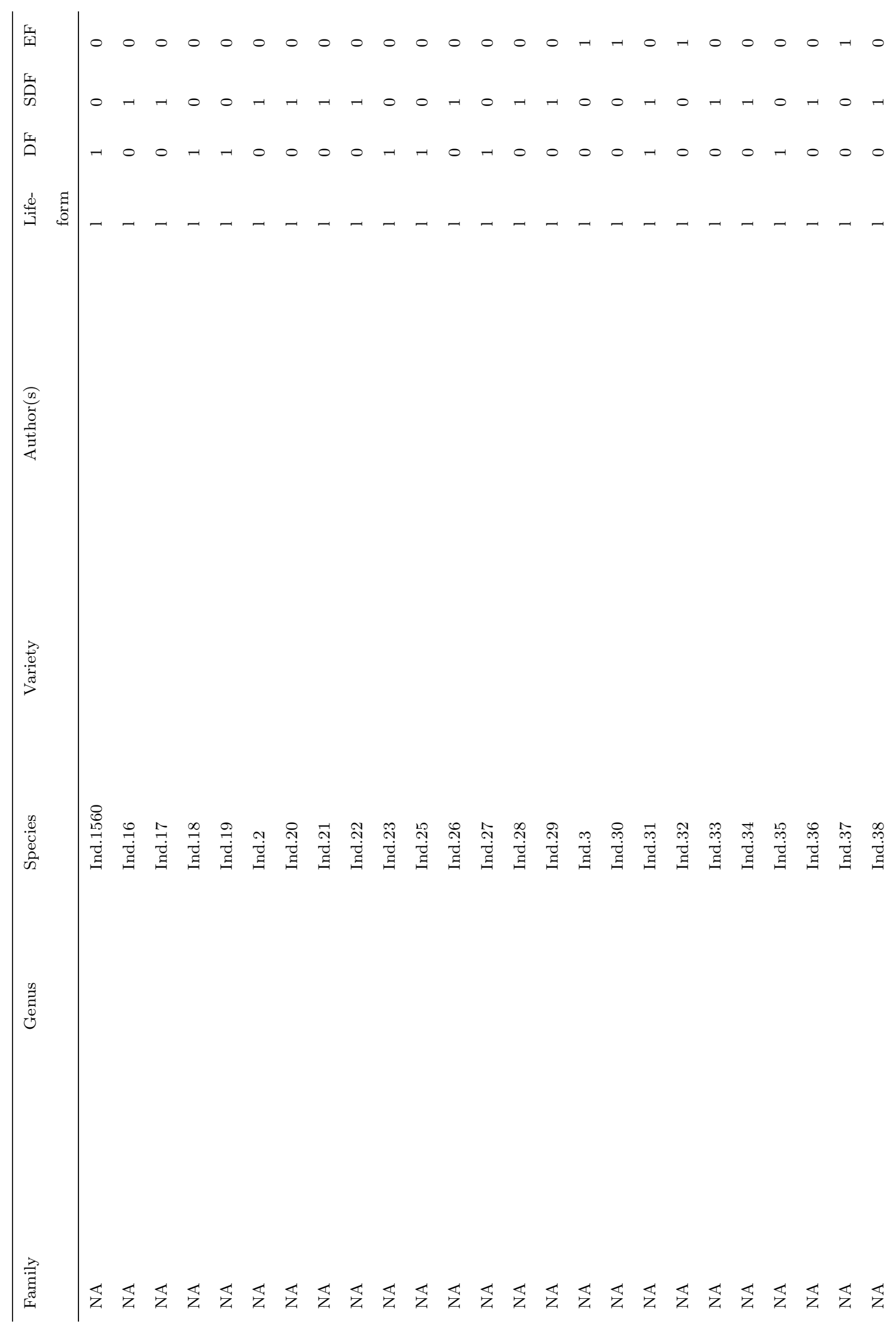




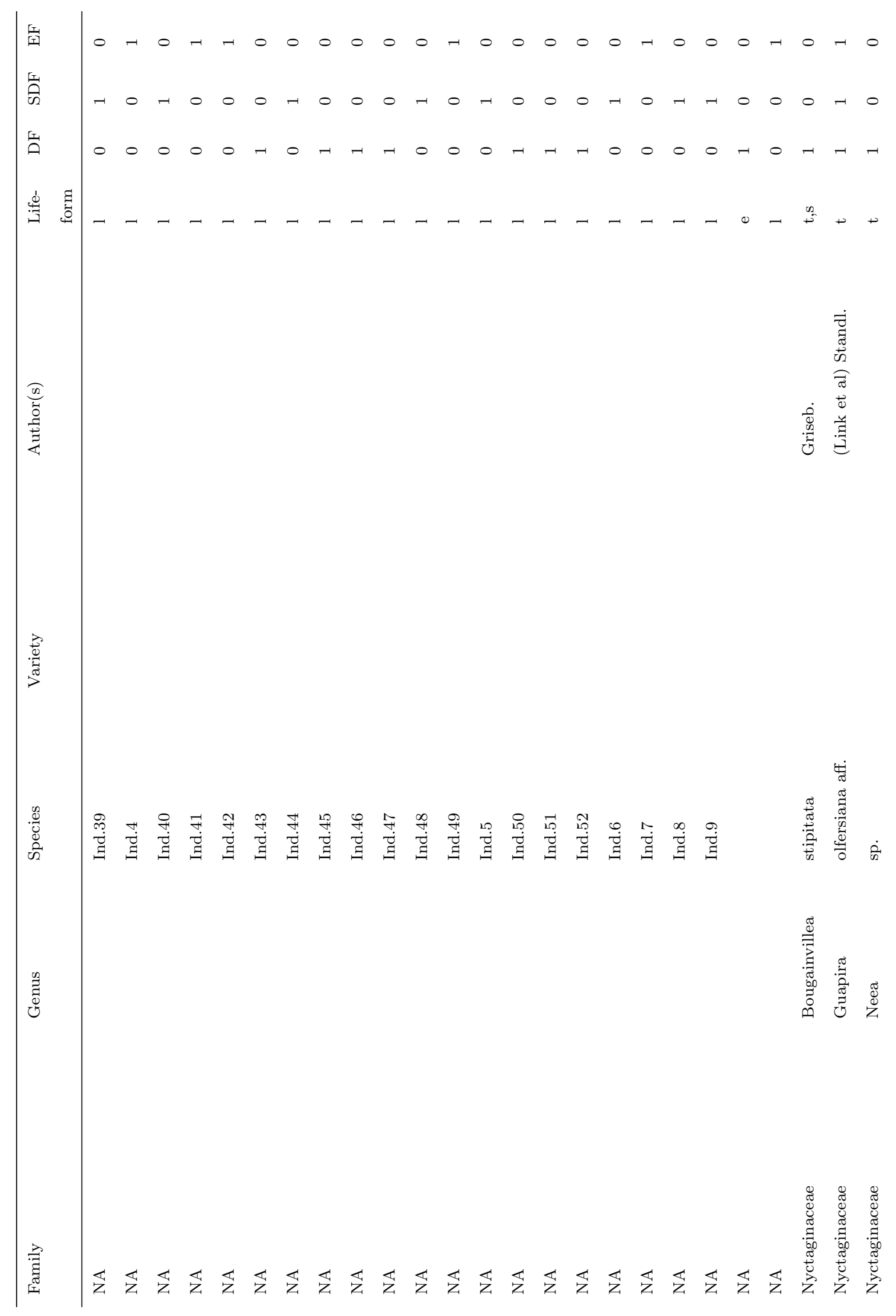




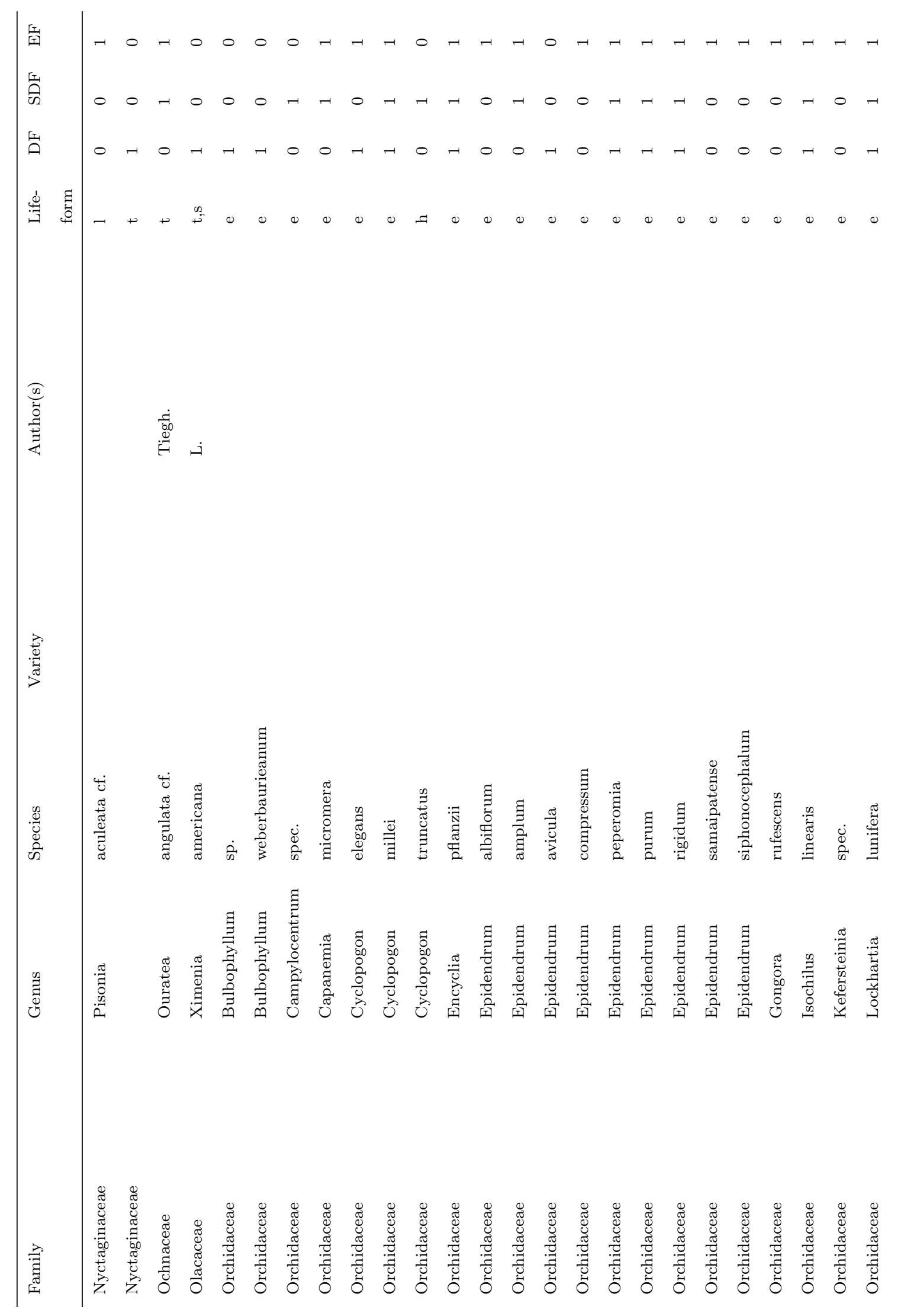




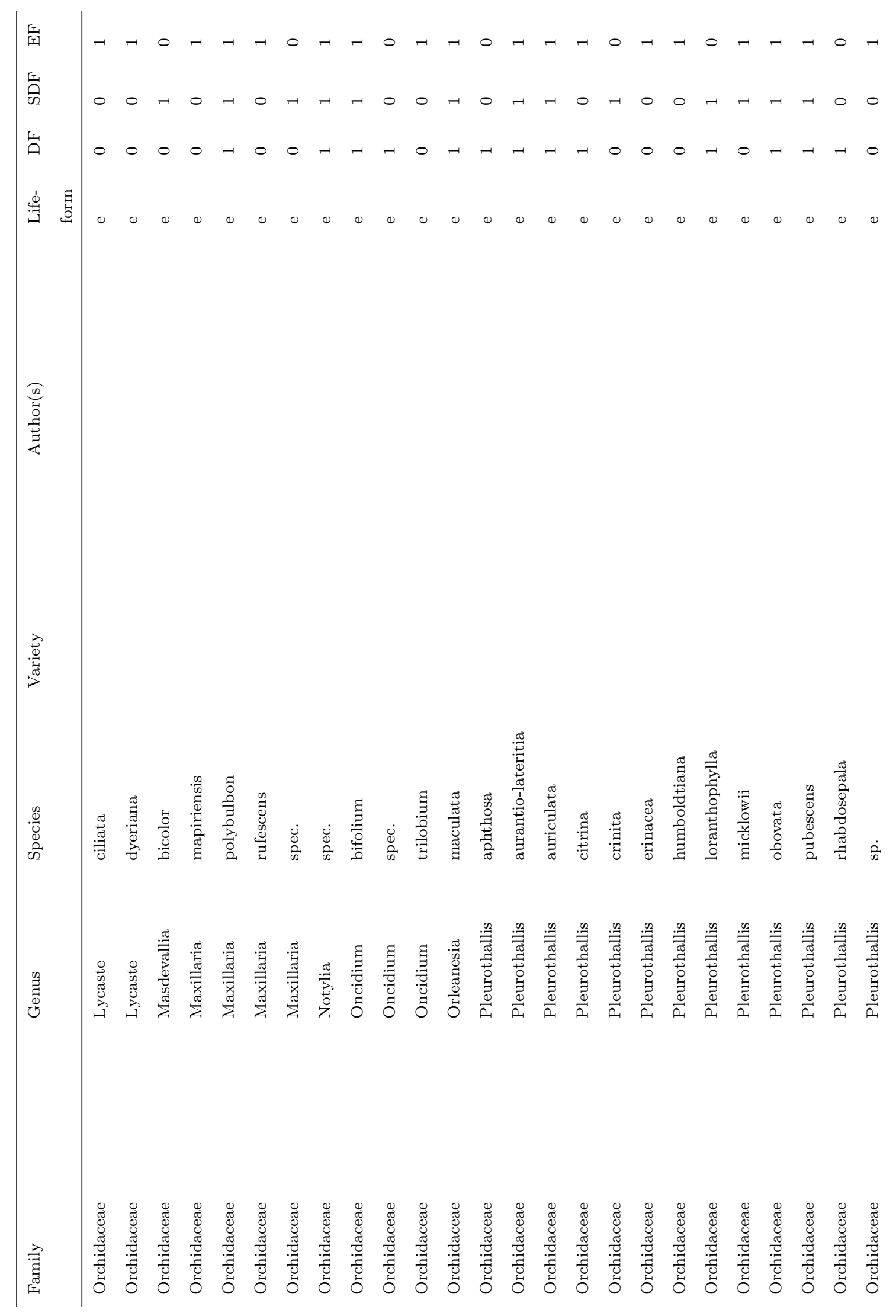




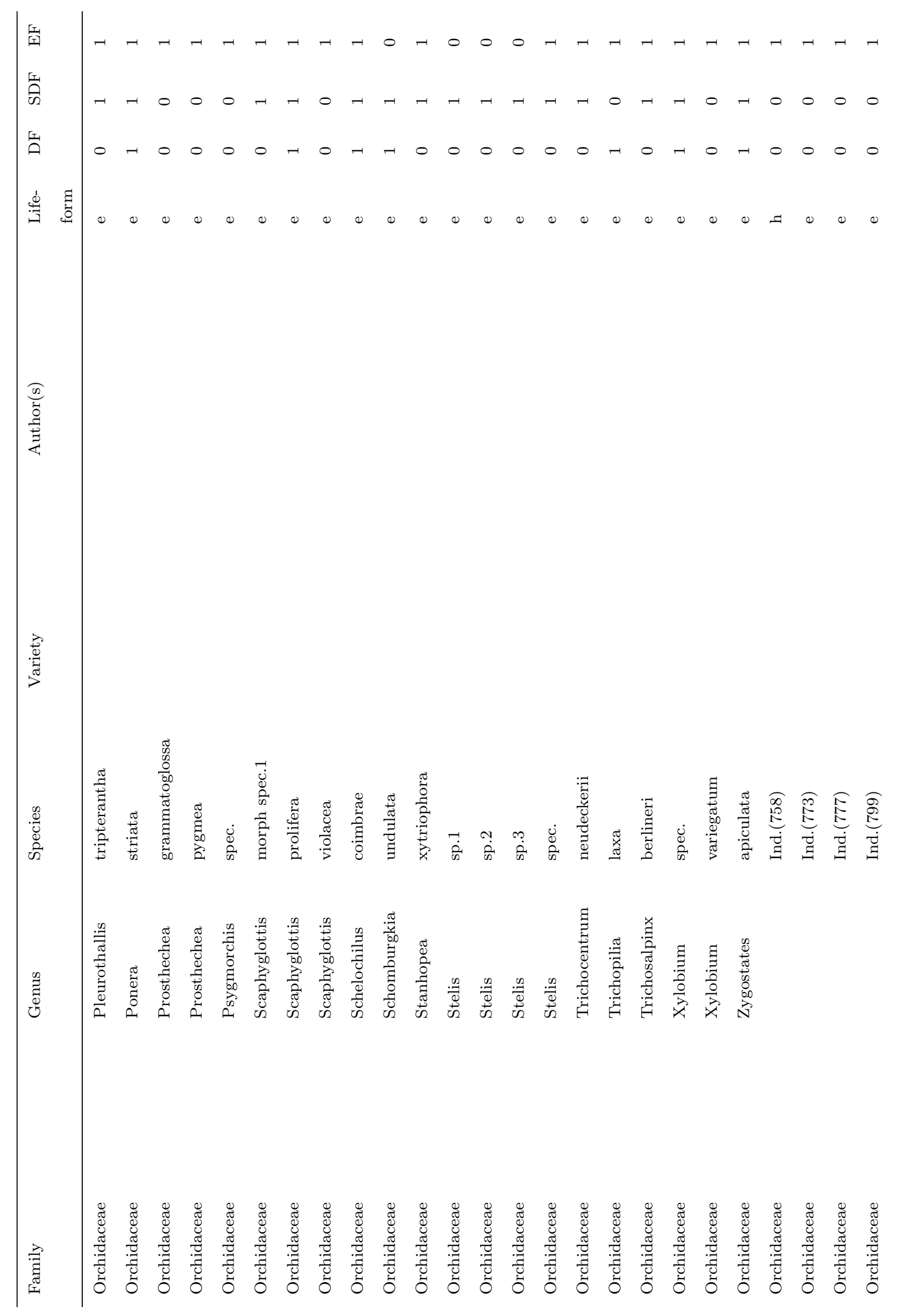




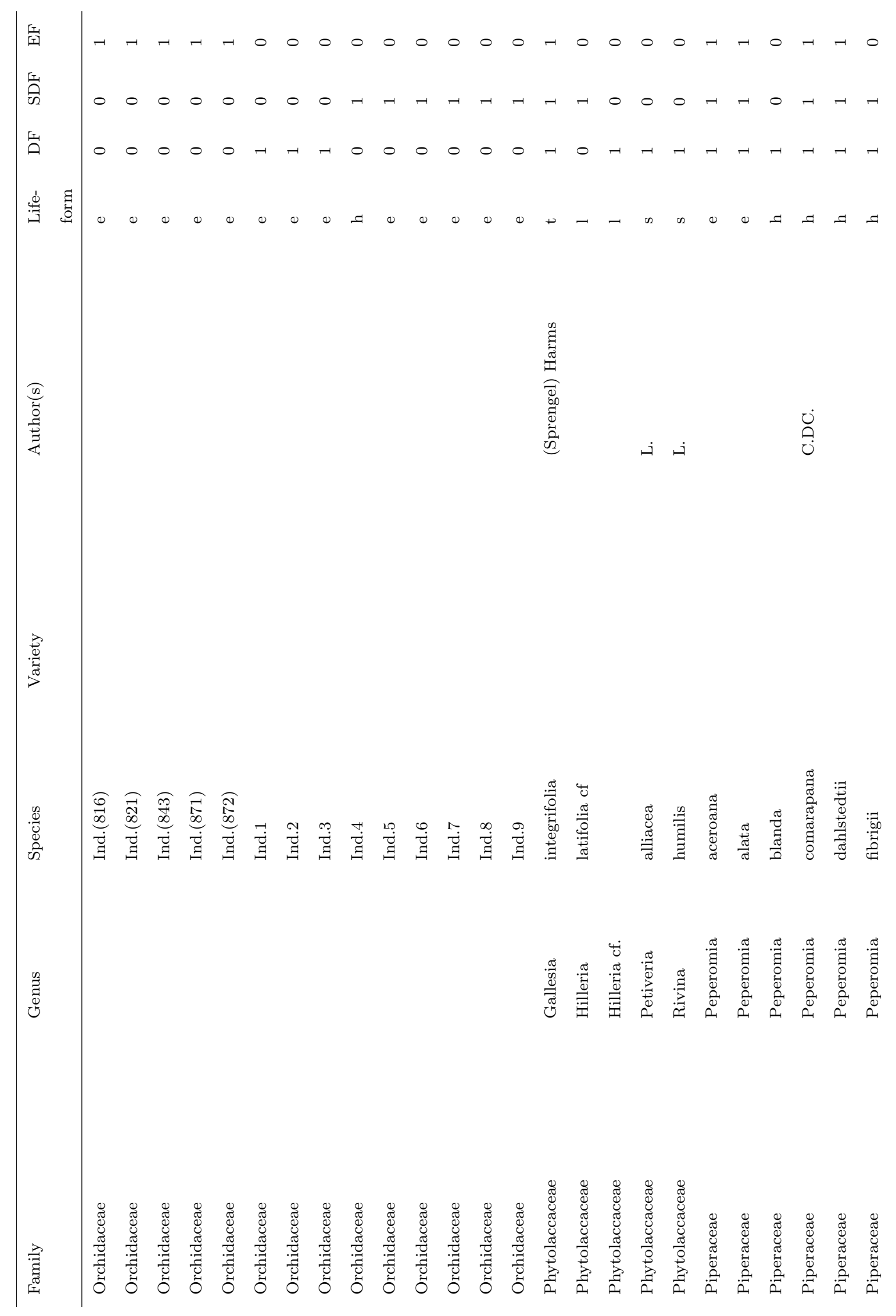




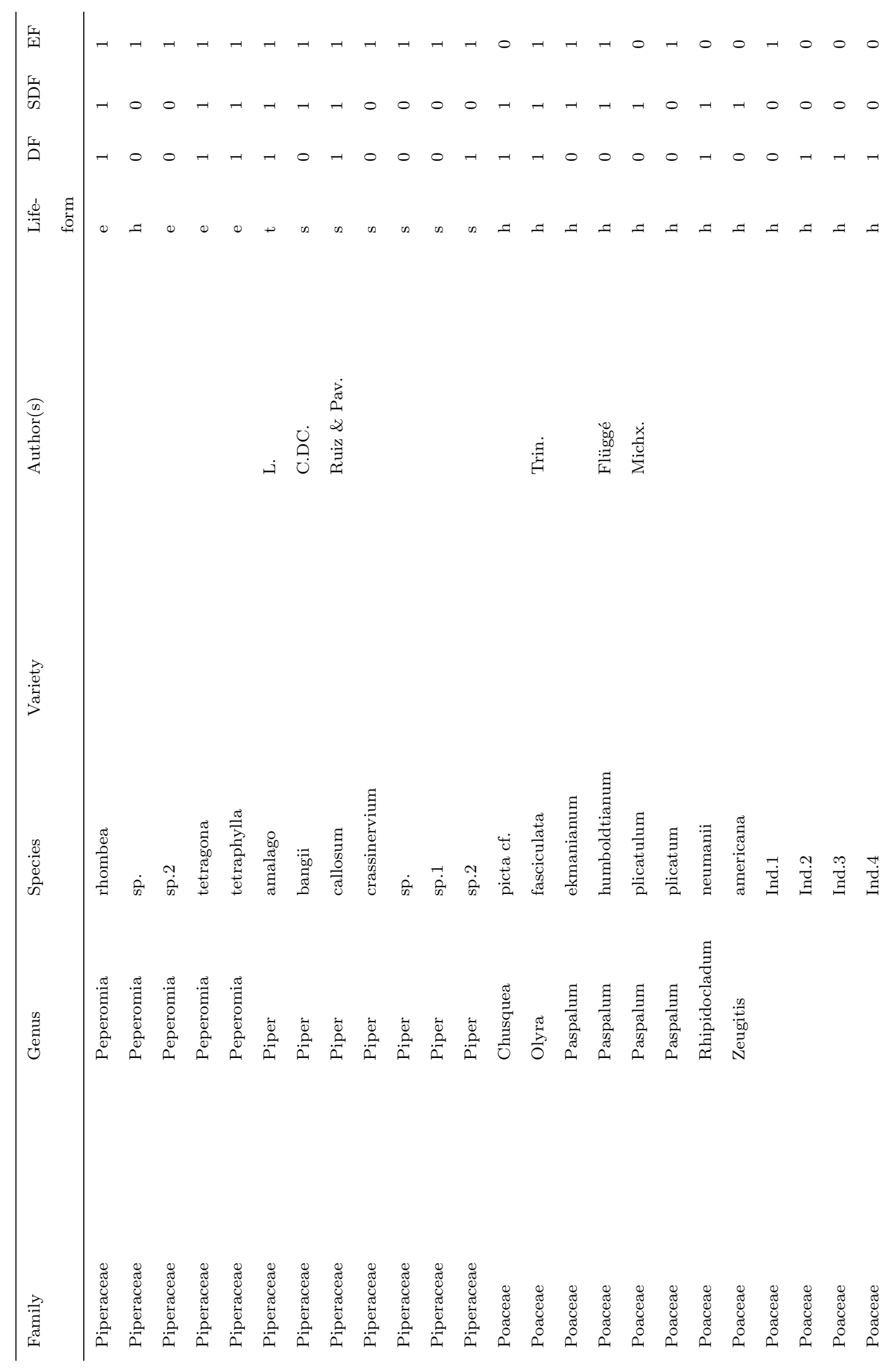




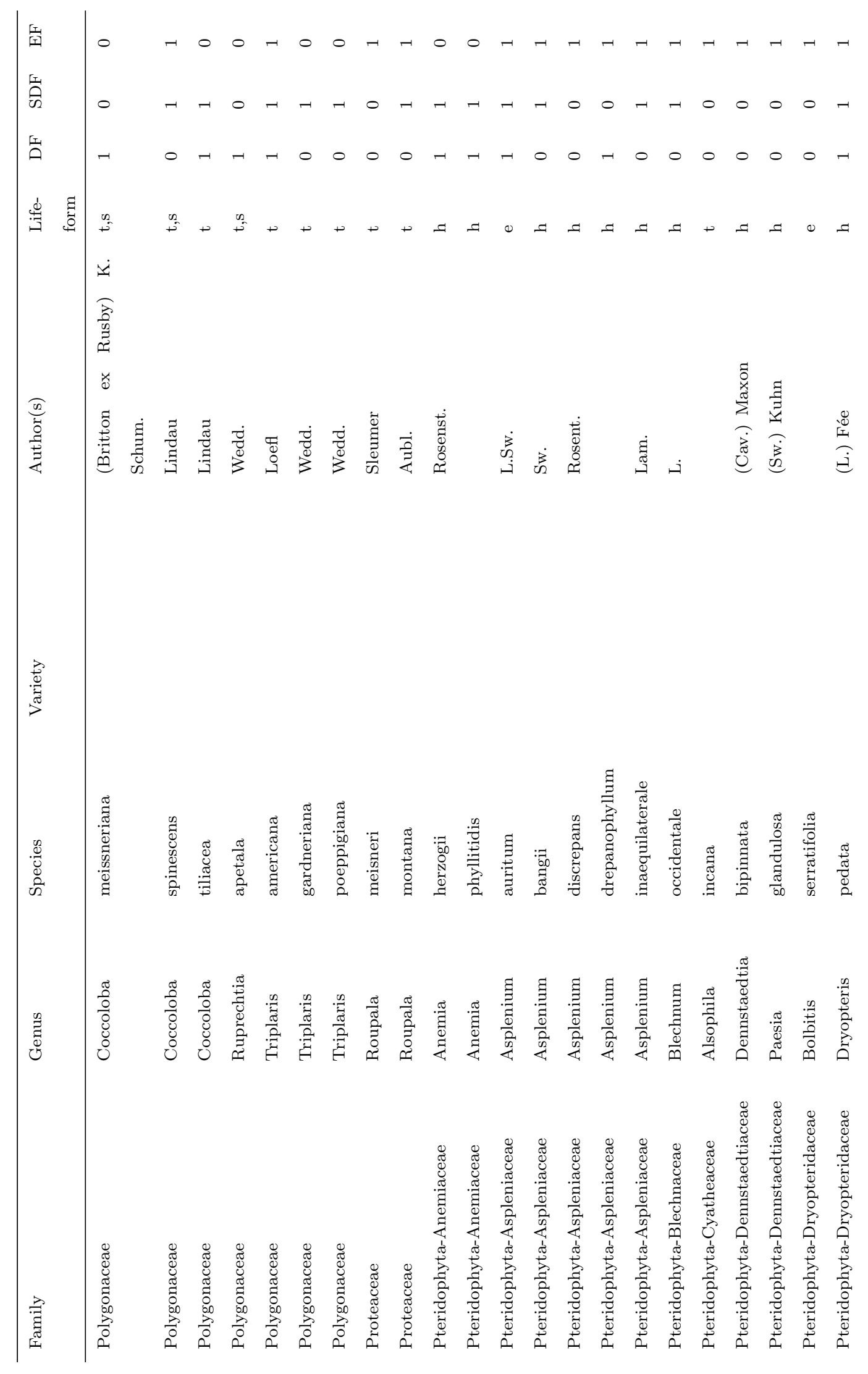




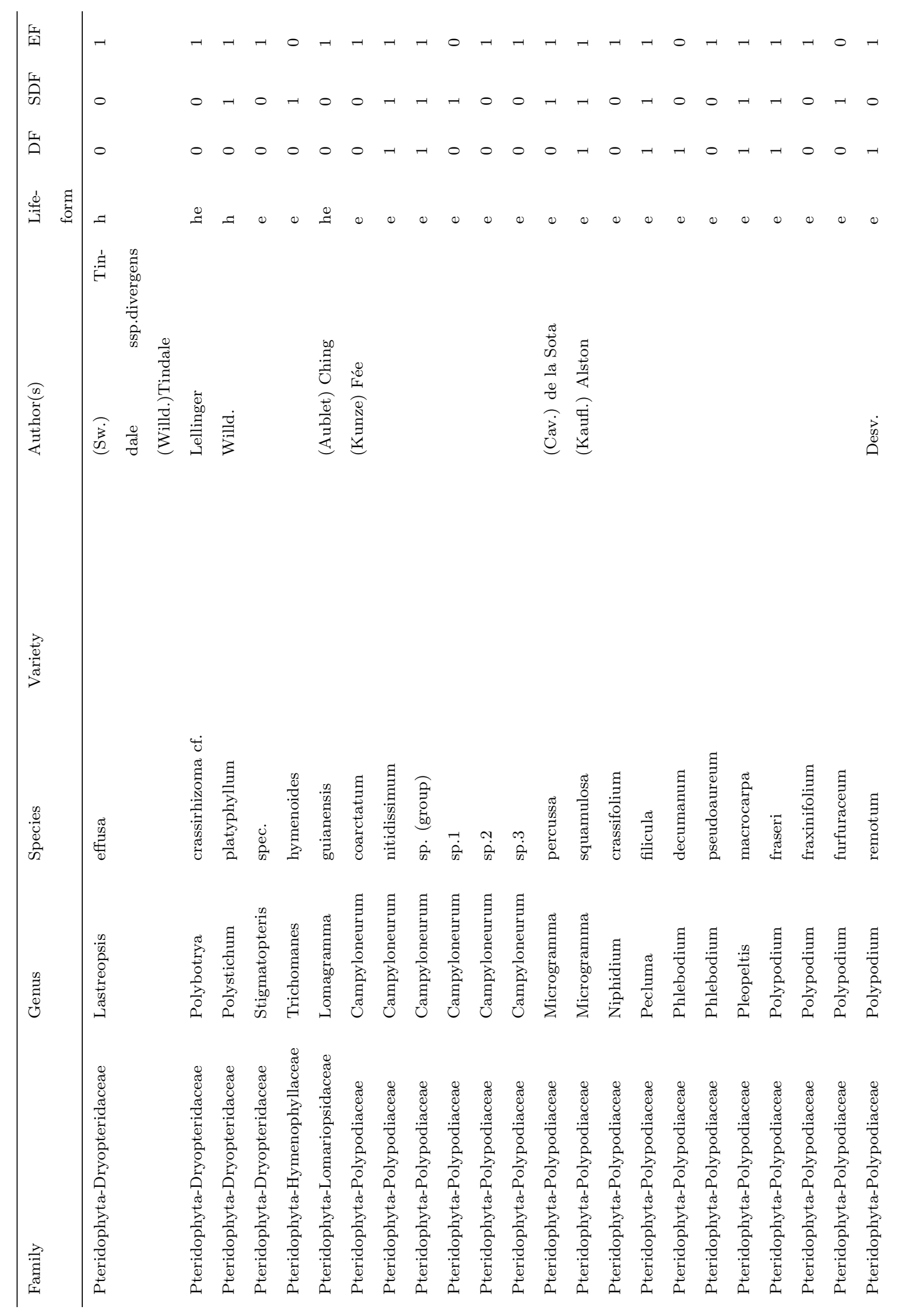




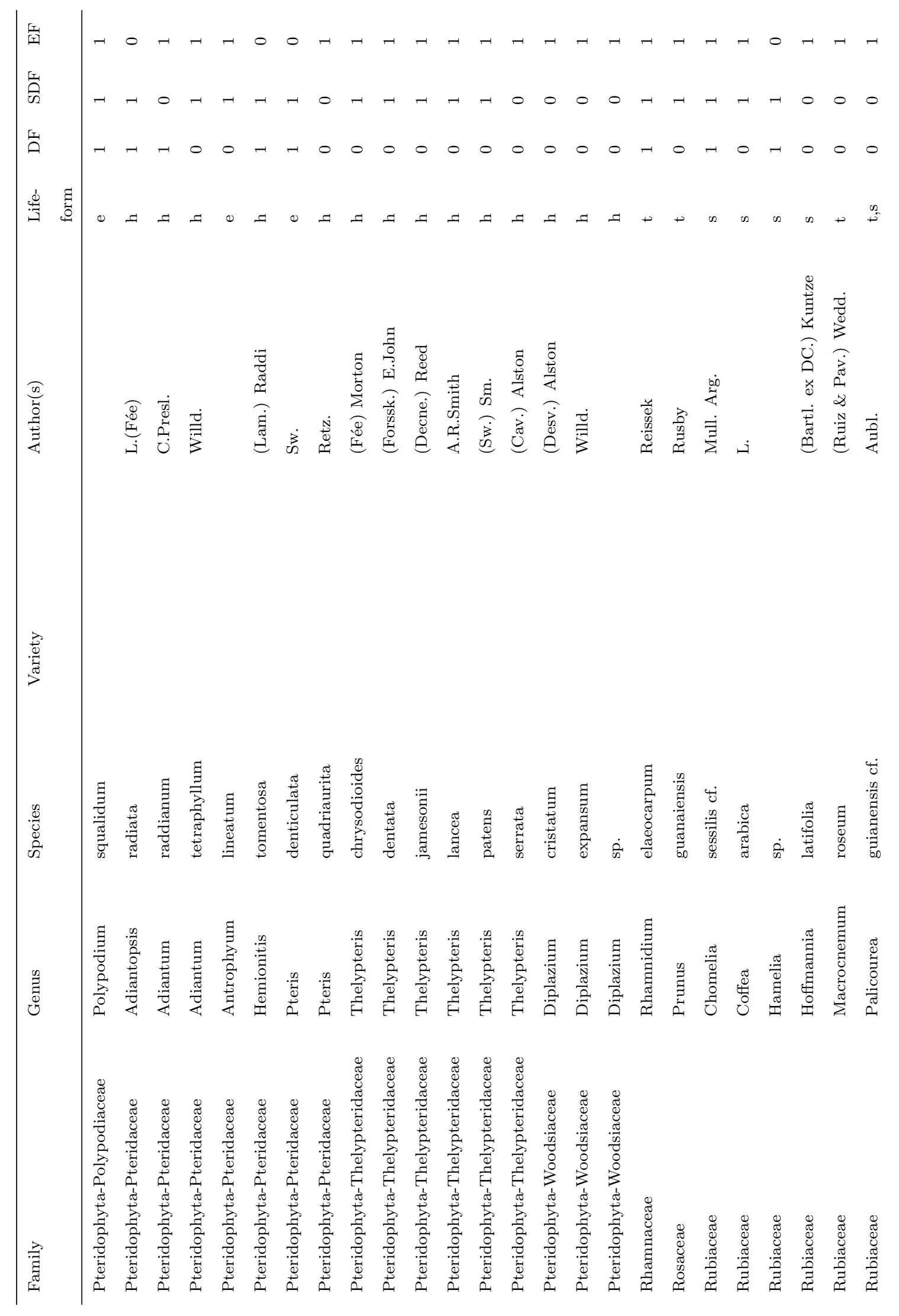




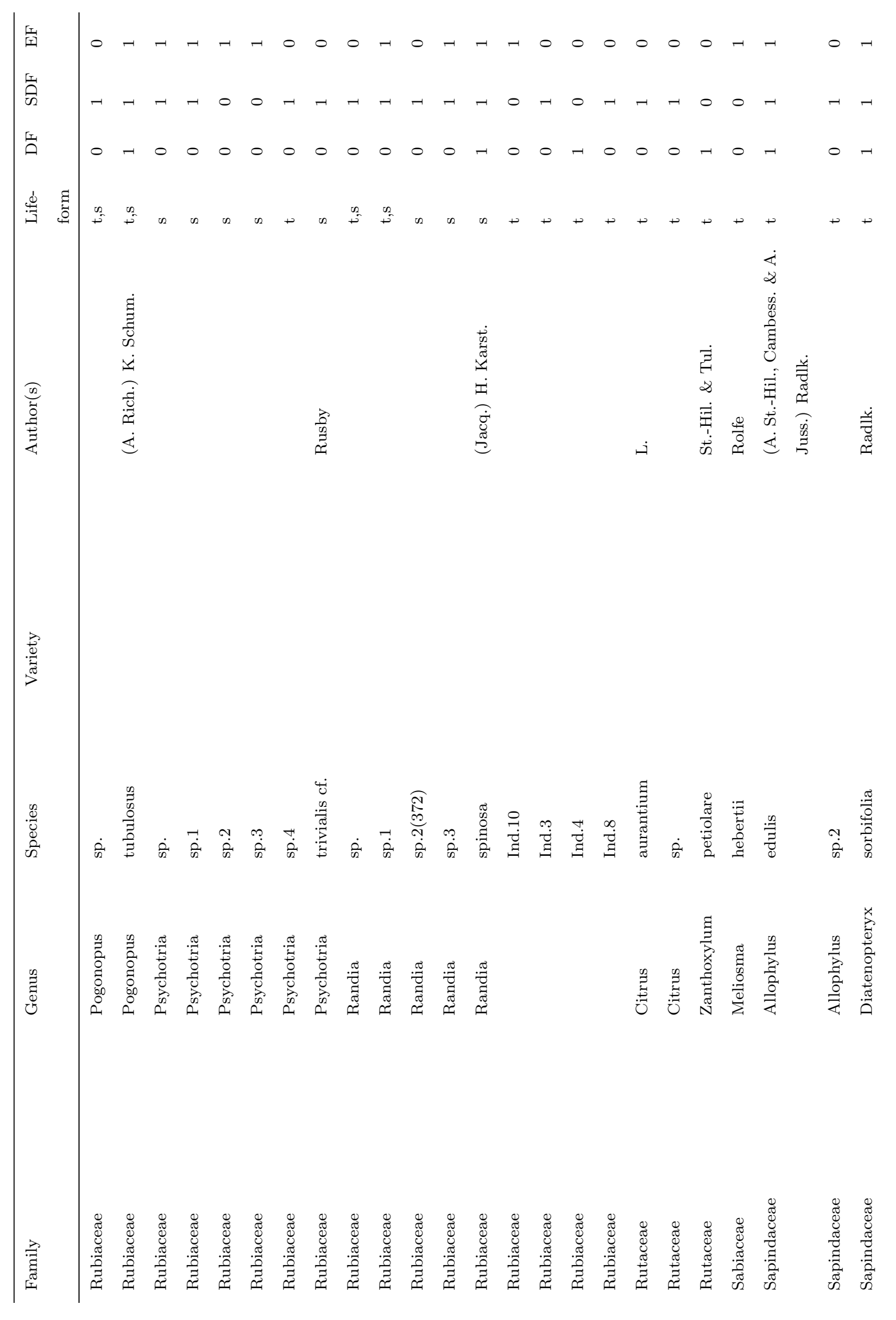




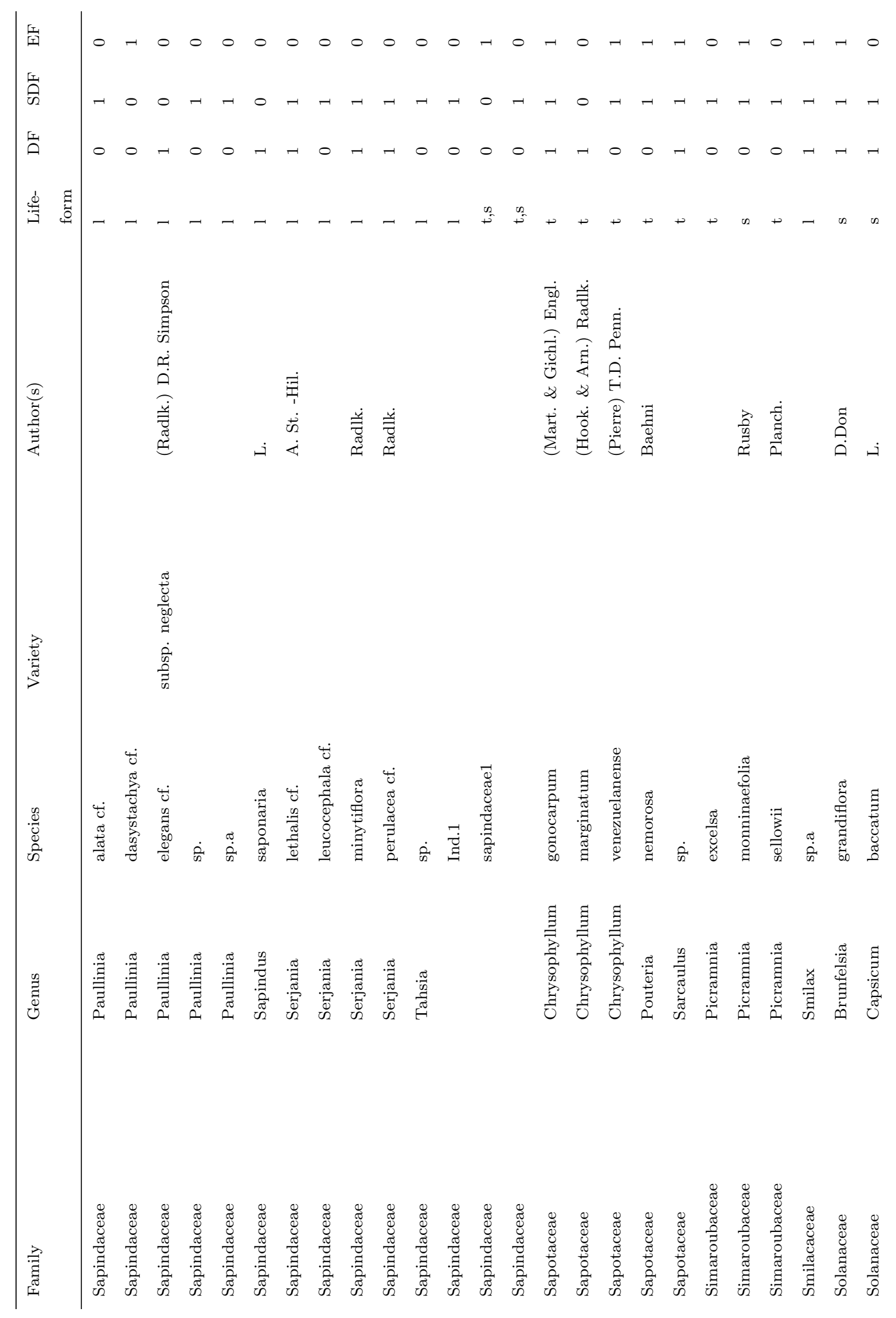




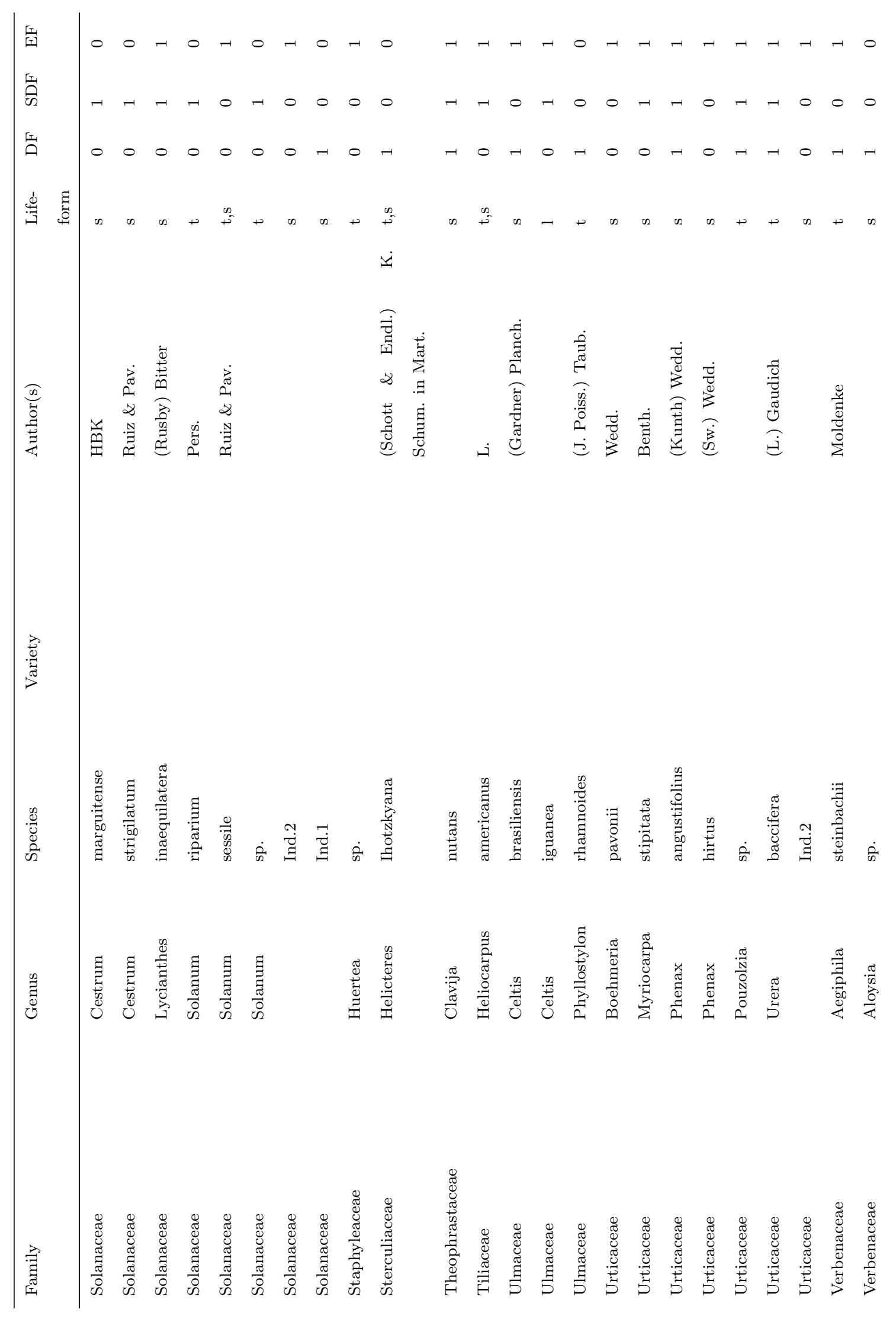




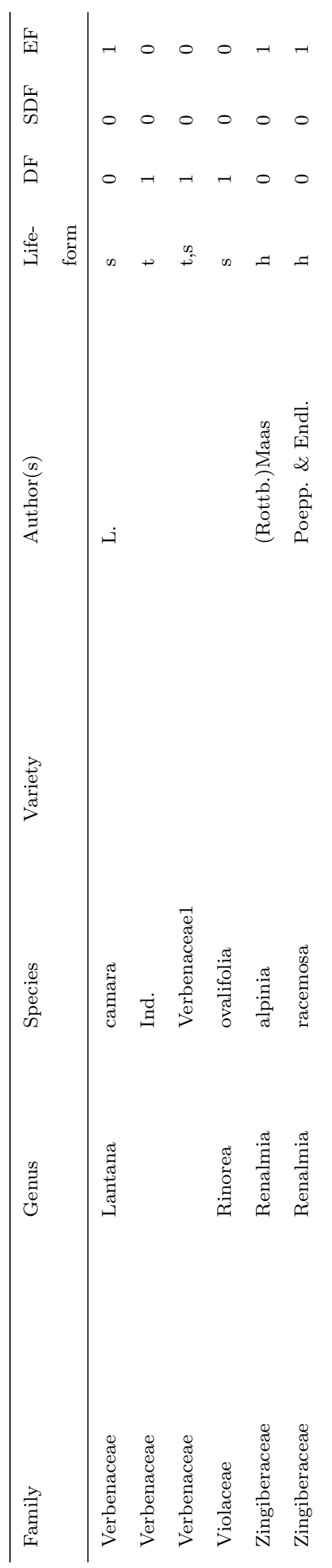




\section{A.3 Appendix to Chapter 3}

Table 3: Presence-absence data of the tree species with diameter at breast height $10 \mathrm{~cm}$ recorded in each plot at the Refugio Los Volcanes, Santa Cruz, Bolivia. DF: deciduous forest plot, SDF: semi-deciduous forest plot, EF: evergreen forest plot.

\begin{tabular}{|c|c|c|c|c|}
\hline Family & Species & $\mathrm{DF}$ & $\mathrm{SDF}$ & $\mathrm{EF}$ \\
\hline $\mathrm{ACT}$ & Saurauria peruviana Buscal. & & & $\mathrm{x}$ \\
\hline ANA & Myracrodruon urundeuva Allemao & $\mathrm{x}$ & & \\
\hline ANA & Schinopsis hankeana Engl. & $\mathrm{x}$ & & \\
\hline ANA & Tapirira cf. guianensis Aubl. & & $\mathrm{x}$ & \\
\hline ANN & Guatteria alutacea Diels var. Steinbachii R. E. Fries & & $\mathrm{x}$ & $\mathrm{x}$ \\
\hline ANN & Rollinia sp.1 & & & $\mathrm{x}$ \\
\hline APO & Aspidosperma cylindrocarpon Mull. Arg. & $\mathrm{x}$ & $\mathrm{x}$ & $\mathrm{x}$ \\
\hline APO & Aspidosperma rigidum Rusby & $\mathrm{x}$ & $\mathrm{x}$ & $\mathrm{x}$ \\
\hline APO & Tabernaemontana cymosa Jacq. & & $\mathrm{x}$ & \\
\hline ARA & Aralia soratensis March. & & $\mathrm{x}$ & \\
\hline ARA & Dendropanax arboreus (L.) Decne. \& Planch. & & $\mathrm{x}$ & $\mathrm{x}$ \\
\hline ARA & Oreopanax cf. steinbachianus Harms & & & $\mathrm{x}$ \\
\hline BIG & Tabebuia heptaphylla (Vell.) Toledo & $\mathrm{x}$ & $\mathrm{x}$ & \\
\hline BOM & Ceiba boliviana Britton \& Baker f. & $\mathrm{x}$ & $\mathrm{x}$ & \\
\hline BOR & Cordia alliodora (Ruiz \& Pav.) Cham. & $\mathrm{x}$ & $\mathrm{x}$ & \\
\hline CAP & Capparis flexuosa (L.) L. & $\mathrm{x}$ & & \\
\hline CAP & Capparis prisca Macbr. & $\mathrm{x}$ & & \\
\hline CEC & Cecropia sp. & & $\mathrm{x}$ & $\mathrm{x}$ \\
\hline CEL & Schaefferia argentinensis Speg. & & & $\mathrm{x}$ \\
\hline CHR & Couepia sp. & & $\mathrm{x}$ & \\
\hline EUP & Alchornea glandulosa Poepp. & & & $\mathrm{x}$ \\
\hline EUP & Croton piluliferus Rusby & $\mathrm{x}$ & & \\
\hline EUP & Drypetes amazonica Steyerm. & $\mathrm{x}$ & $\mathrm{x}$ & $\mathrm{x}$ \\
\hline EUP & Pachystroma longifolium (Nees) I.M. Johnst. & $\mathrm{x}$ & $\mathrm{x}$ & $\mathrm{x}$ \\
\hline EUP & Sebastiania brasiliensis Spreng. & $\mathrm{x}$ & & \\
\hline FLA & Casearia gossypiosperma Briq. & $\mathrm{x}$ & & $\mathrm{x}$ \\
\hline FLA & Casearia sp.1 & & $\mathrm{x}$ & \\
\hline FLA & Casearia sp.2 & & $\mathrm{x}$ & \\
\hline
\end{tabular}




\begin{tabular}{|c|c|c|c|c|}
\hline Family & Species & $\mathrm{DF}$ & SDF & $\mathrm{EF}$ \\
\hline FLA & Hasseltia floribunda Kunth & & $\mathrm{x}$ & $\mathrm{x}$ \\
\hline JUG & Juglans australis Griseb. & & & $\mathrm{x}$ \\
\hline LAC & Lacistema cf. aggregatum (P.J. Bergius) Rusby & & & $\mathrm{x}$ \\
\hline LAU & Aniba sp. & & $\mathrm{x}$ & $\mathrm{x}$ \\
\hline LAU & Lauraceae 1 & & $\mathrm{x}$ & \\
\hline LAU & Lauraceae 2 & & $\mathrm{x}$ & \\
\hline $\mathrm{LAU}$ & Licaria cf. triandra (Sw.) Kosterm. & & $\mathrm{x}$ & $\mathrm{x}$ \\
\hline LAU & Nectandra cf. cuspidata Nees \& Mart. & & $\mathrm{x}$ & \\
\hline LAU & Nectandra sp. 1 & & $\mathrm{x}$ & $\mathrm{x}$ \\
\hline $\mathrm{LAU}$ & Nectandra sp. 2 & & $\mathrm{x}$ & $\mathrm{x}$ \\
\hline LAU & Nectandra sp. 3 & & & $\mathrm{x}$ \\
\hline LAU & Ocotea sp. & & & $\mathrm{x}$ \\
\hline LEC & Cariniana estrellensis (Raddi) Kuntze & $\mathrm{x}$ & $\mathrm{x}$ & $\mathrm{x}$ \\
\hline LEG & Acacia cf. glomerosa Benth. & $\mathrm{x}$ & & \\
\hline LEG & Acacia sp. 3 & $\mathrm{x}$ & & \\
\hline LEG & Anadenanthera colubrina (Vell.) Brenan & $\mathrm{x}$ & & \\
\hline LEG & Erythrina falcata Benth. & & $\mathrm{x}$ & $\mathrm{x}$ \\
\hline LEG & Inga marginata Willd. & & $\mathrm{x}$ & $\mathrm{x}$ \\
\hline LEG & Inga sp. 1 & & $\mathrm{x}$ & $\mathrm{x}$ \\
\hline LEG & Lonchocarpus hedyosmus Miq. & $\mathrm{x}$ & $\mathrm{x}$ & \\
\hline LEG & Machaerium cf. punctatum (Poir.) Pers. & & $\mathrm{x}$ & \\
\hline LEG & Machaerium cf. scleroxylon Tul. & $\mathrm{x}$ & & \\
\hline LEG & Machaerium pilosum Benth. & $\mathrm{x}$ & & \\
\hline LEG & Myroxylon balsamun (L.) Harms. & $\mathrm{x}$ & & \\
\hline LEG & Ormosia bolivarensis C.H. Stirt. & & $\mathrm{x}$ & \\
\hline LEG & Parapiptadenia excelsa (Griseb.) Burkart & $\mathrm{x}$ & $\mathrm{x}$ & \\
\hline LEG & Piptadenia buchtienii Barneby & $\mathrm{x}$ & & \\
\hline LEG & Platymiscium cf. stipulare Benth. & & $\mathrm{x}$ & \\
\hline LEG & Senna sp. & $\mathrm{x}$ & & \\
\hline LEG & Swartzia jorori Harms & $\mathrm{x}$ & $\mathrm{x}$ & $\mathrm{x}$ \\
\hline LEG & Tipuana tipu (Benth.) Kuntze & $\mathrm{x}$ & & \\
\hline MAL & Bunchosia cf. paraguariensis Nied. & $\mathrm{x}$ & & $\mathrm{x}$ \\
\hline MEL & Cedrela lilloi C. DC. & $\mathrm{x}$ & $\mathrm{x}$ & \\
\hline MEL & Trichilia claussenii C. DC. & $\mathrm{x}$ & $\mathrm{x}$ & $\mathrm{x}$ \\
\hline
\end{tabular}




\begin{tabular}{|c|c|c|c|c|}
\hline Family & Species & $\mathrm{DF}$ & SDF & $\mathrm{EF}$ \\
\hline MEL & Trichilia elegans A. Juss. & & $\mathrm{x}$ & $\mathrm{x}$ \\
\hline MEL & Trichilia pleeana (A. Juss.) C. DC. & & $\mathrm{x}$ & $\mathrm{x}$ \\
\hline MELA & Miconia cf. minutiflora (Bonpl.) DC. & & & $\mathrm{x}$ \\
\hline MOR & Clarisia biflora Ruiz \& Pav. & & $\mathrm{x}$ & $\mathrm{x}$ \\
\hline MOR & Ficus cf. eximia Schott in Spreng. & & & $\mathrm{x}$ \\
\hline MOR & Ficus macbridei Standl. & & & $\mathrm{x}$ \\
\hline MOR & Ficus maxima Mill. & & & $\mathrm{x}$ \\
\hline MOR & Ficus obtusifolia Kunth in Humb., Bonpl. \& Kunth & & $\mathrm{x}$ & $\mathrm{x}$ \\
\hline MOR & Ficus pertusa L. f. & & & $\mathrm{x}$ \\
\hline MOR & Ficus sp. & & $\mathrm{x}$ & \\
\hline MOR & Ficus trigona L. f. & & $\mathrm{x}$ & $\mathrm{x}$ \\
\hline MOR & Maclura tinctoria (L.) D. Don ex Steud. & & $\mathrm{x}$ & \\
\hline MOR & Sorocea guilleminiana Gaudich. & & $\mathrm{x}$ & $\mathrm{x}$ \\
\hline MYRS & Myrsine umbellata Mart. & & $\mathrm{x}$ & $\mathrm{x}$ \\
\hline MYRT & Eugenia cf. moraviana O. Berg & & $\mathrm{x}$ & \\
\hline MYRT & Eugenia muricata DC. & & & $\mathrm{x}$ \\
\hline MYRT & Eugenia sp. & $\mathrm{x}$ & $\mathrm{x}$ & $\mathrm{x}$ \\
\hline MYRT & Myrciantes cf. pseudomato (Legrand) Mc. Vough. & $\mathrm{x}$ & $\mathrm{x}$ & \\
\hline MYRT & Myrciantes sp. 1 & $\mathrm{x}$ & & \\
\hline NYC & Bougainvillea stipitata Griseb. & $\mathrm{x}$ & & \\
\hline NYC & Guapira aff. olfersiana (Link et al) Standl. & & $\mathrm{x}$ & $\mathrm{x}$ \\
\hline NYC & Neea sp. & $\mathrm{x}$ & & \\
\hline NYC & Nyctaginaceae Indet & $\mathrm{x}$ & & \\
\hline $\mathrm{OCH}$ & Ouratea cf. angulata Tiegh. & & & $\mathrm{x}$ \\
\hline OLA & Ximenia americana L. & $\mathrm{x}$ & & \\
\hline PHY & Gallesia integrifolia (Sprengel) Harms & $\mathrm{x}$ & $\mathrm{x}$ & $\mathrm{x}$ \\
\hline PIP & Piper amalago L. & & $\mathrm{x}$ & \\
\hline POL & Ruprechtia apetala Wedd. & $\mathrm{x}$ & & \\
\hline POL & Triplaris americana L. & & $\mathrm{x}$ & $\mathrm{x}$ \\
\hline RHA & Rhamnidium elaeocarpum Reissek & & $\mathrm{x}$ & \\
\hline ROS & Prunus guanaiensis Rusby & & $\mathrm{x}$ & \\
\hline RUB & Chomelia cf. sessilis Mull. Arg. & & $\mathrm{x}$ & $\mathrm{x}$ \\
\hline RUB & Macrocnemum roseum (Ruiz \& Pav.) Wedd. & & & $\mathrm{x}$ \\
\hline RUB & Palicourea cf. guianensis Aubl. & & & $\mathrm{x}$ \\
\hline
\end{tabular}




\begin{tabular}{|c|c|c|c|c|}
\hline Family & Species & $\mathrm{DF}$ & $\mathrm{SDF}$ & $\mathrm{EF}$ \\
\hline RUB & Pogonopus sp. & & $\mathrm{x}$ & \\
\hline RUB & Pogonopus tubulosus (A. Rich.) K. Schum. & & $\mathrm{x}$ & \\
\hline $\mathrm{SAB}$ & Meliosma herbertii Rolfe & & & $\mathrm{x}$ \\
\hline SAPI & Allophylus cf. edulis (A. St.-Hil., Cambess. \& A. Juss.) Radlk. & & $\mathrm{x}$ & $\mathrm{x}$ \\
\hline SAPI & Diatenopteryx sorbifolia Radlk. & $\mathrm{x}$ & $\mathrm{x}$ & $\mathrm{x}$ \\
\hline SAPO & Chrysophyllum gonocarpum (Mart. \& Gichl.) Engl. & $\mathrm{x}$ & $\mathrm{x}$ & $\mathrm{x}$ \\
\hline SAPO & Chrysophyllum marginatum (Hook. \& Arn.) Radlk. & $\mathrm{x}$ & & $\mathrm{x}$ \\
\hline SAPO & Chrysophyllum venezuelanense (Pierre) T.D. Penn. & & $\mathrm{x}$ & $\mathrm{x}$ \\
\hline SAPO & Pouteria nemorosa Baehni & & $\mathrm{x}$ & $\mathrm{x}$ \\
\hline SAPO & Sarcaulus sp. & & $\mathrm{x}$ & $\mathrm{x}$ \\
\hline SIM & Picrasma excelsa & & $\mathrm{x}$ & \\
\hline $\mathrm{SOL}$ & Solanum riparium Pers. & & $\mathrm{x}$ & \\
\hline SOL & Solanum sessile Ruiz \& Pav. & & & $\mathrm{x}$ \\
\hline TIL & Heliocarpus americanus L. & & $\mathrm{x}$ & $\mathrm{x}$ \\
\hline ULM & Celtis iguanaea (Jacq.) Sarg. & & $\mathrm{x}$ & \\
\hline URT & Myriocarpa stipitata Benth. & & $\mathrm{x}$ & $\mathrm{x}$ \\
\hline URT & Pouzolzia sp. & $\mathrm{x}$ & $\mathrm{x}$ & \\
\hline URT & Urera baccifera (L.) Gaudich. & & $\mathrm{x}$ & $\mathrm{x}$ \\
\hline VER & Aegiphila steinbachii Moldenke & $\mathrm{x}$ & & $\mathrm{x}$ \\
\hline
\end{tabular}




\section{A.4 Appendix to Chapter 4}

Table S1. Pair-wise Sørensen (Bray-Curtis) similarity coefficients between seasonal forest areas. in Bolivia. RT: Río Tuichi, CA: Camata, CS: Consata, CO: Coroico, RL: Río La Paz, CT: Río Cotacajes, RC: Río Caine, CQ: Chiquitanía, CH: Chaco, GR: Río Grande, PA: Río Parapetí, PI: Río Pilcomayo.

\section{All Plant Groups}

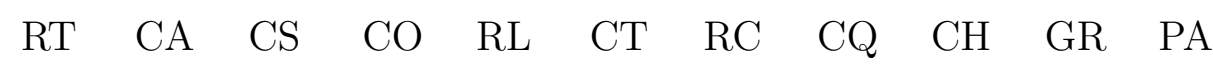

CA $\quad 0.53$

CS $\quad 0.47 \quad 0.66$

$\mathrm{CO} \quad 0.65 \quad 0.58 \quad 0.55$

$\begin{array}{lllll}\text { RL } & 0.58 & 0.60 & 0.54 & 0.69\end{array}$

CT $\quad 0.41 \quad 0.56 \quad 0.54 \quad 0.48 \quad 0.67$

$\begin{array}{lllllll}\mathrm{RC} & 0.26 & 0.42 & 0.46 & 0.28 & 0.39 & 0.50\end{array}$

$\begin{array}{llllllll}\text { CQ } & 0.37 & 0.40 & 0.39 & 0.40 & 0.48 & 0.38 & 0.30\end{array}$

$\begin{array}{lllllllll}\mathrm{CH} & 0.23 & 0.15 & 0.18 & 0.20 & 0.24 & 0.20 & 0.20 & 0.45\end{array}$

$\begin{array}{llllllllll}\text { GR } & 0.37 & 0.41 & 0.41 & 0.44 & 0.52 & 0.43 & 0.45 & 0.53 & 0.40\end{array}$

$\begin{array}{lllllllllll}\mathrm{PA} & 0.37 & 0.37 & 0.38 & 0.44 & 0.47 & 0.39 & 0.39 & 0.47 & 0.43 & 0.69\end{array}$

$\begin{array}{llllllllllll}\text { PI } & 0.26 & 0.39 & 0.34 & 0.32 & 0.42 & 0.42 & 0.49 & 0.47 & 0.37 & 0.65 & 0.57\end{array}$ 


\section{Acanthaceae}

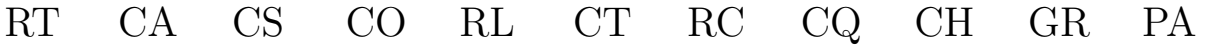

CA $\quad 0.22$

CS $\quad 0.26 \quad 0.62$

$\begin{array}{llll}\mathrm{CO} & 0.67 & 0.26 & 0.36\end{array}$

$\begin{array}{lllll}\text { RL } & 0.53 & 0.25 & 0.34 & 0.77\end{array}$

$\begin{array}{llllll}\mathrm{CT} & 0.55 & 0.26 & 0.43 & 0.68 & 0.87\end{array}$

$\begin{array}{lllllll}\mathrm{RC} & 0.10 & 0.18 & 0.50 & 0.08 & 0.07 & 0.15\end{array}$

$\begin{array}{llllllll}\text { CQ } & 0.19 & 0.06 & 0.11 & 0.21 & 0.24 & 0.21 & 0.11\end{array}$

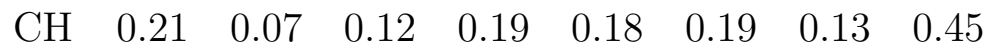

$\begin{array}{llllllllll}\text { GR } & 0.29 & 0.10 & 0.18 & 0.33 & 0.33 & 0.30 & 0.24 & 0.44 & 0.71\end{array}$

$\begin{array}{lllllllllll}\mathrm{PA} & 0.28 & 0.12 & 0.16 & 0.29 & 0.29 & 0.25 & 0.17 & 0.41 & 0.75 & 0.88\end{array}$

$\begin{array}{llllllllllll}\text { PI } & 0.21 & 0.11 & 0.19 & 0.23 & 0.22 & 0.23 & 0.29 & 0.51 & 0.69 & 0.78 & 0.79\end{array}$

\section{Bromeliaceae}

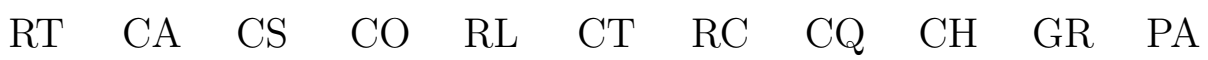

CA 0.63

CS $\quad 0.57 \quad 0.82$

$\mathrm{CO} \quad 0.65 \quad 0.66 \quad 0.63$

$\begin{array}{lllll}\text { RL } & 0.65 & 0.63 & 0.63 & 0.74\end{array}$

CT $\quad 0.48 \quad 0.63 \quad 0.66 \quad 0.54 \quad 0.65$

$\begin{array}{lllllll}\mathrm{RC} & 0.40 & 0.49 & 0.54 & 0.45 & 0.52 & 0.55\end{array}$

$\begin{array}{llllllll}\text { CQ } & 0.37 & 0.25 & 0.29 & 0.27 & 0.30 & 0.29 & 0.24\end{array}$

$\begin{array}{lllllllll}\mathrm{CH} & 0.29 & 0.22 & 0.26 & 0.24 & 0.31 & 0.30 & 0.32 & 0.81\end{array}$

$\begin{array}{llllllllll}\text { GR } & 0.38 & 0.40 & 0.42 & 0.43 & 0.47 & 0.42 & 0.59 & 0.35 & 0.36\end{array}$

$\begin{array}{lllllllllll}\mathrm{PA} & 0.39 & 0.41 & 0.48 & 0.46 & 0.46 & 0.43 & 0.53 & 0.39 & 0.41 & 0.80\end{array}$

$\begin{array}{llllllllllll}\text { PI } & 0.27 & 0.38 & 0.41 & 0.38 & 0.38 & 0.39 & 0.56 & 0.21 & 0.22 & 0.66 & 0.59\end{array}$ 


\section{Cactaceae}

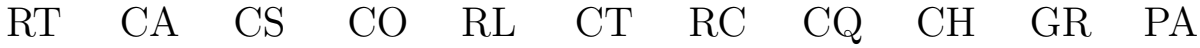

CA $\quad 0.33$

CS $\quad 0.00 \quad 0.00$

$\begin{array}{llll}\mathrm{CO} & 0.40 & 0.67 & 0.00\end{array}$

$\begin{array}{lllll}\text { RL } & 0.13 & 0.53 & 0.12 & 0.44\end{array}$

CT $\quad 0.00 \quad 0.20 \quad 0.11 \quad 0.21 \quad 0.55$

$\begin{array}{lllllll}\mathrm{RC} & 0.00 & 0.00 & 0.00 & 0.00 & 0.00 & 0.32\end{array}$

$\begin{array}{llllllll}\text { CQ } & 0.00 & 0.00 & 0.00 & 0.00 & 0.07 & 0.14 & 0.08\end{array}$

$\begin{array}{lllllllll}\mathrm{CH} & 0.00 & 0.06 & 0.00 & 0.06 & 0.09 & 0.18 & 0.15 & 0.51\end{array}$

$\begin{array}{llllllllll}\text { GR } & 0.06 & 0.22 & 0.00 & 0.17 & 0.26 & 0.21 & 0.29 & 0.17 & 0.23\end{array}$

$\begin{array}{lllllllllll}\text { PA } & 0.29 & 0.73 & 0.00 & 0.60 & 0.40 & 0.29 & 0.13 & 0.10 & 0.11 & 0.26\end{array}$

$\begin{array}{llllllllllll}\text { PI } & 0.05 & 0.13 & 0.00 & 0.14 & 0.15 & 0.18 & 0.16 & 0.19 & 0.38 & 0.42 & 0.22\end{array}$

\section{Pteridophyta}

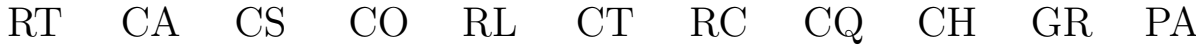

CA $\quad 0.51$

CS $\quad 0.44 \quad 0.59$

$\mathrm{CO} \quad 0.67 \quad 0.59 \quad 0.57$

$\begin{array}{lllll}\text { RL } & 0.61 & 0.67 & 0.59 & 0.67\end{array}$

CT $\quad 0.36 \quad 0.65 \quad 0.58 \quad 0.41 \quad 0.66$

$\begin{array}{lllllll}\mathrm{RC} & 0.18 & 0.44 & 0.44 & 0.23 & 0.44 & 0.59\end{array}$

$\begin{array}{llllllll}\text { CQ } & 0.49 & 0.61 & 0.59 & 0.60 & 0.72 & 0.54 & 0.44\end{array}$

$\begin{array}{lllllllll}\mathrm{CH} & 0.30 & 0.18 & 0.23 & 0.26 & 0.29 & 0.15 & 0.16 & 0.29\end{array}$

$\begin{array}{llllllllll}\text { GR } & 0.49 & 0.60 & 0.62 & 0.58 & 0.71 & 0.58 & 0.47 & 0.78 & 0.33\end{array}$

$\begin{array}{lllllllllll}\text { PA } & 0.40 & 0.39 & 0.43 & 0.47 & 0.58 & 0.46 & 0.38 & 0.59 & 0.35 & 0.65\end{array}$

$\begin{array}{llllllllllll}\text { PI } & 0.36 & 0.61 & 0.50 & 0.41 & 0.65 & 0.65 & 0.68 & 0.66 & 0.21 & 0.69 & 0.56\end{array}$ 


\section{A.5 Appendix to Chapter 5}

Pearson correlation coefficients between environmental factors in three 1-ha plots at Los Volcanes, Santa Cruz, Bolivia. 


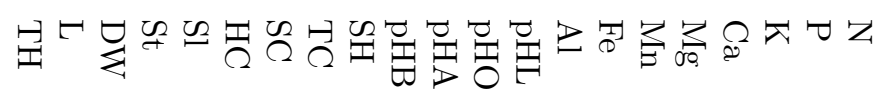

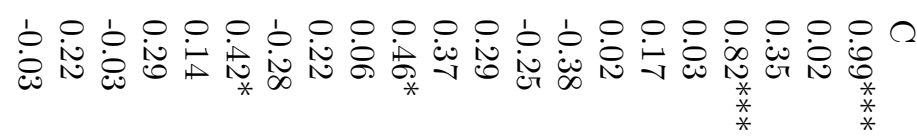

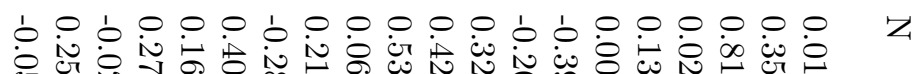

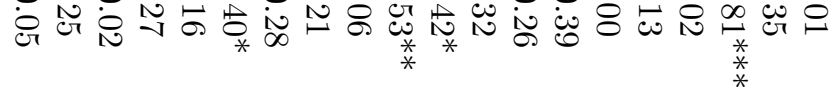

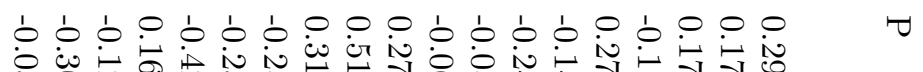

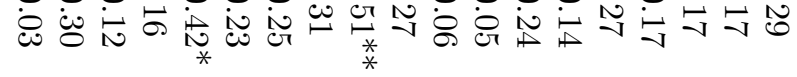

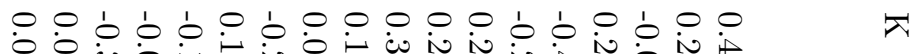

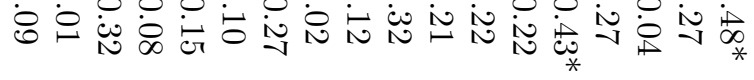

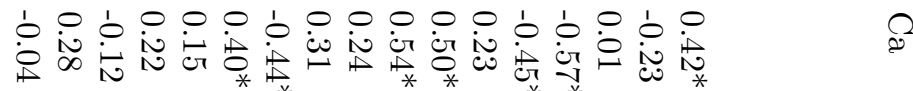

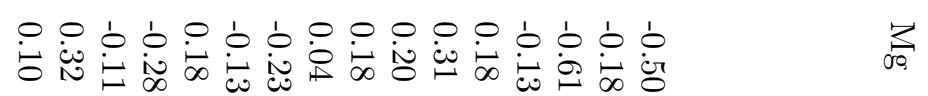

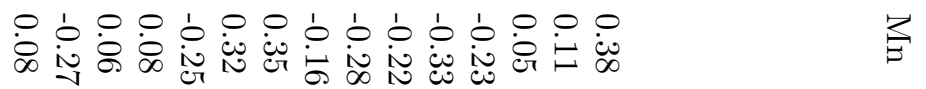

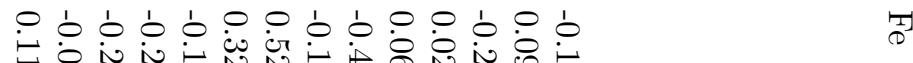

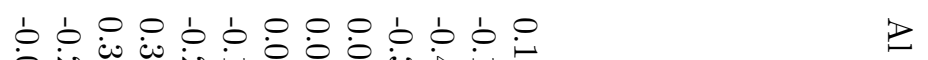

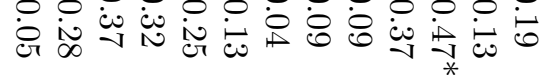

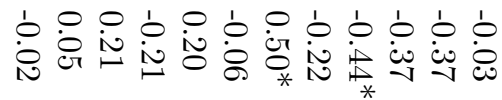

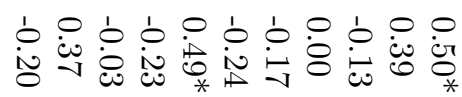

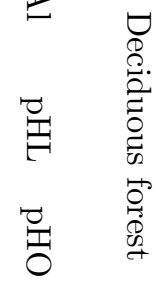

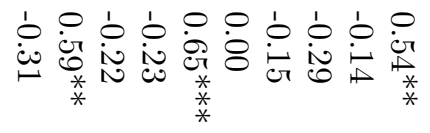

范

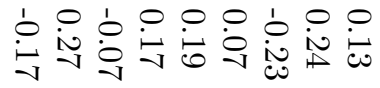

蕒

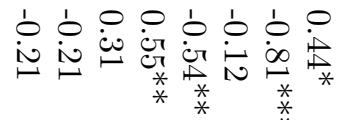

结

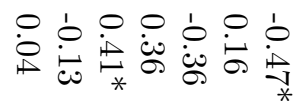

$\stackrel{-1}{\Omega}$

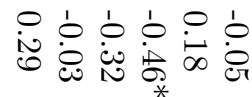

n

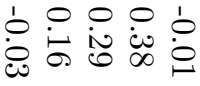

홍

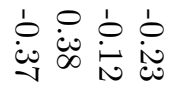

은

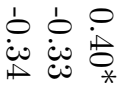

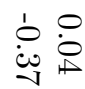

\&े

$\gtreqless$

$r$ 


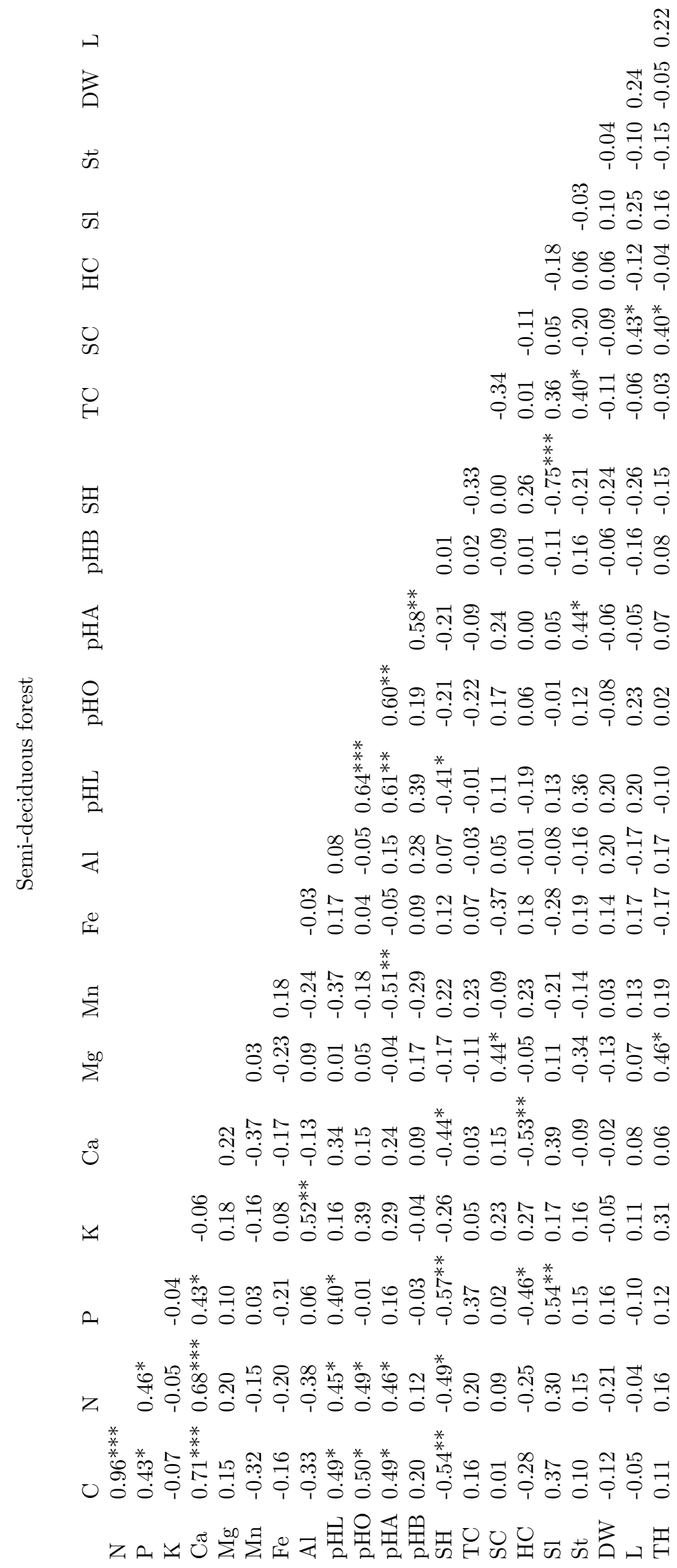




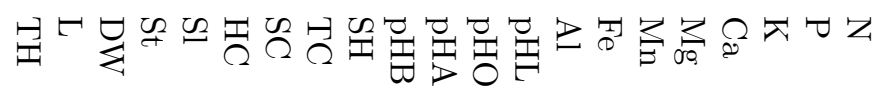

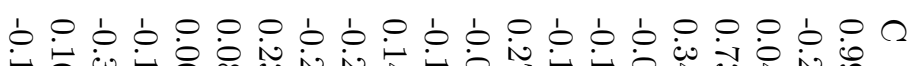

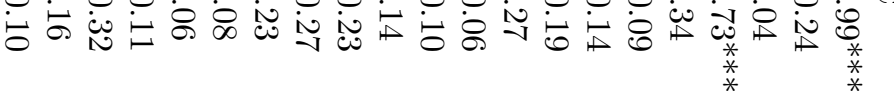

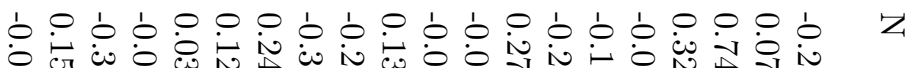

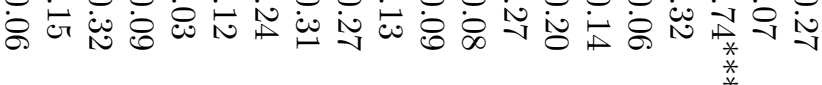

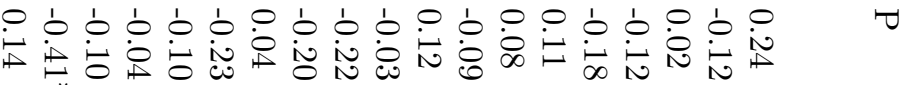

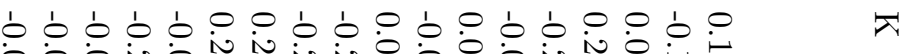

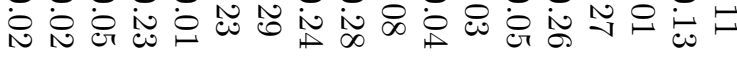

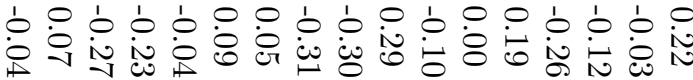

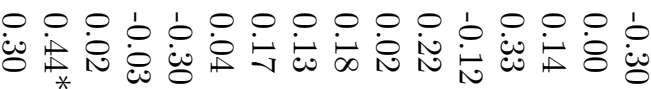

资

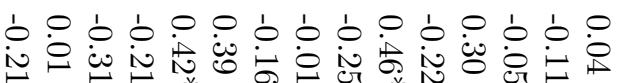

客

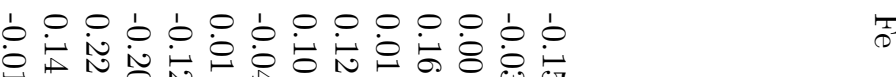

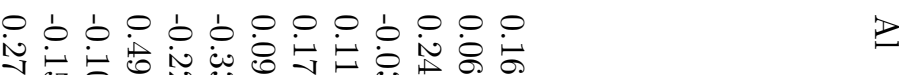

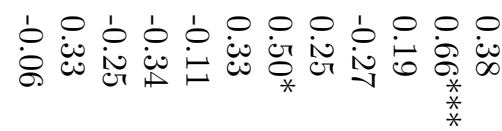

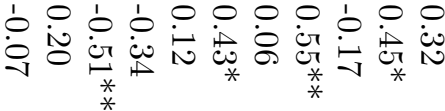

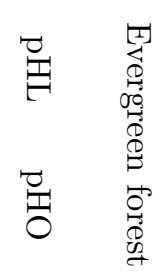

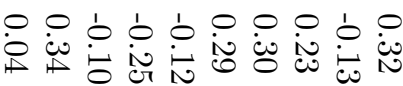

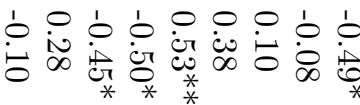

芦

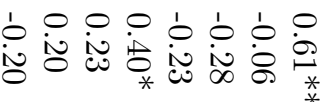

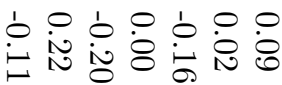

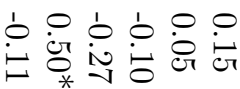

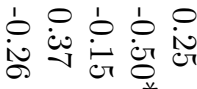

ํㅗㅇ

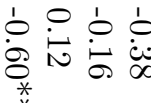

$\underline{10}$

잉엉

if

$\stackrel{\circ}{\circ} \stackrel{\circ}{\circ}$

:

绍

공

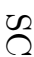

$\gtreqless$ 